\title{
Carbon Fluxes and Pools in a Montane Rainforest in Sulawesi, Indonesia
}

\author{
Dissertation \\ to attain the doctoral degree (Dr. forest.) \\ of the Faculty of Forest Sciences and Forest Ecology \\ Georg-August-Universität Göttingen \\ Submitted by \\ Florian Francis Heimsch
}

Born on the $8^{\text {th }}$ of March 1986 in Filderstadt 
1. Referee: Prof. Dr. Alexander Knohl

2. Referee: Prof. Dr. Dirk Hölscher

Date of oral examination: 20 November 2020 


\section{Abstract: Storage and Respiration of Carbon in a Montane Rainforest in Sulawesi, Indonesia}

Forests play an important part in the global carbon cycle. While carbon balances of many forest types have been studied intensively, such information is very sparse for tropical montane rainforests. This thesis aims to establish a robust estimate of carbon storage, respiration and the overall carbon balance of such a forest in the central mountains of Sulawesi, Indonesia. To this end, three approaches were combined. Forest inventories were used to determine forest stand parameters such as aboveground biomass (AGB), basal area (BA) and changes thereof; soil respiration $\left(\mathrm{R}_{\mathrm{s}}\right)$ measurements provided an insight into the major component of ecosystem respiration and eddy-covariance $(\mathrm{EC})$ measurements were used to estimate net ecosystem exchange (NEE). For long term changes in AGB, results from an inventory carried out in 2006 were used as baseline. These were combined with results from a large scale inventory carried out in 2017, which resulted in an estimated annual increase of AGB of $2.54 \mathrm{Mg} \mathrm{ha}^{-1} \mathrm{y}^{-1}$. Based on the 2017 data, AGB was estimated to be $321.38 \pm 9.64 \mathrm{Mg} \mathrm{ha}^{-1}$ and BA $37.86 \pm 0.38 \mathrm{~m}^{2} \mathrm{ha}^{-1}$. To quantify $\mathrm{R}_{\mathrm{s}}$ and to identify its main drivers, $R_{s}$, soil temperature $\left(T_{s}\right)$ and soil moisture $\left(M_{s}\right)$ were measured 21 times at 22 locations at the study site over the span of one month. Forest density in the form of BA and mean DBH were known for each location through the forest inventory mentioned above. I used a range of models to analyse interactions between $\mathrm{R}_{\mathrm{s}}, \mathrm{T}_{\mathrm{s}}, \mathrm{M}_{\mathrm{s}}$, mean DBH, BA and further variables. BA was the most important factor controlling $\mathrm{R}_{\mathrm{s}}$ rates, exceeding the effects of $\mathrm{T}_{\mathrm{s}}$ and $\mathrm{M}_{\mathrm{s}}$. Linear mixed effect models including BA reached the best results of all models, explaining up to $88 \%$ of $R_{s}$ variability. $R_{s}$ over the measurement period was $6.2 \pm 1.8 \mu \mathrm{mol} \mathrm{m}^{-2} \mathrm{~s}^{-1}$, whereby spatial variability $(C V=137 \%)$ exceeded temporal variability significantly $(C V=60 \%)$. Estimates of NEE based on EC for tropical rainforests are often problematic due to unfavourable measurement conditions at night. Such conditions exist at this study site as well and led to the dismissal of the majority of measured night-time fluxes. Four gap-filling strategies were tested of which only two led to defensible annual NEE rates. The most realistic outcome is achieved by replacing all night-time measurements with modelled data. For this purpose, the Mixfor-SVAT model, which has been used for the site before, was re-parameterised with my new $\mathrm{R}_{\mathrm{s}}$ measurements. This led to a modelled night-time respiration of $9.01 \pm 1.47 \mu \mathrm{mol} \mathrm{CO} \mathrm{CO}^{-2} \mathrm{~s}^{-1}$ which together with day-time EC measurement data resulted in an estimated annual NEE of -4.07 to $-5.29 \mathrm{MgC} \mathrm{ha} \mathrm{y}^{-1}$. The three approaches together show that the forest at the study site is a persistent carbon sink and enabled the first defensible annual NEE estimate of a tropical montane rainforest worldwide.

Keywords: tropical montane rainforest, forest inventory, aboveground biomass, basal area, soil respiration, chamber measurements, eddy-covariance, gap-filling, net ecosystem exchange, carbon cycle, Southeast Asia, Sulawesi 



\section{Zusammenfassung: Speicherung und Respiration von Kohlenstoff in einem Bergregenwald in Sulawesi, Indonesien}

Wälder spielen eine große Rolle im globalen Kohlenstoffkreislauf. Während die Kohlenstoffbilanzen vieler Waldtypen intensiv untersucht wurden, sind Informationen dieser Art über tropische Bergregenwälder noch sehr begrenzt. Ziel dieser Arbeit ist es, eine solide Schätzung der Kohlenstoffspeicherung, -respiration sowie der Kohlenstoffbilanz eines solchen Waldes in den Bergen von Sulawesi, Indonesien, zu erstellen. Zu diesem Zwecke wurden drei Ansätze kombiniert. Forstinventuren wurden verwendet, um Waldbestandsparameter wie oberirdische Biomasse (AGB), Bestandesgrundfläche (BA) und deren Änderungen zu bestimmen; Messungen der Bodenatmung $\left(\mathrm{R}_{\mathrm{s}}\right)$ lieferten einen Einblick in die Hauptkomponente der Ökosystematmung, und Eddy-Kovarianz-Messungen (EC) wurden verwendet, um den Netto-Ökosystemaustausch (NEE) abzuschätzen. Zur Schätzung langfristiger Änderungen der AGB wurden die Ergebnisse einer 2006 durchgeführten Bestandsaufnahme als Basis verwendet. Diese wurden mit den Ergebnissen einer umfangreichen Forstinventur im Jahr 2017 kombiniert und führten zu einem geschätzten jährlichen Anstieg der AGB um 2.54 Mg ha $\mathrm{y}^{-1}$. Basierend auf den Daten von 2017 wurde die $\mathrm{AGB}$ auf $321.38 \pm 9.64 \mathrm{Mg} \mathrm{ha}^{-1}$ und BA auf $37.86 \pm 0.38 \mathrm{~m}^{2} \mathrm{ha}^{-1}$ geschätzt. Um $\mathrm{R}_{\mathrm{s}}$ zu quantifizieren und die wichtigsten Einflussfaktoren zu identifizieren, wurden $\mathrm{R}_{s}$, Bodentemperatur $\left(\mathrm{T}_{\mathrm{s}}\right)$ und Bodenfeuchtigkeit $\left(\mathrm{M}_{\mathrm{s}}\right)$ 21-mal an 22 Standorten am Untersuchungsort über einen Zeitraum von einem Monat gemessen. Die Bestandesdichte in Form von BA und sowie der mittlere BHD war für jeden Standort durch die oben erwähnte Forstinventur bekannt. Eine Reihe von Modellen wurde eingesetzt, um Wechselwirkungen zwischen $\mathrm{R}_{\mathrm{s}}, \mathrm{T}_{\mathrm{s}}, \mathrm{M}_{\mathrm{s}}$, mittlerem BHD, BA und weiteren Variablen zu analysieren. Der Einfluss von $B A$ auf $R_{s}$ übertraf den aller anderen Parameter. Ein „linear mixed effect model“ welches die Einflüsse von $\mathrm{T}_{\mathrm{s}}, \mathrm{BA}$ und Dicke der Humusauflage berücksichtigte erzielte die besten Ergebnisse aller Modelle und erklärt bis zu $88 \%$ der $R_{s^{-}}$ Variabilität. Mittlere $\mathrm{R}_{\mathrm{s}}$ über den Messzeitraum betrug $6.2 \pm 1.8 \mathrm{umol} \mathrm{m}^{-2} \mathrm{~s}^{-1}$, wobei die räumliche Variabilität $(\mathrm{CV}=137 \%)$ die zeitliche Variabilität $(\mathrm{CV}=60 \%)$ signifikant überstieg. Schätzungen von NEE basierend auf EC für tropische Regenwälder sind häufig aufgrund ungünstiger Messbedingungen in der Nacht problematisch. Solche Bedingungen bestehen auch an dem hier diskutierten Untersuchungsort und führten zur Ablehnung der Mehrzahl der gemessenen Nachtflüsse. Es wurden vier Lückenschließungsstrategien getestet, von denen nur zwei zu vertretbaren jährlichen NEE-Raten führten. Das realistischste Ergebnis wird erzielt, indem alle Nachtmessungen durch modellierte Daten ersetzt werden. Zu diesem Zweck wurde das MixforSVAT-Modell, das zuvor schon für den Standort verwendet wurde, mit meinen neuen $\mathrm{R}_{\mathrm{s}}$-Messungen neu parametrisiert. Dies führte zu einer modellierten Nachtatmung von $9.01 \pm 1.47$ $\mu \mathrm{mol} \mathrm{CO}_{2} \mathrm{~m}^{-2} \mathrm{~s}^{-1}$, die zusammen mit den EC-Messdaten am Tage einen geschätzten jährlichen 
NEE von -4.07 bis -5.29 Mg C ha ${ }^{-1} \mathrm{y}^{-1}$ ergab. Die drei Ansätze zusammen zeigen, dass der Wald am Untersuchungsort eine beständige Kohlenstoffsenke ist. Kombiniert ermöglichen sie die weltweit erste realistische Einschätzung von jährlichem NEE eines tropischen Bergregenwaldes.

Schlagwörter: tropischer Bergregenwald, Forstinventur, oberirdische Biomasse, Grundfläche, Bodenatmung, Kammermessungen, Eddy-Kovarianz, Lückenschließung, NettoÖkosystemaustausch, Kohlenstoffkreislauf, Südostasien, Sulawesi 


\section{Content}

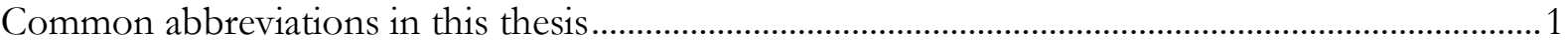

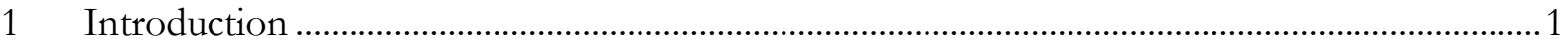

1.1 Forest in the context of the global terrestrial carbon cycle ...................................................1

1.2 Carbon storage and respiration of tropical montane rainforests in Southeast Asia...........2

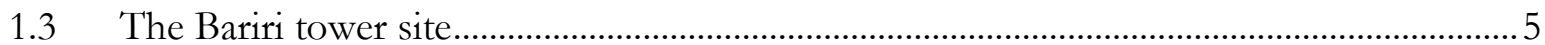

1.4 Methods for identifying $\mathrm{CO}_{2}$ - fluxes and accumulation of carbon in rainforests used in this thesis and previous work in this direction at the Bariri site ..................................................6

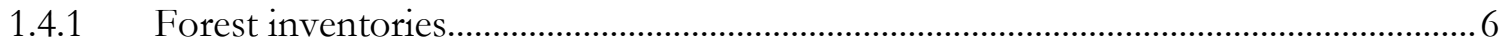

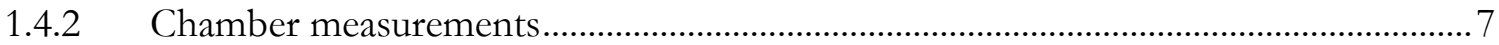

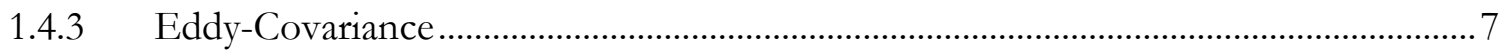

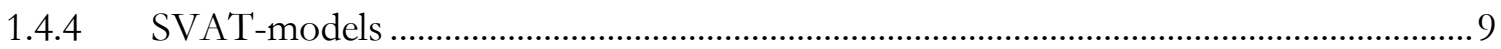

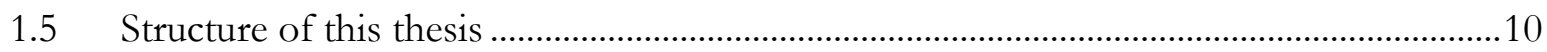

1.5.1 Aboveground biomass storage and changes thereof ………....................................... 10

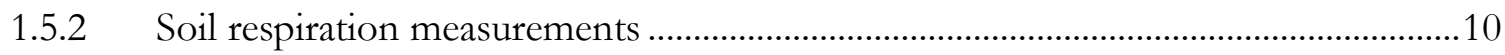

1.5.3 NEE-measurement with Eddy-covariance and canopy air $\mathrm{CO}_{2}$ storage profile......10

1.5.4 Synopsis ……………………………..................................................................... 11

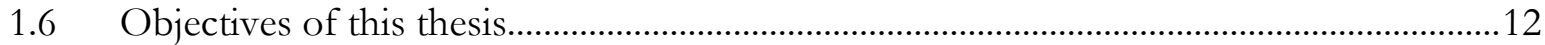

2 Structure and temporal variations of aboveground biomass in an old growth rainforest in central Sulawesi, Indonesia and the influence of height model selection ..........................................13

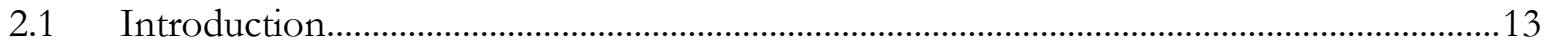

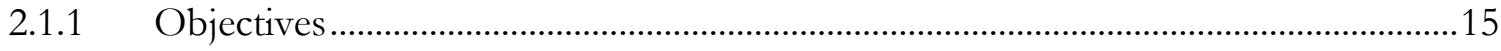

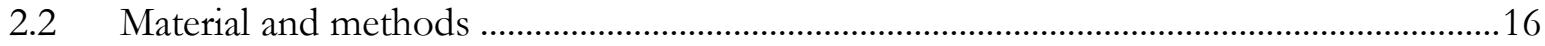

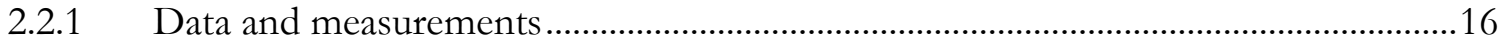

2.2.2 Changes of BA and DBH distribution.......................................................................

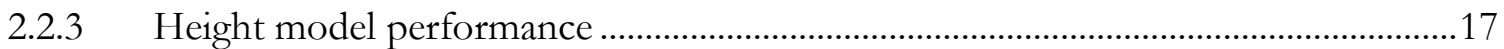

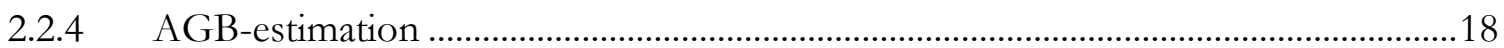

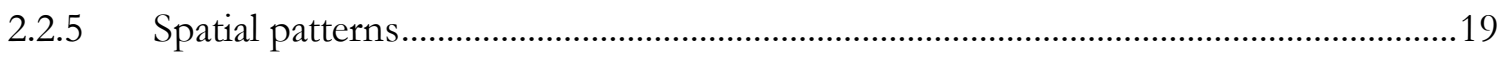

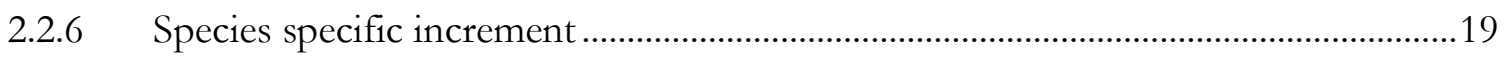

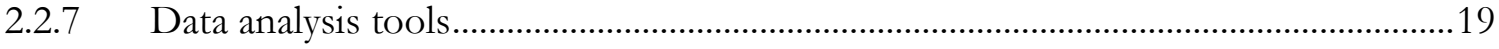

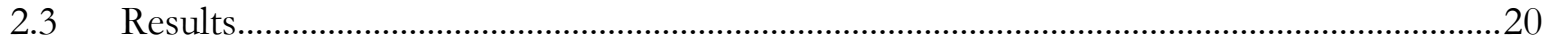

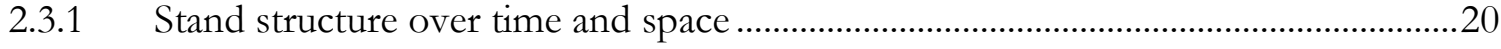

2.3.2 Height model performance ………………..................................................................23

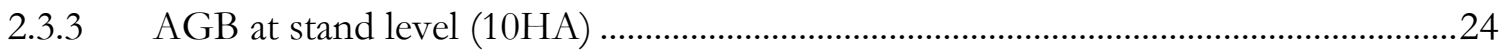

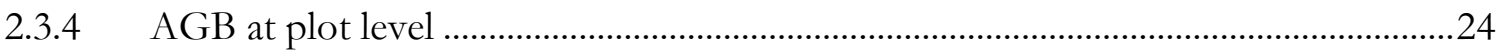




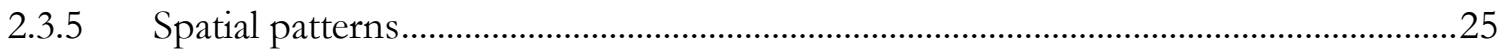

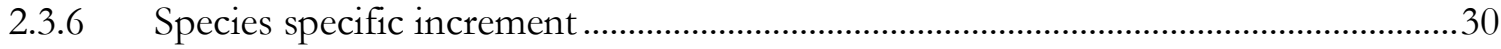

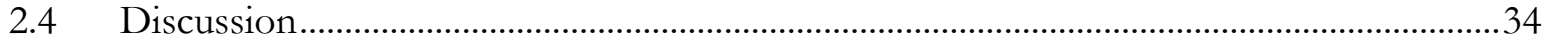

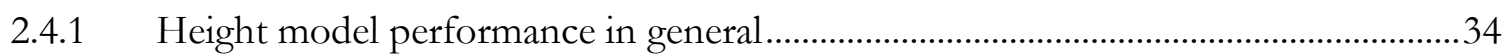

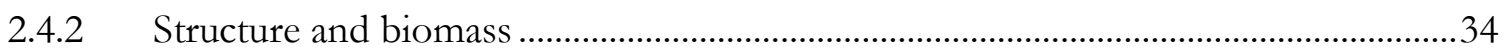

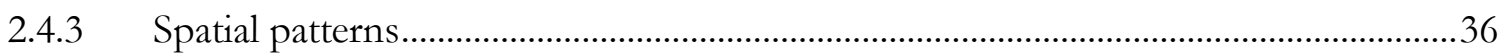

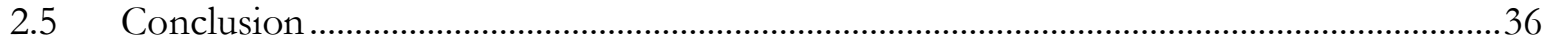

3 Forest density controls soil respiration in a montane rainforest in Central Sulawesi,

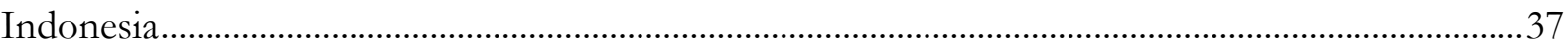

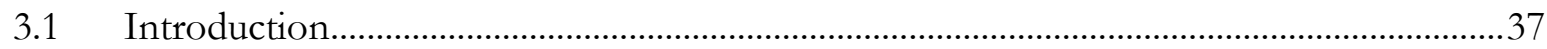

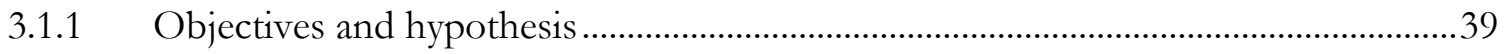

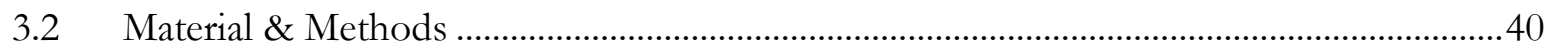

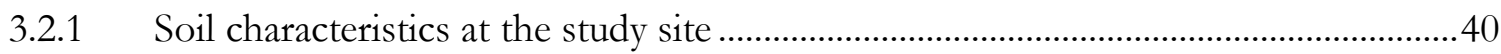

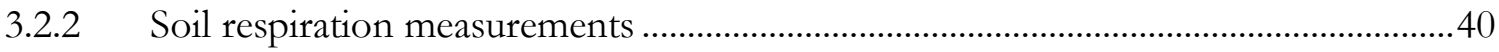

3.2.3 Meteorological long-term measurements and forest inventory ................................... 41

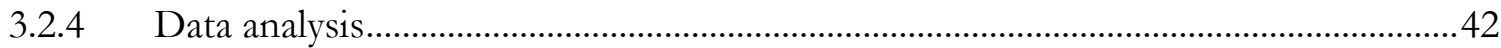

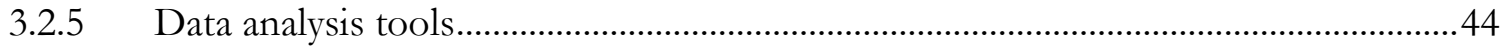

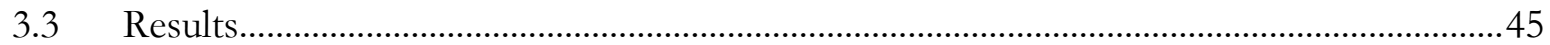

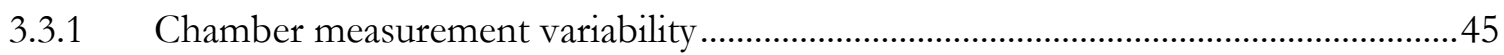

3.3.2 Temporal variability of meteorological parameters and forest spatial variability.....48

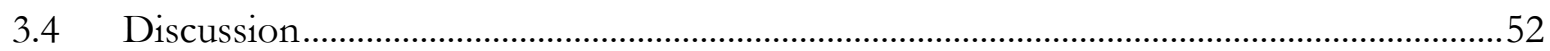

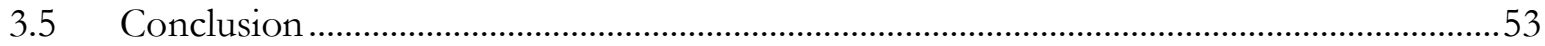

4 Eddy-Covariance based measurements of ecosystem $\mathrm{CO}_{2}$ exchange........................................55

4.1 Eddy-Covariance technique as an approach to estimate total ecosystem carbon

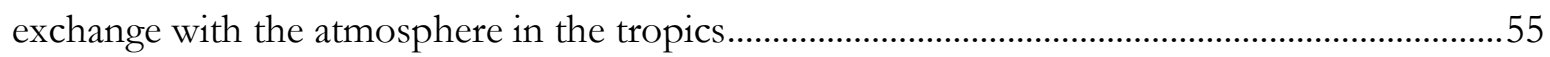

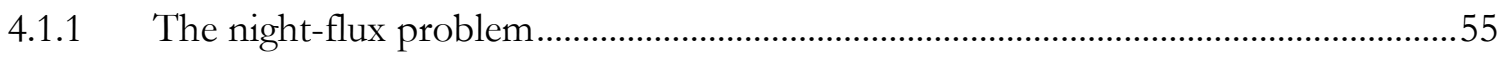

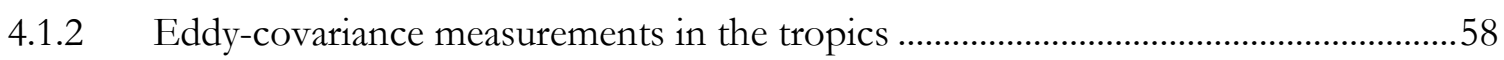

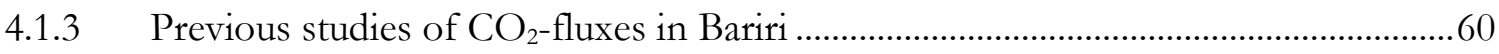

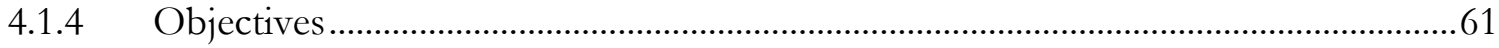

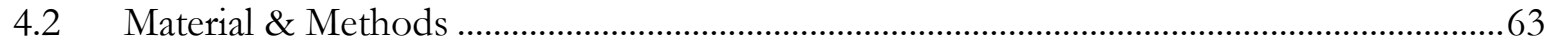

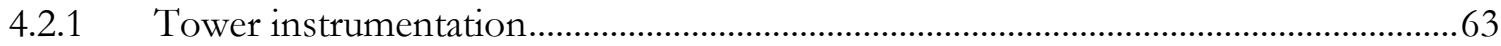

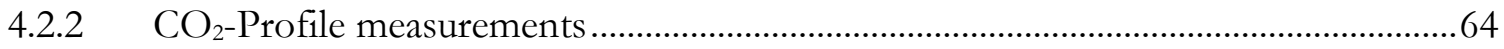

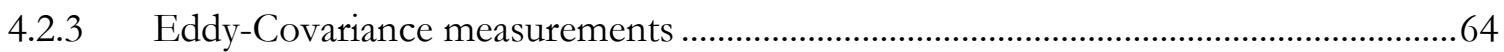

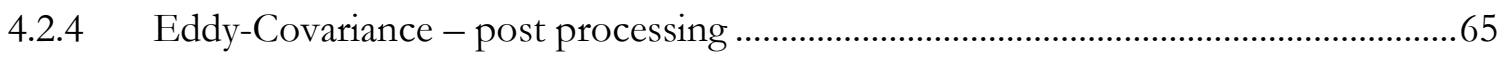

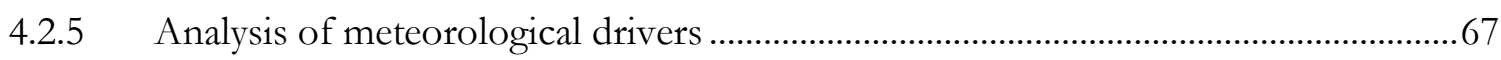




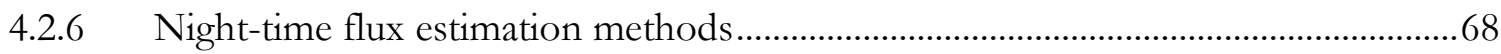

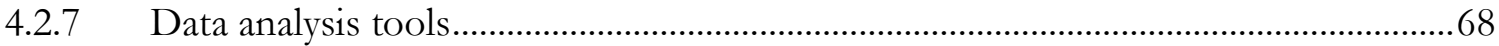

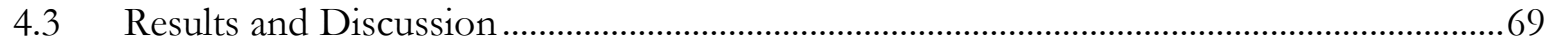

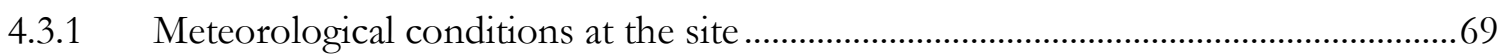

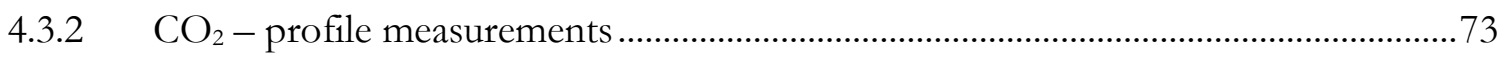

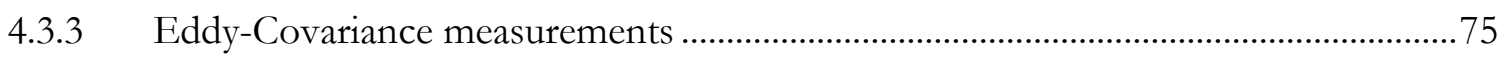

4.3.4 Eddy-Covariance post processing impacts and analysis................................................ 80

4.3.5 Meteorological drivers of EC-derived NEE .................................................................. 85

4.3.6 Eddy-Covariance night-time flux estimation results ..................................................... 91

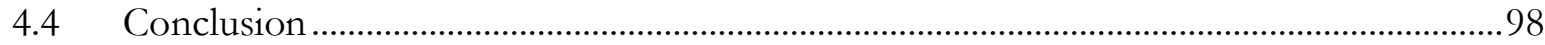

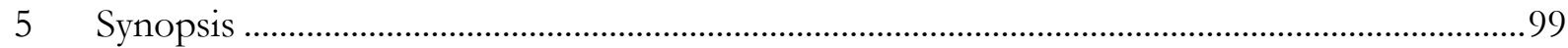

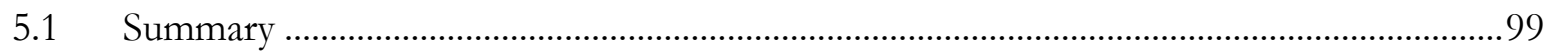

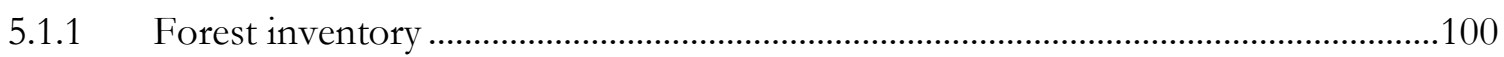

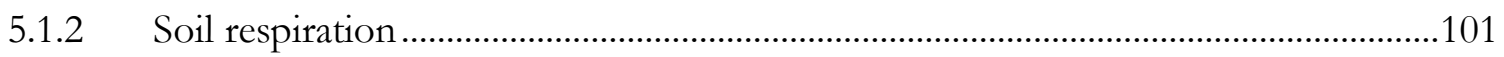

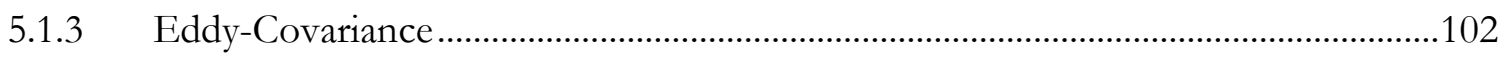

5.2 The Bariri forest in comparison to montane old-growth rainforests around the world and arguments for a strong carbon sink at the site .....................................................................104

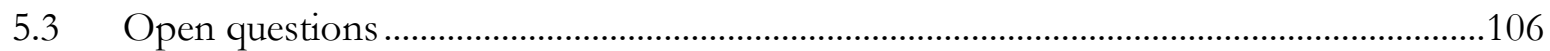

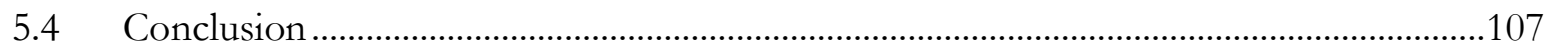

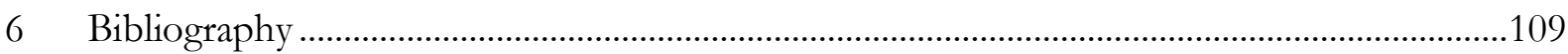

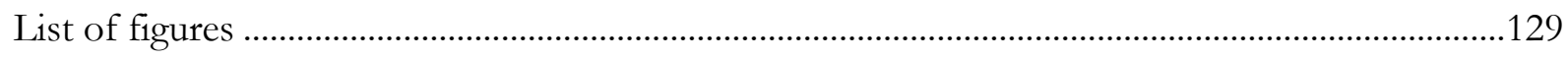

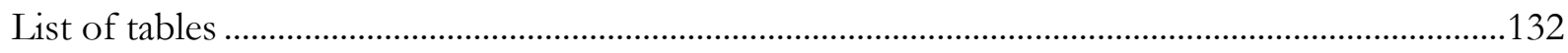

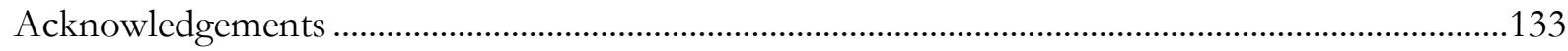





\section{Common abbreviations in this thesis}

Chapter 2

AGB - Aboveground biomass

DBH - Diameter at breast height

BA - Basal area

CSR - Complete spatial randomness

RSE - Residual standard error

Chapter 3

$\mathrm{R}_{\mathrm{s}} \quad$ - Soil respiration

$\mathrm{T}_{\mathrm{s}} \quad$ - Soil temperature

$\mathrm{M}_{\mathrm{s}} \quad$ - Soil moisture

BA - Basal area

DBH - Diameter at breast height

LR - Linear regression

MLR - Multiple linear regression

NLR - Non-linear regression

LME - Linear mixed effect model

$\mathrm{D}_{\mathrm{OL}}$ - Depth of organic layer

\section{Chapter 4}

EC - Eddy-Covariance

NEE - Net ecosystem exchange

MDS - Marginal distribution sampling

ENSO - El-Nino Southern Oscillation

RE - Ecosystem respiration

VPD - Vapour pressure deficit

$\mathrm{H}$ - Sensible heat

LE - Latent heat

$\mathrm{R}_{\mathrm{g}} \quad$ - Global radiation

PAR - Photosynthetically active radiation

QF - Quality flag

PI -Photosynthesis-irradiance 



\section{Introduction}

\subsection{Forest in the context of the global terrestrial carbon cycle}

Forests play an important role amongst terrestrial ecosystems in the context of the global carbon cycle. Not only are they a large carbon storage, containing about $80 \%$ to $92 \%$ of terrestrial plant biomass (Kindermann et al., 2008; Pan et al., 2013), they are also responsible for about half of all terrestrial net carbon uptake (Bonan, 2008; Pan et al., 2013). As forests cover large areas of the globe and grow under vastly different circumstances, species diversity and forest structure (e.g. density of stems, age distribution, vegetation layers) vary greatly (Pan et al., 2013). This leads to carbon uptake, allocation and respiration dynamics which are equally divers. Carbon uptake through photosynthesis and respiration (RE) are responsible for the majority of the $\mathrm{CO}_{2}$ exchange between the atmosphere and an ecosystem, while allocation has a strong impact of its retention time in the ecosystem (De Deyn et al., 2008).

Total ecosystem RE stems from multiple sources, mainly leaf, stem and soil respiration. The latter can be subdivided further into autotrophic respiration, which is a result of plants using stored carbon and heterotrophic respiration stemming from decomposition of dead organic matter by microorganisms (Chambers et al., 2004). Total carbon captured through photosynthesis by an ecosystem is generally referred to as gross primary productivity (GPP), the difference between GPP and RE is denoted as either net ecosystem productivity (NEP) or net ecosystem exchange (NEE). The main difference between NEP and NEE are opposite sign conventions. While NEP has a positive sign for carbon accumulation in an ecosystem, the point of view for NEE is the atmosphere and carbon withdrawn from this pool, i.e. carbon uptake by an ecosystem, has a negative sign. For a schematic overview of the main components of the carbon cycle in a rainforest see Figure 1.

Forests are impacted by climatic and human influences and are constantly changed accordingly. During the last decades however, these changes have been accelerated. Global warming rapidly changes environmental conditions for forests, its long term effects on forests still uncertain (Boisvenue and Running, 2006; Bonan, 2008). While current trends for forest area and therefore biomass in temperate zones are unclear (Hansen et al., 2013; Potapov et al., 2009), tropical forests are under continuous pressure through large scale deforestation and degradation of forests (Baccini et al., 2012; Pan et al., 2011). This has major impacts on the global terrestrial carbon cycle as tropical 
forest account for 34\% of global GPP (Beer et al., 2010), 35\% of global NEE and two-thirds of terrestrial biomass (Pan et al., 2013).

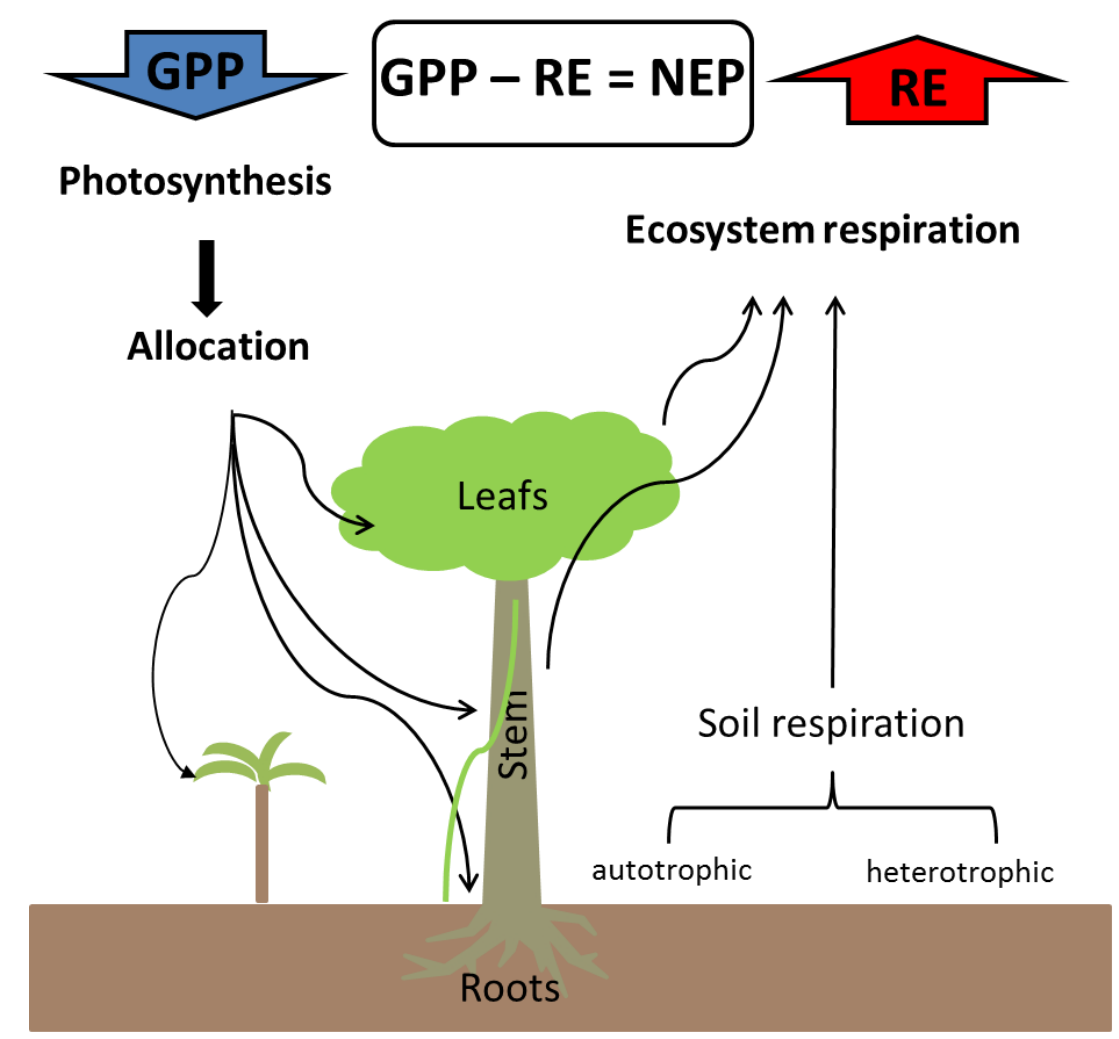

Figure 1: Schematic overview of the main components of the carbon cycle in a rainforest.

\subsection{Carbon storage and respiration of tropical montane rainforests in Southeast Asia}

Tropical forests are estimated to store about $393.3 \mathrm{Pg} \mathrm{C}$ worldwide, $56 \%$ of which is accumulated in biomass and 32\% in soil (Pan et al., 2011, 2013). A recent pantropical study suggests that unmanaged mature tropical forest stands contain 165.49 $\pm 13.74 \mathrm{Mg} \mathrm{C} \mathrm{ha}^{-1}$ (Anderson-Teixeira et al., 2016). These large carbon stocks in the tropics have been reduced through deforestation and degradation of forests by $-2.94 \pm 47 \mathrm{Pg} \mathrm{y}^{-1}$ from 1990-2007 (Pan et al., 2011) and are still declining, especially in Brazil, Indonesia and other regions of Southeast Asia (Zeppetello et al., 2020).

Overall, $26 \%$ of tropical forest biomass is found in Southeast Asia. Including all areas with a tree cover $>10 \%$, the total amount of carbon stored in rainforests in Indonesia alone is approximately 
24 Gt C. About $82 \%$ of this biomass is accumulated in forests with above-ground biomass (AGB) exceeding $250 \mathrm{Mg} \mathrm{ha}^{-1}$ (Saatchi et al., 2011).

Direct measurements of carbon storage in a forest without destructive sampling (e.g. coring) is practically impossible. Therefore, AGB estimates are often used as proxies for carbon storage. As AGB is mostly comprised of woody biomass in forest ecosystems and a carbon content of $\sim 50 \%$ has been found repeatedly for woody biomass (Hughes et al., 1999; Losi et al., 2003), the same proportion of carbon in AGB is often assumed (Brown et al., 1993).

High AGB estimates are often found in tropical montane forests in the region. A forest on Mount Kinabalu on Sumatra has an AGB of $280 \mathrm{Mg} \mathrm{ha}^{-1}$ (Aiba and Kitayama, 1999; Kitayama and Aiba, 2002) whereas Culmsee et al. (2010) found AGBs exceeding $280 \mathrm{Mg} \mathrm{ha}^{-1}$ in 4 forests located above $1000 \mathrm{~m}$ a.s.l. on Sulawesi. For all montane rainforests in insular tropical Asia, a mean AGB of 304 $\mathrm{Mg} \mathrm{ha}^{-1}$ (CV 27\%) was estimated (Brown et al., 1993). Repeated forest inventories of the same sites over longer time periods yield estimates of yearly AGB increases. For 5 sites in old-growth forests above an altitude of $1000 \mathrm{~m}$ a.s.l on Borneo, mean yearly AGB change was estimated as $-0.7 \pm 3.1$ $\mathrm{Mg} \mathrm{ha}{ }^{-1} \mathrm{y}^{-1}$ (Requena Suarez et al., 2019).

Soil respiration is the major component of total ecosystem RE in many rainforests (Chambers et al., 2004; Hutyra et al., 2008; Rubio and Detto, 2017). So far however, there are only two studies from tropical montane old-growth rainforests in South-East Asia investigating this important component which have been published in international scientific journals. The most recent study was carried out in a montane rainforest on Sulawesi, Indonesia, at $1050 \mathrm{~m}$ a.s.l., resulting in a soil respiration estimate of $3.1 \mu \mathrm{mol} \mathrm{m}^{-2} \mathrm{~s}^{-1}$ (van Straaten et al., 2011). Soil respiration more than twice as high were measured by Hashimoto et al. (2004), who reported an estimated annual mean of 6.8 $\mu \mathrm{mol} \mathrm{m} \mathrm{s}^{-1}$ for a montane forest in Thailand.

The two other major components of ecosystem RE are severely understudied in Southeast Asian rainforests. Besides one study on leaf respiration at the site discussed in this thesis (Rakkibu, 2008), no published studies reporting measurements of these $\mathrm{CO}_{2}$ sources could be found.

Besides direct measurements of biomass changes or individual components of total ecosystem RE, measurements of the $\mathrm{CO}_{2}$ exchange between the ecosystem and the atmosphere are possible with the eddy-covariance method (Baldocchi, 2003). Studies using this technique in montane rainforests of Southeast Asia were yet again limited to previous results from the site discussed in this thesis (Ross, 2007). 
While estimates of carbon stocks and rates of changes therein in tropical forests have a high uncertainty (Houghton, 2005), this information is nevertheless critical to assess the role these ecosystems play in the global carbon cycle and for the implementation of measures to reduce degradation of forests and deforestation such as REDD+ (Gibbs et al., 2007). In view of large carbon losses from Southeast Asian tropical rainforests, knowledge about C-stocks and fluxes from the remaining old-growth forests in this biome are important to estimate future impacts on the global carbon cycle. 


\subsection{The Bariri tower site}

The study site is an old-growth tropical montane rainforest in the Lore Lindu national park in Central Sulawesi, Indonesia (1³9.47’ S, 120¹0.409’ E, Figure 2), which is an important conservation area (Cannon et al., 2007). It is located about $1440 \mathrm{~m}$ a.s.l.. Rainfall typically decreases slightly from May to October and local climate is mostly influenced by the Intertropical Convergence Zone. Meteorological parameters and $\mathrm{CO}_{2}$ fluxes are measured at a $70 \mathrm{~m}$ scaffold tower inside the forest (Olchev et al., 2015). Mean annual rainfall from January 2014 - January 2017 was $2307 \mathrm{~mm}$ and mean air temperature $20.5^{\circ} \mathrm{C}$. The forest is very dense with 592 trees ha ${ }^{-1}$ with a DBH $>10 \mathrm{~cm}$ and 74 different tree taxa are present (Culmsee and Pitopang, 2009). Consequently, the leave area index (LAI) is very high with approximately $7.2 \mathrm{~m}^{2} \mathrm{~m}^{-2}$ (Olchev et al., 2015). The soil has been described as Rhodic Ferralsol (Brambach et al., 2017).

The Lore Lindu national park is a UNESCO biosphere reserve and national park since 1977. After forests in the area of the national park recovered for a while since the mid- $18^{\text {th }}$ century, deforestation picked up speed at the start of the $20^{\text {th }}$ century (Biagioni et al., 2016). There was no logging at the site in the recent past, but harvesting of rattan took place until the construction of the tower. Today the Lore Lindu national park is part of the REDD+ framework (Howell, 2015). More specific site details are described in each chapter.

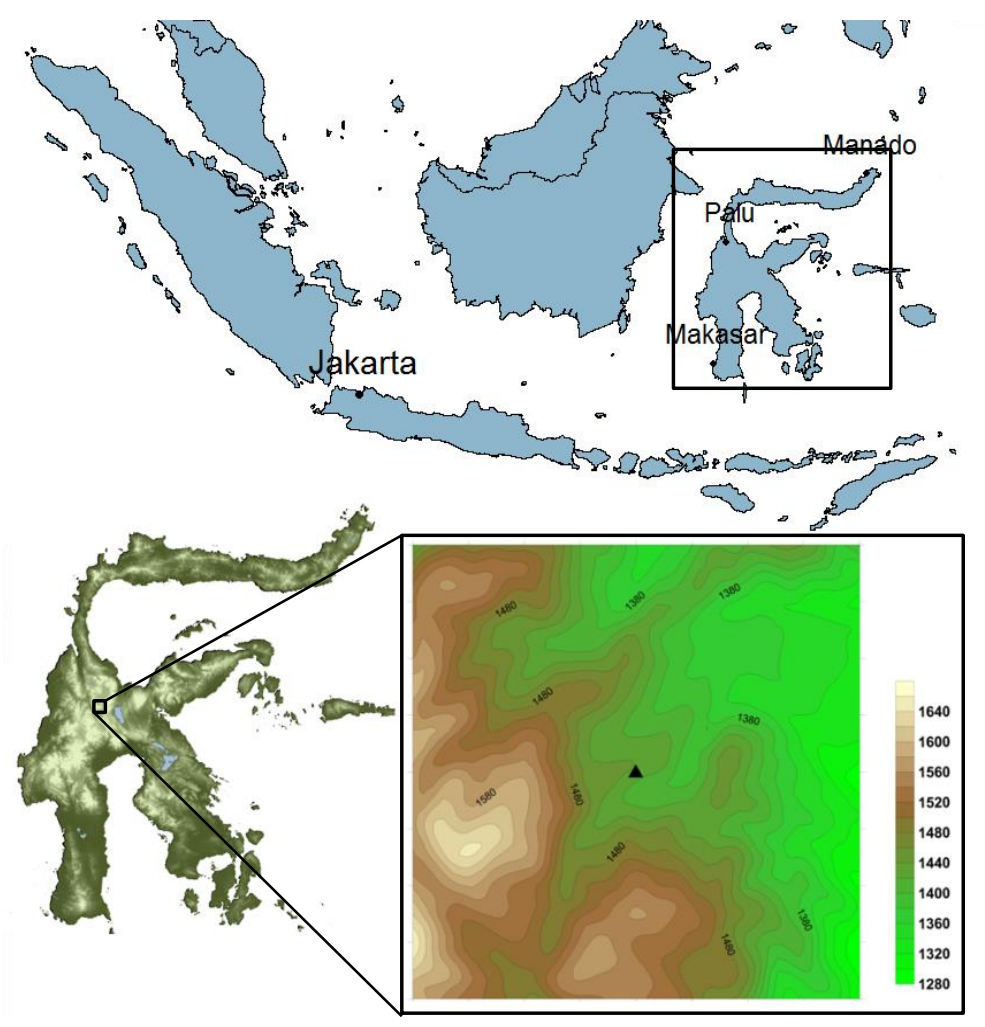

Figure 2: Location of the study site in central Sulawesi, Indonesia. 


\subsection{Methods for identifying $\mathrm{CO}_{2}-$ fluxes and accumulation of carbon in rainforests used in this thesis and previous work in this direction at the Bariri site}

\subsubsection{Forest inventories}

The oldest approach to estimate changes of carbon stocks in tropical forests is probably repeated forest inventories in combination with allometric models. Forest inventories can be carried out in multiple ways, but the core components are generally the measurement of tree diameters $1.3 \mathrm{~m}$ above the ground (diameter at breast height, $\mathrm{DBH}$ ) and the measurement of tree heights at locations (plots) in the forest, selected according to a sampling scheme. This sample of trees is then used to infer $\mathrm{DBH}$ and height characteristics of the general tree population in the forest. To estimate biomass, allometric models are combined with the measured variables (Kleinn, 2007).

These allometric models are calibrated by a combination of forest inventory measurements and subsequent harvesting of trees. After harvesting, a model is fitted to describe the relationship between measurements taken while the trees were standing and their biomass determined after felling. Such calibrated models are then used to infer aboveground tree biomass (AGB) from non-destructive measurements of tree diameter alone, or in combination with tree height (Gibbs et al., 2007). It has been shown however that the utilisation of locally measured heights in these models greatly improves the accuracy of biomass estimates (Chave et al., 2005; Feldpausch et al., 2012; Hunter et al., 2013). While the basic principles of allometric models were developed for managed forests in temperate climates, a wide variety of these models specifically designed for tropical biomes exists today (Brown et al., 1989; Chave et al., 2005, 2014; Feldpausch et al., 2011). For temperate forests, species specific models were developed, whereas models for the tropics are more general and are applied to broad categories such as 'wet tropics', as forest stands can contain more than 300 different species (Chave et al., 2005). This approach obviously has its drawbacks as similarity of biomass to diameter/height ratios in a very diverse biome and across very different species is assumed. Results should therefore always be treated as estimates with an uncertain error term. (Clark and Kellner, 2012).

Measurements using the described forest inventory tools and deriving AGB estimates with a pantropic allometric model at the Bariri site were carried out in 2006 by Culmsee et al.. These resulted in an estimated AGB of 293.4 $\pm 13 \mathrm{Mg} \mathrm{ha}^{-1}$ (Culmsee et al., 2010). 


\subsubsection{Chamber measurements}

To disentangle total ecosystem respiration into its three main sources (soil-, leaf-, stem respiration), direct measurements of those components are required, which is usually achieved through in-situ gas exchange chamber measurements (Chambers et al., 2004). To estimate $\mathrm{CO}_{2}$-fluxes, the source (e.g. leaf, stem surface, soil surface) is covered by a "chamber" which is connected to an infrared gas analyser (IRGA). The air inside the chamber is pumped via non-absorbent tubes to the IRGA over a certain amount of time. The IRGA uses the characteristic wavelength absorption spectrum of $\mathrm{CO}_{2}$ to determine gas concentrations at previously set times during the measurement interval. The differences between these concentrations are then used to infer $\mathrm{CO}_{2}$-fluxes from the source to the chamber airspace (Long et al., 1996).

While accuracy of measurements have increased with technological developments, upscaling of these measurements to ecosystem wide respiration estimates remains difficult in tropical rainforests (Malhi, 2012). Due to high species diversity and structural complexity in combination with difficult work conditions, studies measuring leaf- and stem respiration of many individual trees in rainforests remain rare (Asao et al., 2015; Chambers et al., 2004; Katayama et al., 2016; Stahl et al., 2013). Soil respiration has been measured at more rainforest sites, yet the high spatial variability discovered in many studies suggests that site specific measurements are needed (Metcalfe et al., 2007).

Leaf respiration rates at the study site were investigated by Golam Rakkibu and published in his doctoral thesis (Rakkibu, 2008). Stem and soil respiration were also measured previously, but never published.

\subsubsection{Eddy-Covariance}

Eddy-covariance (EC) measurements provide an estimate of bulk $\mathrm{CO}_{2}$-fluxes between an ecosystem and the atmosphere (Malhi, 2012). The EC-technique's core principle is the turbulent transport of trace gases in the atmosphere by up- and downward moving air. The flux $F_{c}$ of the trace gas $c$ is calculated as the covariance between the vertical wind flux $w$ and the concentration of $c$ while correcting for different air densities $\rho_{a}$, (Baldocchi, 2003):

Eq. 1.1

$$
F_{c}=\bar{\rho}_{a} * \overline{w^{\prime} c^{\prime}}
$$

Overbars denote the Reynolds averaging operator and primes the departure from the time average. This rather simple formula becomes very complicated, if the range of fluxes that usually occur in an ecosystem is accounted for. Generally accepted but still simplified is the following equation for NEE which assumes incompressibility of air (Feigenwinter et al., 2004; Finnigan, 1999; Finnigan et al., 2003): 
Eq. 1.2

$$
\begin{gathered}
N E E=\overline{w^{\prime} c^{\prime}}\left(z_{r}\right)+\int_{0}^{z_{r}} \frac{\overline{\partial c(z)}}{\partial t} d z+\int_{0}^{z_{r}}\left(\bar{w}(z) \frac{\partial \bar{c}(z)}{\partial z}\right) d z \\
\text { I } \\
+\int_{0}^{z_{r}}\left(\bar{u}(z) \frac{\partial \bar{c}(z)}{\partial x}+\bar{v}(z) \frac{\partial \bar{c}(z)}{\partial y}\right) d z
\end{gathered}
$$

IV

Longitudinal, lateral and vertical wind velocities are denoted by $v, u$ and $w$, respectively. Correspondingly, $x, y$ and $z$ stand for the axes of a Cartesian coordinate system while overbars continue to stand for the Reynolds averaging operator and primes for departures from the time average. This equation is comprised of the vertical flux (I), the storage flux below the ECmeasurement setup (II) and vertical (III) as well as horizontal (IV) advection. Horizontal turbulent flux divergence and horizontal variation of vertical turbulent fluxes are not accounted for in this formulation (Feigenwinter et al., 2008).

The importance of the different terms depends on the circumstances at the measurement site as well as atmospheric conditions at the time measurements are taken. Ideal conditions for EC are given if the terrain is flat and homogeneous, while mean vertical wind speed over longer time spans has to be zero and atmospheric turbulence must be fully developed for this technique to work properly (Baldocchi, 2003; Burba and Anderson, 2010).

Under perfect conditions, the vertical flux (I) would be the only important flux. Especially under tall vegetation however, the storage flux (II) can become large, although it should be zero over long time spans. Horizontal (III) and vertical (IV) advection are important if stable atmospheric conditions prevail and are most pronounced at sites on sloped terrain or with recurring breezes (Aubinet, 2008; Feigenwinter et al., 2008).

Such stable atmospheric conditions as well as low wind speeds are common in tropical forests, especially during the night (de Araújo et al., 2008). Coupled with large night-time ecosystem respiration relative to daytime uptake in such forests, NEE estimates of rainforests derived from EC measurements are dispositioned to overestimate carbon uptake rates in tropical rainforests (Hayek et al., 2018; Tóta et al., 2012).

Such considerations so far prevented all attempts to publish NEE estimates based on EC measurements at the Bariri site in peer-reviewed journals. The only citable resource is the doctoral thesis by Thomas Roß (Ross, 2007), who measured EC-fluxes from $15^{\text {th }}$ October 2003 to $15^{\text {th }}$ June 2005 at the site, leading to an estimated sink strength of $-9.58 \mathrm{Mg} \mathrm{C} \mathrm{ha}^{-1} \mathrm{y}^{-1}$ (Ross, 2007). 


\subsubsection{SVAT-models}

In order to better understand ecosystem processes and to fill gaps in observational data, a range of SVAT-models (Soil-Vegetation-Atmosphere-Transport) have been developed. These range from 'big-leaf' to multi-layer models and while the latter may include more detailed process descriptions, the former are often used to describe large-scale phenomena (Falge et al., 2005). One of these multi-layer models is Mixfor-SVAT, built to investigate the energy, $\mathrm{H}_{2} \mathrm{O}$ and $\mathrm{CO}_{2}$ fluxes between structurally complex forests and the atmosphere (Olchev et al., 2008).

For Bariri, the Mixfor-SVAT model was parameterised by Olchev et al. (2008) with the aforementioned locally measured leaf respiration data (Rakkibu, 2008), EC-measurements (Ross, 2007) and the unpublished stem and soil respiration rates. 


\subsection{Structure of this thesis}

While this first section of the thesis gives a broad overview of carbon storage and respiration in montane tropical rainforests as well as their importance for the global terrestrial carbon cycle, the following sections will focus on different parts of this cycle.

\subsubsection{Aboveground biomass storage and changes thereof}

In the second section of this thesis (chapter 2), temporal changes in aboveground-biomass (AGB) stored in trees with a $\mathrm{DBH} \geq 10 \mathrm{~cm}$ will be described based on results of consecutive forest inventories (Figure 3 (a)). This approach is well established and provides conservative estimates of total ecosystem AGB, as it considers larger trees only and completely disregards non-tree biomass. Measured changes in AGB presented in this section will be invaluable as independent benchmark for ecosystem carbon storage changes based on EC-measurements.

Furthermore, three different DBH-height models are compared and the feasibility to apply these models with unchanged parameters over a longer time span is tested. The underlying idea is to enable forest inventories of the same area in the future without measuring heights each time.

\subsubsection{Soil respiration measurements}

The third section (chapter 3) focuses on the main component of $R E$, soil respiration $\left(R_{s}\right.$, Figure 3 (b)). Over the course of one month, $R_{s}$ at 22 locations was measured 21 times with an LI-8100103 (LI-COR Biosciences, USA) survey chamber. Measurements were undertaken during 4 time windows: 05:00 - 07:00 hours, 11:00 - 13:00 hours, 17:00 - 19:00 hours and 23:00 - 01:00 hours. Afterwards, the influence of meteorological as well as forest stand parameters on these measurements were investigated. To this end, simple linear, multiple linear and non-linear regression models as well as linear fixed-effect models were used to establish correlations between these parameters and $R_{s}$.

Finally, the temporal variability of meteorological parameters and forest biomass was investigated to determine, if the $\mathrm{R}_{\mathrm{s}}$ measurements could be seen as representative for the larger area and longer time spans.

\subsubsection{NEE-measurement with Eddy-covariance and canopy air $\mathrm{CO}_{2}$ storage profile}

The fourth section (chapter 4) covers NEE estimates based on EC measurements. The ECmeasurement setup consists of a LI-7500A (Licor Inc., USA) open-path IRGA and an USA-1 omnidirectional sonic anemometer (METEK, Germany). A canopy air $\mathrm{CO}_{2}$ storage measurement profile consisting of air intakes at $0.25,1,2,24,38$ and $48 \mathrm{~m}$ height, which were connected to an LI-820 IRGA (Licor Inc., USA) was added later on (Figure 3 c). 
As there are large data-gaps especially during night-time, four gap-filling strategies and their influences on estimates of annual NEE are discussed in detail. Results of section 2 and 3 are then used to evaluate if these strategies lead to defensible NEE estimates for the Bariri site.

\subsubsection{Synopsis}

The final section of this thesis combines the results presented in chapters $2-4$, compares them to findings from rainforests around the world and discusses possible explanations for deviations from these findings. It closes with considerations concerning information still missing for a complete picture of the $\mathrm{CO}_{2}$ cycle at the Bariri site and an overall conclusion.

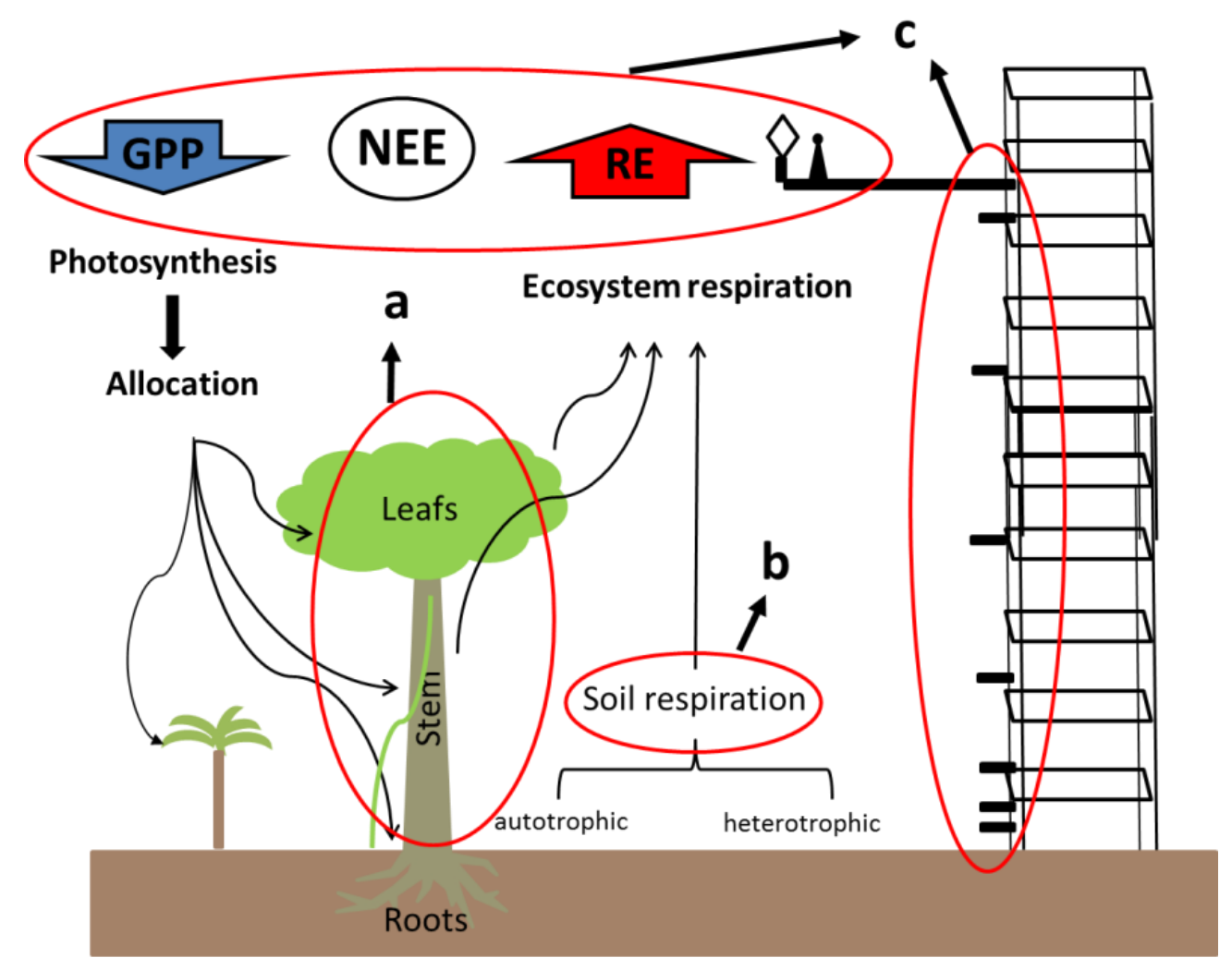

Figure 3: Overview of the $\mathrm{CO}_{2}$-cycle components estimated by the three approaches used in this thesis. a) Estimation of aboveground biomass and changes therein through forest inventories; $b$ ) Soil respiration measurements along a transect with a mobile soil chamber system; c) NEE estimation through eddy-covariance measurements coupled with a $\mathrm{CO}_{2}$-concentration profile measurement system. 


\subsection{Objectives of this thesis}

This thesis has three major objectives:

- To estimate aboveground biomass and changes therein. This objective is addressed through forest inventory measurements and discussed in detail in chapter 2

- To estimate soil respiration and its variations in time and space. $R_{s}$ measurements were carried out to achieve this objective and are covered in detail in chapter 3

- To achieve defensible annual Net Ecosystem Exchange estimates. To address this objective, results from chapter 2 and 3 are combined with EC measurements in chapter 4. Possible explanations for the results presented in chapter 4 are furthermore discussed in chapter 5 . 


\section{Structure and temporal variations of aboveground biomass in an old growth rainforest in central Sulawesi, Indonesia and the influence of height model selection}

\subsection{Introduction}

Estimates of global tropical forest carbon stocks are often derived from biome averages and have a wide error margin (Gibbs et al., 2007). Accurately assessing geographic distributions of biomass are necessary to report and evaluate changes in carbon storage (Feldpausch et al., 2012). To improve the precision of biomass estimates, especially for dense tropical forests (Pan et al., 2011), ground-based forest inventories are useful. However for certain forest types, their availability is sparse. For instance, a recent new estimate of aboveground biomass (AGB) change over time in old-growth tropical montane rainforests in Asia relied on data from 5 sites only and resulted in an estimate of $-0.7 \pm 3.1 \mathrm{Mg} \mathrm{ha}^{-1} \mathrm{y}^{-1}$ (Requena Suarez et al., 2019). This means that for many regions, no data is available at all. While there have been multiple studies on tree diversity and biogeographic patterns on Sulawesi (Brambach et al., 2017; Culmsee et al., 2011; Culmsee and Pitopang, 2009; Kessler et al., 2005; Roos et al., 2004), studies on AGB in old-growth rainforests of Sulawesi are rare (Culmsee et al., 2010; Hertel et al., 2009). Records from long-term plots are non-existent to my knowledge.

In order to obtain precise estimates from forest inventories, these have to be planned carefully and objectives should be defined clearly (Kleinn, 2007). A priori knowledge of spatial patterns in a forest are helpful in selecting proper inventory protocols for such inventories, which aim to cover as much of the variability of the forest as possible (Fortin et al., 1990; Häbel et al., 2019). Additionally, spatial patterns in forests are indicators of tree interactions and can help to understand ecological processes. The spatial arrangement of trees in a forest is an artefact of all processes influencing germination, growth and mortality. Some of these factors can be quantified using second-order measures of point processes and thus yield insights into the dynamics of tree stands (Chiu et al., 2013; Gavrikov and Stoyan, 1995).

To estimate tree AGB from forest inventory data, a variety of allometric equations adapted to local conditions were developed for tropical regions (Brown, 1997; Brown et al., 1989; Chave et al., 2005, 
2014). While equations which solely require diameter at breast height (DBH) as biomass predictor exist (Chave et al., 2005), models incorporating wood density and tree height are more precise (Chave et al., 2005, 2014; Feldpausch et al., 2012). This poses a challenge as height measurements are time consuming if done correctly, especially in dense forests (Larjavaara and Muller-Landau, 2013). Therefore, it would be advantageous to develop strategies which minimise the height measurement efforts for a certain accuracy (Hunter et al., 2013). A widely used approach is measuring tree heights of a sub-sample, to which DBH-height models are subsequently fitted. Diameter-height models for tropical forest on continental scale, to be used in case height data is missing, have been developed but localised measurements and site specific height models are preferable (Feldpausch et al., 2011; Ledo et al., 2016; Sullivan et al., 2018).

Ledo et al. (2016) found that of those locally derived DBH-height models the three parameter Weibull function, followed by the Michaelis-Menten model performed best in three different tropical forest stands. The performance of these two models as well as a log-log linear model in conjunction with different sampling strategies was tested for 73 plots across the tropics by Sullivan et al. (2018). However, the temporal stability of these relationships has not been evaluated.

Additionally, height measurements themselves can be a source of errors. Larjavaara and MullerLandau (2013) found that height measurements as such can yield very robust results even in the tropics when carried out by trained personnel. When untrained personnel was involved, strong biases were observed (Larjavaara and Muller-Landau, 2013). As height measurements of every tree are labour intensive, it would also be advantageous to measure only sub-samples of all trees. 


\subsubsection{Objectives}

The three objectives addressed in this chapter are:

- To estimate AGB, DBH and changes thereof. To estimate changes in AGB and DBH at different spatial and temporal scales, possibly the first repeated and thorough inventories in this area had to be planned and conducted. This information is necessary to assess changes in carbon storage of AGB and to constrain further carbon budget estimations

- To investigate spatial patterns in tree distribution at the site and to establish if these changed from one inventory to the next. To decide whether the long-term plot is suitably sized to capture the dynamics of the forest at the site and to inform the planning of the large scale inventory, special patterns in tree distribution were investigated by using spatial statistics.

- To investigate the temporal and spatial stability of DBH-height models. To establish if allometric relationships stay stable over longer periods of time and to decide if height measurements could be undertaken at longer time intervals than diameter measurements, DBH-height model performance over time had to be investigated. 


\subsection{Material and methods}

\subsubsection{Data and measurements}

In 2006, three 40x60 m plots were established at the Bariri site. Of all trees with an DBH $\geq 10 \mathrm{~cm}$ inside those plots, DBH, height and position as well as species were recorded (Culmsee et al., 2010; Culmsee and Pitopang, 2009). I used this spatially referenced data to analyse spatial patterns of tree positions as well as tree competition and to describe differences in $\mathrm{DBH}$ density distribution, $\mathrm{BA}$ and AGB between 2006 and 2017. A common error source in repeated forest inventories are non-documented changes of diameter measurement heights. Such changes are frequent in the available data from 2006 and it was therefore not used to calculate individual tree diameter increment to avoid over- or underestimations.

In one of these plots however, DBH and height for all trees with a DBH equal or greater than 10 cm were again measured in August 2011 by Brambach et al. as part of a larger study of tree diversity in Sulawesi (Brambach et al., 2017), this time with deviations from $1.3 \mathrm{~m}$ measurement height documented. Because of its position North-East of a meteorological tower, it will be referred to as NE-plot. Re-inventories of the NE-plot were conducted in October 2014 and April 2017. These data sets will be referred to from now on as NE11, NE14 and NE17. An additional 10 ha of the old-growth rainforest surrounding the meteorological tower was surveyed in 2017 (referred to as $10 \mathrm{HA}$ further on) to examine if the NE-plot was representative for the area and to expand the analysis to a larger area. Concerning the NE-plot, the measurement protocol established by Brambach et al. (2017) was followed in 2014 and 2017. DBH or the diameter at a previously established point of measurement was measured (if it was still feasible) for all trees with a diameter $\geq 10 \mathrm{~cm}$ with a diameter tape. Interfering lianas or epiphytes were removed. Each tree height was recorded as arithmetic mean of three consecutive height measurements with a Vertex III hypsometer (Haglöf, Sweden).

From preliminary analysis of spatial statistics for the years 2006, 2011 and 2014, complete spatial randomness (CSR) of tree distribution was assumed and a regular 40x40 $\mathrm{m}$ grid sampling design was chosen for the 10 ha inventory. The survey covers the area around the meteorological tower in a parallelogram oriented along the main wind direction. At each grid intersection, a circular plot with $7.98 \mathrm{~m}$ radius $\left(200 \mathrm{~m}^{2}\right)$ was established, resulting in 64 plots covering $12.8 \%$ of the area. Plot radius was corrected for terrain inclination. Tree DBH and height were measured according to the protocol applied at the NE-plot. While $\mathrm{DBH}$ of all trees with $\mathrm{DBH} \geq 10 \mathrm{~cm}$ inside the plots were measured, only one tree height per diameter class was recorded per plot. Diameter classes were set to 10 to $<30 \mathrm{~cm}, 30$ to $<50 \mathrm{~cm}$ and $>50 \mathrm{~cm}$. As a result, tree heights were measured for 154 out 
of $731(21 \%)$ trees on all 64 plots. Based on an analysis of height model performances (see later sections), the missing 533 tree heights were estimated with the Weibull diameter-height model. All measurements were conducted by the same team for NE14, NE17 an 10HA.

\subsubsection{Changes of $\mathrm{BA}$ and $\mathrm{DBH}$ distribution}

$\mathrm{BA}$ is used to compare stand density observed during different inventories. Additionally, I tested if the means of the DBH distributions of the inventory from 2006 and the 10HA inventory were significantly different via t-test to establish, if both inventories covered structurally similar areas of the forest. To discover a potential topographic gradient in the $10 \mathrm{HA}$ inventory, means of transects were tested for significant differences with an ANOVA. Furthermore, a visual overview of DBHdistributions of all data sets is given.

\subsubsection{Height model performance}

To establish how height model selection influences height estimations and to select the best model for predicting the missing heights of the 10HA inventory, I compared the performance of log-log linear least squares regression (Eq.2.1), Weibull (Eq.2.2) and Michaelis-Menten (Eq.2.3) height model fits based on all trees with known height for the $10 \mathrm{HA}$ inventory and the three measurement years $(2011,2014,2017)$ from the NE-plot.

Eq. 2.1

$$
\ln (H)=a+b *(\ln (D B H))
$$

Eq. 2.2

$$
H=a *\left(1-\exp \left(-(D B H / b)^{c}\right)\right)
$$

Eq. 2.3

$$
H=(a * D B H) /(b+D B H)
$$

I chose those models for compatibility with biogeographic studies from Ledo et al. (2016) and Sullivan et al. (2018) and their performances therein. $H$ denotes tree height, $D B H$ is diameter at breast height and $a, b$ and $c$ model parameters to be fitted.

Model performance was ranked according to the Residual Standard Error (RSE) defined as 
Eq. 2.4

$$
R S E=\sqrt{\frac{\sum\left(\hat{X}_{i}-X_{i}\right)^{2}}{d . f .}}
$$

where $d . f$. denotes degrees of freedom of the model, $\widehat{X}_{i}$ the model derived height estimate of tree $i$ and $X_{i}$ its measured height and model bias calculated as

Eq. 2.5

$$
H_{\text {bias }}=\frac{\sum \hat{X}_{i}-X_{i}}{n}
$$

with $n$ being the number of trees in the sample.

To test robustness of model performance over time, models were fitted to all trees from one data set (e.g. NE11) and applied to DBH values from the remaining sets (e.g. NE14 and NE17). The resulting modelled heights where then compared with the actually measured values of those year via RSE (Eq. 2.4) and bias (Eq. 2.5).

\subsubsection{AGB-estimation}

To derive AGB, an allometric model (Eq. 2.6) by Chave et al. (2005) was used instead of an updated model from 2014 (Chave et al., 2014), as it has been employed at the site by Culmsee et al. (2010) in the past.

Eq. 2.6

$$
A G B_{[k g]}=\exp \left(-2.557+0.94 * \ln \left(\rho * D B H^{2} * H\right)\right)
$$

A mean wood density of $\rho=0.535 \mathrm{~g} \mathrm{~cm}^{-3}$ was assumed, based on previous studies on the site (Culmsee et al., 2010). Using a different model would complicate the calculation of changes in AGB since their inventory. Parameterising a localised model would rely on harvesting trees, which is impossible in the national park and was therefore not considered. The variability of total AGB calculated with this model for the 10HA data and its susceptibility to plot selection was estimated using AGB sums of all 64 plots of the inventory to derive a $95 \%$ confidence interval via bootstrapping. For AGB of the NE-plot no CI was calculated, as it consists of only one plot. 


\subsubsection{Spatial patterns}

For the analysis of spatial patterns, I used data from the 3 plots surveyed by Culmsee et al. (2010) as well as all NE-data from later years. In a first step, I was interested in the relative density of trees (events) which can be expressed in a pair-correlation function $g(r)$ with an expectation of $g(r)=1$ in a circle of $r$ meters under complete spatial randomness (CSR), i.e. a point pattern created by a Poisson process. A $g(r)>1$ indicates clumping while $g(r)<1$ indicates regularity in events (Chiu et al., 2013; Gavrikov and Stoyan, 1995; Law et al., 2009). In a second step, I looked at competition of neighbouring trees based on their DBH. For this, I used Stoyan's $K_{m m}$-function with $K_{m m}(r)=1$ if DBH of neighbouring trees is independent at scale $r, K_{m m}(r)<1$ if there is a negative influence and $K_{m m}(r)>1$ for positive influence (Chiu et al., 2013; Gavrikov and Stoyan, 1995). For both steps, simulation envelopes with a significance level of 0.95 were calculated. It is important to note however, that for this analysis of spatial patterns I had to sum up DBH of trunks which shared the same rooting system. Otherwise this would automatically lead to assumptions of clumping.

\subsubsection{Species specific increment}

I used the 2011, 2014 and 2017 NE-plot data to calculate species specific DBH increment for the 10 most common species. For all other species, the number of individuals on the NE-plot was too low for a meaningful analysis. For each inventory interval I looked at trees of all sizes combined. For the 3 species with the most individuals I divided the data sets further into two height classes of $<20 \mathrm{~m}$ and $\geq 20 \mathrm{~m}$ respectively. Height classes were chosen instead of DBH classes as it is likely that light availability is most important for increment differences when all other parameters are the same (King D. A. et al., 2005; Pan et al., 2013; Purves et al., 2008). As a last step, increment was standardised to a yearly average. Because of the small sample size, I did not test for significance of difference but present the data as observed.

\subsubsection{Data analysis tools}

I adopted code from the 'BIOMASS' R package (Réjou-Méchain et al., 2017) to fit the 3 DBHheight models and to compare their performance. Bootstrapping was done in all cases with the Rpackage 'boot' (Canty and Ripley, 2017). For the analysis of spatial patterns I used the R-package 'spatstat' (Baddeley and Turner, 2005). All further statistical analysis was done in R (R Core Team, 2016). 


\subsection{Results}

\subsubsection{Stand structure over time and space}

The DBH distribution mean of the 2006 study and my 10HA survey did not differ significantly (t-test, $\mathrm{p}=0.22$ ), although there was a greater proportion of small trees in 2006 (Figure 4). For better comparability with other forest inventory results, a traditional bar plot showing proportional representation of DBH-classes can be seen in Figure 5. BA in 2017 is with $37.86 \pm 0.38 \mathrm{~m}^{2} \mathrm{ha}^{-1}$ very similar to the $37.1 \pm 0.9 \mathrm{~m}^{2} \mathrm{ha}^{-1}$ measured in 2006 (Culmsee et al., 2010). There is also no indication that DBH depends on the location of plots inside our survey grid in 2017. Bundled into 8 transects running East to West and containing 8 plots each, there is no significant difference (ANOVA, $\mathrm{p}=0.54, \mathrm{~F}=0.853$ ) in mean $\mathrm{DBH}$ per transect (Figure 6).

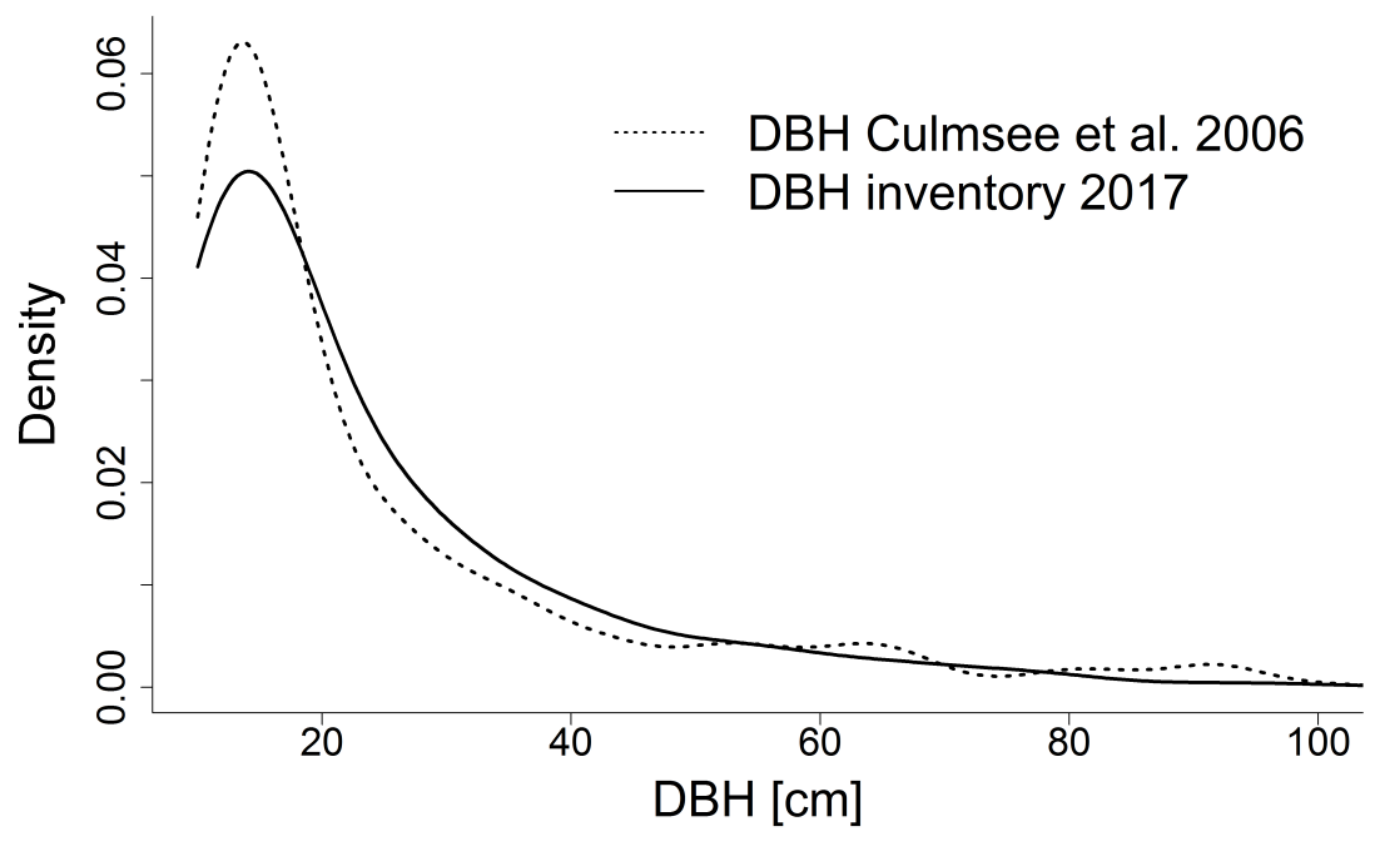

Figure 4: Probability density curves of the DBH-distribution 2006 and 2017. Means are not significantly different (t-test). The $\mathrm{x}$-axis has been cut off at the maximum of the 2006-data to allow better visual comparison. 


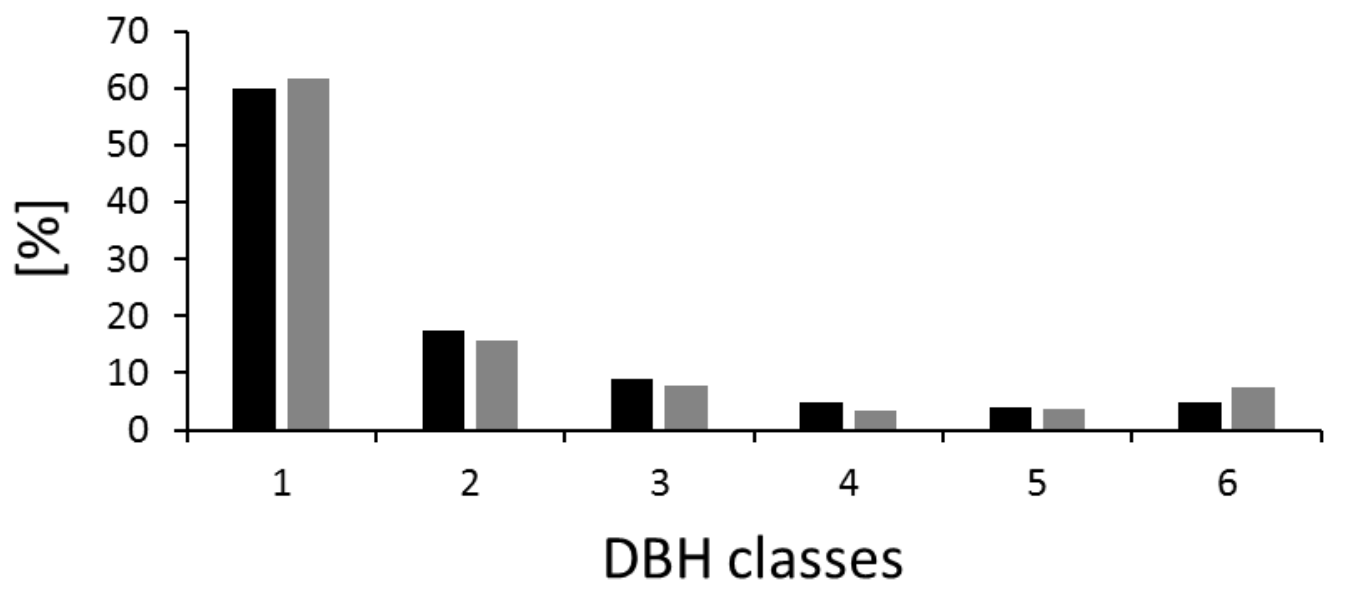

- 10HA Culmsee 2006

Figure 5: Proportion of DBH classes in the 4 data sets. DBH classes are set to 10-20 (1), >20-30 (2), $>30-40$ (3), $>40-50$ (4) and $>60$ (5) cm DBH.

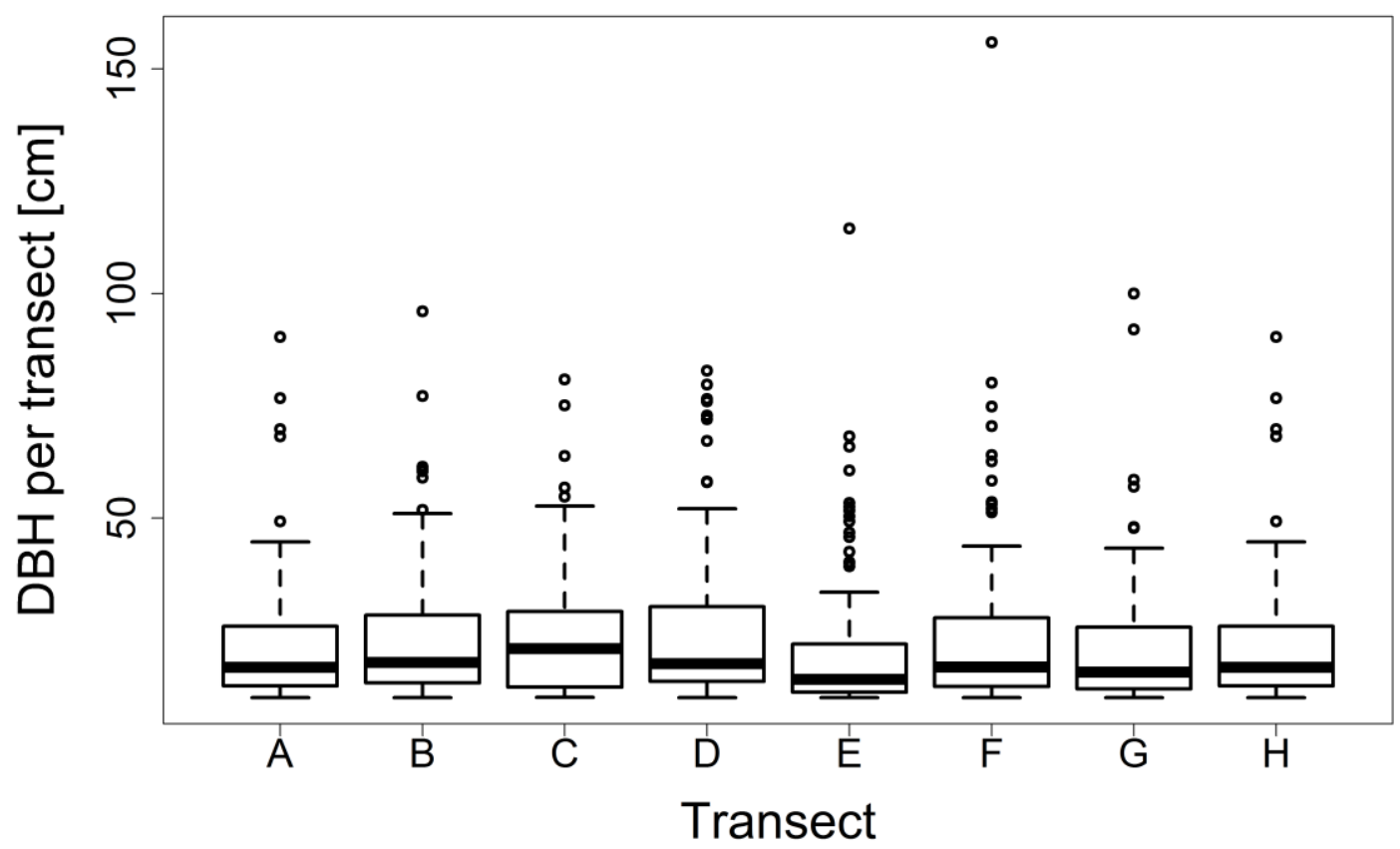

Figure 6: There is no significant difference (ANOVA) in mean DBH per transect.

DBH density distributions for the 4 data sets used in comparing height models are shown in Figure

7. For better comparability with other forest inventory results, a traditional bar plot showing proportional representation of DBH-classes can be seen in Figure 8. The NE-Plot shows small variations in diameter distribution between 2011 and 2017 with the notable exception of the largest trees, of which three fell down between 2014 and 2017. The diameter distribution of the NE-plot is also very close to that of the $10 \mathrm{HA}$ inventory (Figure 7 , Figure 8 ). 


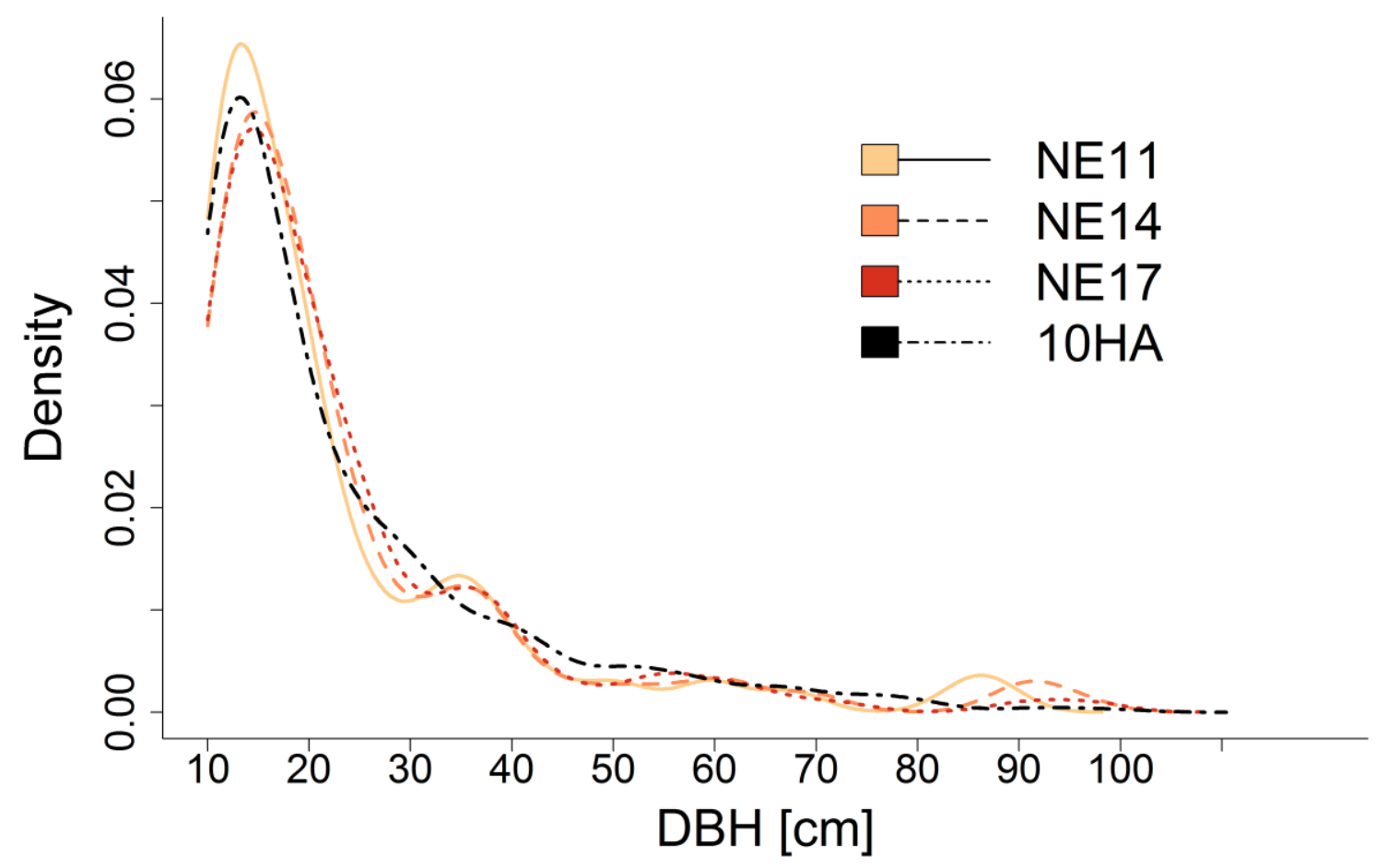

Figure 7: Probability density-curves of DBH for all 4 data sets. The two largest trees of the $10 \mathrm{HA}$ inventory have been removed from the calculation for this plot to allow for visual comparison.

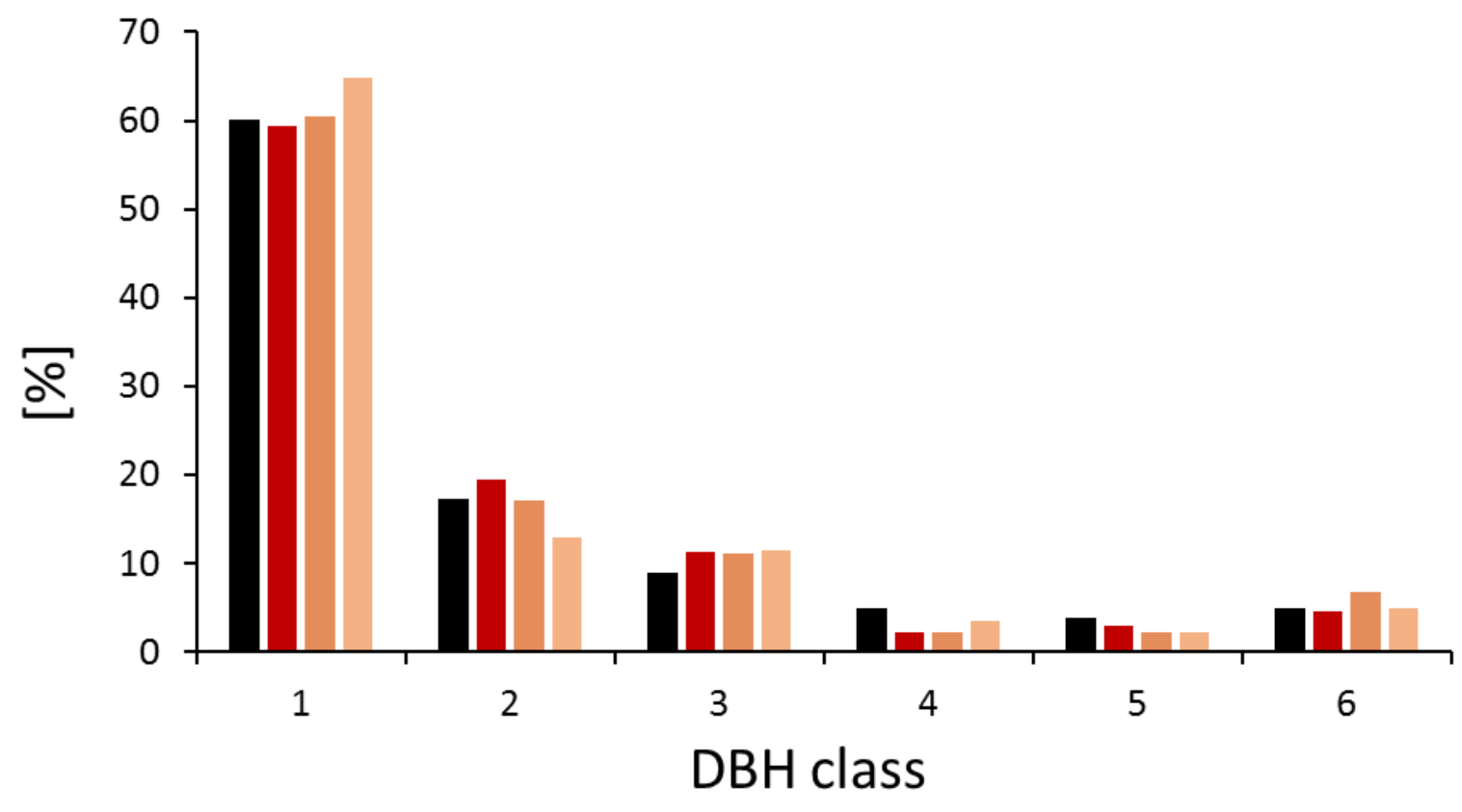

ロ 10HA $\square$ NE17 $\square$ NE14 NE11

Figure 8: Proportion of DBH classes in the 4 data sets. DBH classes are set to 10-20 (1), >20-30 (2), $>30-40$ (3), $>40-50$ (4) and $>60$ (5) $\mathrm{cm} \mathrm{DBH.}$ 


\subsubsection{Height model performance}

The Michaelis-Menten model had the lowest RSE in 3 out of 4 cases, when using all available tree heights to parametrise the models, while the Weibull model always had the lowest bias (Table 1). If the same models are subsequently used to predict tree heights for other years or areas, the Michaelis-Menten model performed better in both regards, albeit only by a small margin (Table 2). The Log-log model performed much worse (not shown for better readability of the table).

Table 1: Performance of height models parametrized using all available tree heights per inventory.

\begin{tabular}{lccccccccc}
\hline & \multicolumn{2}{c}{$\mathbf{1 0 H A}$} & \multicolumn{2}{c}{ NE 2011 } & \multicolumn{2}{c}{ NE 2014 } & \multicolumn{2}{c}{ NE 2017 } \\
\hline Model & RSE & bias & RSE & bias & RSE & bias & RSE & bias \\
Log-log & 4.9267 & 0.0028 & 3.4471 & 0.0051 & 4.9998 & 0.0058 & 4.6166 & 0.006 \\
Weibull & 4.741 & $\mathbf{- 0 . 0 0 0 1}$ & 3.3078 & $\mathbf{0 . 0 0 0 1}$ & $\mathbf{4 . 6 2 9 8}$ & $\mathbf{0 . 0 0 0 1}$ & 4.2841 & $\mathbf{0 . 0 0 0 2}$ \\
Michaelis-Menten & $\mathbf{4 . 7 3 0 8}$ & 0.0003 & $\mathbf{3 . 3 0 6}$ & -0.0011 & 4.6319 & 0.0012 & $\mathbf{4 . 2 7 4 2}$ & 0.001 \\
\hline
\end{tabular}

Table 2: Residual standard error (RSE) and bias of Weibull and Michaelis-Menten (M-M) models fitted to different inventories (column names) when applied to all height trees of another inventory (row names).

\begin{tabular}{lrrrrrrrrr}
\hline \multicolumn{10}{c}{ RSE } \\
& fitted to: & NE11 & fitted to: & NE14 & fitted to: & NE17 & fitted to: & 10HA \\
& Weibull & M-M & Weibull & M-M & Weibull & M-M & Weibull & M-M \\
\hline NE 11 & & & 4.12 & $\mathbf{4 . 0 6}$ & 4.12 & $\mathbf{4 . 0 9}$ & 3.20 & $\mathbf{3 . 1 9}$ \\
NE 14 & 5.12 & $\mathbf{5 . 0 5}$ & & & 4.69 & 4.70 & 4.63 & $\mathbf{4 . 5 9}$ \\
NE 17 & 4.80 & $\mathbf{4 . 7 4}$ & $\mathbf{4 . 3 0}$ & $\mathbf{4 . 3 0}$ & & & 4.34 & $\mathbf{4 . 3 0}$ \\
10HA & 5.07 & $\mathbf{5 . 0 1}$ & 5.48 & $\mathbf{5 . 3 7}$ & 5.72 & $\mathbf{5 . 6 8}$ & & \\
\hline
\end{tabular}

\section{Bias}

\begin{tabular}{lrrrrrrrr}
\hline & $\begin{array}{l}\text { fitted to: } \\
\text { Weibull }\end{array}$ & NE11 & fitted to: & NE14 & fitted to: & NE17 & fitted to: & 10HA \\
& & & 2.12 & $\mathbf{2 . 1 6}$ & $\mathbf{2 . 1 3}$ & 2.18 & $\mathbf{0 . 4 3}$ & 0.54 \\
NE 11 & & & & & $\mathbf{0 . 0 4}$ & 0.09 & -1.73 & $\mathbf{- 1 . 6 1}$ \\
NE 14 & -2.17 & $\mathbf{- 2 . 1 6}$ & & & & & -1.76 & $\mathbf{- 1 . 6 6}$ \\
NE 17 & -2.24 & $\mathbf{- 2 . 2 2}$ & $\mathbf{0 . 0 0}$ & -0.01 & & & & \\
10HA & -0.38 & $\mathbf{- 0 . 3 1}$ & 1.80 & $\mathbf{1 . 6 2}$ & 2.29 & $\mathbf{2 . 2 3}$ & & \\
\hline
\end{tabular}




\subsubsection{AGB at stand level (10HA)}

The sum of AGB in $\mathrm{kg}$ of all 155 trees for which height was measured is 195445.8, the mean = 1269.13, SE $=38.50$ and relative standard error 3\%. AGB off all 578 trees for which height was modelled is $215530.7 \mathrm{~kg}$ with a height model uncertainty induced SE $=3119.64$ (95\% CI of the SE 2283, 4065). The combined AGB off all 733 trees is $411370.8 \mathrm{~kg}$ or $321.38 \mathrm{Mg} \mathrm{ha}{ }^{-1}$. The $95 \%$ confidence interval estimated from bootstrapped plot sums gives 215.9 and $379.1 \mathrm{Mg} \mathrm{ha}$. Assuming the relative standard error for trees with measured heights holds for all trees (the chosen Weibull model has a bias of only 0.0002) leads to an SE $=9.64$. In 2006 AGB was estimated to be 293.4 Mg ha ${ }^{-1}$ with a plot based variation $\pm 13.0 \mathrm{Mg} \mathrm{ha}^{-1}$ (Culmsee et al., 2010). The difference between AGB estimated from the 10HA inventory and their data leads to an estimated annual increase in $\mathrm{AGB}$ of $2.54 \mathrm{Mg} \mathrm{ha}^{-1} \mathrm{y}^{-1}$ at the site.

\subsubsection{AGB at plot level}

AGB at the NE-plot was $309.64 \mathrm{Mg} \mathrm{ha}^{-1}$ in 2011, $346.54 \mathrm{Mg} \mathrm{ha}^{-1}$ in 2014 and $303.93 \mathrm{Mg} \mathrm{ha}^{-1}$ in 2017 (Table 3). The relative contribution of small trees to total AGB was lowest in 2014 (Figure 9).

Table 3: AGB of trees $\geq 10 \mathrm{~cm} \mathrm{DBH}$ at the NE-plot 2011-2017.

\begin{tabular}{cccccc}
\hline Year & $\begin{array}{c}\text { Mean AGB } \\
{[\mathrm{kg}]}\end{array}$ & SD $[\mathrm{kg}]$ & $\begin{array}{c}\text { AGB sum } \\
{[\mathrm{kg}]}\end{array}$ & $\begin{array}{c}\text { AGBha }[\mathbf{M g} \\
\left.\mathbf{h a}^{-1}\right]\end{array}$ & $\mathbf{n}$ \\
\hline 2011 & 533.60 & 1132.02 & 74170.57 & 309.07 & 139 \\
2014 & 619.61 & 1258.39 & 83027.40 & 345.97 & 134 \\
2017 & 548.41 & 1094.20 & 72938.48 & 303.93 & 133 \\
\hline
\end{tabular}




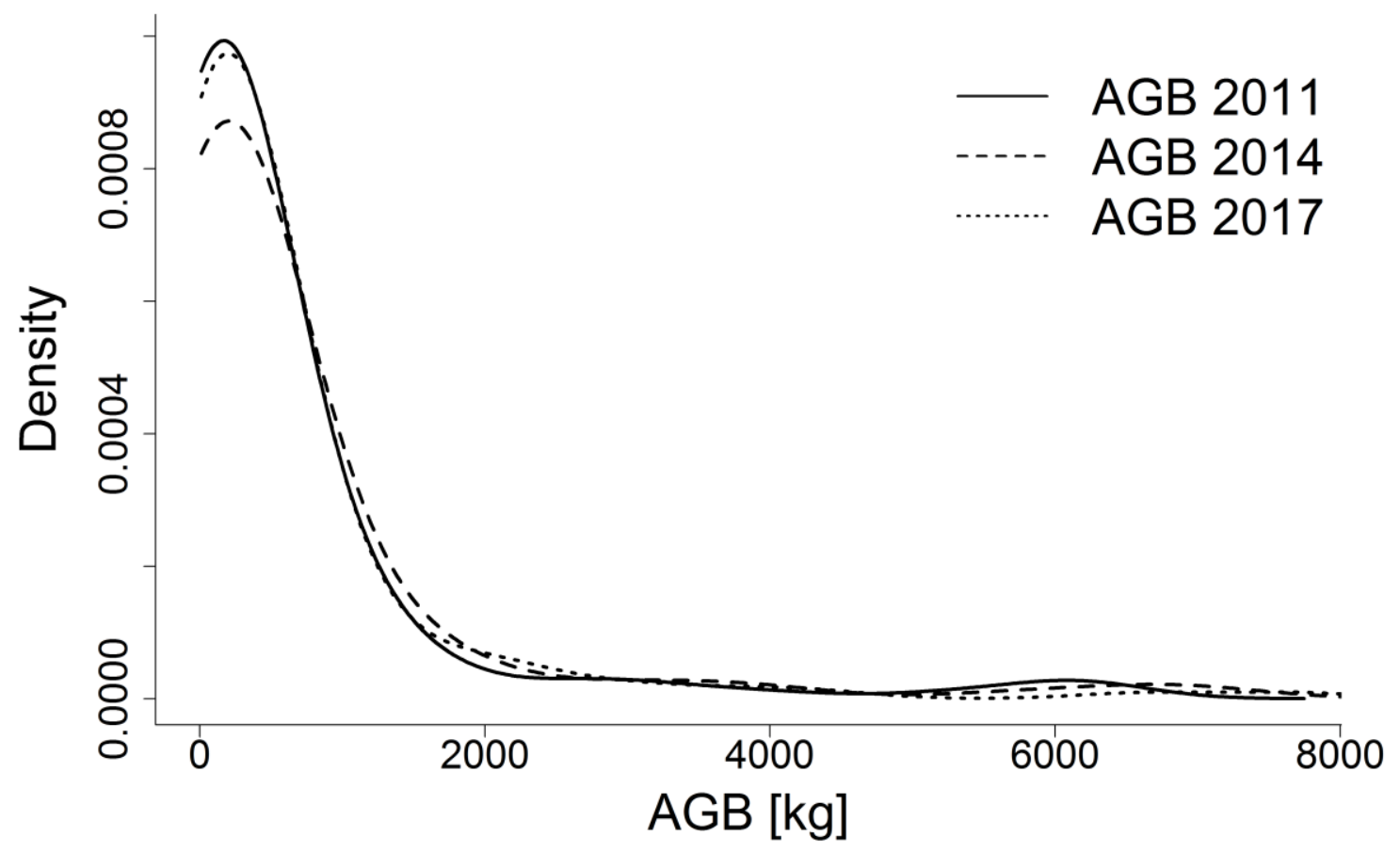

Figure 9: Above-ground biomass distribution of trees inside the NE-plot over time.

\subsubsection{Spatial patterns}

As evident in Figure 10, CSR can generally be assumed to be true for all three plots surveyed in 2006, although there are signs of regularity in both NE- and S-plot. Tree competition based on DBH of neighbouring trees is not significant overall with only two significant deviations in the W-plot (Figure 11). When looking at changes in spatial patterns at the NE-Plot from 2006 to 2017, it is important to point out, that stems of Castanopsis acuminatissima died off, evident in the decrease of their accumulated DBH (Figure 12). While it does not lead to a significant deviation of $K_{m m}(r)$ from 1 (Figure 13), it is likely one of the reasons for the apparent decrease in competition. In 2006, two significant deviations from CSR towards regularity at close distances can be observed at the NE-plot, in 2011 and 2014 one and in 2017 three (Figure 14). 


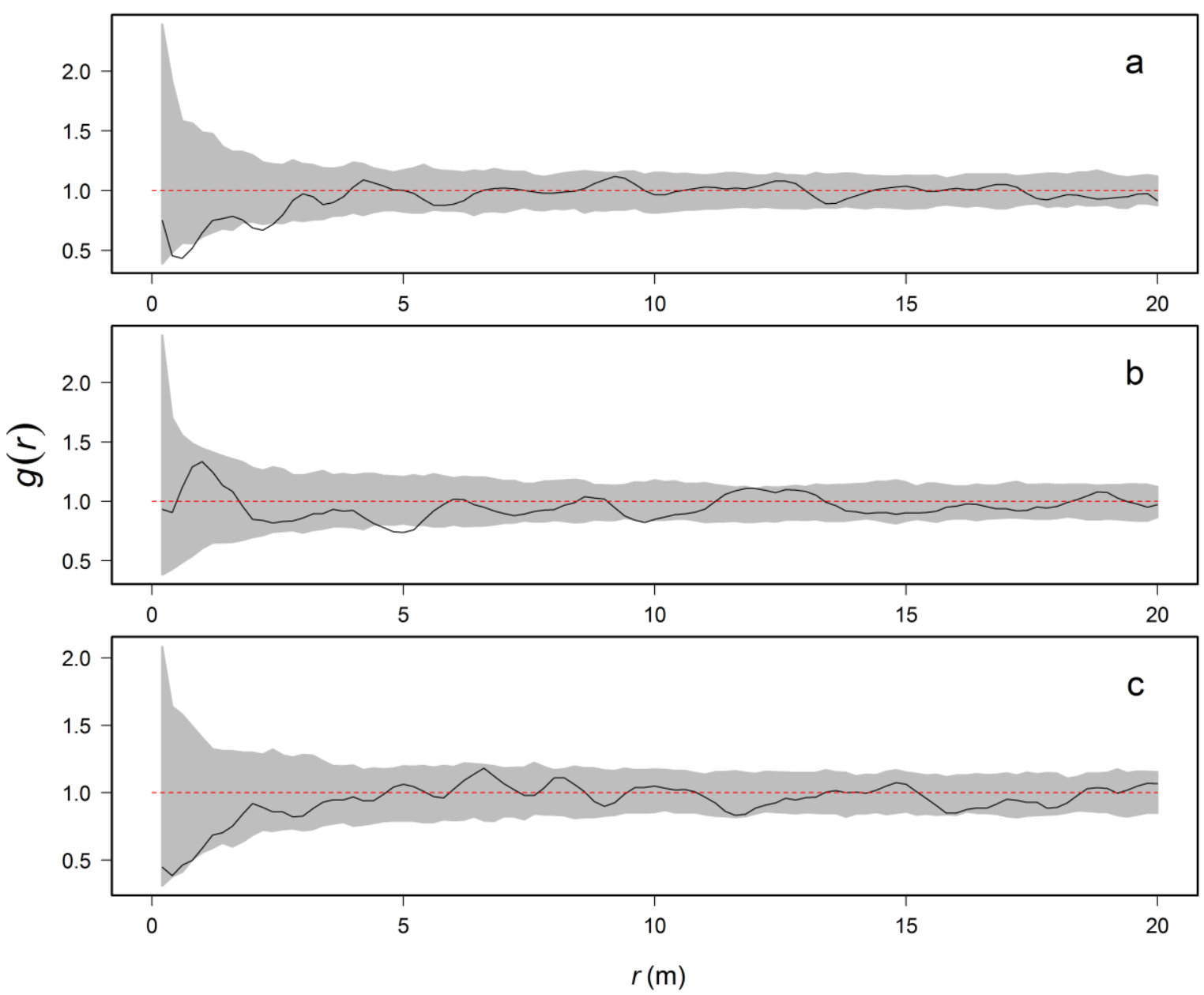

Figure 10: Point-correlation functions describing the spatial relatedness of trees inside the 3 plots from Culmsee et al. Sequence is NE (a), S (b), W (c). Red line represents CSR, black lines observed $\hat{g}$ at different radii, gray area defines the $95 \%$ significance level of CSR. 


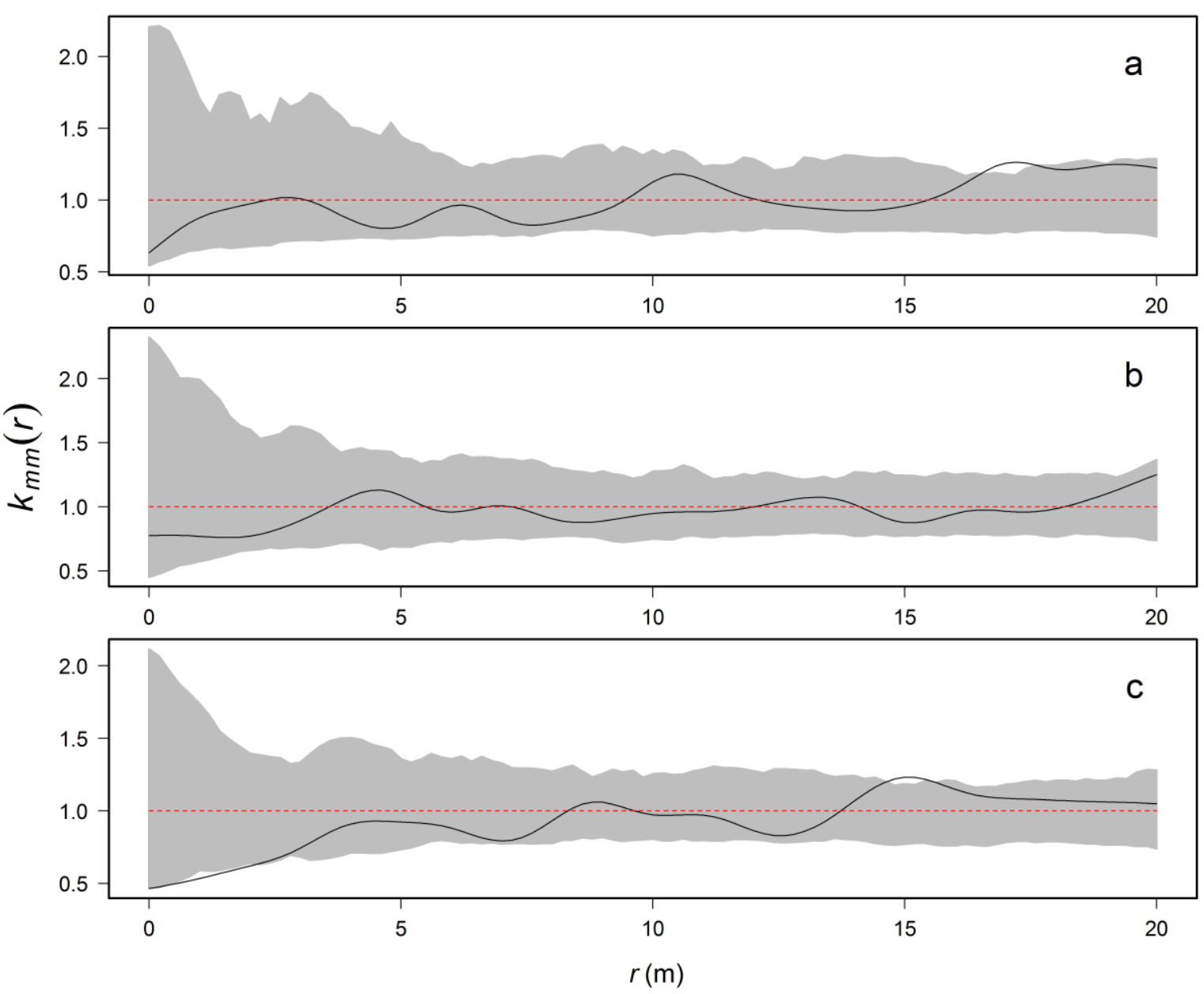

Figure 11: Stoyan's kmm-functions describing the competition of trees based on DBH measurements at certain distances to each other inside the 3 plots from Culmsee et al. Sequence is NE (a), S (b), W (c). The red line represents no competition, black lines observed $\hat{k}$ at different radii, gray area defines the $95 \%$ significance level.

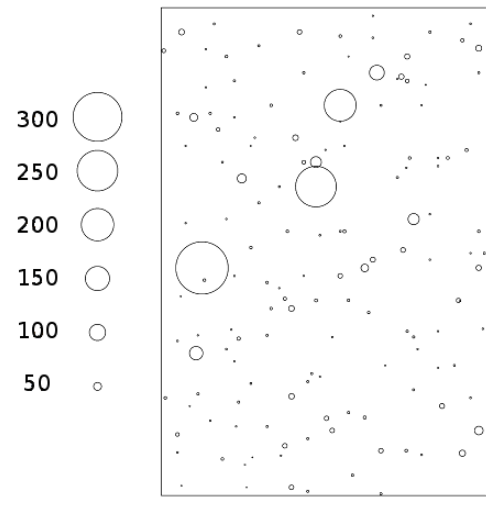

2006

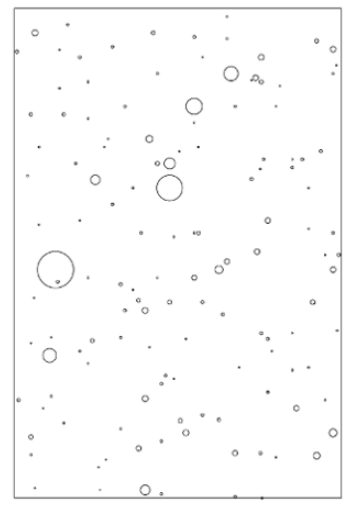

2011

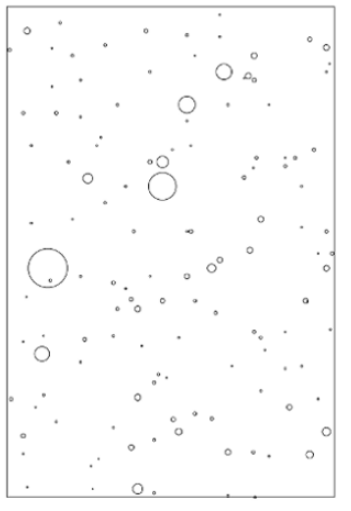

2014

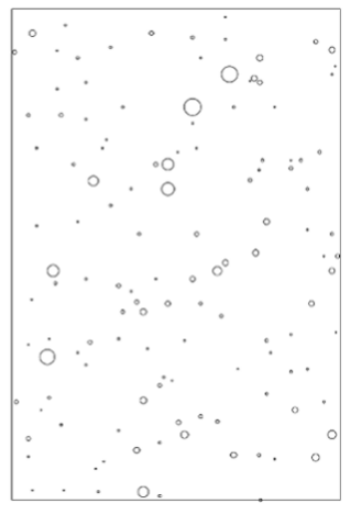

2017

Figure 12: Tree positions inside the so-called North-East plot established by Culmsee et al. 2006. Circle size indicates DBH. 


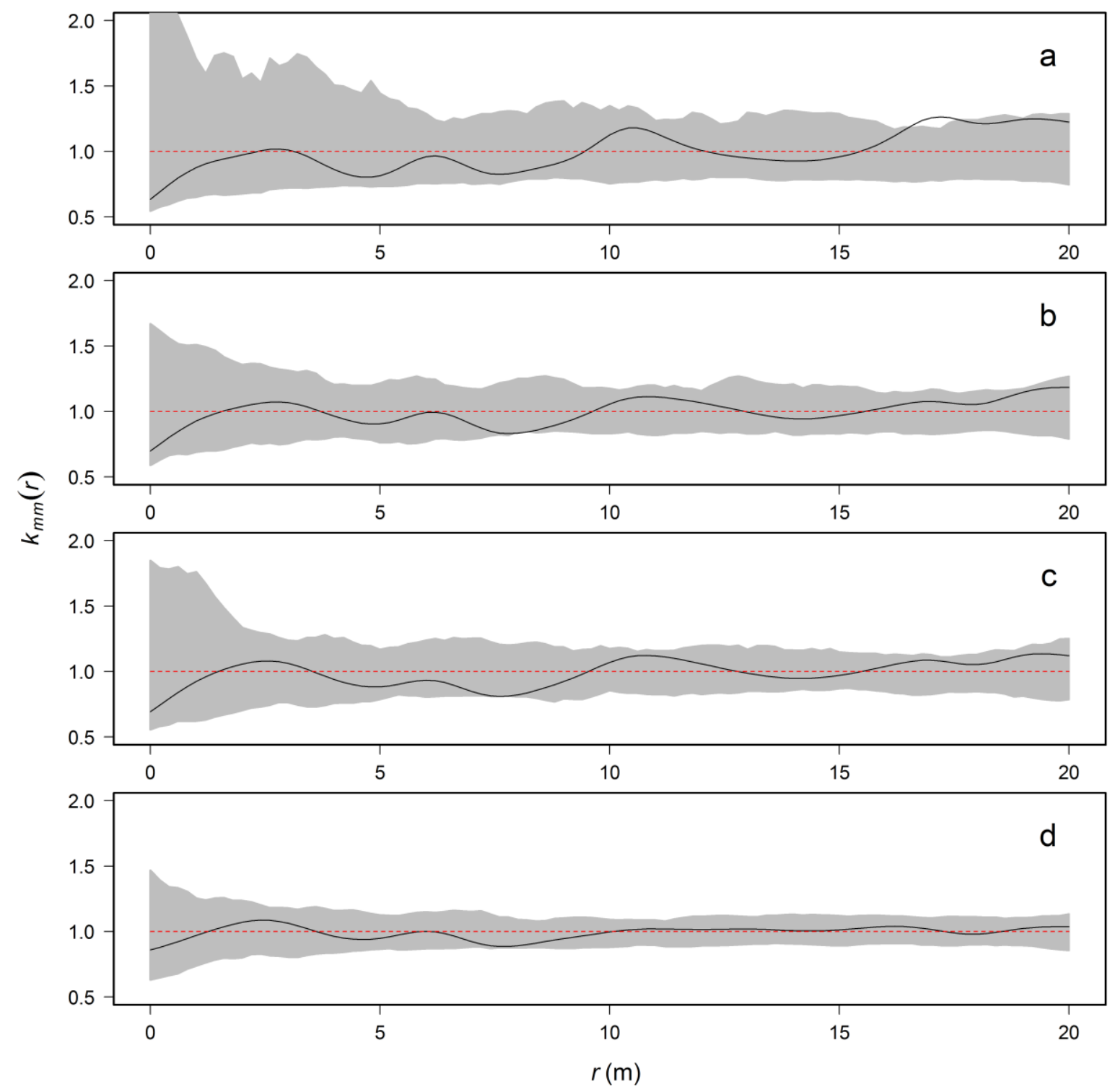

Figure 13: Stoyan's kmm-functions describing the competition of trees based on DBH measurements at certain distances to each other inside the NE plot established by Culmsee et al. in 2006 in chronological order a) 2006, b) 2011, c) 2014, d) 2017. The red line represents no competition, black lines observed $\hat{k}$ at different radii, gray area defines the $95 \%$ significance level. 


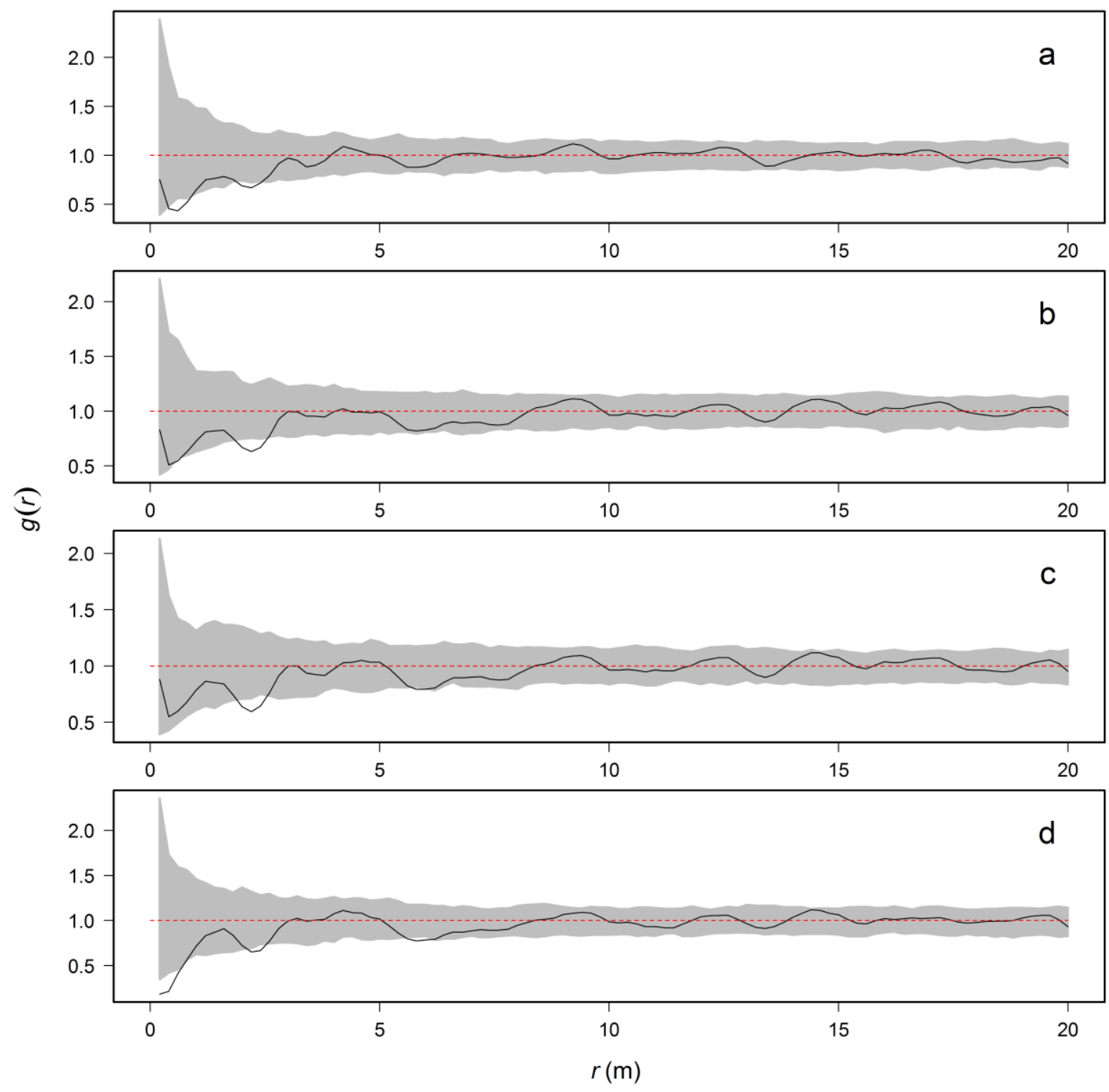

Figure 14: Point-correlation functions describing the spatial relatedness of trees inside the NE plot established by Culmsee et al. in 2006 in chronological order a) 2006, b) 2011, c) 2014, d) 2017. Red line represents CSR, black lines observed $\hat{g}$ at different radii, gray area defines the 95\% significance level of CSR. 


\subsubsection{Species specific increment}

The percentage of total plot AGB accumulated in the most common species ( $\mathrm{n} \geq 5$ ) changed in parts dramatically from 2011 to 2017. Whereas Castanopsis acuminatissima accounted for $\sim 30 \%$ of AGB in 2011 and 2014, the death of 4 trees of this species between 2014 and 2017 decreased this quota to $13 \%$ (Table 4). Species specific increment for all trees of species with $\mathrm{n} \geq 5$ individuals regardless of height can be seen in Table 5 and Table 6 , height class specific increases ( $\mathrm{n} \geq 4$ ) in tables 7-10.

Table 4: Percentage of total plot AGB per tree species

\begin{tabular}{lccc}
\hline Species & $\begin{array}{c}\text { Propotion of } \\
\text { AGB 2011 }\end{array}$ & $\begin{array}{c}\text { Propotion of } \\
\text { AGB 2014 }\end{array}$ & $\begin{array}{c}\text { Propotion of } \\
\text { AGB 2017 }\end{array}$ \\
\hline Castanopsis acuminatissima (Blume) A.DC. & 0.31 & 0.3 & 0.13 \\
Cbionanthus polygamus (Roxb.) Kiew & 0.02 & 0.02 & 0.02 \\
Elaeocarpus culminicola Warb. & 0.04 & 0.03 & 0.03 \\
Elaeocarpus erdinii Coode & 0.01 & 0.02 & 0.02 \\
Planchonella firma (Miq.) Dubard & 0.1 & 0.1 & 0.13 \\
Platea latifolia Blume & 0.06 & 0.05 & 0.06 \\
Porterandia celebica M.S.Zabid & 0.01 & 0.01 & 0.01 \\
Santiria apiculata A.W.Benn. var. apiculata & 0.17 & 0.18 & 0.22 \\
Streblus glaber (Merr.) Corner ssp. glaber & 0.02 & 0.03 & 0.03 \\
Sysygium acuminatissimum (Blume) DC. & 0.02 & 0.03 & 0.03 \\
\hline
\end{tabular}


Table 5: Species specific increment per year for all trees from 2011 to 2014

\begin{tabular}{lccc}
\hline Species & $\begin{array}{c}\text { median } \\
\text { increment } \\
\text { [cm/y] }\end{array}$ & SD & n \\
\hline Castanopsis acuminatissima (Blume) A.DC. & 0.62 & 0.54 & 14 \\
Chionanthus polygamus (Roxb.) Kiew & 0.19 & 0.21 & 17 \\
Elaeocarpus culminicola Warb. & 0.32 & 0.26 & 7 \\
Elaeocarpus erdinii Coode & 0.54 & 0.2 & 9 \\
Planchonella firma (Miq.) Dubard & 0.39 & 0.18 & 6 \\
Platea latifolia Blume & 0.35 & 0.18 & 12 \\
Porterandia celebica M.S.Zabid & 0 & 0.16 & 5 \\
Santiria apiculata A.W.Benn. var. apiculata & 0.66 & 0.85 & 7 \\
Streblus glaber (Merr.) Corner ssp. glaber & 0.16 & 0.16 & 6 \\
Sysygium acuminatissimum (Blume) DC. & 0.16 & 0.23 & 9 \\
\hline
\end{tabular}

Table 6: Species specific increment per year for all trees from 2014 to 2017

\begin{tabular}{lccc}
\hline Species & $\begin{array}{c}\text { median } \\
\text { increment } \\
{[\mathbf{c m} / \mathbf{y}]}\end{array}$ & SD & n \\
\hline Castanopsis acuminatissima (Blume) A.DC. & 0.34 & 0.96 & 10 \\
Chionanthus polygamus (Roxb.) Kiew & 0.08 & 0.27 & 16 \\
Elaeocarpus culminicola Warb. & 0.28 & 0.39 & 7 \\
Elaeocarpus erdinii Coode & 0.44 & 0.34 & 7 \\
Planchonella firma (Miq.) Dubard & 0.28 & 0.62 & 6 \\
Platea latifolia Blume & 0.3 & 0.22 & 12 \\
Porterandia celebica M.S.Zabid & 0.04 & 0.17 & 5 \\
Santiria apiculata A.W.Benn. var. apiculata & 0.36 & 0.26 & 7 \\
Streblus glaber (Merr.) Corner ssp. glaber & 0.26 & 0.31 & 6 \\
Syzygium acuminatissimum (Blume) DC. & 0.12 & 0.41 & 9 \\
\hline
\end{tabular}


Table 7: Species specific increment per year for all trees $<20 \mathrm{~m}$ from 2011 to 2014

\begin{tabular}{lccc}
\hline Species & $\begin{array}{c}\text { median } \\
\text { increment } \\
\mathbf{1 1 - 1 4}[\mathbf{c m} / \mathbf{y}]\end{array}$ & SD & $\mathbf{n}$ \\
\hline Chionanthus polygamus (Roxb.) Kiew & 0.32 & 0.22 & 15 \\
Platea latifolia Blume & 0.3 & 0.18 & 6 \\
Sysygium acuminatissimum (Blume) DC. & 0.06 & 0.11 & 5 \\
\hline
\end{tabular}

Table 8: Species specific increment per year for all trees $<20 \mathrm{~m}$ from 2014 to 2017

\begin{tabular}{lccc}
\hline Species & $\begin{array}{c}\text { median } \\
\text { increment } \\
\mathbf{1 - 1 7}[\mathbf{c m} / \mathbf{y}]\end{array}$ & SD & $\mathbf{n}$ \\
\hline Chionanthus polygamus (Roxb.) Kiew & 0.08 & 0.29 & 12 \\
Platea latifolia Blume & 0.16 & 0.17 & 5 \\
Sysygium acuminatissimum (Blume) DC. & 0.04 & 0.52 & 5 \\
\hline
\end{tabular}

Table 9: Species specific increment per year for all trees $\geq 20 \mathrm{~m}$ from 2011 to 2014

\begin{tabular}{lccc}
\hline Species & $\begin{array}{c}\text { median } \\
\text { increment } \\
\mathbf{1 1 - 1 4}[\mathbf{c m} / \mathbf{y}]\end{array}$ & $\mathbf{S D}$ & $\mathbf{n}$ \\
\hline Castanopsis acuminatissima (Blume) A.DC. & 0.81 & 0.54 & 10 \\
Elaeocarpus erdinii Coode & 0.55 & 0.19 & 8 \\
Planchonella firma (Miq.) Dubard & 0.41 & 0.17 & 5 \\
Platea latifolia Blume & 0.38 & 0.19 & 6 \\
Santiria apiculata A.W.Benn. var. apiculata & 1.37 & 0.92 & 4 \\
Streblus glaber (Merr.) Corner ssp. glaber & 0.16 & 0.17 & 5 \\
Sysygium acuminatissimum (Blume) DC. & 0.39 & 0.24 & 4 \\
\hline
\end{tabular}


Table 10: Species specific increment per year for all trees $\geq 20 \mathrm{~m}$ from 2014 to 2017

\begin{tabular}{lccc}
\hline Species & $\begin{array}{c}\text { median } \\
\text { increment } \\
\text { 1-17 [cm/y] }\end{array}$ & SD & n \\
\hline Castanopsis acuminatissima (Blume) A.DC. & 0.38 & 1.05 & 8 \\
Elaeocarpus erdinii Coode & 0.44 & 0.34 & 7 \\
Planchonella firma (Miq.) Dubard & 0.8 & 0.64 & 4 \\
Platea latifolia Blume & 0.36 & 0.24 & 7 \\
Santiria apiculata A.W.Benn. var. apiculata & 0.38 & 0.24 & 6 \\
Streblus glaber (Merr.) Corner ssp. glaber & 0.08 & 0.22 & 5 \\
Sysygium acuminatissimum (Blume) DC. & 0.26 & 0.29 & 4 \\
\hline
\end{tabular}




\subsection{Discussion}

\subsubsection{Height model performance in general}

In terms of height RSE and bias, results for log-log, Michaelis-Menten and Weibull models applied to all available tree heights of the NE plot are close to those found by Ledo et al (2016) in Pasoh, Malaysia. When the latter two models are fitted to one year of NE-data and subsequently applied to different data sets, their accuracy in predicting tree heights is still higher than regional and pantropical models tested in Pasoh (Ledo et al., 2016). Locally parameterised Weibull and Michaelis-Menten models lead to less height bias than the measurements techniques themselves, if a measurement precision similar to Larjavaara and Muller-Landau (2013) is assumed. Also, large effects of individual height measurement biases on model performance over time are unlikely, as the NE14, NE17 and 10HA inventories were carried out by the same personnel. Especially the differences between NE17 and 10HA are unlikely to result from such a bias, as the data for both was acquired from March-April 2017. All three locally fitted models have less variability over time than regional and climate based models had at a different site (Sullivan et al., 2018).

\subsubsection{Structure and biomass}

My BA estimate of $37.86 \pm 0.38 \mathrm{~m}^{2} \mathrm{ha}^{-1}$ lies well inside the range of $35.4-46.5 \mathrm{~m}^{2} \mathrm{ha}^{-1}$ measured by Culmsee et al. (2010) in four forest stands at different altitudes in Central Sulawesi and very close to their estimate of the same site $\left(37.1 \pm 0.9 \mathrm{~m}^{2} \mathrm{ha}^{-1}\right)$. Hertel et al. (2009) measured a BA of $40.3 \pm 1.6 \mathrm{~m}^{2} \mathrm{ha}^{-1}$ on $610 \times 10 \mathrm{~m}$ plots at $1050 \mathrm{~m}$ a.s.l. in a neighbouring valley (Poso) which is still within the Lore Lindu national park. Kessler et al. (2005) measured a BA of $108-139.7 \mathrm{~m}^{2} \mathrm{ha}^{-1}$ in a valley close to the Bariri site, but there is no indication where this huge discrepancy could come from. Based on literature research, their estimate is extremely high. For a site at similar altitude on Mount Kinabalu on the neighbouring island of Borneo, a BA of $36.4 \mathrm{~m}^{2} \mathrm{ha}^{-1}$ was reported (Aiba and Kitayama, 1999). In South America, BA values in rainforest at similar altitudes are mostly between 20 and $40 \mathrm{~m}^{2}$ ha $^{-1}$ (Malizia et al., 2020). For instance, one forest stand in southern Ecuador at $1050 \mathrm{~m}$ a.s.l. had a BA of $33.6 \mathrm{~m}^{2} \mathrm{ha}^{-1}$, while another at $1540 \mathrm{~m}$ a.s.1. $27.5 \mathrm{~m}^{2} \mathrm{ha}^{-1}$ (Moser et al., 2011).

In terms of $\mathrm{AGB}$, the new $320.56 \pm 9.64 \mathrm{Mg} \mathrm{ha}^{-1}$ estimate is above the $293.4 \pm 13 \mathrm{Mg} \mathrm{ha}^{-1}$ reported for the site by Culmsee et al. (2010), indicating a mean increase of $2.54 \mathrm{Mg} \mathrm{ha}^{-1} \mathrm{y}^{-1}$. The difference in AGB in combination with the similarity in BA can be explained by the higher proportion (Figure 4) of trees with small DBH observed in 2006. These are likely to be comparatively short and in turn have less AGB. 
The 6 plots in the Poso valley had an estimated AGB of 285.5 $\pm 30.3 \mathrm{Mg} \mathrm{ha}^{-1}$ and biomass production by stems and branches was estimated as $5.62 \pm 0.27 \mathrm{Mg} \mathrm{ha}^{-1} \mathrm{y}^{-1}$ (Hertel et al., 2009). The high variability of $\mathrm{AGB}$ as well as the higher annual biomass production reported in that study is likely due to the limited area surveyed. With 0.06 ha covered, it is even smaller than the NE-plot (0.24 ha) at the Bariri site, where substantial changes occurred between each inventory. For instance, the sharp decline in my AGB estimate for the NE-plot from 2014 to 2017 can be explained by the death of three exceptionally large trees. In 2014, these individuals alone had an estimated AGB of $15.7 \mathrm{Mg}$ which amounts to $65.43 \mathrm{Mg} \mathrm{ha}^{-1}$.

In a wider geographical context, Brown et al. (1993) estimate a mean AGB of $304 \mathrm{Mg} \mathrm{ha}^{-1}$ (CV 27\%) for montane rainforests in insular tropical Asia. The site on Mount Kinabalu mentioned above has an AGB of $280 \mathrm{Mg} \mathrm{ha}^{-1}$ (Aiba and Kitayama, 1999; Kitayama and Aiba, 2002). Based on 5 reports from sites on Borneo, Requena Suarez et al. (2019) estimated a mean AGB change for Asian old-growth forests above an altitude of $1000 \mathrm{~m}$ a.s.l. of $-0.7 \pm 3.1 \mathrm{Mg} \mathrm{ha}^{-1} \mathrm{y}^{-1}$. Tropical Atlantic moist forests in Brazil showed increased AGB with elevation, with $271.7 \mathrm{Mg} \mathrm{ha}^{-1}$ (95\% CI $(243,311.6))$ at the highest site at $1000 \mathrm{~m}$ a.s.l. (Alves et al., 2010). Forest inventory results from Colombia show an annual AGB increase similar to the Bariri site with $3.79 \pm 0.42 \mathrm{Mg} \mathrm{ha}^{-1} \mathrm{y}^{-1}$ at 977 $\mathrm{m}$ a.s.l. and $2.45 \pm 0.48 \mathrm{Mg} \mathrm{ha}^{-1} \mathrm{y}^{-1}$ at $1740 \mathrm{~m}$ a.s.l., but much lower (189.22 \pm 7.96 and $222.22 \pm 12.85$ $\mathrm{Mg} \mathrm{ha}^{-1}$ ) total AGB (Peña et al., 2018). At Mount Kilimanjaro, tree biomass in natural forests between 1200 and $2000 \mathrm{~m}$ a.s.l. is $355.4 \pm 89 \mathrm{Mg} \mathrm{ha}^{-1}$ (Ensslin et al., 2015). In Tanzania, forests located at nearly the same altitude as Bariri displayed an AGB range from $340 \mathrm{Mg}$ ha $^{-1}$ to $406.2 \mathrm{Mg}$ ha $^{-1}$ (Marshall et al., 2012).

\subsubsection{Species specific increments}

The loss of the aforementioned three large trees is also responsible for the smaller contribution of Castanopsis acuminatissima (Blume) A.DC. to the total AGB estimate as all three belonged to that species. While the generally small numbers of trees per species and the unequal proportion of large to small trees between species limit the usefulness of the species specific increment rates, I nevertheless hold it to be valuable information, as such data is scarce. I found one record of increment rates of $0.171 \pm 0.196 \mathrm{~cm} \mathrm{y}^{-1}$ for Castanopsis acuminatissima from a montane rainforest in Java (Simbolon, 2001), but no information on any of the other species. The overall smaller increment rates between 2014 and 2017 could be due to the strong ENSO event 2015/2016, during which I observed the longest time without precipitation (2 weeks) in the sites records and trees visibly shed leaves (personal observation). However, this can't be corroborated with the available data. 


\subsubsection{Spatial patterns}

There are no strong signs for a deviation from CSR or for significant changes from it over time in my analysis of point patterns. This result of the spatial patterns analysis is counterintuitive in so far, as one would expect more evidence of light competition and therefore clumping in a closed forest (Gavrikov and Stoyan, 1995). However, this could be explained by the minimum size of trees $(\mathrm{DBH} \geq 10 \mathrm{~cm})$ included in this study. A similar argument can be made for the apparent lack of significant competition between trees as expressed in DBH of individuals inside a certain range, as many seedlings will never reach that stage. Additionally, a diverse forest will comprise species for all available niches. This could lead to the masking of other, more species specific patterns. For instance, Wiegand et al. (2007) found a cluster structure at different distances for Shorea congestiflora in Sri Lanka, possibly due to two different seed dispersal mechanisms. With the limited area and number of individuals per species observed in my study, combined with a lack of data on saplings, such in-depth analyses are impossible. Additionally, all three plots are situated on terrain with an slope $<5 \%$ and patterns might change with topographic location (Pélissier, 1998).

\subsection{Conclusion}

This study indicates that locally parameterised Michaelis-Menten and Weibull models can be used to accurately predict tree heights at the site in general as well as in the temporal domain, as long as the forest structure stays comparably similar. Overall, BA, total AGB and mean annual AGB changes of the forest at the Bariri site presented here fall well within typical ranges for rainforests found at this altitude. While spatial patterns do not change significantly over time, DBH distributions and therefore AGB changes constantly. On small plots, a few large trees dominate the picture and can lead to large deviations from the mean, but over longer periods of time and based on larger inventory areas the forest at the Bariri site seems to be in a relatively stable state. 


\section{Forest density controls soil respiration in a montane rainforest in Central Sulawesi, Indonesia}

\subsection{Introduction}

Of all ecosystems, forests hold the largest amounts of soil carbon, containing about half of the estimated $2344 \mathrm{Gt}$ C stored globally in the top $3 \mathrm{~m}$ of soil (Jobbágy and Jackson, 2000). Forest soils can therefore have a significant impact on the global carbon cycle by acting as sinks or sources of $\mathrm{CO}_{2}$, making it imperative to understand processes like soil respiration $\left(\mathrm{R}_{\mathrm{s}}\right)$ that influence these carbon stocks. $R_{s}$ data, useful for studying the carbon cycle and calibrating models, is, however, rare for tropical forests. Of all $\mathrm{R}_{\mathrm{s}}$ rates represented in the soil-respiration-database (SRDB, (BondLamberty and Thomson, 2014)), only $\sim 6 \%$ are from tropical forests. Of these, many studies targeting natural rainforests originate from Amazonia with mean annual $\mathrm{R}_{\mathrm{s}}$ estimates based on infrared gas analyser (IRGA) measurements ranging from $2.6 \mu \mathrm{mol} \mathrm{m} \mathrm{m}^{-2} \mathrm{~s}^{-1}$ (Chambers et al., 2004) to $6.2 \mu \mathrm{mol} \mathrm{m} \mathrm{m}^{-2}$ (Sotta et al., 2004). $\mathrm{R}_{\mathrm{s}}$ is subject to influences and interactions of a plethora of parameters, including climate, vegetation and soil type (Raich and Tufekciogul, 2000) while dominating factors differ for contrasting biomes (De Deyn et al., 2008). This is evident in a high variability in $\mathrm{R}_{\mathrm{s}}$ values even within small geographical regions. For example, three studies conducted in the same area of Malaysia (Pasoh) showed quite different results ranging between $2.2 \mu \mathrm{mol} \mathrm{m}{ }^{-2}$ $\mathrm{s}^{-1}$ (Adachi et al., 2006), $3.8 \mu \mathrm{mol} \mathrm{m} \mathrm{m}^{-1}$ (Kosugi et al., 2007) and $4.7 \mu \mathrm{mol} \mathrm{m} \mathrm{s}^{-2} \mathrm{~s}^{-1}$ (Itoh et al., 2010). This highlights another problem when dealing with $\mathrm{R}_{\mathrm{s}}$ from tropical forests, namely the concentration of study sites in certain areas such as Amazonia and associated uncertainty when extrapolating these findings to regions differing in e.g. soil type and vegetation composition.

Among the already small group of $\mathrm{R}_{\mathrm{s}}$ studies from tropical old-growth rainforests, montane regions are poorly represented. I am aware of only two other studies on $\mathrm{R}_{\mathrm{s}}$ that took place in montane old-growth rainforests of South-East Asia. Hashimoto et al. (2004) reported the highest value of

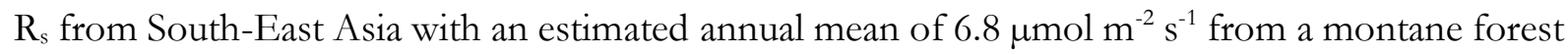
in Thailand. Van Straaten et al. (2011) measured annual mean $\mathrm{R}_{\mathrm{s}}$ of $3.1 \mu \mathrm{mol} \mathrm{m} \mathrm{m}^{-2}$ in a forest close to my study site at $1050 \mathrm{~m}$. Studies from montane rainforests located in other parts of the world cover a wide range of $R_{s}$ estimates. Zhou et al. (2013) found annual mean rates of $4.4 \mu \mathrm{mol} \mathrm{m} \mathrm{m}^{-2}$ on Hainan Island, China whereas Koehler et al. (2009) measured $2.5 \mu \mathrm{mol} \mathrm{m} \mathrm{m}^{-2}$ on their control plots in Panama. Measurements at different altitudes in the southern Ecuadorian Andes showed a 
trend of decreasing $\mathrm{R}_{\mathrm{s}}$ rates with increasing elevation $\left(12.9 \mu \mathrm{mol} \mathrm{m} \mathrm{s}^{-1}\right.$ at $1050 \mathrm{~m} ; 16.7 \mu \mathrm{mol} \mathrm{m} \mathrm{s}^{-2}$ at $1540 \mathrm{~m} ; 9.02 \mu \mathrm{mol} \mathrm{m} \mathrm{s}^{-1}$ at $1890 \mathrm{~m}$ and $3.5 \mu \mathrm{mol} \mathrm{m} \mathrm{m}^{-2} \mathrm{~s}^{-1}$ at $2380 \mathrm{~m}$ as well as $3060 \mathrm{~m}$, (Iost, 2007), while the opposite was found for average annual daytime fluxes in the Peruvian Andes (4.04 $\mu \mathrm{mol} \mathrm{m} \mathrm{s}^{-1}$ at $1000 \mathrm{~m} ; 4.33 \mu \mathrm{mol} \mathrm{m} \mathrm{s}^{-1}$ at $1500 \mathrm{~m} ; 4.45 \mu \mathrm{mol} \mathrm{m} \mathrm{s}^{-1}$ at $3030 \mathrm{~m}$, difference not significant) with night-time values being up to $61 \%$ lower (Zimmermann et al., 2010).

$\mathrm{R}_{\mathrm{s}}$ is closely linked to plant functional traits and stand structure (De Deyn et al., 2008). It is therefore not surprising that forest structure and density can have an impact on $\mathrm{R}_{\mathrm{s}}$. For temperate regions, a positive correlation between mean diameter at breast height $(\mathrm{DBH})$ of trees in certain distances of the measurement locations and $R_{s}$ has been shown (best correlation with trees inside a $4 \mathrm{~m}$ radius, $\mathrm{R}^{2}=0.126$, (Søe and Buchmann, 2005). Yet again, little data from tropical forests is available. Sotta et al. (2004) found no spatial correlation between $R_{s}$ and plot based basal area (BA) estimates in an Amazonian forest, while Bréchet et al. (2011) observed a strong positive correlation between a tree diameter derived index, litterfall and root biomass, but only a weak positive link to $R_{s}\left(R^{2}=0.17\right)$ in French Guiana. Rubio and Detto (2017) discovered a weak positive connection between BA of trees inside a $5 \mathrm{~m}$ radius and $\mathrm{R}_{\mathrm{s}}\left(\mathrm{R}^{2}=0.05\right)$ on Barro Colorado Island in Panama while temporal variation was mostly controlled by soil moisture $\left(\mathrm{M}_{\mathrm{s}}\right)$. The geographically closest study of the spatial link between $\mathrm{R}_{\mathrm{s}}$, forest structure parameters and density was undertaken in Borneo, Malaysia. Here, a strong positive link between $R_{s}$ spatial variation and mean $\mathrm{DBH}$ within a $6 \mathrm{~m}$ radius was found $\left(\mathrm{R}^{2}=0.6\right)$ while the positive correlation with maximum $\mathrm{DBH}$ and $\mathrm{BA}$ in the same distance was moderate $\left(\mathrm{R}^{2}=0.38, \mathrm{R}^{2}=0.37\right.$ (Katayama et al., 2009)). However, to my knowledge no study considering such effects in montane rainforests has yet been published.

Effects of soil temperature $\left(T_{\mathrm{s}}\right)$ and $\mathrm{M}_{\mathrm{s}}$ on $\mathrm{R}_{\mathrm{s}}$ in tropical forests vary greatly between sites. Studying two different tropical forest sites on Oxisol in the Amazon basin, Davidson et al. (2000) did not find a correlation between $R_{s}$ and $T_{s}$, while Sotta et al. (2004) observed a strong, overall positive and significant exponential connection $\left(\mathrm{R}^{2}=0.6\right)$. Regarding $\mathrm{M}_{\mathrm{s}}$ effects on $\mathrm{R}_{s}$, the picture is similarly diverse. While it is generally understood that $M_{s}$ and $T_{s}$, and therefore their control over $R_{s}$, co-vary in temperate regions (Davidson et al., 1998), the relationship is less clear in the tropics. Throughfall exclusion experiments in the tropics led to contrasting results ranging from no significant treatment differences in $\mathrm{R}_{\mathrm{s}}$ (Davidson et al., 2004) between control and treatment plots, to significant decreases of $\mathrm{R}_{\mathrm{s}}$ (Sotta et al., 2007; van Straaten et al., 2011; Wood et al., 2013) with decreasing $\mathrm{M}_{\mathrm{s}}$. In general, controls of $T_{s}$ and $M_{s}$ over $R_{s}$ in tropical forests are as varied as the ecosystems subsumed under this term.

Spatial and temporal heterogeneity of $\mathrm{R}_{\mathrm{s}}$ are regulated by $\mathrm{T}_{\mathrm{s}}, \mathrm{M}_{\mathrm{s}}$, soil type, topographic position, plant cover as well as their interactions. Chambers et al. (2004) found that if month and topography 38 
were taken into account, these explained most of the variation in $\mathrm{R}_{\mathrm{s}}$ otherwise attributed to changes in $T_{s}$ and $M_{s}$. This showed that topographic position influenced $M_{s}$ while $T_{s}$ was controlled by the season. Sotta et al. (2006) observed the strongest differences of $R_{s}$ between sand and clay soil and attributed it to their respective drought susceptibility while topography played a role in seasonal variability but none for the annual average. Whereas the influence of ecosystem seasonality on $R_{s}$ has been studied quite often in the past, diel variations are less well known. This does not reflect their importance, as these can be decisive for annual $\mathrm{CO}_{2}$ efflux estimates. Zimmermann et al. (2009b) found that night-time $R_{s}$ is $39 \%$ of daily rates in a tropical montane cloud forest in Peru, while the importance of measurement time differed between dry and wet season in an Amazonian forest (Sotta et al., 2004). Clearly, both temporal and spatial resolution are of interest, but a compromise between spatial and temporal resolution of chamber based $R_{s}$ measurements is generally required for practical purposes (Rubio and Detto, 2017).

\subsubsection{Objectives and hypothesis}

The two main objectives for this part of my research were:

- To measure $\mathbf{R}_{\mathrm{s}}$ in a montane tropical rainforest in Indonesia and to identify its main meteorological drivers.

- To evaluate the spatial and temporal representativeness of these measurements.

I hypothesise that $\mathrm{R}_{\mathrm{s}}$ at my site is influenced by a combination of abiotic (temperature, moisture and radiation) and biotic factors (forest density). Given the small day-to-day variation in abiotic factors, I expect them to result mainly in diel variations in $R_{s}$ whereas biotic factors such as forest density are likely to be the main drivers of spatial variability. I define forest density as BA and use these terms interchangeably. While being diverse in structure, age and species composition, forest cover is uniform in the surrounding landscape and I expected to find similar mean DBH and BA at my $\mathrm{R}_{\mathrm{s}}$ measurement locations compared to the wider area. 


\subsection{Material \& Methods}

\subsubsection{Soil characteristics at the study site}

The underlying geological parent material of high grade metapelites was formed during the Upper Cretaceous epoch. The overlying soils are heavily weathered, having a low $\mathrm{pH}(3.8 \pm 0.0$; mean \pm SE; $n=52 ; 0-10 \mathrm{~cm}$ depth), a very low effective cation exchange capacity $(34.5 \pm 1.1$ $\left.\mathrm{mmol}_{\mathrm{c}} \mathrm{kg}^{-1}\right)$ and a low base saturation $(37 \% \pm 2 \%$ ) (van Straaten, unpublished data). There is an accumulation of undecomposed litter (thickness of $9.2 \pm 2.1 \mathrm{~cm}$ ), which varies spatially across the study site from $4 \mathrm{~cm}$ depth to $12 \mathrm{~cm}$.

\subsubsection{Soil respiration measurements}

$\mathrm{R}_{\mathrm{s}}$ was measured with a LI-8100A soil gas flux analyser, LI-8100-103 $20 \mathrm{~cm}$ survey chamber (LI-COR Biosciences, USA) and PVC soil collars. During each measurement, $\mathrm{T}_{\mathrm{s}}$ (6000-09TC soil temperature probe, OMEGA, USA) and $\mathrm{M}_{\mathrm{s}}$ (8100-204 ThetaProbe, Delta-T, UK) were recorded at $10 \mathrm{~cm}$ depth next to the soil collar. Soil collars were $16 \mathrm{~cm}$ in height and inserted into the ground to such a depth as was necessary to reach mineral soil one week before measurements started. I measured at 22 locations, 18 of which were located $20 \mathrm{~m}$ from each other along a transect following the main wind direction along a north-south axis and 4 were located $10 \mathrm{~m}$ apart near the installed EC tower (Figure 15). The set of locations includes canopy gaps as well as dense forest areas. $R_{s}$ was measured for 2 minutes at each location. Including chamber transfer time, one measurement cycle including all 22 locations was generally finished within two hours. Northern and southern transect parts were always measured as block, starting with the location closest to the tower. Which of the two blocks came first was decided arbitrarily to avoid systematic bias in measurement time of day. 


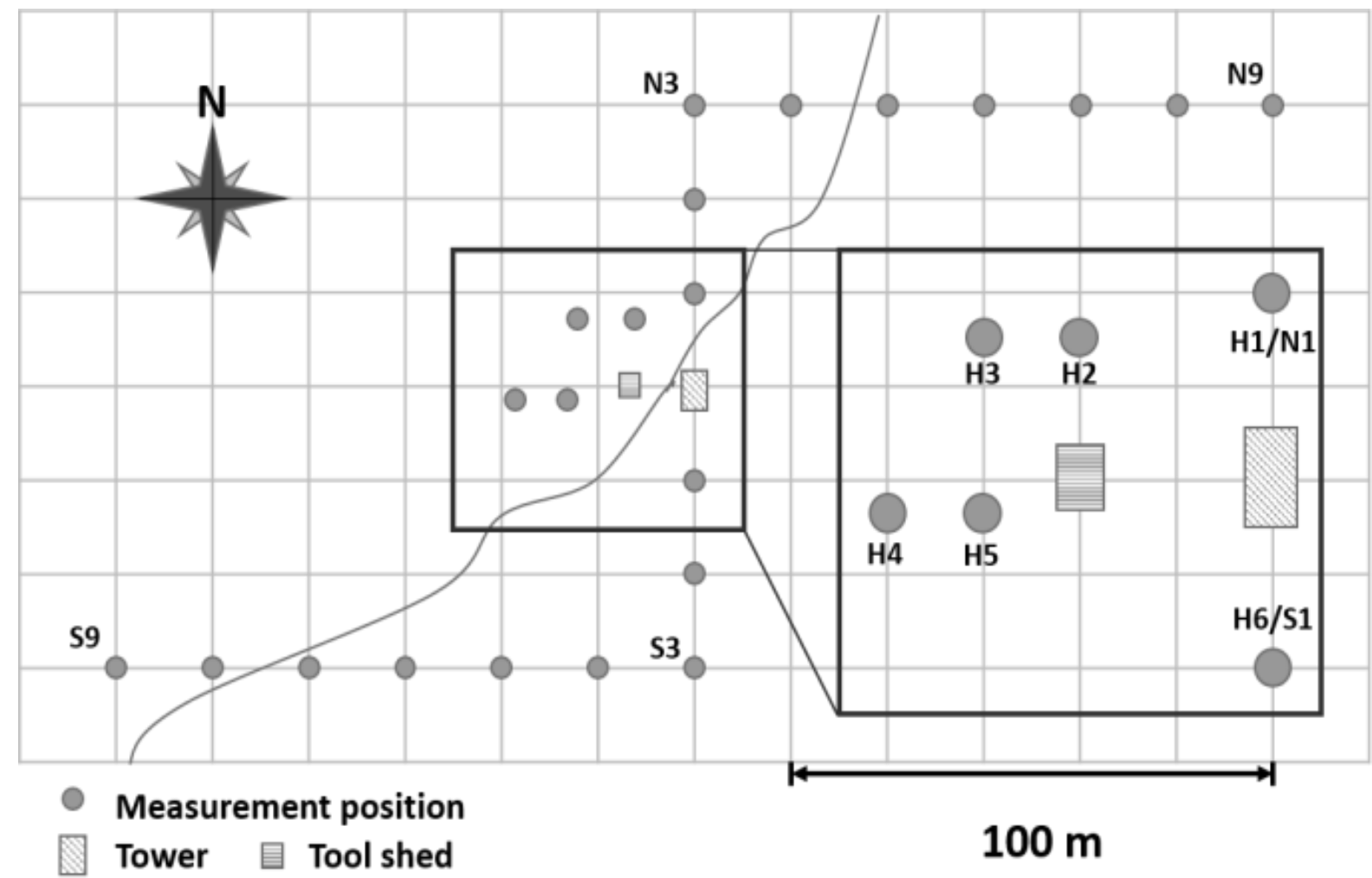

Figure 15: Measurement locations, hut and eddy covariance tower. Sampling design was chosen to cover spatial heterogeneity along the main wind direction and measurability during night time.

Measurements campaigns were generally carried out from 05:00 - 07:00 hours ("Dawn"), 11:00 - 13:00 hours ("Day"), 17:00 - 19:00 hours ("Dusk") and 23:00 - 01:00 hours ("Night") with small deviations due to weather and instrument conditions. One campaign was carried out from 20:00 - 22:00 hours and is only included in the general analysis of the full dataset. Measurements could not be taken after longer intervals of heavy rain as those led to an increase in falling branches and trees. As rainfall often started in the evening and abated overnight, night-time measurements suffered the most from this restriction. As a result, from $1^{\text {st }}$ of April to $28^{\text {th }}$ of April 2017, I measured "Dawn" and "Day" 6 times, "Dusk" 5 times and "Night" 3 times.

\subsubsection{Meteorological long-term measurements and forest inventory}

A forest inventory following the guidelines of Phillips et al. (2002) was conducted during the same time period, covering 10 ha around the tower (chapter 2). At $79200 \mathrm{~m}^{2}$ circular sample plots, including all soil respiration measurement locations, $\mathrm{DBH}$ and distance from the centre of the plot of trees with $\mathrm{DBH} \geq 10 \mathrm{~cm}$ were measured. From this data, mean $\mathrm{DBH}$ and $\mathrm{BA}$ were calculated for different radii around each measurement location. BA is defined as the stem area calculated from $\mathrm{DBH}$, thus representing the area of the plot covered by stems. After the last $\mathrm{R}_{\mathrm{s}}$ measurements, 
I determined the depth of the organic layer ( $\left.\mathrm{D}_{\mathrm{OL}}\right)$ inside each soil collar. Long-term meteorological data such as global radiation (SPN-1, Delta-T, UK), soil moisture at $30 \mathrm{~cm}$ depth (Trime-Pico 32, IMKO, Germany), soil temperature at $10 \mathrm{~cm}$ depths (Friedrichs Co., Germany), air temperature at $48 \mathrm{~m}$ height above the canopy (Friedrichs Co., Germany) and precipitation (Friedrichs Co., Germany) originate from the EC tower at the centre of the transect shown in Figure 15.

\subsubsection{Data analysis}

\subsubsection{Soil respiration data}

$\mathrm{R}_{\mathrm{s}}$ fluxes were calculated with SoilFluxPro 4.0 (LI-COR Biosciences, USA). All further data analysis, statistics and modelling was done in R (R Core Team, 2016), supported by a range of $\mathrm{r}$ packages (3.2.5). To estimate the influence of location selection and measurement time, I calculated 95\% confidence intervals based on 9999 bootstrap replicates with replacement of mean $\mathrm{R}_{\mathrm{s}}$ flux per sampling location $(n=22$, sample size $=21)$ and campaign $(n=21$, sample size $=20)$. Linear regressions (LR), multiple linear regressions (MLR), non-linear regressions (NLR) and linear mixed effect models (LME) were used to explain $\mathrm{R}_{\mathrm{s}}$ dependencies.

Simple LR models were fitted using all available data (i.e. using all times and locations) with variables measured simultaneously and at the same location as $R_{s}\left(T_{s}, M_{s}\right)$ or within the same half hour period (global radiation). To understand if variability in $\mathrm{R}_{\mathrm{s}}$ originates from variability in $\mathrm{T}_{\mathrm{s}}$, a LR was fitted to their respective variances per location over all campaigns. LRs were additionally used to test for significant correlations between the temporal mean $R_{s}$ values of all locations and $\mathrm{BA}$ and mean DBH calculated for 2 to 8 meters radii. LRs were finally also used to detect a possible lagged influence of photosynthetic activity from days prior to measurements. For this, I fitted regression models to night-time $\mathrm{R}_{\mathrm{s}}$ (defined as global radiation $<5 \mathrm{~W} \mathrm{~m}^{-2}$ ) and preceding daily global radiation sums for up to seven days.

MLRs tested for multi-variate models relating temporally averaged $R_{s}$ (i.e. the mean of each location) with $\mathrm{BA}, \mathrm{DBH}$, organic layer $(\mathrm{OL})$ depth and mean $\mathrm{T}_{\mathrm{s}}$ in the form of

Eq. 3.1

$$
R_{S}=\alpha+\beta_{1} S+\beta_{2} D_{O L}+\beta_{3} S D_{O L}
$$

Eq. 3.2

$$
R_{S}=\alpha+\beta_{1} T_{S}+\beta_{2} S+\beta_{3} D_{O L}+\beta_{4} S D_{O L}
$$


where $S$ denotes a structural variable, i.e. either BA or DBH. In case of MLRs, selection was based on multiple $\mathrm{R}^{2}$, Akaike information criterion (AIC) and $\mathrm{p}$-values for each independent variable.

In terms of NLRs, I tested the dependency of $R_{s}$ on $T_{s}$ with an Arrhenius type function and a restricted Lloyd \& Taylor function (Lloyd and Taylor, 1994). As a measure of predictive power and for comparability with the linear model, I calculated a $\mathrm{R}^{2}$ from the linear regressions of predicted and measured $\mathrm{R}_{\mathrm{s}}$ values for the Arrhenius and restricted Lloyd \& Taylor functions.

LMEs are a way to account for persistent underlying effects which might distort a simple linear model. LMEs consist of fixed effects which are assumed to have the same effect on all values of the dependent variable and random effects which are inherent to subsets of the dependent variable. In this case, $R_{s}$ is the dependent variable, $T_{s}$ a fixed effect while $B A$ and $D_{O L}$ are random effects. $\mathrm{M}_{\mathrm{s}}$ as fixed effect and $\mathrm{DBH}$ as random effect were discarded due to linear regression results. The result of a LME is a different slope for the correlation of the dependent variable with fixed effects for each subset of random effects. AIC can still be used for model selection, but the only way to check for significance is to perform a series of ANOVAs between the full model and versions of the model with each fixed and random effect removed consecutively. For LMEs, all data was $\log$-transformed to achieve maximum normality of model residuals. To determine the explanatory power of a certain LME, I follow the approach suggested by Nakagawa and Schielzeth (2013), quantifying the contribution of model fixed effects via marginal $\mathrm{R}^{2}\left(R_{(m)}^{2}\right)$ and fixed plus random effects via conditional $\mathrm{R}^{2}\left(R_{(c)}^{2}\right)$.

LME models of $\mathrm{R}_{\mathrm{s}}$ with $\mathrm{BA}$ and $\mathrm{D}_{\mathrm{OL}}$ as grouping variables (i.e. random effects) and $\mathrm{T}_{\mathrm{s}}$ as fixed effects were applied for three different scenarios (equations in lme4 R-package syntax):

Eq. 3.3

$$
\mathrm{R}_{s}=T_{s}+(1 \mid B A)
$$

(fixed intercept)

Eq. 3.4

$$
R_{s}=T_{s}+(1 \mid B A)+\left(1 \mid D_{O L}\right)
$$

(fixed intercept) 
Eq. 3.5

$$
R_{s}=T_{s}+\left(1+T_{s} \mid B A\right)+\left(1 \mid D_{O L}\right)
$$

(variable intercept per level of $\mathrm{BA}$ )

\subsubsection{Meteorological long-term data and forest inventory data}

As I aimed to extrapolate my findings to other times of the year, the representativeness of meteorological conditions measured at the EC-tower during the campaigns was compared to meteorological data measured since September 2014. For this, the long-term $\mathrm{T}_{\mathrm{s}}$ which sporadically contained unrealistic high values, was despiked. T-tests were used to test if the means of those two time periods were significantly different for $T_{s}, M_{s}$, air temperature and global radiation. For visualisation, point density functions (pdf) were plotted, which show a smoothed frequency distribution of data points. The areas below the curves always equal 1.

For a better extrapolation of results to longer time spans, I also checked if $\mathrm{R}_{\mathrm{s}}$ could be modelled based on $\mathrm{T}_{\mathrm{s}}$ measured in $10 \mathrm{~cm}$ depth at the tower. Again I tested a linear, Arrhenius type and a restricted Lloyd \& Taylor model. As a measure of predictive power and for comparability with the linear model, I calculated a $\mathrm{R}^{2}$ from the linear regressions of predicted and measured values for the Arrhenius and restricted Lloyd \& Taylor functions.

I was also interested in $\mathrm{BA}$ and mean $\mathrm{DBH}$ at the $\mathrm{R}_{\mathrm{s}}$ measurement locations in comparison to the surrounding forest, as this gives us a measure for spatial representativeness of our findings. Again t-tests were performed and pdf-functions plotted for visualisation.

\subsubsection{Data analysis tools}

I used the r-packages 'Ime4' (Bates et al., 2015) for linear mixed effect model; the 'reco' function of the R-package 'flux' (Jurasinski et al., 2014) for non-linear regressions; 'boot' (Canty and Ripley, 2017) for bootstrapping and establishment of confidence intervals; 'piecewiseSEM' (Lefcheck, 2016) to calculate conditional and marginal $\mathrm{R}^{2}$; the R-package 'oce' (Kelley and Richards, 2017) for despiking; 'xts' (Ryan and Ulrich, 2014) and 'zoo' (Zeileis and Grothendieck, 2005) for time series operations; 'reshape' (Wickham, 2007) and 'plyr' (Wickham, 2011) for data frame operations; 'ggplot2' (Wickham, 2009) for plotting. 


\subsection{Results}

\subsubsection{Chamber measurement variability}

All $\mathrm{R}_{\mathrm{s}}$ measurements combined had a mean of $6.2 \mu \mathrm{mol} \mathrm{m} \mathrm{m}^{-2} \mathrm{~s}^{-1}$ with a standard deviation of $1.84 \mu \mathrm{mol} \mathrm{m} \mathrm{m}^{-1}$. The bootstrap derived $95 \%$ confidence interval of the mean for sampling location was $5.4 \mu \mathrm{mol} \mathrm{m} \mathrm{m}^{-1}$ and $7.4 \mu \mathrm{mol} \mathrm{m} \mathrm{m}^{-2}$, for measurement date and time $6.0 \mu \mathrm{mol} \mathrm{m}^{-2} \mathrm{~s}^{-1}$ and 6.4 $\mu \mathrm{mol} \mathrm{m} \mathrm{m}^{-2}$. Spatial variability of $\mathrm{R}_{\mathrm{s}}(\mathrm{CV}=136 \%)$ was significantly larger than temporal variability $\left(\mathrm{CV}=60 \%\right.$, Figure 16, Figure 17, Mann-Whitney-U test, $\left.\mathrm{p}=3.8^{-12}\right) . \mathrm{R}_{\mathrm{s}}$ means of different measurement campaigns showed no significant difference (ANOVA, $\mathrm{p}=0.98, \mathrm{~F}=0.001$ ).

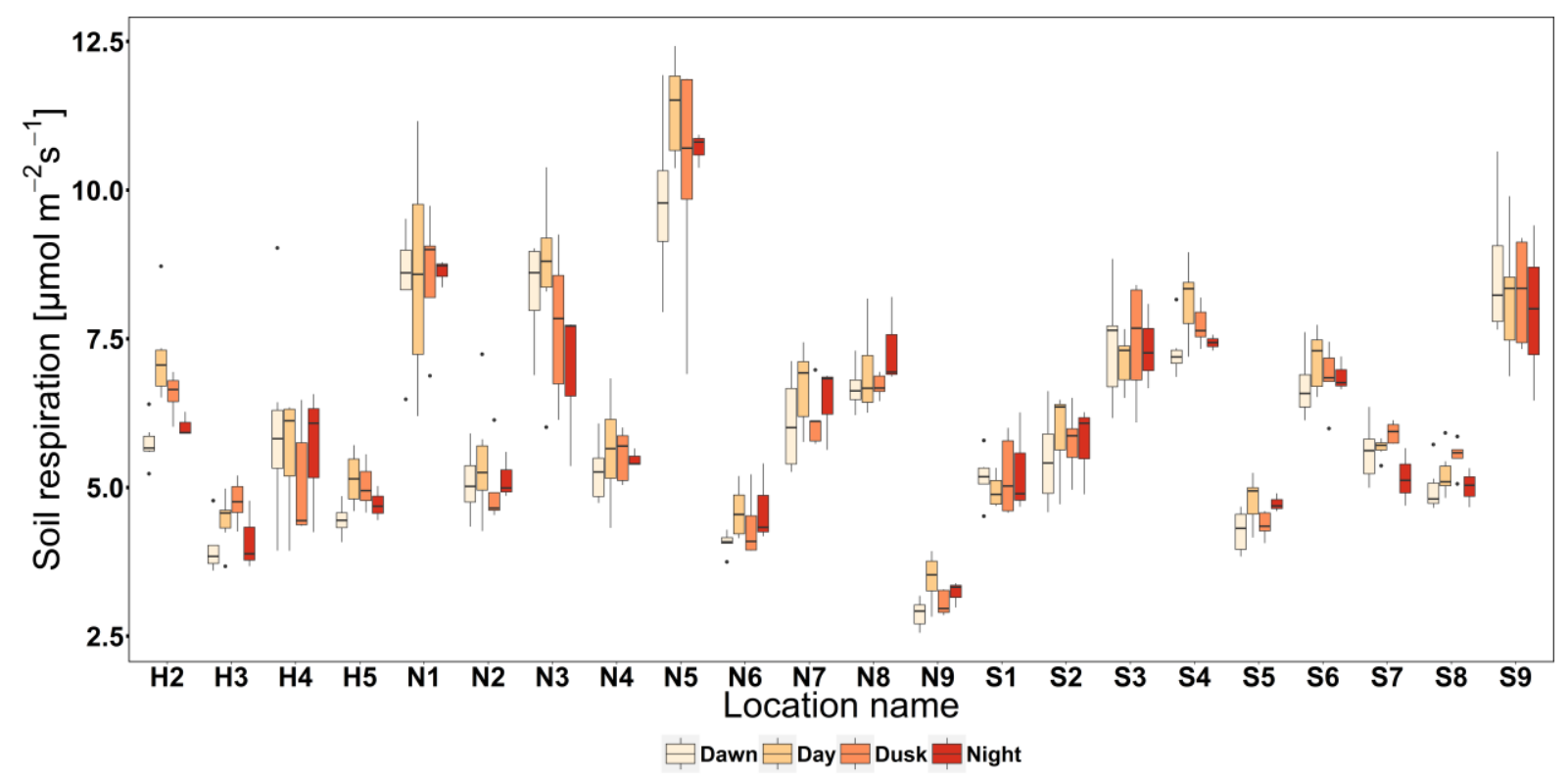

Figure 16: Average soil respiration in $\mu \mathrm{mol} \mathrm{m} \mathrm{m}^{-2} \mathrm{~s}^{-1}$ per location and time of the day. Data from 21 measurements campaigns from $1^{\text {st }}$ of April to $28^{\text {th }}$ of April 2017. Number of measurements per time window are: Dawn=6, Day=6, Dusk=5, Night $=3$. 


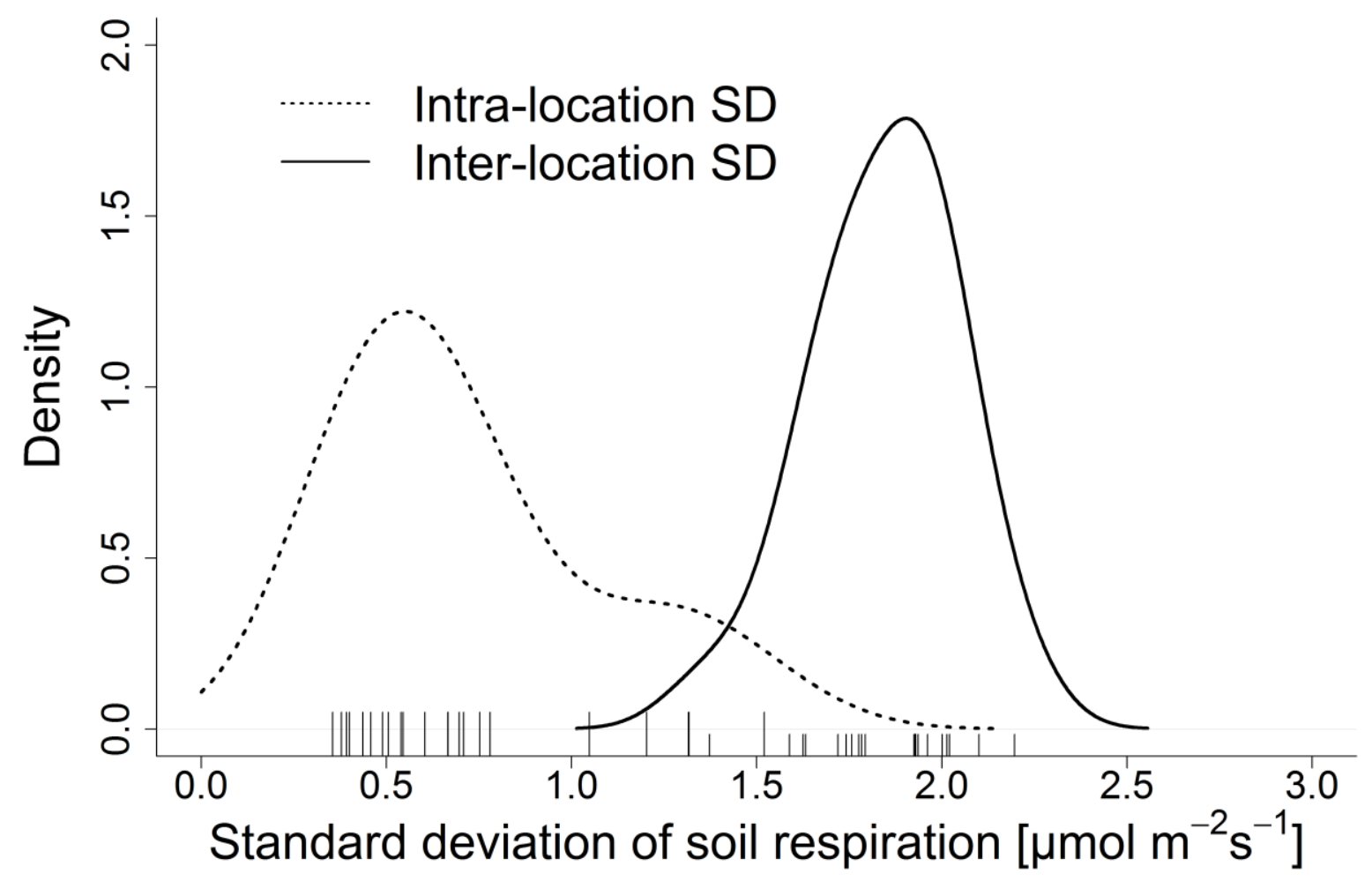

Figure 17: Probability density curves of inter-location (full line, short tick marks) and intra-location standard deviation (dashed line, long tick marks) of measured soil respiration. Inter-location variance represents the $R_{s}$ variability among the individual locations observed in separate measurement campaigns, while intra-location variance is $R_{s}$ variability over time measured at the individual locations.

LRs (using data for all times and locations) resulted in $\mathrm{R}_{\mathrm{s}}$ having a significant positive linear correlation with $\mathrm{T}_{\mathrm{s}}$, but not with $\mathrm{M}_{\mathrm{s}}$, or global radiation (Table 11). However, variances of $\mathrm{T}_{\mathrm{s}}$ and $R_{s}$ were not significantly correlated $\left(R^{2}=0.004, p=0.78\right)$. Neither was there a significant correlation of spatially and temporally aggregated night time $\mathrm{R}_{\mathrm{s}}$ with global radiation sums of preceding days ( $p>0.05$ ). Mean $\mathrm{T}_{\mathrm{s}}$ was significantly and positively correlated with mean DBH and BA (e.g. in a 3 $\mathrm{m}$ radius, $\left.\mathrm{R}^{2}=0.53, \mathrm{p}<2^{-16}\right)$. Mean $\mathrm{R}_{\mathrm{s}}$ was significantly and strongly positively correlated to mean $\mathrm{DBH}$ and $\mathrm{BA}$ of trees inside a radius of $3 \mathrm{~m}$ (Table 12). 
Table 11: Correlation of $R_{s}$ with simultaneously measured $T_{s}, M_{s}$ and global radiation across all times and locations. Day defined as global radiation $>5 \mathrm{~W} \mathrm{~m}^{-2}$.

\begin{tabular}{lllllll}
\hline & \multicolumn{2}{l}{ Soil temperature } & \multicolumn{2}{l}{ Soil moisture } & \multicolumn{2}{l}{ Global radiation } \\
\hline & $\mathrm{R}^{2}$ & $\mathrm{p}$ & $\mathrm{R}^{2}$ & $\mathrm{p}$ & $\mathrm{R}^{2}$ & $\mathrm{p}$ \\
\hline All $\mathrm{n}=461$ & 0.2417 & $<2.2^{-16}$ & 0.0001 & 0.8112 & - & \\
Day $\mathrm{n}=269$ & 0.2508 & $<2.2^{-16}$ & 0.0017 & 0.502 & 0.0008 & 0.6377 \\
Night $\mathrm{n}=192$ & 0.2372 & $9.059^{-13}$ & 0.0007 & 0.7141 & - & \\
\hline
\end{tabular}

Table 12: $\mathrm{R}^{2}$ and respective $\mathrm{p}$-values for correlations between mean $\mathrm{R}_{\mathrm{s}}$ (per location using all measurement times or during the day with 'Day' defined as global radiation $>5 \mathrm{~W} \mathrm{~m}^{-2}$ ) with mean $\mathrm{DBH}$ and $\mathrm{BA}$ in different radii around each measurement locations as well as with organic layer depth, $\mathrm{D}_{\mathrm{OL}}$. All correlations are positive.

\begin{tabular}{ccccc}
\hline Variable & $\mathbf{R}^{\mathbf{2}}(\mathbf{a l l})$ & $\mathbf{p}$ & $\mathbf{R}^{\mathbf{2}}$ (Day) & $\mathbf{p}$ \\
\hline DBH 2m & 0.06 & 0.29 & 0.04 & 0.393 \\
DBH 3m & $\mathbf{0 . 5 5}$ & $\mathbf{< 0 . 0 0 5}$ & $\mathbf{0 . 6}$ & $<\mathbf{0 . 0 0 5}$ \\
DBH 4m & 0.08 & 0.21 & 0.1 & 0.15 \\
DBH 5m & 0.03 & 0.44 & 0.05 & 0.316 \\
DBH 6m & 0.05 & 0.3 & 0.07 & 0.223 \\
DBH 7m & 0.00 & 0.81 & 0.01 & 0.68 \\
DBH 8m & 0.00 & 0.804 & 0.01 & 0.73 \\
BA 2m & 0.12 & 0.122 & 0.00 & 0.952 \\
BA 3m & $\mathbf{0 . 4 6}$ & $<\mathbf{0 . 0 0 5}$ & $\mathbf{0 . 5 8}$ & $<\mathbf{0 . 0 0 5}$ \\
BA 4m & 0.11 & 0.132 & 0.00 & 0.988 \\
BA 5m & 0.03 & 0.432 & 0.03 & 0.411 \\
BA 6m & 0.07 & 0.226 & 0.05 & 0.304 \\
BA 7m & 0.00 & 0.997 & 0.01 & 0.695 \\
BA 8m & 0.00 & 0.936 & 0.00 & 0.81 \\
D 0 OL & 0.05 & 0.01 & 0.02 & 0.006 \\
\hline
\end{tabular}

MLR models, based on formulas 3.1 and 3.2 (section 2.3), resulted in a stronger and more significant fit to the data (Table 13) compared to simple LR models. The best model (lowest AIC) explained $69 \%$ of the measured variation and was obtained using soil temperature, $\mathrm{BA}, \mathrm{D}_{\mathrm{OL}}$ and a BA-D ${ }_{\mathrm{OL}}$ interaction term. 
Table 13: Correlation coefficients, $p$-values and AIC of multiple linear regressions of Rs with DOL, Ts and either DBH or BA. The equation used is denoted by the numbers (3.1) and (3.2).

\begin{tabular}{cccccccc}
\hline Model & $\mathbf{R}^{\mathbf{2}}$ & $\mathbf{p}\left(\mathbf{T}_{\mathbf{s}}\right)$ & $\mathbf{p ~ ( S )}$ & $\mathbf{p}\left(\mathbf{D}_{\mathrm{OL}}\right)$ & $\begin{array}{c}\mathbf{p} \\
\left(\mathbf{S} * \mathbf{D}_{\mathbf{O L}}\right)\end{array}$ & $\mathbf{p}$ (model) & $\mathbf{A I C}$ \\
\hline DBH (3.1) & 0.596 & & 0.092 & 0.151 & 0.346 & $<0.005$ & 75.048 \\
DBH (3.2) & 0.639 & 0.173 & 0.076 & 0.075 & 0.211 & 0.001 & 74.577 \\
BA (3.1) & 0.615 & & 0.008 & 0.042 & 0.023 & $<0.005$ & 74.031 \\
BA (3.2) & 0.690 & 0.057 & 0.009 & 0.018 & 0.017 & $<0.005$ & 71.218 \\
\hline
\end{tabular}

All NLRs showed a significant $(p<0.05)$ correlation between $R_{s}$ and $T_{s}$ measured at the same time and same location. However, differences in $\mathrm{R}^{2}$ between LRs and NLRs are extremely small and below 0.01 . Therefore I only expanded the analysis for the less complex LRs.

Lastly, I considered LME models as described in section 2.3. All complexity levels are significantly different (ANOVA) to their corresponding reduced versions. The multiple linear model using BA (MLR, Eq. 3.2), and applied to the log-transformed data, is included for comparison. LME models perform considerably better than MLRs (Table 14). Including all variables $\left(\mathrm{T}_{\mathrm{s}}, \mathrm{BA}, \mathrm{D}_{\mathrm{OL}}\right)$ resulted in the best model as indicated by the AIC and $\mathrm{R}^{2}{ }_{(\mathrm{c})}$. It is evident, that $\mathrm{T}_{\mathrm{s}}$ alone $\left(\mathrm{R}^{2}(\mathrm{~m})\right)$ has a very small effect on $\mathrm{R}_{\mathrm{s}}$ in LMEs in comparison to the combined model $\mathrm{R}_{(\mathrm{c})}$.

Table 14: Multiple linear model (MLR) and linear mixed effect model (LME) comparison.

\begin{tabular}{lcccc}
\hline Class & $\mathbf{N}$ & Marginal $\mathbf{R}_{(\mathbf{m})}$ & Conditional $\mathbf{R}_{(\mathbf{c})}$ & AIC \\
\hline MLR (3.2) & 22 & 0.59 & & -9.7 \\
$\operatorname{LME~(3.3)~}$ & 460 & 0.04 & 0.73 & -530.336 \\
$\operatorname{LME~(3.4)~}$ & 460 & 0.02 & 0.86 & -720.640 \\
$\operatorname{LME~(3.5)~}$ & 460 & 0.02 & 0.88 & -747.075 \\
\hline
\end{tabular}

\subsubsection{Temporal variability of meteorological parameters and forest spatial variability}

$\mathrm{T}_{\mathrm{s}}$ measurements at the EC tower varied only slightly over the measurement period while air temperature, global radiation and $\mathrm{M}_{\mathrm{s}}$ changed more (Figure 18). Global radiation $(\mathrm{t}=-1.0601, \mathrm{df}=$ 1400.2, $\mathrm{p}$-value $=0.2893)$ and $\mathrm{M}_{\mathrm{s}}(\mathrm{t}=0.066316, \mathrm{df}=1722.2, \mathrm{p}$-value $=0.9471$, Figure 19) were not significantly different during this month compared to the long-term meteorological measurements from September 2014 to April 2017 while air temperature was on average $1.05{ }^{\circ} \mathrm{C}$ colder (95\% CI 1.18, 0.91, Figure 20) and $\mathrm{T}_{\mathrm{s}}$ was $0.28{ }^{\circ} \mathrm{C}$ warmer $(95 \% \mathrm{CI} 0.26,0.29$, Figure 21). $T_{s}$ and $M_{s}$ values measured at the same time and location as $R_{s}$ show greater variability, with $T_{s}$ ranging from $18.76{ }^{\circ} \mathrm{C}$ to $20.49{ }^{\circ} \mathrm{C}$ and $\mathrm{M}_{\mathrm{s}}$ from 22.8 [vol\%] to 60.2 [vol\%]. 
$R_{s}$ could not be approximated well based on $T_{s}$ measured in $10 \mathrm{~cm}$ depth at the tower. The tested linear, Arrhenius type and a restricted Lloyd \& Taylor functions predicted values which were not significantly ( $p>0.05)$ correlated with measured $R_{s}$ values.

There was no significant difference between the distribution of $\mathrm{DBH}$ and consequently $\mathrm{BA}$ at the $22 \mathrm{R}_{\mathrm{s}}$ measurement locations compared to all 79 inventory plots (Figure 22, $\mathrm{t}=0.10843$, $\mathrm{df}=41.549, \mathrm{p}$-value $=0.9142)$.
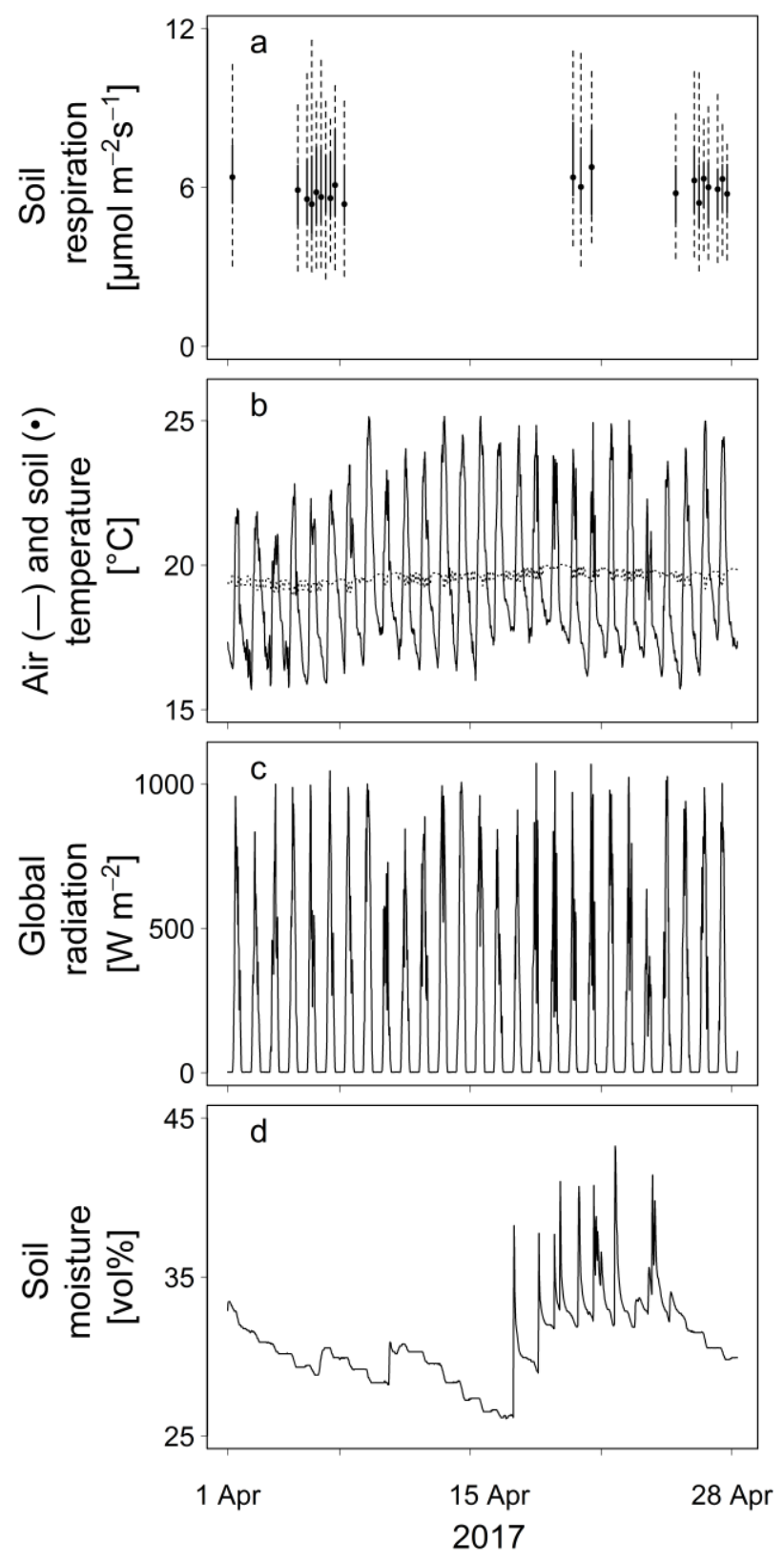

Figure 18: From top to bottom a) Soil respiration from $n=22$ soil collars measured in $n=21$ campaigns, outliers have been removed; b) air temperature (line) at $48 \mathrm{~m}$ above the ground and soil temperature (dots) in $10 \mathrm{~cm}$ depth; c) global radiation at $70 \mathrm{~m}$ above the ground, d) soil moisture in $30 \mathrm{~cm}$ depth. Parameters b-d were measured at the EC-tower. 


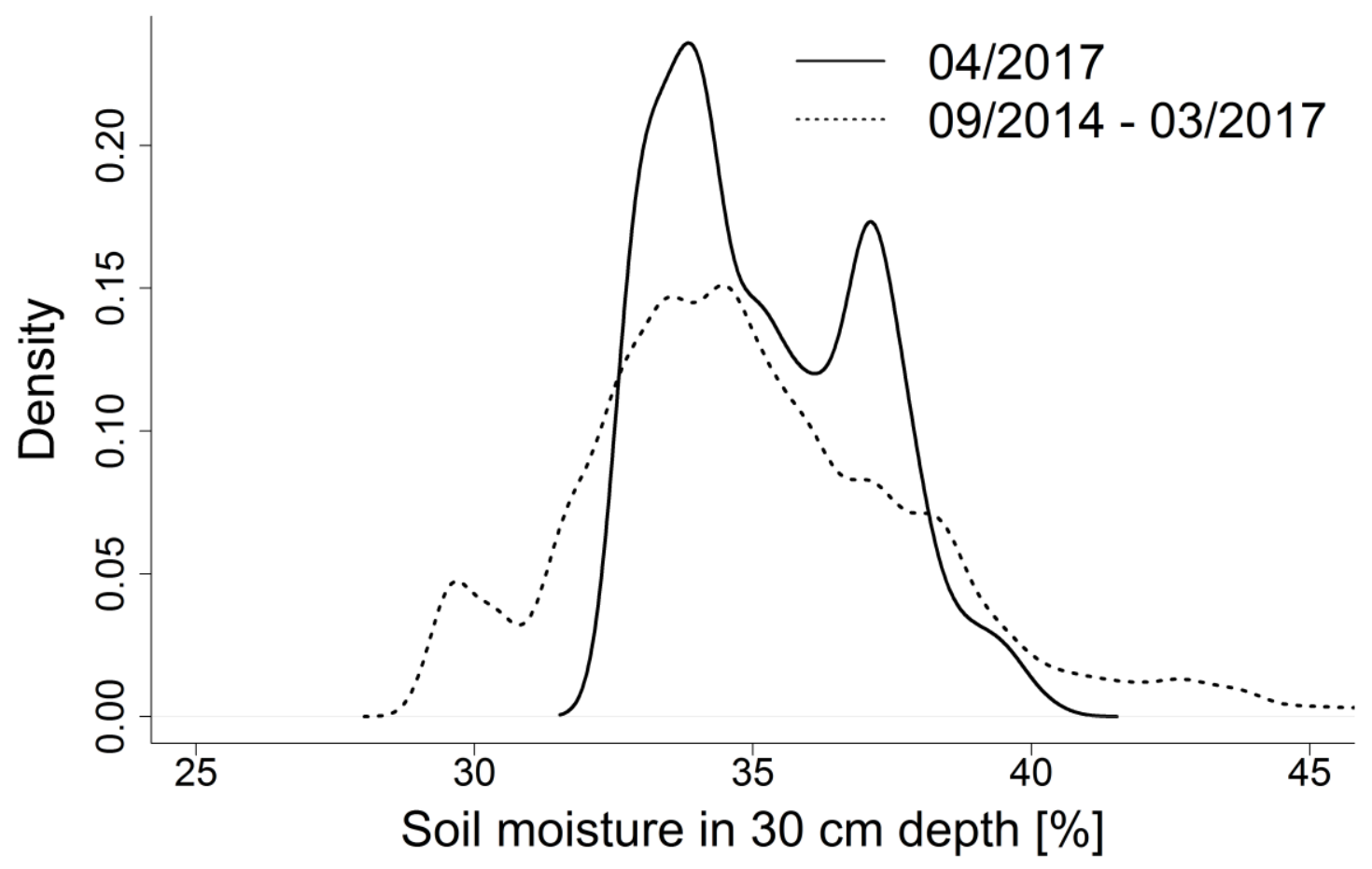

Figure 19: Probability density-curves of mean soil moisture [\% volume] measured half-hourly in $30 \mathrm{~cm}$ depth at a soil moisture and temperature profile near the EC-tower. The full line represents the time from $1^{\text {st }}$ to $28^{\text {th }}$ of April 2017, when des $R_{s}$ measurements took place and the dashed line data from the $1^{\text {st }}$ of September 2014 to the $31^{\text {st }}$ of March 2017 as long-term reference.

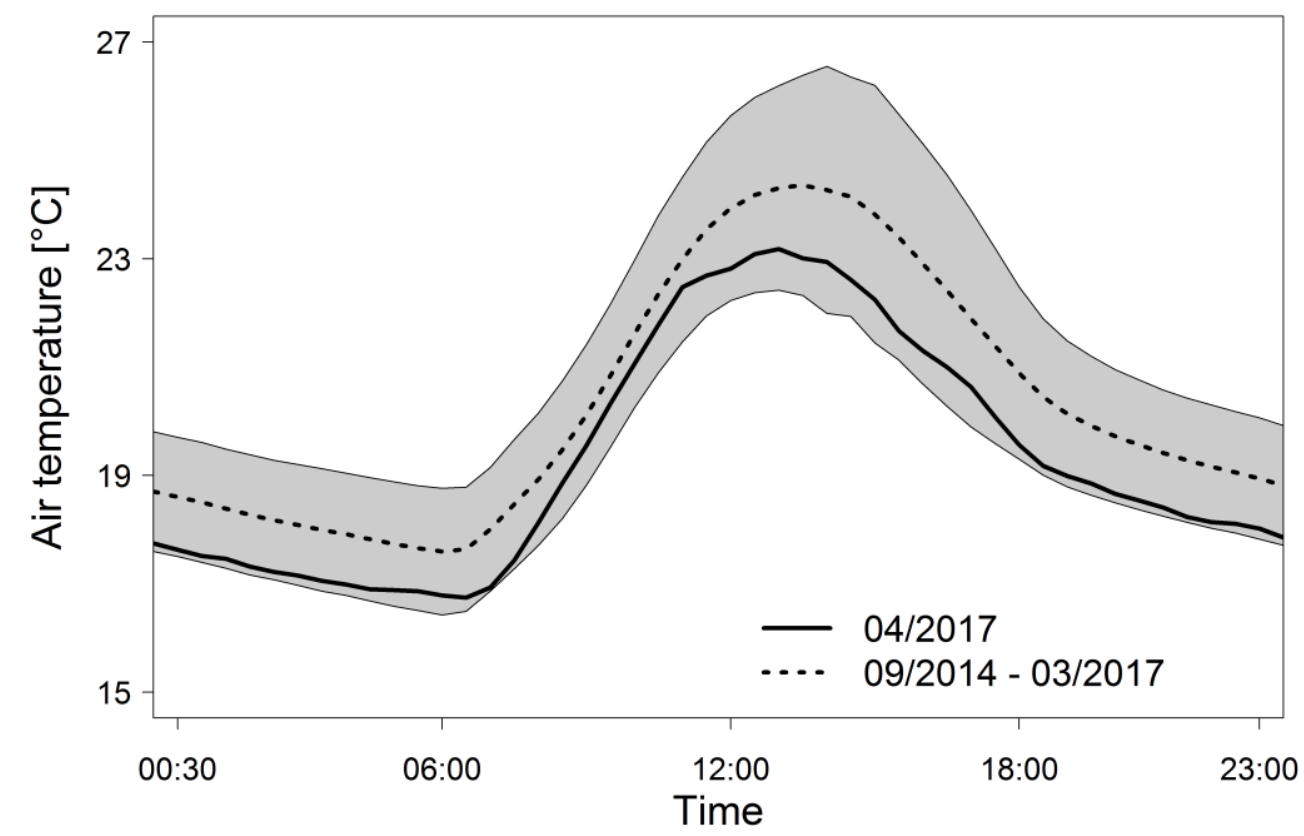

Figure 20: Diel cycle of mean air temperature $\left[{ }^{\circ} \mathrm{C}\right]$ measured half-hourly in $48 \mathrm{~m}$ height at the EC-tower. The full line represents the time from 1-28 April 2017. The dashed line is based on data from the $1^{\text {st }}$ of September 2014 to the $31^{\text {st }}$ of March $2017 \pm$ one standard deviation (shaded area). 


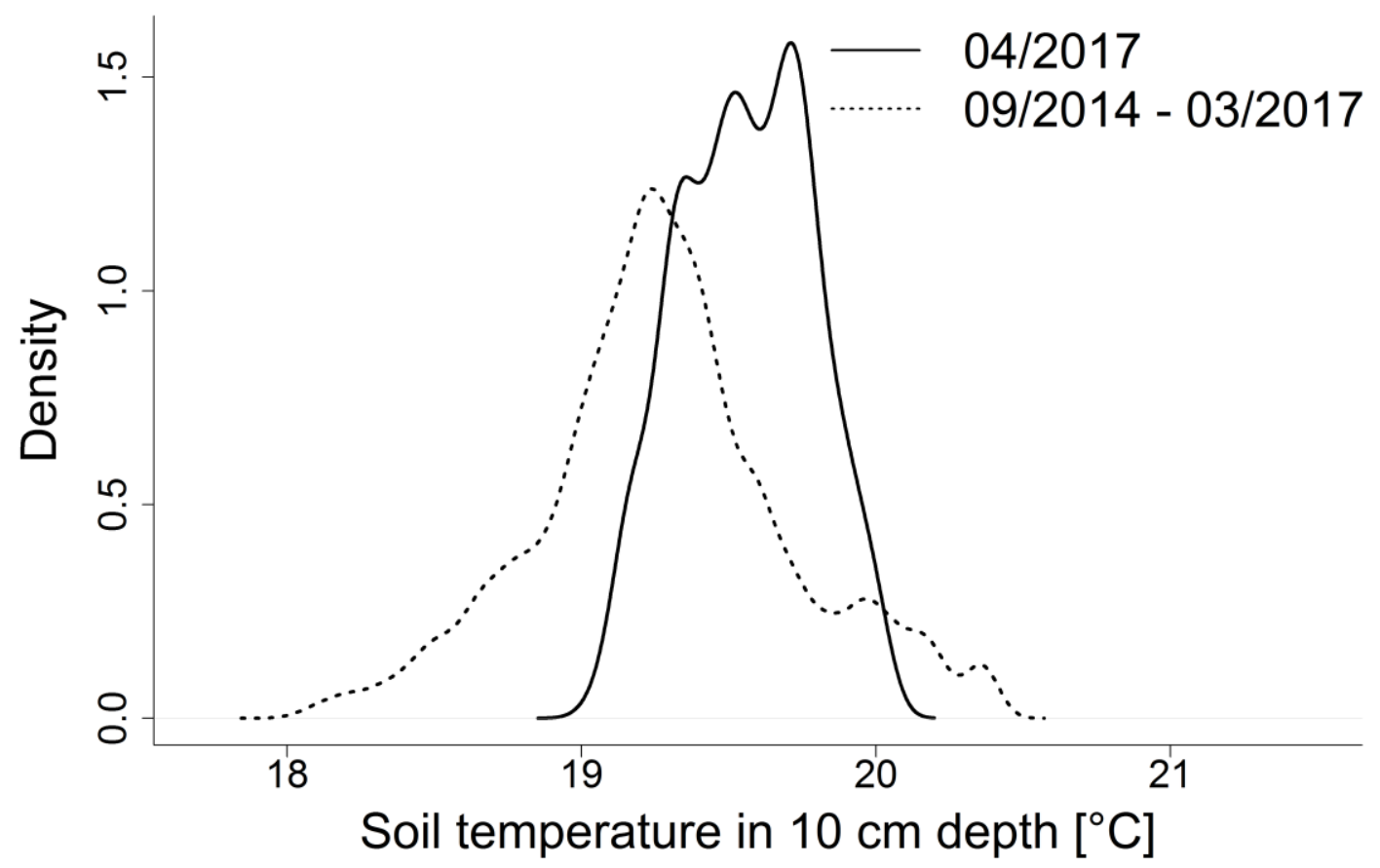

Figure 21: Probability density-curves of mean soil temperature $\left[{ }^{\circ} \mathrm{C}\right]$ measured half-hourly in $10 \mathrm{~cm}$ depth at a soil moisture and temperature profile near the EC-tower. The full line represents the time from $1^{\text {st }}$ to $28^{\text {th }}$ of April 2017 and the dashed line data from the $1^{\text {st }}$ of September 2014 to the $31^{\text {st }}$ of March 2017.

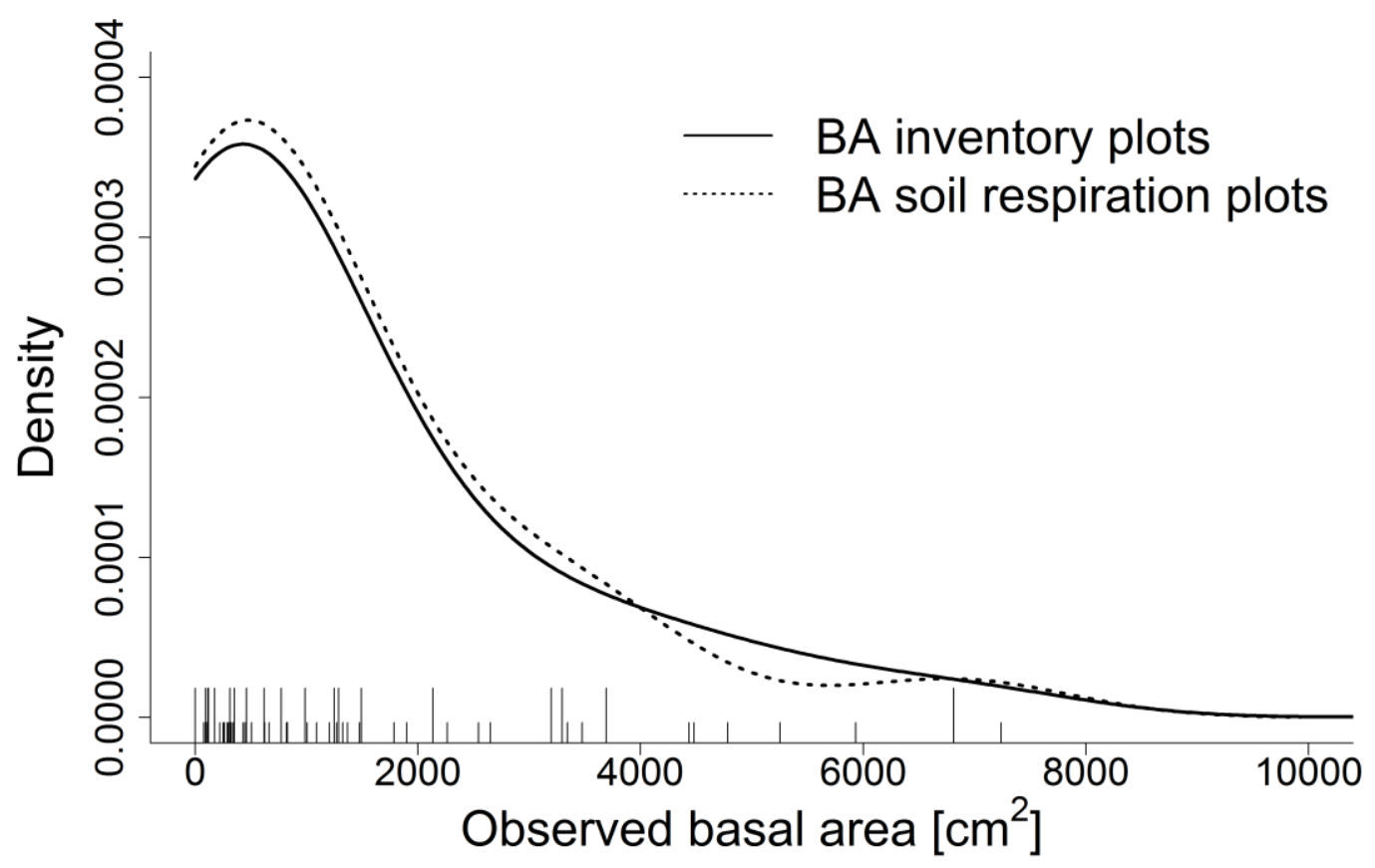

Figure 22: Probability density-curves of BA in an $8 \mathrm{~m}$ radius at a) all forest inventory plots (full line, short tick marks) and $b) R_{s}$ measurement locations (dashed line, long tick marks). The forest at the $R_{s}$ measurement locations is nearly identical in distribution of BA to the surrounding 10 ha. There are two outliers from the inventory not visible in this graph. 


\subsection{Discussion}

I was able to establish a robust estimate of $R_{s}$ for my study site in a remote montane rainforest. My estimate of $6.2 \pm 1.84 \mu \mathrm{mol} \mathrm{m}^{-2} \mathrm{~s}^{-1}$ is in the upper range for old-growth tropical forest $R_{s}$, which ranges from $2.64 \mu \mathrm{mol} \mathrm{m}^{-2} \mathrm{~s}^{-1}$ (Davidson et al., 2004) to $6.76 \mu \mathrm{mol} \mathrm{m}^{-2} \mathrm{~s}^{-1}$ (Hashimoto et al., 2004). $M_{s}$ seems to be relatively unimportant for $R_{s}$ at the site which is quite surprising given results from another forests relatively close by, where $\mathrm{M}_{\mathrm{s}}$ was the only significant environmental driver on control plots and rainfall exclusion led to significant decreases in $\mathrm{R}_{\mathrm{s}}$ (van Straaten et al., 2011). I can only speculate why that is not the case at this site. Although I measured after as well as during the onset of rainfall, I was not able to detect possible pore space $\mathrm{CO}_{2}$ displacement from heavy rain as safety concerns kept us from entering the forest during these times. It is also possible that impact of $M_{s}$ on $R_{s}$ would appear during phases with significantly less precipitation, like the strong ENSO event in 2015-2016.

As hypothesized, I found an influence of mean $\mathrm{DBH}$ and $\mathrm{BA}$ on $\mathrm{R}_{\mathrm{s}}$, yet the expected diel variation was not detected. I attribute this to the relatively stable $\mathrm{T}_{\mathrm{s}}$ which has been shown to control diel variations in a montane cloud forest at $3030 \mathrm{~m}$ a.s.l. (Zimmermann et al., 2009b) but less so at 1500 $\mathrm{m}$ a.s.l. and $1000 \mathrm{~m}$ a.s.l. (Zimmermann et al., 2010). Contribution of litter to total $\mathrm{R}_{\mathrm{s}}$ was high in other studies (Sotta et al., 2006; Zimmermann et al., 2009b) but linear regression models with DOL indicated only a minor role of this variable at the site. I found that only trees closer than $3 \mathrm{~m}$ had a significant impact on $R_{s}$ in contrast to a lowland rainforests where correlation was strongest with mean DBH inside $6 \mathrm{~m}$ radius (Katayama et al., 2009). Studies which found no (Bréchet et al., 2011; Sotta et al., 2004) or weak (Rubio and Detto, 2017) correlations generally did not consider BA or mean DBH in different radii. If limited to a $2 \mathrm{~m}$ radius or less the correlation with mean DBH and $\mathrm{BA}$ is no longer significant, which I attribute to the increasing numbers of plots where no trees with a $\mathrm{DBH} \geq 10 \mathrm{~cm}$ are present inside this range. Consequently, it is quite likely that plant area index derived from hemispheric photography would be an even more accurate estimator as it would include smaller trees and other important plant types like rattan.

The observed correlations at the site indicate that forest density exceeds all other influences. While Rubio and Detto (2017) found neither an impact of gap fraction nor an effect of $T_{s}$ on efflux rates, my findings show a small dependence of $R_{s}$ on $T_{s}$ but a significant and strong relationship between mean $T_{s}$, mean DBH and BA. Additionally, variances of $T_{s}$ and $R_{s}$ measured at the same location over all measurement campaigns were not significantly correlated. However, a lagged response of $R_{s}$ to $T_{s}$ is possible. The dominant role of forest density is furthermore evident in LME models 
when comparing the low values of $\mathrm{R}^{2}{ }_{(\mathrm{m})}$, given by the effect of $\mathrm{T}_{\mathrm{s}}$ only, and the higher value of $\mathrm{R}^{2}{ }_{(\mathrm{c})}$, given by the full model including BA.

As initially expected, mean $\mathrm{DBH}$ and $\mathrm{BA}$ close to the $\mathrm{EC}$ tower is similar to the surrounding area. The weak or lack of response of $R_{s}$ to the measured ranges of $T_{s}$ and $M_{s}$ combined with stable climatic conditions indicates a low temporal variation of $\mathrm{R}_{\mathrm{s}}$ over the year (Katayama et al., 2009) with possible exceptions during extreme climate conditions and associated higher tree mortality (Condit, 1995). The results therefore suggest that my $\mathrm{R}_{\mathrm{s}}$ estimate is representative of the wider landscape where conditions remain comparable.

\subsection{Conclusion}

I observed temporally stable $\mathrm{R}_{\mathrm{s}}$ over one month and at different times of the day; hypothesised diel variations were not detected. Forest density represented by BA was shown to be a strong predictor of $\mathrm{R}_{s}$, while $\mathrm{T}_{\mathrm{s}}$ and $\mathrm{M}_{\mathrm{s}}$ varied little at the site and had limited to no impact. The similar distribution of trees in the surrounding forest compared to my measurement locations, in conjunction with average weather conditions during my measurement campaigns, make the observed fluxes a good estimate of annual $R_{s}$ in this area and ecosystem type. With this study, I give the first estimation of tree density impacts on $\mathrm{R}_{\mathrm{s}}$ in a tropical montane forest, providing a basis for other studies investigating the possible impacts of climate change on these tropical ecosystems. 


\section{Eddy-Covariance based measurements of ecosystem $\mathrm{CO}_{2}$ exchange}

\subsection{Eddy-Covariance technique as an approach to estimate total ecosystem carbon exchange with the atmosphere in the tropics}

The main challenge in estimating carbon uptake of tropical rainforests is rooted in their immense structural and functional diversity. In comparison to forests in temperate regions, $\mathrm{CO}_{2}$ budgets of non-tree plants such as epiphytes or lianas have a much higher and even detrimental impact on the total ecosystem carbon budget (van der Heijden et al., 2015) and woody stem growth amounts to a lower percentage of net primary productivity (Anderson-Teixeira et al., 2016). While forest inventory methods developed in temperate regions have been used nevertheless to estimate carbon uptake and loss of such forests, they therefore cannot capture the full carbon cycle.

One method that has emerged as a tool to measure net ecosystem carbon exchange (NEE) is the eddy-covariance technique (EC). EC is a micrometeorological approach and uses the covariance of the vertical wind flux with a scalar $c$ while taking into account the air density $\bar{\rho}_{a}$, to estimate the total flux of said scalar (Baldocchi, 2003):

Eq. 4.1

$$
F_{c}=\bar{\rho}_{a} * \overline{w^{\prime} c^{\prime}}
$$

In this equation, $w$ stands for the vertical wind and $c$ for the scalar, while the overbar denotes the Reynolds averaging operator and primes the departure from the time average. In order to successfully measure net fluxes, the mean vertical wind speed over longer time spans must be zero and atmospheric transport must be turbulent. The highest accuracy of measurements is achieved when the land surface upwind from an EC-installation is relatively flat (Baldocchi, 2003; Burba and Anderson, 2010).

\subsubsection{The night-flux problem}

The most prevalent criticism of net ecosystem exchange (NEE) estimates based on EC is uncertainty of night-time fluxes at many sites and the underlying assumption of constant turbulent atmospheric mixing by many early studies (Kruijt et al., 2004). As Moncrieff et al. (1996) were first to point out, a completely systematic error between day-time and night-time measurements of $\mathrm{CO}_{2}$-fluxes would cancel out because of the different signs. However, due to the dependence of $\mathrm{EC}$ on turbulent atmospheric transport, a biased estimation of the true ecosystem flux is more 
likely at night when the atmospheric stratification is often stable, especially over tall vegetation and sloped terrain (Lee, 1998). Under such conditions, horizontal advective transport can lead to vertical entrainment of air with a lower $\mathrm{CO}_{2}$-concentration from above the canopy (Aubinet et al., 2003).

Therefore, as perfect conditions are basically never present, a generally accepted simplified but expanded equation (Feigenwinter et al., 2004; Finnigan, 1999; Finnigan et al., 2003) for ecosystem-atmosphere net fluxes when incompressibility of air is assumed is given by:

Eq. 4.2

$$
\begin{gathered}
N E E=\overline{w^{\prime} c^{\prime}}\left(z_{r}\right)+\int_{0}^{z_{r}} \frac{\overline{\partial c(z)}}{\partial t} d z+\int_{0}^{z_{r}}\left(\bar{w}(z) \frac{\partial \bar{c}(z)}{\partial z}\right) d z \\
\text { I } \\
+\int_{0}^{z_{r}}\left(\bar{u}(z) \frac{\partial \bar{c}(z)}{\partial x}+\bar{v}(z) \frac{\partial \bar{c}(z)}{\partial y}\right) d z
\end{gathered}
$$

IV

Here $v, u$ and $w$ denote longitudinal, lateral and vertical wind velocity components while $x, y$ and $z$ stand for the three dimensions in a Cartesian coordinate system. The scalar is given by $c$, and $z_{r}$ is the height of observations. Again overbars denote Reynolds averaging operator and primes departures from the time average. Term I is the vertical turbulent flux e.g. the eddy-covariance from Eq. 4.1, term II the storage flux below the measurement height, term III the vertical advection and term IV the horizontal advection. This equation leaves out horizontal turbulent flux divergence and horizontal variation of vertical turbulent fluxes (Feigenwinter et al., 2008)

While term I would be the only significant flux under perfect conditions, the other terms can significantly alter flux estimates under many real-world circumstances. Term II is expected to be zero on average over time, as $\mathrm{CO}_{2}$ accumulated in the storage during times without turbulent mixing is vented when turbulent atmospheric transport is re-established. Under field conditions, the accumulation phase usually starts when unstable atmospheric conditions become stable, as is often the case after sunset and the reverse is happening after dawn (van Gorsel et al., 2007). The advection terms III and IV become important during night under stable atmospheric conditions, especially at sites with sloped terrain or were breezes are present (Aubinet, 2008; Feigenwinter et al., 2008).

A common approach to correct for systematic night-time biases is the usage of a friction velocity $\left(u^{*}\right)$ threshold, which theoretically discards fluxes measured during times of advective loss, e.g. 
when term III and IV are significant (Aubinet et al., 2005; Barr et al., 2013; Goulden et al., 1996; Gu et al., 2005; Papale et al., 2006). However, above-canopy u* does not indicate all instances of horizontal advection (Tóta et al., 2008) and the effect of $\mathrm{u}^{*}$ on vertical and horizontal fluxes differs between sites (Aubinet et al., 2010). A similar approach using the standard deviation of the vertical velocity fluctuation as a threshold has been put forward (Acevedo et al., 2009), but did not lead to better results when compared to the standard $\mathrm{u}^{*}$ method (Hayek et al., 2018).

A completely different method to derive night-time fluxes was developed by van Gorsel et al. (2007). It extrapolates maximum NEE fluxes measured at the beginning of the night when good conditions for EC are still given, to times when such conditions are not met anymore. The assumption is, that for those measurements in the early hours after sunset the advection terms III and IV (Eq. 4.2) are still negligible and the measurable terms I and II dominate the total flux (van Gorsel et al., 2007). The difference in annual NEE estimates based on this approach and the traditional $\mathrm{u}^{*}$-threshold method was $5.6 \pm 0.5 \mathrm{Mg} \mathrm{C} \mathrm{ha}^{-1} \mathrm{y}^{-1}$ at a site in a tall, open wet sclerophyll forest in Australia (van Gorsel et al., 2008). When coupled with a temperature dependent response function based on soil chamber measurements, night-fluxes derived via this method proved to be in good agreement with chamber based respiration measurements, light-response function derived estimates and ecosystem model outputs at 25 sites (van Gorsel et al., 2009).

\subsubsection{Gap-filling techniques and the night flux problem}

To understand ecosystem carbon processes and for gap-filling, a separation of NEE into its main components gross primary productivity (GPP) and respiration (RE) is needed (Reichstein et al., 2005). There is a wide range of approaches to achieve this. Methods using night-time or day-time flux data only as well as both combined have been developed. The standard techniques for flux partitioning employed by the FLUXNET community are the night-time data based approach by Reichstein et al. (2005) and the day-time data based approach developed by Lasslop et al. (2010) (Reichstein et al., 2012).

Lasslop et al. (2010) proposed a method to derive RE mainly from the intercept of a light-response curve. They combined a rectangular hyperbolic light response curve with a Lloyd and Taylor (Lloyd and Taylor, 1994) model accounting for temperature dependency and an exponential decrease function for conditions with high vapour pressure deficit (VPD) after Körner (1995). While the temperature dependency of respiration is still based on night-time data, the rest of the model is fitted to day-time data only. Therefore, this approach opens up the possibility to mostly circumvent the use of possibly erroneous night-time data by using predominantly less problematic day-time data. In such a capacity it has been used successfully to fill data-gaps of an EC site with problematic 
night-time fluxes in Thuringia, Germany (Rebmann et al., 2010). This method will be referred to by the first authors name from here on.

A frequently used gap-filing approach is the marginal distribution sampling method (MDS) after Reichstein et al. (2005), which has been adopted as standard strategy by FLUXNET and shows good performance and low bias in comparison with other techniques. It is based on a look-up table approach where bins of NEE data are created according to similar meteorological conditions. From these bins NEE data for gap-filling is then chosen according to the meteorological conditions when the gap occurred (Moffat et al., 2007). RE however is inferred from night-time data only by this approach (Reichstein et al., 2005).

\subsubsection{Eddy-covariance measurements in the tropics}

EC-measurements have been deployed with great success in a range of ecosystems around the world. However, most sites are situated in the hemispheric North. Of all 856 sites that had been registered in 2017 with FLUXNET, the global EC-tower network, 84\% were located north of the Tropic of Cancer. Of the remaining 138 towers, another 28\% are concentrated in Australia. The Amazonas basin where $9 \mathrm{EC}$-towers were operational at some time is also relatively well observed. In other tropical regions the amount of measurement sites is far less (Chu et al., 2017; Malhi, 2012). While not all existing EC-sites are members of the FLUXNET community for a variety of reasons (e.g. high standards, data sharing guidelines), I could not find evidence that this changes the overall pattern of distribution.

$\mathrm{NEE}$ estimates of $\mathrm{CO}_{2}$-fluxes measured in a range of old-growth rainforests in the Amazonas basin region of Brazil indicate either a strong sink of -2 to $-7 \mathrm{Mg} \mathrm{C} \mathrm{ha}^{-1} \mathrm{y}^{-1}$ (Aguilos et al., 2018; Andreae et al., 2002; Grace et al., 1995; Malhi et al., 1998; Zeri et al., 2014) or a source of 0.4 to $1.3 \mathrm{Mg} \mathrm{C}$ ha $^{-1} \mathrm{y}^{-1}$ (Hutyra et al., 2008; Miller et al., 2004; Saleska et al., 2003). The positive (loss of carbon to the atmosphere) fluxes were corroborated by consecutive forest biomass inventories at the same sites, but the estimated source strength differed (Hutyra et al., 2008; Miller et al., 2004). However, measured fluxes can be quite different from year to year and forests change from sinks to sources (Hutyra et al., 2008; Zeri et al., 2014).

Further research in Latin America into NEE of tropical forests with EC-measurements has been undertaken in an Amazonian lowland rainforest in French Guiana and a lowland rainforest in Costa Rica. The study site in French Guiana has an estimated sink strength of $-1.97 \pm 0.44 \mathrm{Mg} \mathrm{C} \mathrm{ha-1} \mathrm{y}^{-1}$ during the 6-month long wet season and $-7.66 \pm 0.55 \mathrm{MgC} \mathrm{ha}^{-1} \mathrm{y}^{-1}$ during the 4-month of dry season while the mean annual flux is $-3.35 \mathrm{MgC} \mathrm{ha}^{-1} \mathrm{y}^{-1}$ (Aguilos et al., 2018). This difference is attributed to increased solar irradiance and decreased soil respiration during the dry season (Rowland et al., 2013). For the Costa Rican site, researchers report an NEE of 0.05 to $-1.33 \mathrm{Mg} \mathrm{C} \mathrm{ha}^{-1} \mathrm{y}^{-1}$ in 
1998, -1.53 to $-3.14 \mathrm{MgC} \mathrm{ha} \mathrm{y}^{-1}$ in 1999 and -5.97 to $-7.92 \mathrm{Mg} \mathrm{C} \mathrm{ha}^{-1} \mathrm{y}^{-1}$ in 2000. The ranges in annual estimates stem from different night-time data treatments while differences between years were attributed to El Ninõ - Southern Oscillation (ENSO) effects (Loescher et al., 2003).

For all these sites, the difference in measured NEE is attributed to a range of factors, such as disturbances in the recent past (Hutyra et al., 2008) or ENSO activity (Bonal et al., 2008; Loescher et al., 2003; Rowland et al., 2013) but most authors see the uncertainty of night-time fluxes as the biggest hindrance for achieving robust and comparable estimates of tropical rainforest carbon fluxes based on EC (de Araújo et al., 2010; Hayek et al., 2018; Hutyra et al., 2008; Loescher et al., 2003; Miller et al., 2004).

For tropical South-East Asia, EC based NEE estimates are even sparser. There are only two sites in undisturbed old-growth rainforests besides the one described here, where NEE has been recorded with EC-towers (Kosugi et al., 2007) and both are outside the Wallacea biogeographic region where the Bariri site is located. NEE estimates from these sites, both located on Borneo, are also subject to problematic night-time data. Without corrections and based upon 1.5 years of measurements, the site in Lambir Hills, Malaysia, was an estimated sink of $-4.83 \mathrm{MgC} \mathrm{ha}^{-1} \mathrm{y}^{-1}$. After corrections of night-time measurements based on a light-interception curve were applied, it turned into a weak source of $0.75 \mathrm{MgC} \mathrm{ha}^{-1} \mathrm{y}^{-1}$ (Saitoh et al., 2005). The second site, located in Pasoh, Malaysia, remained a sink when night-time correction was done using a friction-velocity filter, with initial values ranging from -8.2 to $-9.5 \mathrm{Mg} \mathrm{C} \mathrm{ha}^{-1} \mathrm{y}^{-1}$ and corrected values from -5.8 to $-8.0 \mathrm{Mg} \mathrm{C}$ $\mathrm{ha}^{-1} \mathrm{y}^{-1}$ respectively. However when measured soil respiration was used to approximate $40-60 \%$ of night-time ecosystem respiration, mean annual NEE fluxes were -3.9 to $2.7 \mathrm{MgC} \mathrm{ha}^{-1} \mathrm{y}^{-1}$ (Kosugi et al., 2008). Other tower measurements in SE-Asia take place at sites where recent human induced disturbances such as peat drainage dominate measurements or where strong monsoon effects lead to pronounced dry seasons (Hirano et al., 2007, 2012; Huete et al., 2008) and were not considered for comparison of fluxes.

To my knowledge, no further NEE estimates of natural tropical forest ecosystems in SE-Asia based on EC-measurements have been reported and the next EC-tower sites in such ecosystems are located far away. For instance, a well-researched site in an old-growth tropical seasonal rain forest exists at Xishuangbanna in South-Western China, were EC-based measurements and forest inventory studies resulted in an estimated sink of $-1.19 \mathrm{MgC} \mathrm{ha}^{-1} \mathrm{yr}^{-1}$ and $-3.59 \mathrm{MgC} \mathrm{ha} \mathrm{yr}^{-1}$ respectively (Tan et al., 2010). A wet tropical evergreen broad leaf forest in North-East Australia at an altitude of $\sim 700 \mathrm{~m}$ a.s.l. and with an aboveground living biomass of about $418.5 \mathrm{Mg} \mathrm{ha}{ }^{-1}$ (Bradford et al., 2014) had an estimated NEE of $-3.2 \pm 2.3 \mathrm{Mg} \mathrm{C} \mathrm{ha}^{-1} \mathrm{yr}^{-1}$ (Beringer et al., 2016). 
Based on this extensive literature review, the Bariri tower is the sole EC measurement station located in an old-growth montane rainforest worldwide.

\subsubsection{Previous studies of $\mathrm{CO}_{2}$-fluxes in Bariri}

At the Bariri site, the first annual NEE estimate based on EC-measurement from $15^{\text {th }}$ October 2003 to $15^{\text {th }}$ June 2005 was $-9.58 \mathrm{Mg} \mathrm{C} \mathrm{ha}^{-1} \mathrm{y}^{-1}$ (Ross, 2007). The sink strength was highest for overcast days and lowest under clear skies. For the measurement period from $15^{\text {th }}$ October 2003 to $15^{\text {th }}$ June 2005 considered in his analysis, Ross had to discard $86.5 \%$ of night-time data after data quality procedures were applied. This was mostly due to an analysis of measured night-time $\mathrm{CO}_{2}$-fluxes' dependency on $\mathrm{u}^{*}$ which led to a $\mathrm{u}^{*}$-threshold of $0.3 \mathrm{~m} \mathrm{~s}^{-1}$. However, no vertical $\mathrm{CO}_{2}$-concentration profile measurements were carried out for estimating the $\mathrm{CO}_{2}$ storage term. Instead the storage term was simulated with a process based 1-D model (Mixfor-SVAT, Olchev et al., 2008). Using this model, night-flux losses through advective vertical transport during stable atmospheric stratification were estimated to amount to $2.04 \mathrm{Mg} \mathrm{C} \mathrm{ha}^{-1} \mathrm{y}^{-1}$. Furthermore, based on the results of a 3-D canopy-boundary layer simulation model (Sogachev et al., 2002) Ross concluded that fluxes are likely to be influenced by orographic factors (Ross, 2007).

The above-mentioned Mixfor-SVAT (Soil-Vegetation-Atmosphere-Transport) model was developed by Olchev et al. (2008) and parameterised based on measured data to simulate the transport processes of energy, $\mathrm{H}_{2} \mathrm{O}$ and $\mathrm{CO}_{2}$ between the forest and the atmosphere at the Bariri site. A comparison of simulated and measured $\mathrm{CO}_{2}$-fluxes at Bariri with a threshold of $\mathrm{u}^{*}>0.3 \mathrm{~m}$ $\mathrm{s}^{-1}$ led to a $\mathrm{R}^{2}=0.6$ and a $\mathrm{R}^{2}=0.66$ for data with $\mathrm{u}^{*}>0.15 \mathrm{~m} \mathrm{~s}^{-1}$ (no information on slope and intercept or is given in the paper). The contribution of soil respiration to total ecosystem respiration reached 20\% during day-time and 40\% at night, but no clear diel dynamics could be established (Olchev et al., 2008).

Two more recently published studies about forest-atmosphere interactions at the Bariri site investigated the effect of ENSO events on $\mathrm{CO}_{2}$ fluxes (Gushchina et al., 2019; Olchev et al., 2015). During two moderate Modoki type ENSO events observed between 2003 and 2008, these fluxes were sensitive to ENSO patterns, mainly through ENSO impacts on incoming solar radiation. ENSO activities led to an increase in GPP via a reduction of cloud cover, but had only a very weak correlation with RE and NEE. The weak reaction of RE was attributed to negative temperature deviations (Olchev et al., 2015). The strong, conventional ENSO event 2015/2016 in contrast led to a decrease in $\mathrm{CO}_{2}$ uptake through increased temperatures and subsequently higher $\mathrm{RE}$ (Gushchina et al., 2019).

Olchev et al. (2008) was based on measurements from January 2004 - June 2008 for which the $\mathrm{u}^{*}$-threshold was determined as $0.25 \mathrm{~m} \mathrm{~s}^{-1}$ and, together with other filters, removed $85 \%$ of 
night-time data. As the Mixfor-SVAT model (Olchev et al., 2008) has the advantage to be able to estimate fluxes under conditions for which no measured values are available (e.g. rain, insufficient turbulence), it was again used to fill gaps. The average annual NEE for this five year period indicated a strong sink of $-7.82 \pm 24 \mathrm{MgC} \mathrm{ha}^{-1} \mathrm{y}^{-1}$ (Olchev et al., 2015).

Gushchina et al. (2019) is based on the data discussed in this chapter, with data gaps being filled with the Mixfor-SVAT model (Gushchina et al., 2019; Olchev et al., 2008).

\subsubsection{Objectives}

- To characterise meteorological conditions, instrument performance and flux measurements.

To establish a general knowledge of the site and the meteorological conditions during the full project period from December 2013 to April 2017, an overview of important meteorological variables, instrument performance tests, storage flux calculations and Eddy-Covariance measurements without gap-filling was needed. The $\mathrm{CO}_{2}$-concentration profile in the volume beneath the EC-sensor was measured over a long period for the first time. The storage flux calculations based on these measurements are urgently needed to understand the $\mathrm{CO}_{2}$-flux at the site and to make carbon budget estimations more reliable. Furthermore, the influence of different data filtering strategies on data representation had to be investigated.

\section{- To identify the impact of meteorological drivers on Eddy-covariance measurements}

There has been evidence that similar to other tropical forests (Goulden et al., 2004; Kosugi et al., 2008; Loescher et al., 2003; Saleska et al., 2003; Yamasoe et al., 2006) the amount of solar irradiance (Olchev et al., 2015) and the proportion of diffuse radiation (Ross, 2007) play an important role in controlling $\mathrm{CO}_{2}$-fluxes at the Bariri site. These interactions as well as influences of air temperature and VPD need to be understood for proper gap-filling and to estimate possible effects of climate change at this site. Therefore, further examinations of flux-irradiance interactions and a measurement campaign aiming at quantifying canopy light transmissivity were undertaken to better understand meteorological drivers of $\mathrm{CO}_{2}$-fluxes at the site. 
- To compare night-time flux estimation approaches and their influence on the annual carbon budget of the site

Finally, the effect of applying different night-time flux estimation methods on annual $\mathrm{CO}_{2}$ budgets of a montane rainforest will be determined in this chapter. To this end, using the standard MDS gap-filling model from Reichstein et al. (2005), which uses night-time measurements, will be compared to:

- The approach developed by Lasslop et al. (2010) which uses a light-response curve based on day-time data to estimate RE

- The strategy proposed by van Gorsel et al. (2007), where night-time fluxes are estimated based on maximum fluxes at the beginning of the night

- A data set where values modelled with Mixfor-SVAT (Olchev et al., 2008) replaced all night-time measurements

The more an ecosystem changes in times when there is a data gap, the higher the uncertainty of the gap-filling technique. Therefore, gap-filling techniques have a higher uncertainty when data-gaps become large (Papale, 2012). From this perspective a day-time data based approach should have a lower uncertainty, if night-time data is filtered out by a higher proportion. I therefore hypothesise that all three approaches will lead to more reliable estimates than the standard MDS approach. 


\subsection{Material \& Methods}

\subsubsection{Tower instrumentation}

Measurements were undertaken at the $70 \mathrm{~m}$ high scaffolding tower mentioned in the site description or near its base. Incoming and reflected long-wave radiation was measured with CG1 pyrgeometers (Kipp\&Zonen, Delft, The Netherlands), incoming and reflected solar radiation with CM6B pyranometers (Kipp\&Zonen, Delft, The Netherlands), both at $48 \mathrm{~m}$. At the same height, two PQS 1 PAR quantum sensors (Kipp\&Zonen, Delft, The Netherlands) were installed in August 2014 to quantify incoming and reflected photosynthetically active radiation (PAR). Simultaneously a SPN1 (Delta-T Inc., UK) direct/diffuse radiation sensor was added at the top of the tower.

Air temperature and air humidity were measured at three heights below and four heights above the canopy (Friedrichs Co., Germany). Precipitation was measured at the top of the tower by two Hellmann type rain gauges (Friedrichs Co., Germany). Soil temperature profiles were measured twice in 2, 5, 10, 20, 30 and $50 \mathrm{~cm}$ depth, soil humidity in $10 \mathrm{~cm}$ depth (Friedrichs Co., Germany). In August 2014, an additional two soil profiles with temperature and humidity measurements at 30 and $60 \mathrm{~cm}$ (Trime-Pico 32, IMKO, Germany) were added. Wind speed was measured once below and twice above the canopy with cup anemometers (Friedrichs Co., Germany), wind direction with a wind wane at $48 \mathrm{~m}$ (Friedrichs Co., Germany).

For EC measurements, three-dimensional wind direction and wind speed were measured with a sonic anemometer (USA-1, METEK, Germany), $\mathrm{CO}_{2}$ - and $\mathrm{H}_{2} \mathrm{O}$-concentration with an open-path infrared gas analyser (LI-7500A, Licor Inc., USA), both operating at $10 \mathrm{~Hz}$. To determine sub-sensor $\mathrm{CO}_{2}$-storage flux, a $\mathrm{CO}_{2}$-concentration measurement profile was installed with intakes at $0.25,1,2,24,38$ and $48 \mathrm{~m}$ height. All intakes were connected by $50 \mathrm{~m}$ long Teflon tubes to a closed-path infrared sensor (LI-820, Licor Inc., USA) at the bottom of the tower. The flow rate was set to average $0.9 \mathrm{l} / \mathrm{min}$ as the air pump reacted to different charging levels of the batteries and the maximum flow rate the LI-820 can safely accommodate is $11 / \mathrm{min}$.

EC data was directly transmitted to a Windows-PC running EddyMeas (Eddysoft, MPI Jena, Germany) while all other data was first send to data loggers (Friedrichs Co., Germany) and then transferred to the same computer. All power was provided by solar panels and accompanying batteries mounted on the tower. 


\subsection{2 $\mathrm{CO}_{2}$-Profile measurements}

Profile measurements to establish $\mathrm{CO}_{2}$-storage fluxes started in October 2014. Air was sampled by the LI-820 for one minute from each of the six intake heights in turn. Initial trials indicated that it took about $24 \mathrm{sec}$. for air from a new intake height to replace air from the previously sampled height in the measurement setup. Therefore, $\mathrm{CO}_{2}$-concentrations measured over one minute were averaged over 15 second intervals and the first two data points per intake height (first $30 \mathrm{sec}$.) discarded. The remaining data points were averaged over half hourly time steps, corresponding to EC time intervals. Each intake height was taken to represent the $\mathrm{CO}_{2}$-concentration of an air volume with $1 \mathrm{~m}$ depth and width and a height equal to the half way distance to the next intake height above and below it. To calculate storage $\mathrm{CO}_{2}$-concentration $\left(\mathrm{S}_{\mathrm{ppm}}\right)$, the concentration measured at a certain height was weighted accordingly (Eq. 4.3). This means e.g. that the intake at $1 \mathrm{~m}$ height $\left(h_{1}\right)$ represents the air volume from 0.625 to $1.5 \mathrm{~m}$ height.

Eq. 4.3

$$
\begin{gathered}
S_{\text {ppm }}=0.013020831 * h_{0.25}+0.018229167 * h_{1}+0.2395831 * h_{2}+0.375 \\
* h_{24}+0.25 * h_{38}+0.104167 * h_{48}
\end{gathered}
$$

The $\mathrm{CO}_{2}$ flux in and out of the profile volume was then calculated as the difference in concentration between two half-hourly means $\left(\mathrm{S}_{\mathrm{ppm}_{-} \mathrm{t}+1}-\mathrm{S}_{\mathrm{ppm}_{-}}\right)$and converted to $\mu \mathrm{mol} \mathrm{m}^{-2} \mathrm{~s}^{-1}$. In October 2015 it was discovered that leaks in the tubing contaminated measurements from the two highest levels. Previous storage flux estimates were corrected by applying a correction factor based on linear correlation between flux derived from the lower four levels and flux derived from all levels during times of correct measurements after October $2^{\text {nd }} 2015\left(R^{2}=0.93\right)$. Due to a failure in the LI-820 light source, there is a complete lack of profile data from August $17^{\text {th }} 2016$ to September $23^{\text {rd }} 2016$, at which point the instrument was replaced.

\subsubsection{Eddy-Covariance measurements}

EC measurements were carried out intermittently from 4 ${ }^{\text {th }}$ of December 2013 to $28^{\text {th }}$ of April 2017. Over time, degrading battery capacities led to power outages especially in the hours before sunrise. Redistributing power loads in February 2015 led to a stable performance, but in March 2015 the LI-7500A started to fail and could only be replaced six month later due to security concerns. Because of this, most in-depth analysis was restricted to the period from May 2016 to April 2017 (referred to as reference period from here on). 


\subsubsection{Eddy-Covariance-raw data processing}

EC data was processed with EddyPro version 6.0.0 (Licor Inc., USA). Fluxes were averaged over $30 \mathrm{~min}$. To correct for axis tilt, the unbiased planar fit rotation method (Wilczak et al., 2001) was employed. Based on Ross (2007), a $25^{\circ}$ wind sector was excluded to minimise tower influences. Detrending was done via block averaging, fluctuations of density compensated via established principles (Burba et al., 2008; Webb et al., 1980). To allow a fine grained selection of data later in the process, the 1-9 quality flag scheme was adopted (Foken, 2006). All further processing steps were done using default settings, including the calculation of spectra and co-spectra.

\subsubsection{Eddy-Covariance - post processing}

From the EddyPro output, the $5 \%$ of data points with the highest variance in $\mathrm{H}_{2} \mathrm{O}$ and $\mathrm{CO}_{2}$ fluxes were removed before any further processing as they typically reflect unrealistic measurements (filter 1). An additional filter applied to all $\mathrm{CO}_{2}$-flux processing steps was the removal of data points with a flux $>50$ or $<-50 \mu \mathrm{mol} \mathrm{CO} \mathrm{m}^{-2} \mathrm{~s}^{-1}$ (filter 2). Further filters (filters 3,4,5) applied were a friction velocity $\left(\mathrm{u}^{*}\right.$ ) threshold filter (see 4.2.4.3) and filters based on $\mathrm{CO}_{2}$ quality flag (QF) values of 6 and 8 (Foken, 2006) in conjunction with $\mathrm{u}^{*}$-thresholds. While it is generally advised to use high quality data with QF 3 or lower to determine fundamental principles (Foken, 2006), this was not feasible at the Bariri site, as less than $2 \%$ of night time data remained with a $\mathrm{QF}<=3$, even before a $\mathrm{u}^{*}$ threshold was applied.

The impact of filtering steps on the representation of different atmospheric stability classes in the full EC data set as well as on the fluxes during the reference period, which included storage measurements, were analysed. All further analysis was limited to data remaining after the first two filtering steps were applied. The storage flux measured according to 4.2.3 was only included in NEE estimations for the reference period.

\subsubsection{EC-instrument performance}

To analyse if both LI-7500A infrared gas analysers deployed were performing adequately, one spectra and one co-spectra per LI-7500A were selected arbitrarily from the EddyPro output from time periods with good measurement conditions and subsequently analysed. For the first IRGA data from the $2^{\text {nd }}$ of July 2014, 13:00 was used, for the second the data was recorded on $30^{\text {th }}$ of September 2015, 11:00.

\subsubsection{Energy balance closure}

Energy balance closure (EBC) is reached, if the available energy at the surface is in equilibrium with sensible $(\mathrm{H})$ and latent heat fluxes (LE). It is generally calculated as the proportion of the sum of $\mathrm{H}$ and $\mathrm{LE}$ to the sum of net radiation $\left(\mathrm{R}_{\mathrm{n}}\right)$ and ground heat flux $(\mathrm{G})$ : 
Eq. 4.4

$$
E B C=\frac{H+L E}{R_{n}-G}
$$

As no measurements of $\mathrm{G}$ took place at the site during the project period it has to be calculated without. However, due to the low variability observed in soil temperature near the tower base and the dense canopy, $G$ is probably very low in any case. Additionally, this calculation was limited to the reference period as it was impossible to calibrate $\mathrm{H}_{2} \mathrm{O}$ measurements of the first LI-7500A. After visual inspection of the data it was inferred, that the sensor measuring outgoing radiation received light reflected off the tower around noon. This data was therefore removed for this analysis. After cleaning the data an EBC-ratio estimate was then calculated from daily sums of $\mathrm{H}+\mathrm{LE}$ as well as $\mathrm{R}_{\mathrm{n}}$ measured from 10:31-13:30 to investigate EBC under conditions of high fluxes. Additionally, an EBC-ratio was calculated based on the cleaned data for all half-hourly fluxes of the reference period.

\subsubsection{EC-friction velocity threshold and gap-filling}

A friction velocity $\left(\mathrm{u}^{*}\right)$ threshold per season was determined to filter out data measured during times of insufficient turbulent mixing of the atmosphere. The change-point detection method according to Barr et al. (2013) was utilised with estimates of different robustness via bootstrapping. Here the $95 \% \mathrm{u}^{*}$ value estimate per season (which were defined by the software) was selected to filter out data which was measured under insufficiently turbulent conditions. The standard moving point method proposed by Papale et al. (2006) could not be used due to insufficient data points at night-time. The $\mathrm{u}^{*}$ threshold was determined for each level of filtering (4.2.5) separately and results are discussed in relation to the original method proposed by Goulden et al. (1996). After establishing the $\mathrm{u}^{*}$ threshold, data gaps were filled for the reference period according to the MDS strategy described by Reichstein et al. (2005).

\subsubsection{EC-footprint analysis}

Flux footprints were analysed for the reference period to verify that $\mathrm{CO}_{2}$-fluxes measured at the tower came from forest areas only. The input data consists of EddyPro output after filters $1 \& 2$ were applied, but before any gap-filling occurred. Footprints were estimated with the FFPonline tool (Kljun et al., 2015) for unstable, neutral and stable conditions as well as for day-time and night-time fluxes separately. 


\subsubsection{Analysis of meteorological drivers}

As ecosystem productivity has been shown to be mainly driven by photosynthesis at this site, the first step in analysing the impact of different meteorological conditions on $\mathrm{CO}_{2}$-absorption was to quantify the impact of different irradiance parameters (I). The photosynthesis-irradiance (PI) curve was used to explore the predictive power of global radiation and PAR on day-time EC-CO $\mathrm{CO}_{2}$ fluxes. These were used instead of NEE including storage because the storage term is heavily influenced by factors independent of plant productivity, such as wind patterns. The following non-linear model was fitted to day-time flux values, after filters 1 and 2 were applied and outliers were removed:

Eq. 4.5

$$
N E E_{\text {day }}=\frac{P_{\max } *[I]}{\left(K_{I}+[I]\right)}
$$

with start parameters $P_{\max }=50 ; K_{I}=25$

Here $P_{\max }$ stands for the maximum photosynthetic rate at the light intensity $I$, whereas $K_{I}$ is the half saturation constant. Model performance was judged based on $\mathrm{R}^{2}$ of the linear regression between predicted and measured values. A possible half-hour time-lag between irradiance and flux data due to the speed of biophysical processes was investigated by fitting the PI-curve to lagged data. To see the effect of different wind conditions on the irradiance-flux relationship, the PI-curve was additionally estimated for different bins of the friction velocity $u^{*}$. This was done for all day-time data and for fluxes above an absolute threshold of $-25 \mu \mathrm{mol} \mathrm{CO} \mathrm{CO}^{-2} \mathrm{~s}^{-1}$. The threshold was applied as preliminary analysis revealed that the PI-curve fitted to all data did not predict values above $-21 \mu \mathrm{mol} \mathrm{CO}_{2} \mathrm{~m}^{-2} \mathrm{~s}^{-1}$.

In a second step, the influence of air temperature, VPD and diffuse radiation on residuals of the model fitted to all data was estimated via separate linear, second order polynomial and logistic regressions. All of the above was done for the reference period only, to avoid artificial effects due to the different infrared gas analysers involved.

To investigate if a strong effect of diffuse radiation transmissivity of the canopy on NEE exists, which had been postulated in a previous study (Ross, 2007), a PAR study campaign was undertaken on the forest floor in late September and early October 2015. One PQS 1 PAR quantum sensor (Kipp\&Zonen, Delft, The Netherlands) was connected to a battery pack and a data logger (Friedrichs Co., Germany) to allow for mobility. Measurements were taken along a transect of 36 points $1 \mathrm{~m}$ above ground. Over the course of 8 days, measurements were taken 9 times at each 
point at varying times of day. Additionally, the sensor was placed at one point for a total of 9 days to capture complete diel cycles. PAR measured under the canopy was then compared to mean half-hourly PAR measured above the canopy at the same time and correlations with diffuse and global radiation as well as $\mathrm{CO}_{2}$-fluxes investigated.

\subsubsection{Night-time flux estimation methods}

The effect of different night-time flux estimation methods on night-time data was tested for the reference period by using data for which day-time gaps had been filled according to the MDS strategy. All other techniques were then applied to estimate night-time flux only. The methods compared are night-time data filled by MDS too; night-time flux estimations predominantly based on day-time data according to Lasslop et al. (2010); night-time data replacement by a fixed value based on mean maximum flux values measured at the beginning of the night (van Gorsel et al., 2007) and finally night-time fluxes derived from a locally parameterised model (Olchev et al., 2008). Night-time data from the Mixfor-SVAT model (Olchev et al., 2008) was provided by Alexander Olchev after recalibrating the model with the new soil respiration data presented in chapter 3.

For the approach described by van Gorsel et al. (2007), the mean maximum night-time flux was determined for filters 3-5 separately, with the $\mathrm{u}^{*}$ threshold value determined as above. In their study, soil respiration was correlated with soil temperature measured at the tower and an equal dependency for total respiration was assumed. As soil temperature at Bariri is extremely stable (mean $=19.29 \pm 0.43{ }^{\circ} \mathrm{C}$ in $10 \mathrm{~cm}$ depth from September 2014 to April 2017), similar to other tropical rainforests (van Gorsel et al., 2009; Hutyra et al., 2007), a constant value was assumed.

\subsubsection{Data analysis tools}

'R' (R Core Team, 2016) and the 'R'-packages 'xts' (Ryan and Ulrich, 2014) and 'zoo' (Zeileis and Grothendieck, 2005) for time-series were used for all data processing. Data transformations utilises 'R'-packages 'dplyr' (Wickham et al., 2019) and 'utils' (Bengtsson, 2019).

The 'ReddyProc' (Wutzler et al., 2018) R-package was used to determine a friction velocity $\left(\mathrm{u}^{*}\right)$ threshold per season via the change-point detection method according to Barr et al. (2013), including measures of robustness via bootstrapping. The same package was also used to fill gaps for the reference period according to the MDS strategy described by Reichstein et al. (2005) and the night-time flux estimations according to Lasslop et al. (2010). 


\subsection{Results and Discussion}

\subsubsection{Meteorological conditions at the site}

Figure 23 shows an overview of the main meteorological variables aggregated to 30 min intervals, from $4^{\text {th }}$ December 2013 to $28^{\text {th }}$ April 2017. Data gaps are results of power outage or, as in the case of the largest gap, a consequence of disruption of data storage due to a failure of the central computer.

Mean annual rainfall from January 2014 - January 2017 was $2307 \mathrm{~mm}$ and mean annual air temperature $20.5^{\circ} \mathrm{C}$. A mean daily air temperature of $20.23{ }^{\circ} \mathrm{C}$ with a standard deviation of \pm 1.01 and a mean monthly air temperature $20.25 \pm 0.82{ }^{\circ} \mathrm{C}$ show that air temperature is very stable at the site during the considered period. However, Ross (2007) reports a mean annual air temperature of $19.1 \pm 2.5{ }^{\circ} \mathrm{C}$, indicating a trend of increasing temperature in line with global temperature developments. It has to be taken into consideration though that the temperature sensors used in Bariri are quite old and the air fans of their housing did not work all the time.
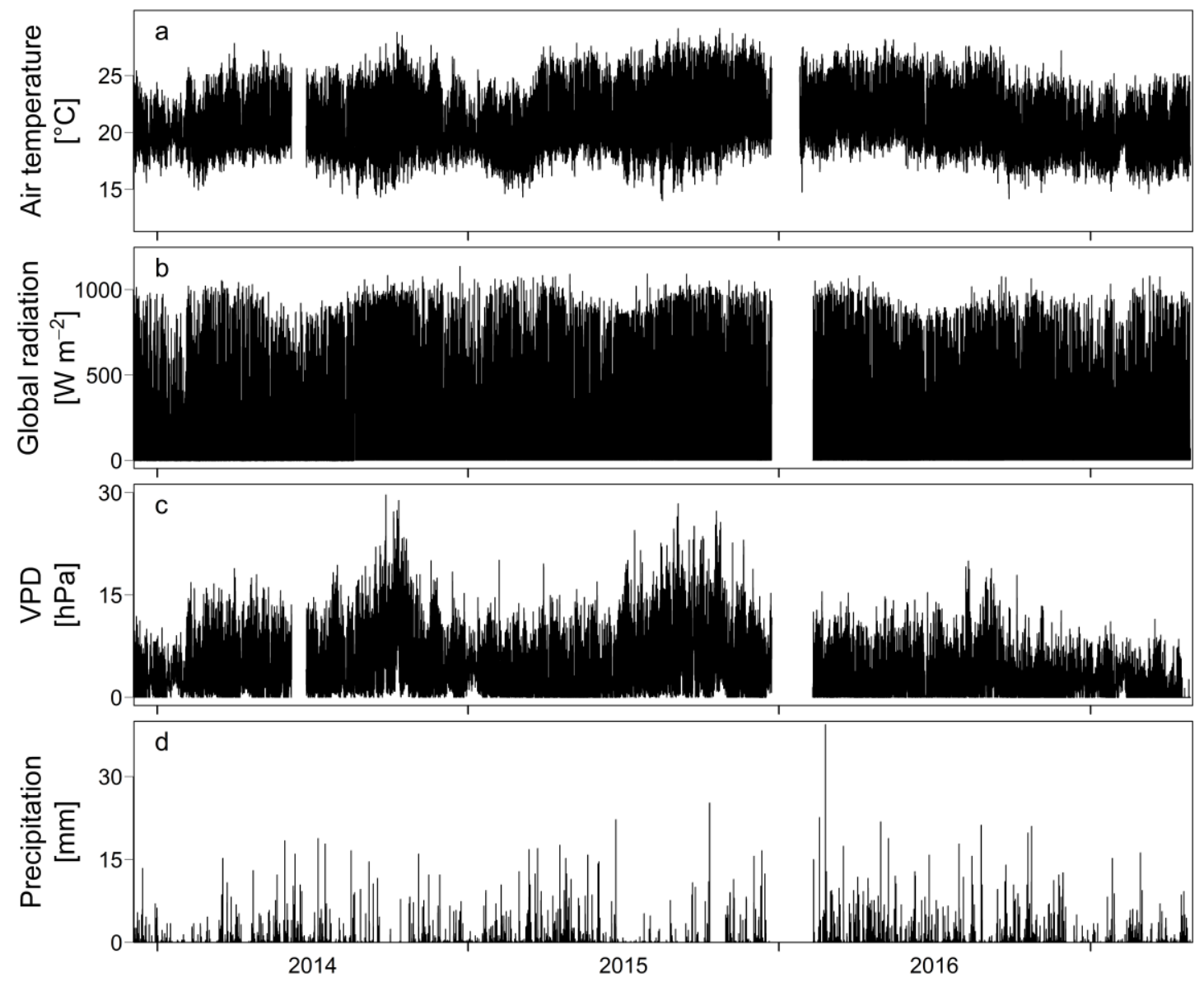

Figure 23: Overview of air temperature a), global radiation b), VPD c) and precipitation d) at the study site from December 2013 to April 2017. 
Mean monthly precipitation is $175 \pm 98.24 \mathrm{~mm}$, with the lowest record of $12.2 \mathrm{~mm}$ in July 2015 observed during the strong ENSO event 2015/2016. During the rest of the study period, monthly precipitation is always above $50 \mathrm{~mm}$. With $1641 \mathrm{~mm}$, the annual precipitation in 2004 (Ross, 2007) was much lower than the mean annual precipitation of $2307 \mathrm{~mm}$ observed between January 2014 and January 2017. A reason for this difference could not be discerned, especially as the strong ENSO event 2015/2016 lead to unusually dry conditions during this time, as is apparent in precipitation and VPD data. Mean monthly sum of global radiation is $190.46 \pm 24.66 \mathrm{~W} \mathrm{~m}^{-2}$.

The geographically closest sites on Borneo experienced climatic conditions very different to Bariri. At the site in the Lambir Hills national park, situated at only $200 \mathrm{~m}$ a.s.l. and described in Saitoh et al. (2005), mean annual temperature is $27^{\circ} \mathrm{C}$, mean annual rainfall measured $20 \mathrm{~km}$ away $2700 \mathrm{~mm}$ without much seasonal variations (Kumagai et al., 2004). The Pasoh research site is at an even lower altitude of $75-150 \mathrm{~m}$ a.s.l and therefore unsurprisingly with $26.3 \pm 1.2{ }^{\circ} \mathrm{C}$ mean daily temperature and $24.9 \pm 0.5^{\circ} \mathrm{C}$ soil temperature in $20 \mathrm{~cm}$ depth much warmer than Bariri too, but it is drier with $1730 \mathrm{~mm}$ mean annual rainfall over a three years period (Kosugi et al., 2008).

With a mean monthly air temperature of $21.7 \pm 2.6^{\circ} \mathrm{C}$ the EC-site in North-West Australia is the only other EC-site worldwide in a tropical rainforest with in a comparable air temperature, but it shows much larger seasonal variations (Fu et al., 2018). Annual rainfall is approximately $1394 \mathrm{~mm}$ (Kitching et al., 2004) and has a strong seasonal pattern with 61\% of annual precipitation occurring between January and March (Bradford et al., 2014).

\subsubsection{Wind system at the site}

The wind system at the study site is characterised by a strong diurnal pattern. While the wind was mostly coming from the West during the day (defined by EddyPro based on geographical coordinates of the site), the main wind direction during night-time is South-West (Figure 24). With few exceptions, wind speed and turbulence and as a result friction velocity $\left(\mathrm{u}^{*}\right)$ was very low during the night (Figure 24, Figure 25). Wind speed is significantly lower (t-test, $\mathrm{p}<0.005$ ) during the night than during the day. Atmospheric stratification was generally stable during the night, changed to turbulent conditions after dawn and returned to stable stratification over the course of the day (Figure 25). Overall, stable and turbulent atmospheric conditions were observed in similar quantities (Figure 26).

The same strong diurnal wind and turbulence patterns combined with little changes over the course of a year had already been observed at the site in the years 2003-2005. The low wind speeds during the night, coupled with stable atmospheric stratification and results from temperature profile measurements were seen as evidence for drainage flows (Ross, 2007). Such mechanisms have been 
observed at multiple sites across the globe and can lead to strong systematic biases in the measurement of NEE with the EC method (Aubinet et al., 2005; Sun et al., 2007; Tóta et al., 2008), especially in tropical rainforests (Miller et al., 2004; van Gorsel et al., 2007). Further evidence for the existence of drainage flows at the Bariri site will be shown and discussed later in this chapter.

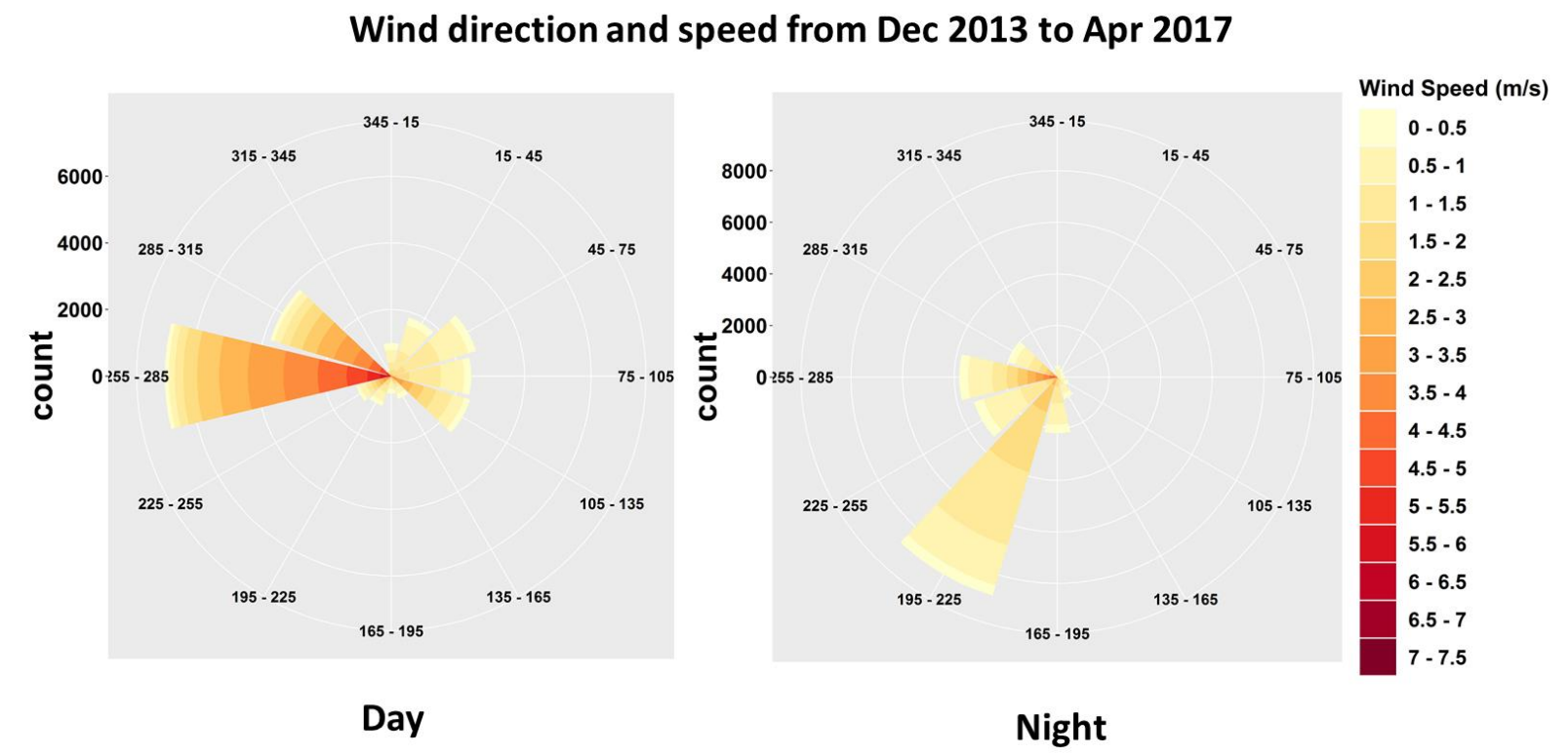

Figure 24: Wind direction and wind speed separated into day and night, aggregated from $4^{\text {th }}$ December 2013 to $28^{\text {th }}$ April 2017 

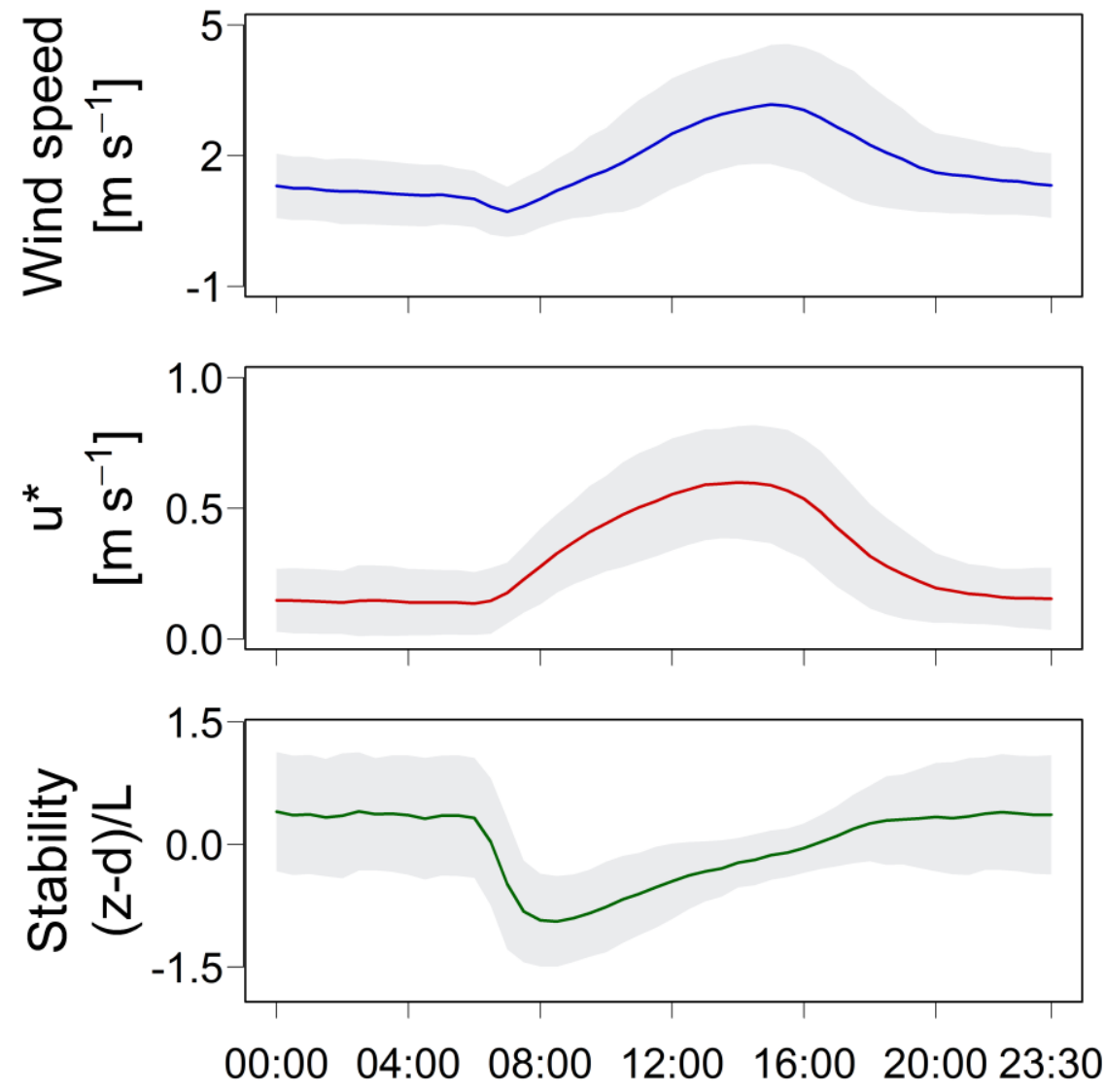

Figure 25: Diel cycle of wind speed, friction velocity and atmospheric stability at the site. The grey area represents the standard deviation. 


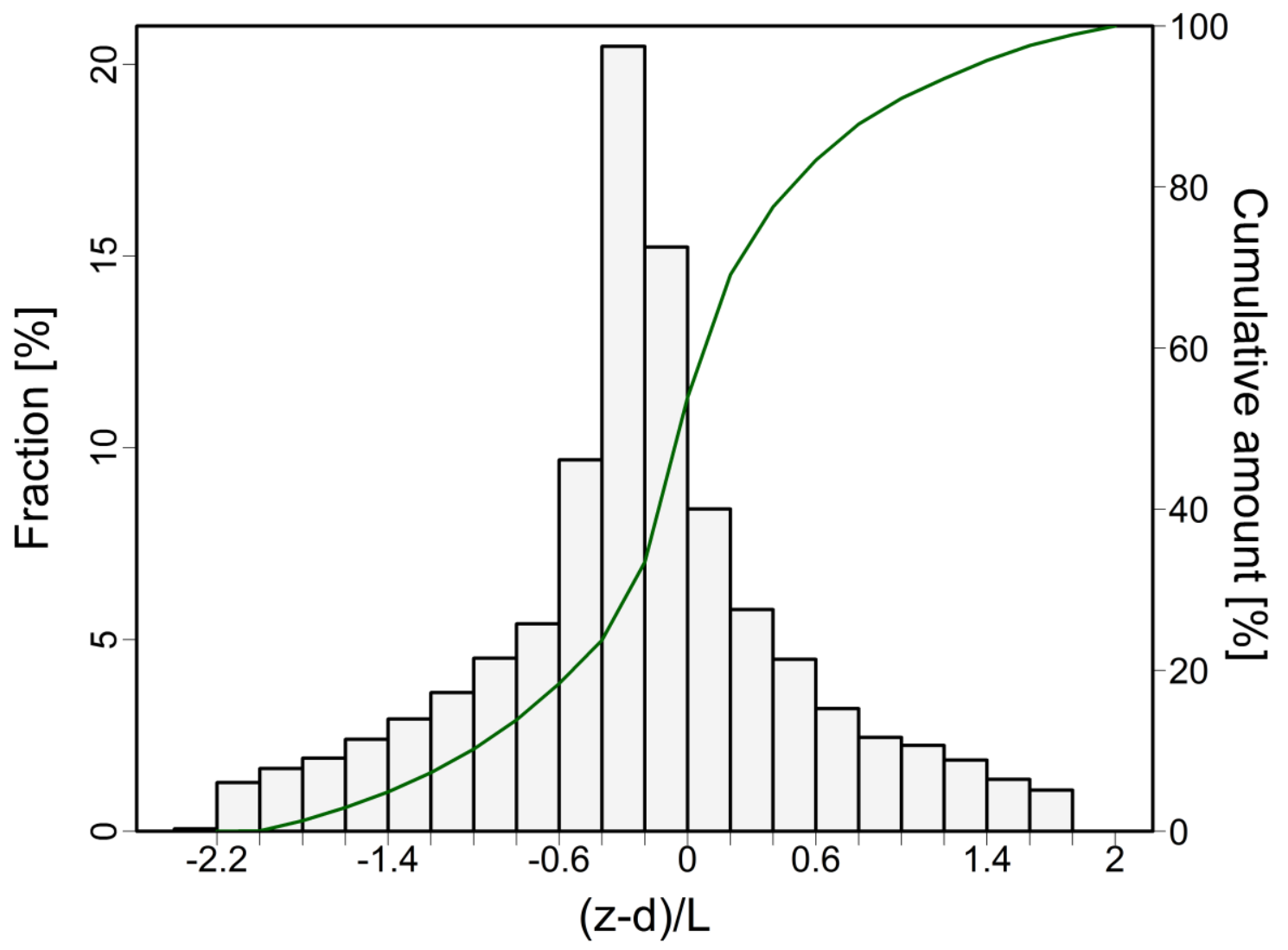

Figure 26: Distribution of stability classes of the mean vertical wind $((\mathrm{z}-\mathrm{d}) / \mathrm{L}$ is a dimensionless parameter)

\subsection{2 $\mathrm{CO}_{2}-$ profile measurements}

The $\mathrm{CO}_{2}$-profile measurements confirmed a strong diel pattern in $\mathrm{CO}_{2}$-concentration below the EC-sensors. Concentrations were always highest near the forest floor (Level 025) while the lowest values were measured inside the bulk of the canopy during the day (Level 24), presumably due to photosynthetic activity (Figure 27). The sharp increase of the $\mathrm{CO}_{2}$ concentrations measured at the lower three measurement heights in the early morning are likely an effect of increased wind speeds at the forest floor, which could disturb an enriched laminar soil boundary layer. It has been shown in the past that soil $\mathrm{CO}_{2}$ respiration is positively correlated with wind speeds and increased turbulence (Hanson et al., 1993; Le Dantec et al., 1999). A similar pattern of $\mathrm{CO}_{2}$-concentrations was observed in an Amazonian rainforest (de Araújo et al., 2008), the decline in storage $\mathrm{CO}_{2}$ concentrations thereafter is likely due to venting and the start of assimilation (de Araújo et al., 2008; Aubinet et al., 2005; Loescher et al., 2003). Enrichment in the early afternoon could be an effect of circadian rhythms of canopy gas exchange (Doughty et al., 2006), leading to decreased light-use efficiency and photosynthetic inhibition (Goulden et al., 2004; Kosugi et al., 2008). 
In accordance with atmospheric stability patterns at the site, $\mathrm{CO}_{2}$-storage flux (Figure 28) shows a strong efflux (negative) with the onset of turbulent conditions after sunrise which lessens over the course of the day and becomes positive after 15:00 on average. The peak of positive storage flux e.g. enrichment of $\mathrm{CO}_{2}$ in the profile volume is reached on average at 18:00 and the rate of enrichment declines thereafter. Such a decrease in storage flux during the night was also observed in conjunction with horizontal advection flows in Amazonia rainforests (Goulden et al., 2006; Tóta et al., 2008) and at various other sites around the world suspected of unobserved night-time respiration due to advection (Aubinet et al., 2005; van Gorsel et al., 2008).

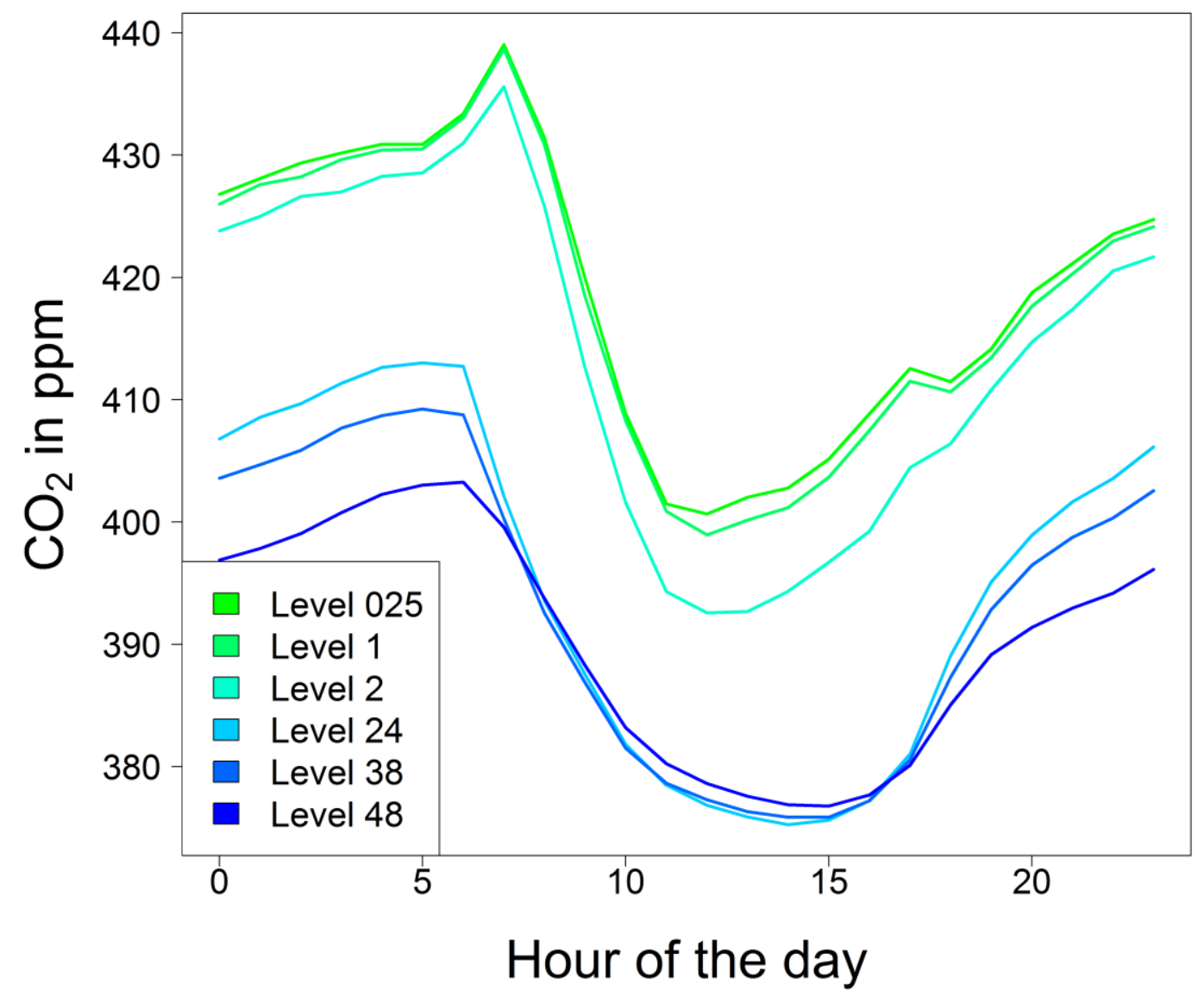

Figure 27: Diel pattern of $\mathrm{CO}_{2}$ - concentration per measurement level, averaged over all available measurements from $2^{\text {nd }}$ October 2015 to $28^{\text {th }}$ April 2017. Level 025 is $0.25 \mathrm{~m}$ above the ground, Level 1 one meter and so forth. 


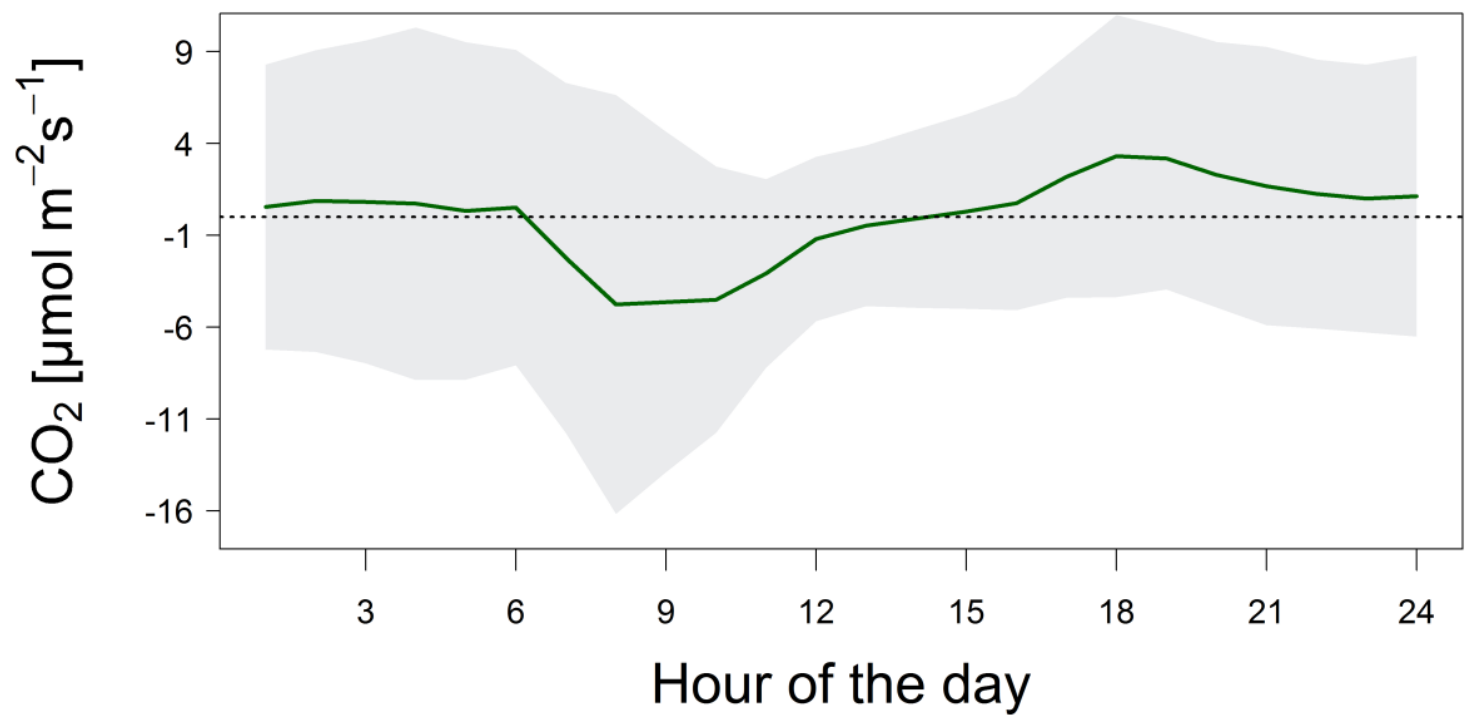

Figure 28: Diel pattern of hourly $\mathrm{CO}_{2}-$ storage flux aggregated from $2^{\text {nd }}$ October 2015 to $28^{\text {th }}$ April 2017. The grey area represents the hourly standard deviation, the dotted line zero flux.

\subsubsection{Eddy-Covariance measurements}

Eddy-Covariance measurements were performed from $4^{\text {th }}$ December 2013 to $28^{\text {th }}$ April 2017. Many gaps were small $(<12 \mathrm{~h})$ and due to power outages or rainfall disturbing the open-path LI-7500. The longest gap occurred in 2015, after the first LI-7500A started to show signs of measuring $\mathrm{CO}_{2}$ incorrectly in March, but could only be replaced in August of the same year. A fingerprint of NEE and latent heat (LE) exchange after the second filtering step (4.2.4), but before gap-filling was applied, can be seen in Figure 29. 

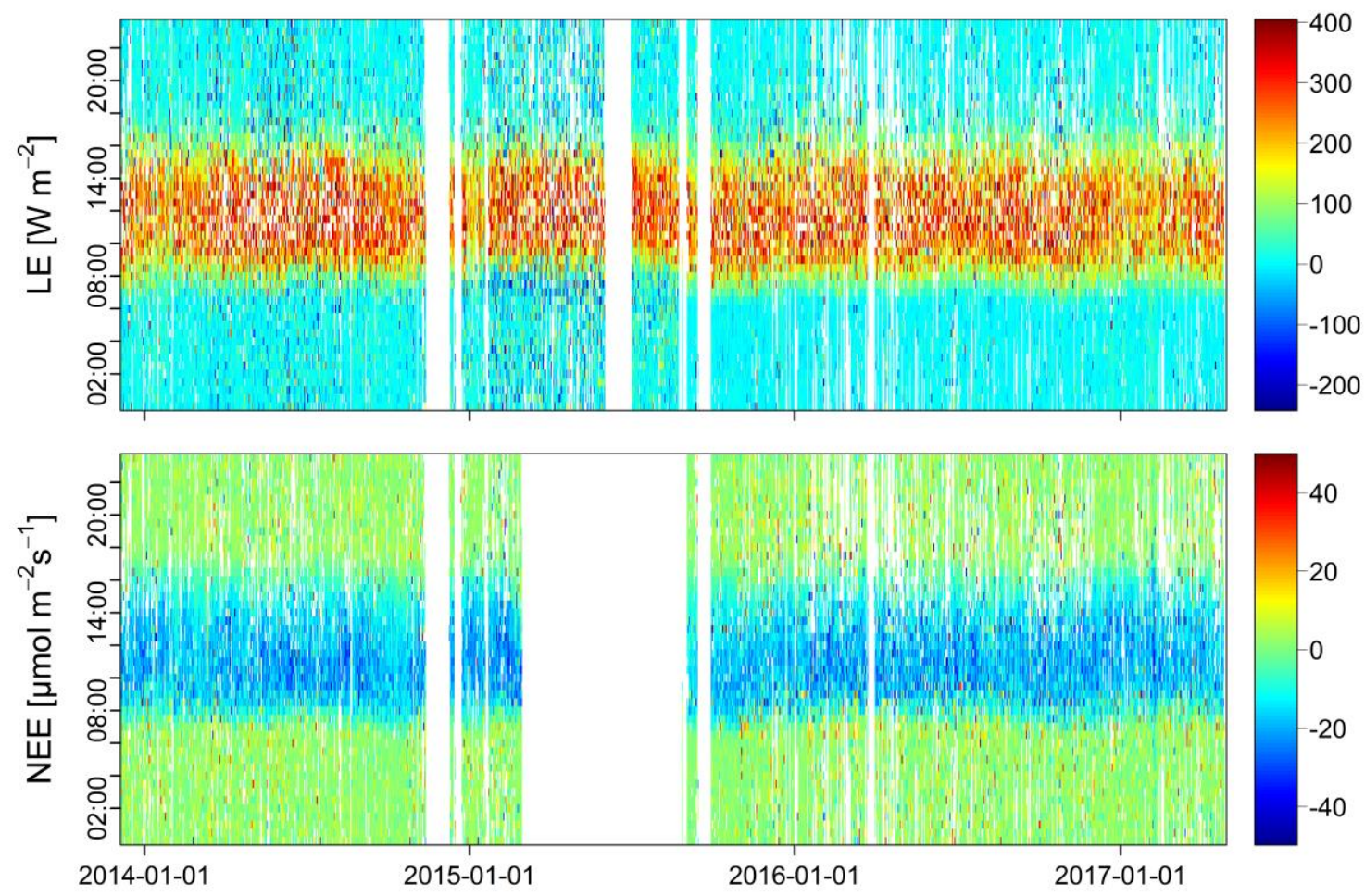

Figure 29: Fingerprint of NEE and latent heat (LE) fluxes observed at the site from $4^{\text {th }}$ of December 2013 to $28^{\text {th }}$ of April 2017.

\subsubsection{EC instrument performance}

Under ideal conditions, spectra of fluctuations of sonic temperature, $\mathrm{CO}_{2}$ and $\mathrm{H}_{2} \mathrm{O}$ are well captured by both infrared gas analysers installed from 2013 to 2017 and follow the theoretic slope of $-2 / 3$ (Kaimal et al., 1972) closely (Figure 30). The same can be stated for the co-spectrum of sonic temperature, $\mathrm{CO}_{2}$ and $\mathrm{H}_{2} \mathrm{O}$ with the vertical wind where the theoretical slope of $-4 / 3$ (Kaimal et al., 1972) is approximated well (Figure 31). 

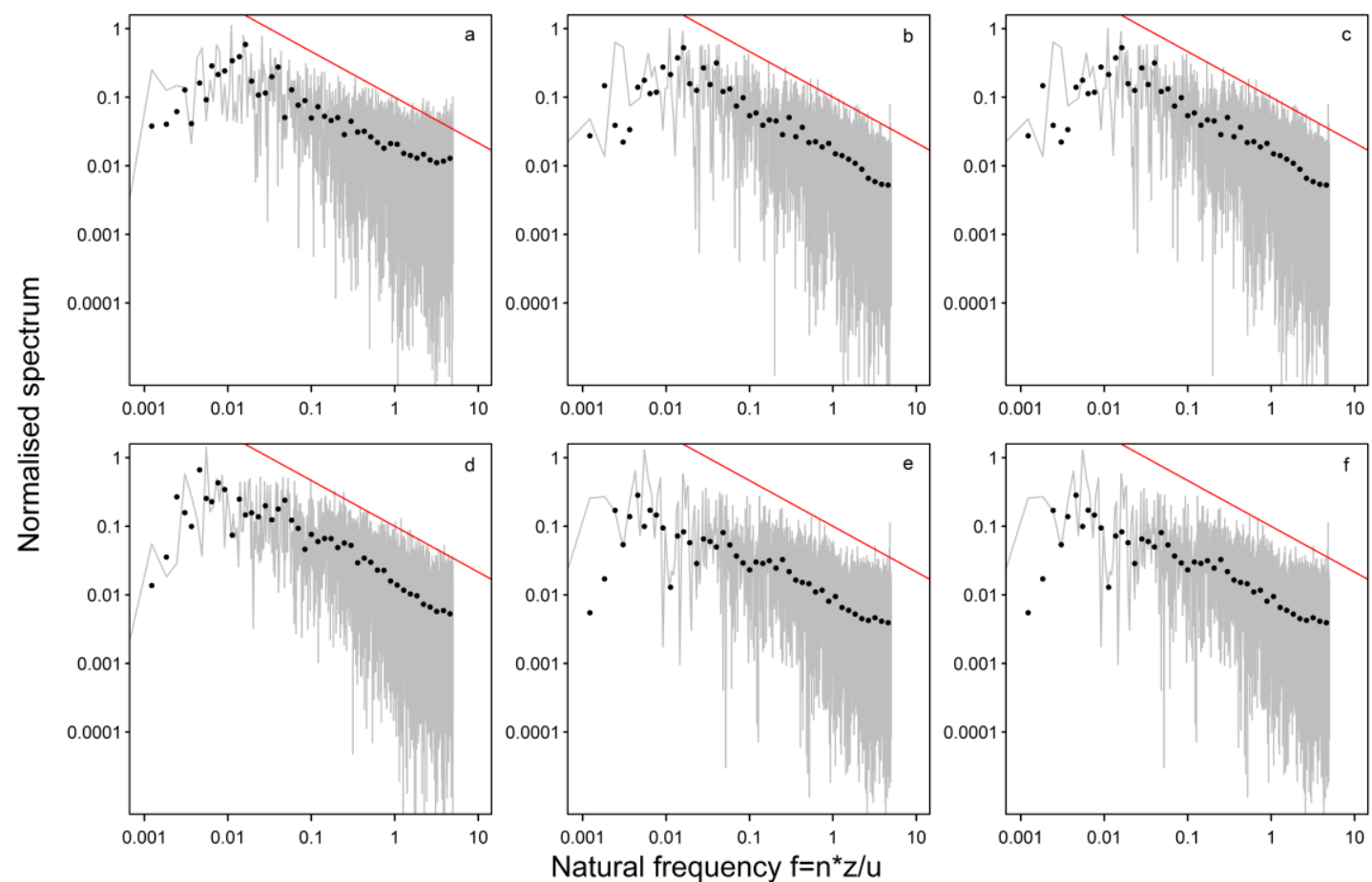

Figure 30: Exemplary spectra of sonic temperature a), $\mathrm{CO}_{2}$ b) and $\mathrm{H}_{2} \mathrm{O}$ c) measurements performed by the first $(2013$ - 2015) and the second $(2015$ - 2017, d/e/f) LI-7500A infrared gas analyser installed. Dots represent binned averages, red lines the theoretical $-2 / 3$ slope and grey lines raw data.
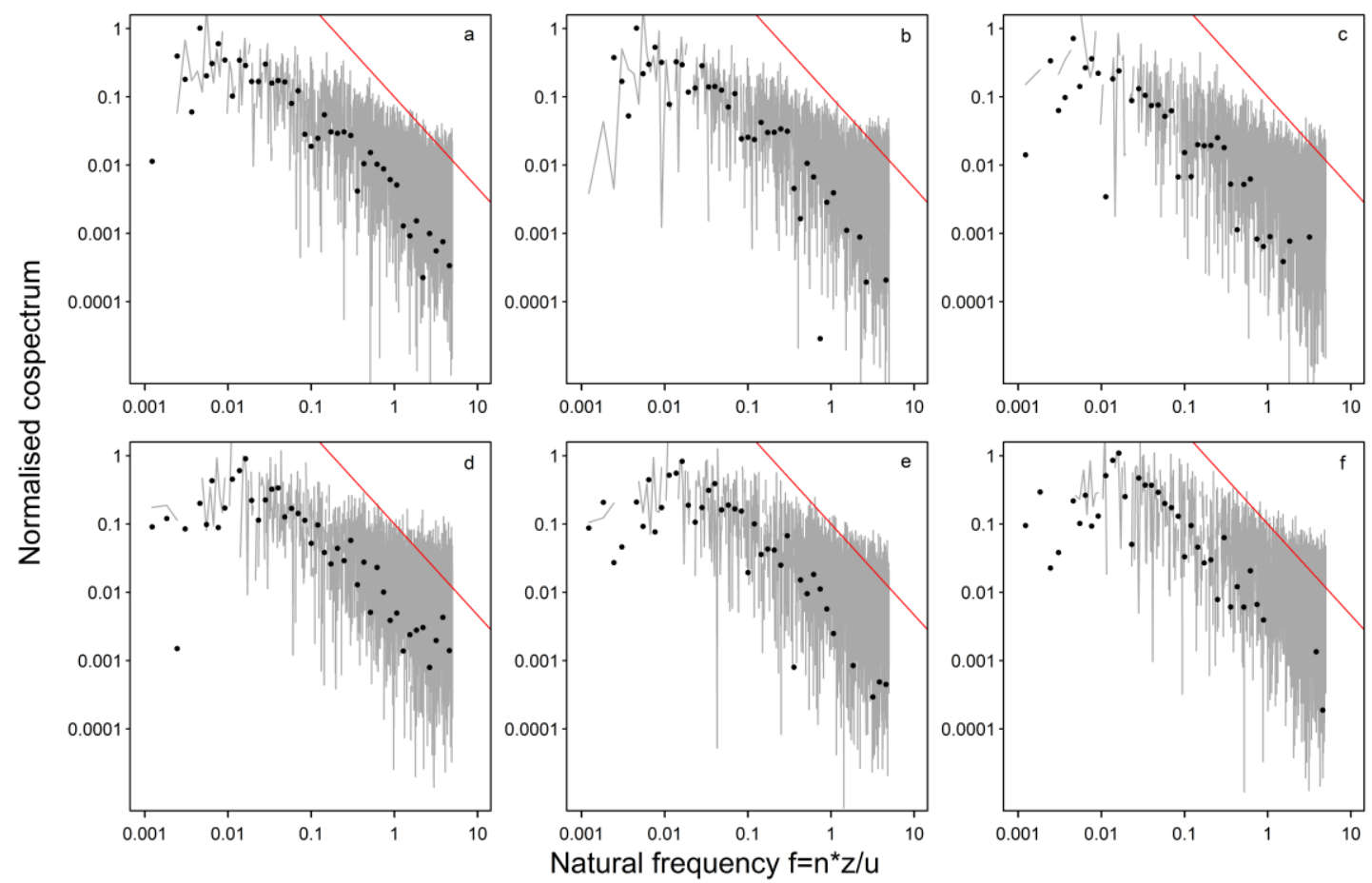

Figure 31: Exemplary co-spectra of sonic temperature a), $\mathrm{CO}_{2}$ b) and $\mathrm{H}_{2} \mathrm{O}$ c) measurements performed by the first $(2013$ - 2015) and the second $(2015$ - 2017, d/e/f) LI-7500A infrared gas analyser installed at the tower. Dots represent binned averages, red lines the theoretical $-4 / 3$ slope and grey lines raw data. 


\subsubsection{Energy balance closure at the Bariti site}

Data records from 12:00 were removed from this analysis as light was obviously reflected off the tower during the preceding 30 minutes (Figure 32). For Bariri, the EBC ratio is $84 \%$ for the cleaned midday values (Figure 33). The same EBC is reached, if all half-hourly fluxes of the reference period (without further data cleaning) are taken into account (Figure 34). This level of EBC is in line with many observations at other flux tower sites with tall vegetation where values around $80 \%$ are common (Aubinet et al., 1999; Foken, 2008). Besides further, non-obvious influences of light reflected off the tower on outgoing radiation measurements, the missing ground heat flux measurements as well as energy transport by large eddies are likely reasons for the missing $16 \%$ (Foken, 2008).

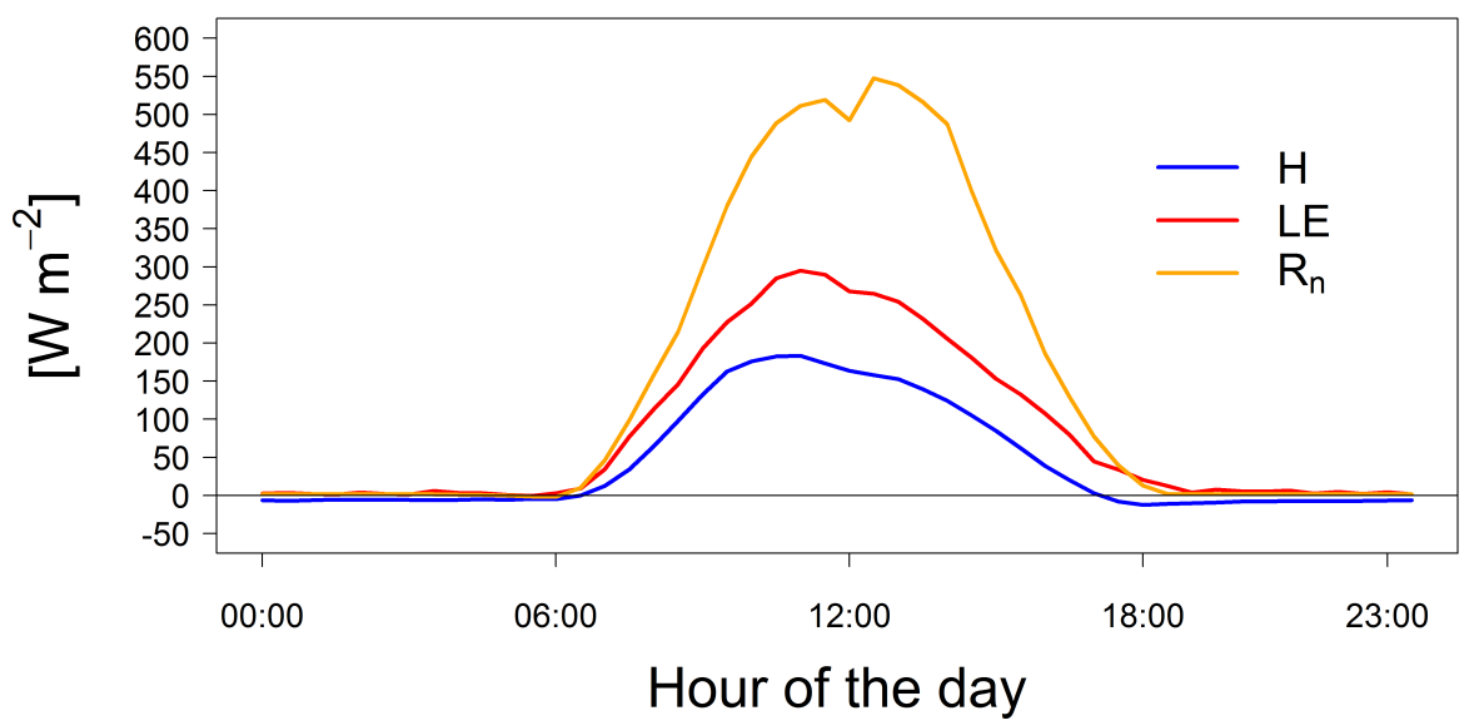

Figure 32: Mean daily fluxes of $H, L E$ and $R_{n}$ during the reference period and before the removal of $\mathrm{R}_{\mathrm{n}}$-data measured at noon 


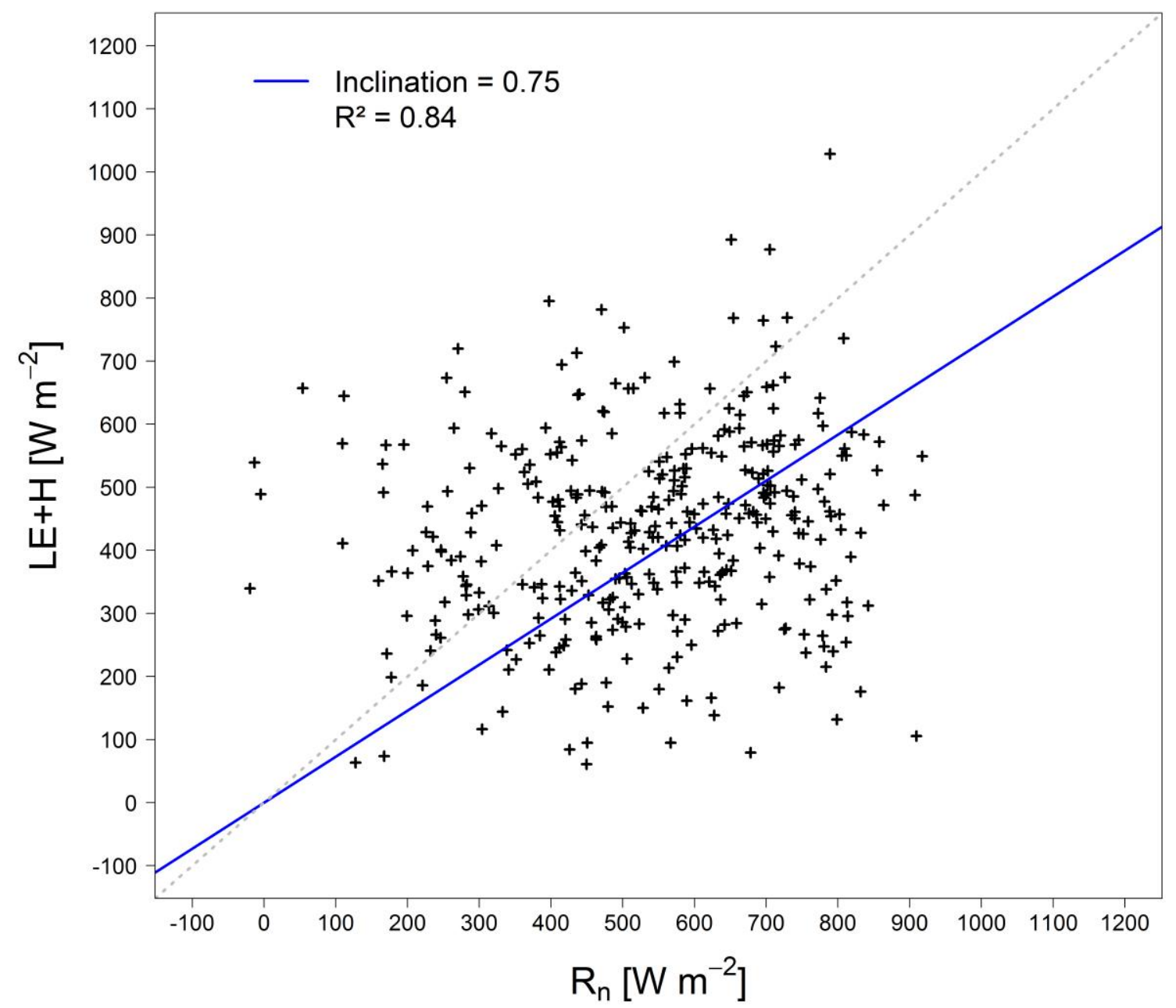

Figure 33: Latent and sensible heat flux vs. net radiation, based on midday 30-min values. The blue line is the regression with intercept 0 , the dashed line is the 1:1 line 


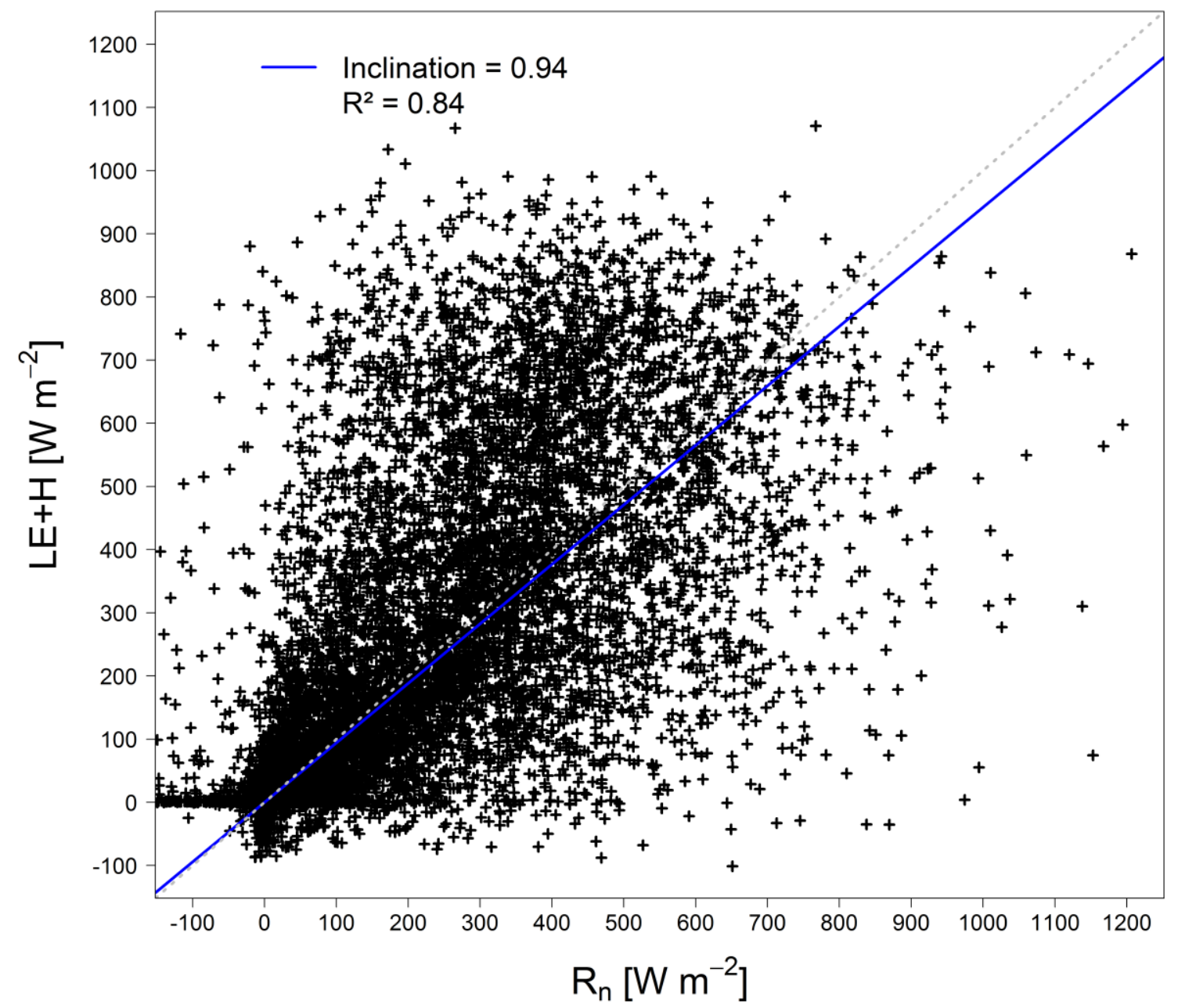

Figure 34: Latent and sensible heat flux vs. net radiation, based on all 30-min values besides 12:00. The blue line is the regression with intercept 0 , the dashed line is the 1:1 line

\subsubsection{Eddy-Covariance post processing impacts and analysis}

While the amount of data remaining after filters 1 and 2 were applied was nearly the same, applying a $u^{*}$-threshold (filter 3) removed a lot of data. Applying different filtering steps impacted the representation of stability classes in data from the whole measurement period (Figure 35) and from the reference period (Figure 36) profoundly. It is apparent, that proportionately more data measured during stable atmospheric conditions is lost. This effect was much higher for the full data set from 2013 - 2017, for which the exclusion of storage flux measurements due to their limited availability led to a comparatively high mean $\mathrm{u}^{*}$-threshold estimate of $0.34 \mathrm{~m} \mathrm{~s}^{-1}$. 


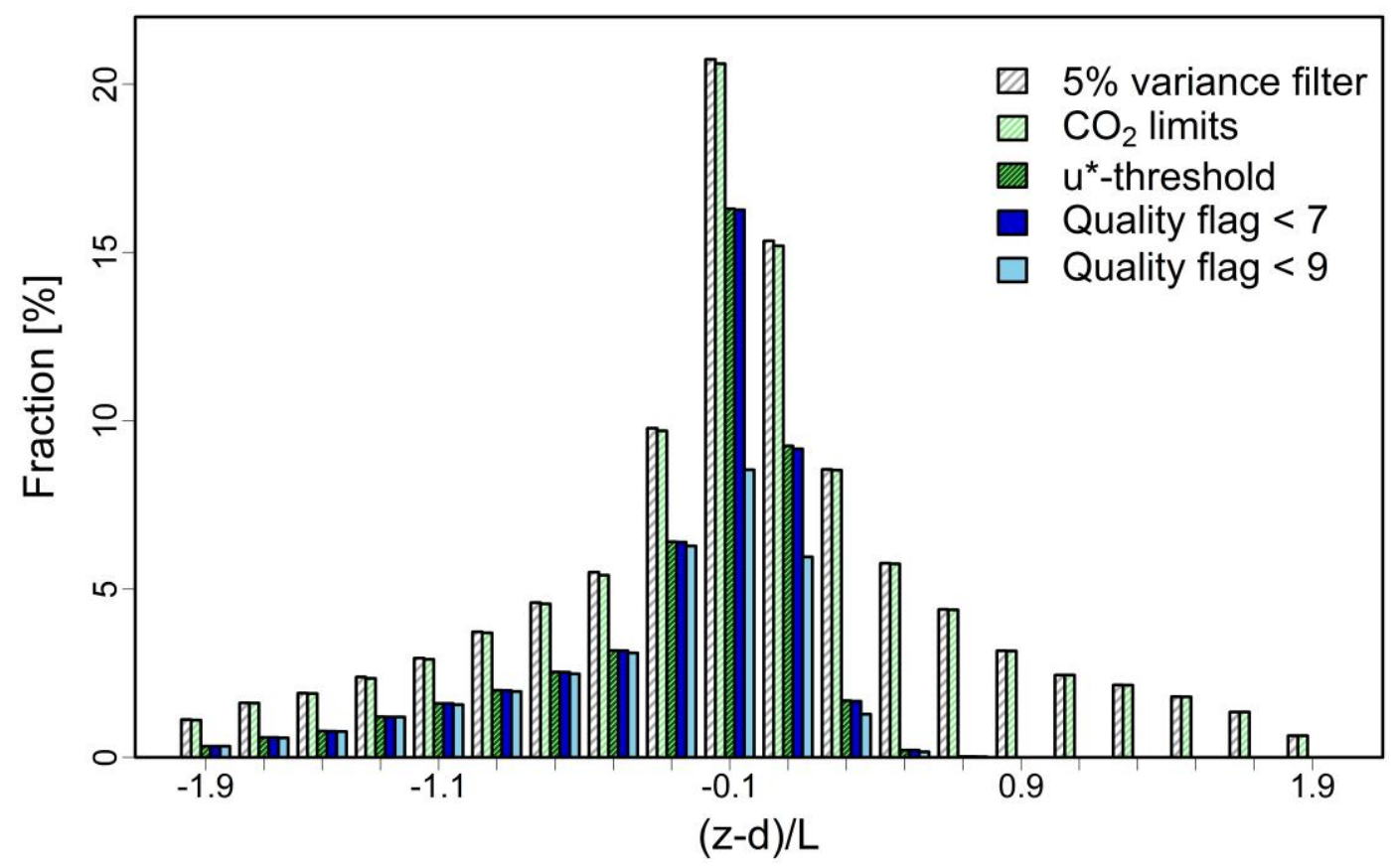

Figure 35: Stability classes remaining in all data from 2013 to 2017 after each filter is applied. The fraction is always relative to the total amount of data points after the first filter has been applied.

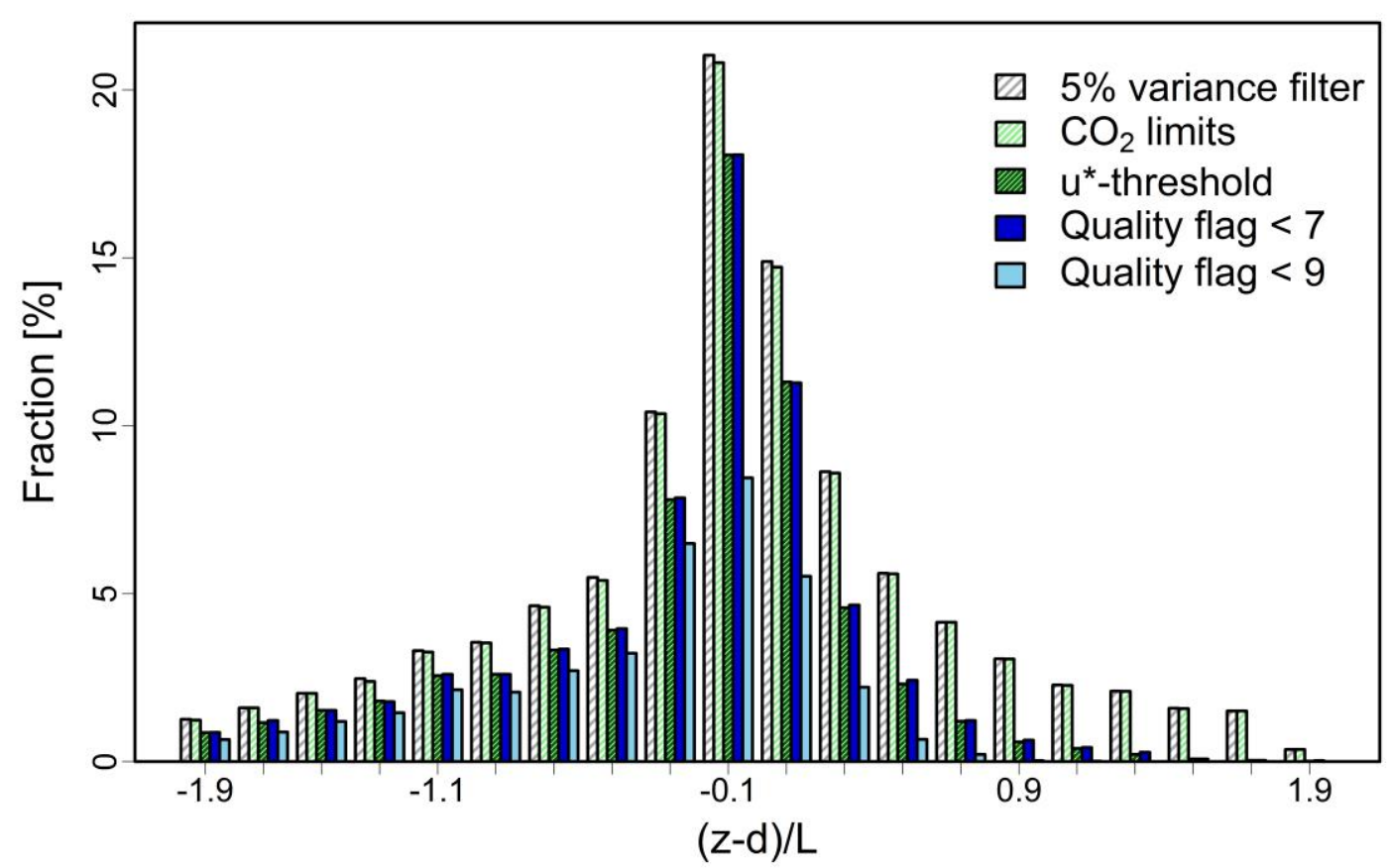

Figure 36: Stability classes remaining during the reference period after each filter is applied. The fraction is always relative to the total amount of data points after the first filter has been applied. 
For the reference period, for which storage flux measurements were included in the flux calculations, the mean $\mathrm{u}^{*}$-threshold estimate weighted by season length for data after applying filters 1 and 2 is $0.1659 \mathrm{~m} \mathrm{~s}^{-1}$. The choice of QFs of 8 or 6 as a threshold is also reflected in the $\mathrm{u}^{*}$-threshold determined via break point detection. A QF threshold of 8 leads to a slightly lower estimated $\mathrm{u}^{*}$-threshold of $0.1617 \mathrm{~m} \mathrm{~s}^{-1}$, very close to data without QF-filter. However, when only data with a QF of 6 or better is accepted, this increases to $0.2363 \mathrm{~m} \mathrm{~s}^{-1}$.

A visual inspection of night-time fluxes and canopy storage in relation to $u^{*}$ (Figure 37) gives no indication that any of these values guarantees turbulent mixing of the full air volume below the EC-system, as storage flux remains unaffected by even high $\mathrm{u}^{*}$ values. This is similar to observations from Costa Rica (Loescher et al., 2003), however there the EC-flux was linearly dependent on $\mathrm{u}^{*}$, which is not the case in Bariri. The $\mathrm{u}^{*}$ threshold was introduced as an indicator for conditions when turbulent flux dominates transport and terms III and IV in equation 4.2 would become irrelevant (see 4.1.1). As such, all approaches to define the $\mathrm{u}^{*}$ filter criterion aim to identify the level of $\mathrm{u}^{*}$ after which storage flux and EC-measurements are independent of $\mathrm{u}^{*}$ (Aubinet et al., 2005; Barr et al., 2013; Goulden et al., 1996; Gu et al., 2005; Papale et al., 2006). It could be argued, that a storage and EC-flux seemingly completely independent from $\mathrm{u}^{*}$ is an indication for ideal measurement conditions, as night-time respiration as a biological process should not be dependent on atmospheric turbulence (Hutyra et al., 2008). This is not supported however by a mean night-time NEE of $3.28 \mu \mathrm{mol} \mathrm{m} \mathrm{m}^{-2} \mathrm{~s}^{-1}$ in comparison to a mean soil respiration of $6.2 \mu \mathrm{mol}$ $\mathrm{m}^{-2} \mathrm{~s}^{-1}$ (see chapter 3), as NEE measured by the EC-system should be at least as high as soil respiration during the night.

Therefore, a decoupling of above and below canopy air volume during the night is a more likely explanation for the independence of storage fluxes from above-canopy $\mathrm{u}^{*}$ at the site. Such conditions have been observed in Amazonian rainforests in several studies (Santana et al., 2018, 2017; Tóta et al., 2008, 2012). Wind profile measurements in multiple Amazonian rainforests showed wind speeds in the lower $75 \%$ of the canopy below $0.25 \mathrm{~m} \mathrm{~s}^{-1}$ under near neutral atmospheric stability conditions (Santana et al., 2017) and turbulence rarely reaching the lower 50\% (Santana et al., 2018). Correlations between vertical wind speeds measured at canopy height and below the canopy decreased quickly with height at one of those measurement locations and an examination of the turbulent kinetic energy budget led the authors to conclude that the lower half of the canopy is mainly decoupled from the upper canopy (Santana et al., 2018). This is furthermore supported by an ozone mixing study at the same site which concluded that during the night the lower $80 \%$ of the canopy react to above canopy turbulence changes only within 3.5-6.5 hours and that the lower half of the canopy is poorly mixed $79 \%$ of the time (Freire et al., 2017). 

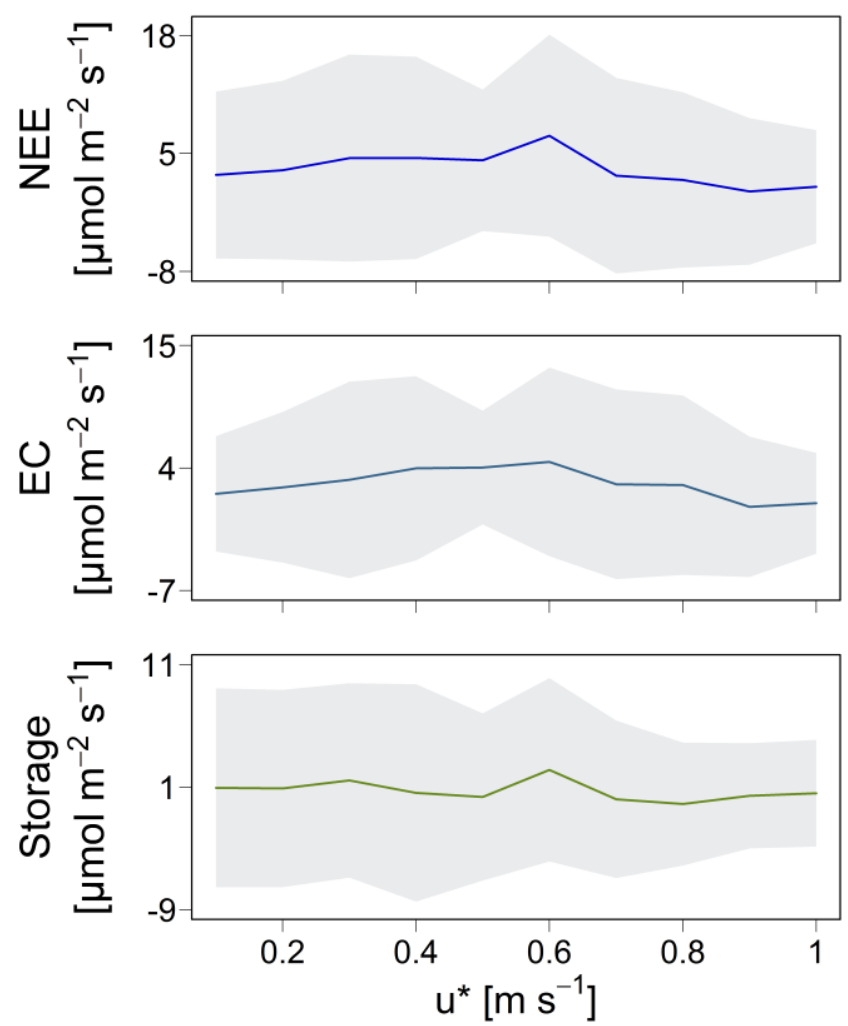

Figure 37: Night-time fluxes of canopy storage, eddy-covariance (EC) and both combined (NEE) in relation to friction velocity $\left(\mathrm{u}^{*}\right)$. No clear dependence of storage enrichment on $\mathrm{u}^{*}$ is apparent.

A $\mathrm{u}^{*}$ threshold was nevertheless applied to the data of the reference period and changed data representation profoundly. While filters 1 and 2 already removed $22 \%$ of all available half-hour flux data, a total of $55.8 \%$ of all data points were discarded after setting the $\mathrm{u}^{*}$-threshold. In conjunction with a QF of 8 this level stays nearly the same with $55.6 \%$, but with a QF of 6 already $70.8 \%$ are lost. Especially night-time data is affected. For the same filtering steps as above, the remaining data-points amount to a mere $18.9 \%, 19.8 \%$ and $6.4 \%$ of originally measured half-hour night-time intervals. This comes not as a surprise, as a $\mathrm{u}^{*}$-threshold of $0.3 \mathrm{~m} \mathrm{~s}^{-1}$ applied to data from 2003 to 2005 lead to $13.5 \%$ remaining night-time data (Ross, 2007). While this information is very interesting to evaluate the robustness of night-time flux estimations, as it gives an indication as to how uncommon good condition for measurements are and thus on how little data gap-filling is based, it is rarely published. The only tropical site for which it could be found was French Guiana, where $37.7 \%$ of night-time data remained after quality checks and a $\mathrm{u}^{*}$ threshold of $0.15 \mathrm{~m} \mathrm{~s}^{-1}$ were applied (Aguilos et al., 2018). 


\subsubsection{NEE flux footprint}

The flux footprint at our site is as expected dependent on atmospheric stability (Figure 38). As stability is closely related to time of the day (Figure 25), this leads to very different footprint areas for day- and night-time NEE (Figure 39). Under stable atmospheric conditions, a small patch of grassland lies inside the footprint area, but represents only a fraction of the total area, which is otherwise covered by forest (Figure $38 \mathrm{a}$ ). As recommendations range from a minimum of $70 \%$ of the fluxes originating from the target ecosystem (Mauder et al., 2013) to 80\% to $95 \%$ for representative measurements (Göckede et al., 2007), our site is very well situated to examine NEE of the surrounding forest based on EC-measurements.

\section{Eddy-covariance footprint area}

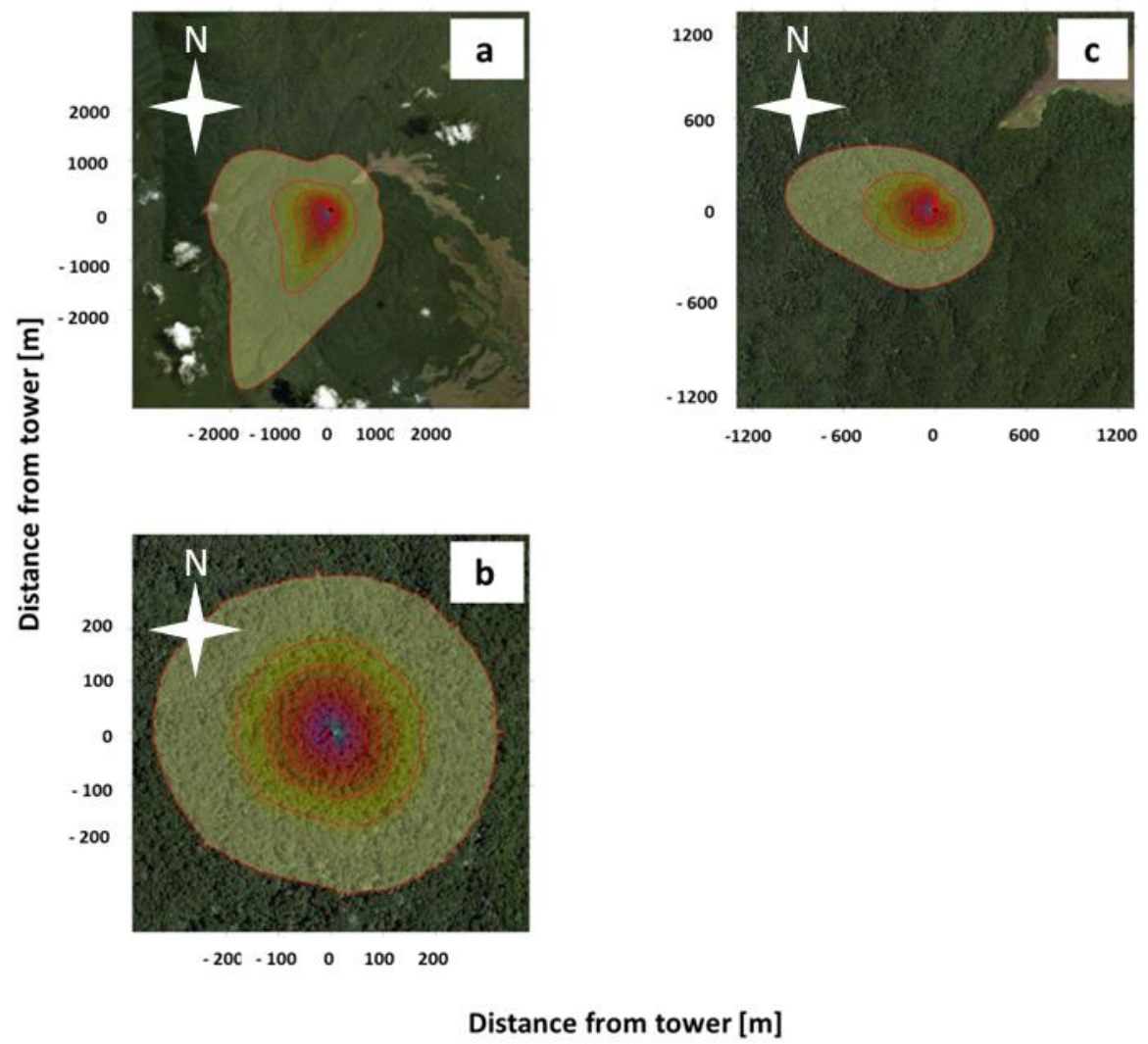

Figure 38: Eddy-covariance footprint area during the reference period for a) ( $z$-d)/L $>0.2, \quad$ b) $0.2 \geq(\mathrm{z}-\mathrm{d}) / \mathrm{L} \leq-0.2$, and c) $-0.2>(\mathrm{z}-\mathrm{d}) / \mathrm{L}$. Red lines delineate 10 to $90 \%$ of footprint area in $10 \%$ steps. 


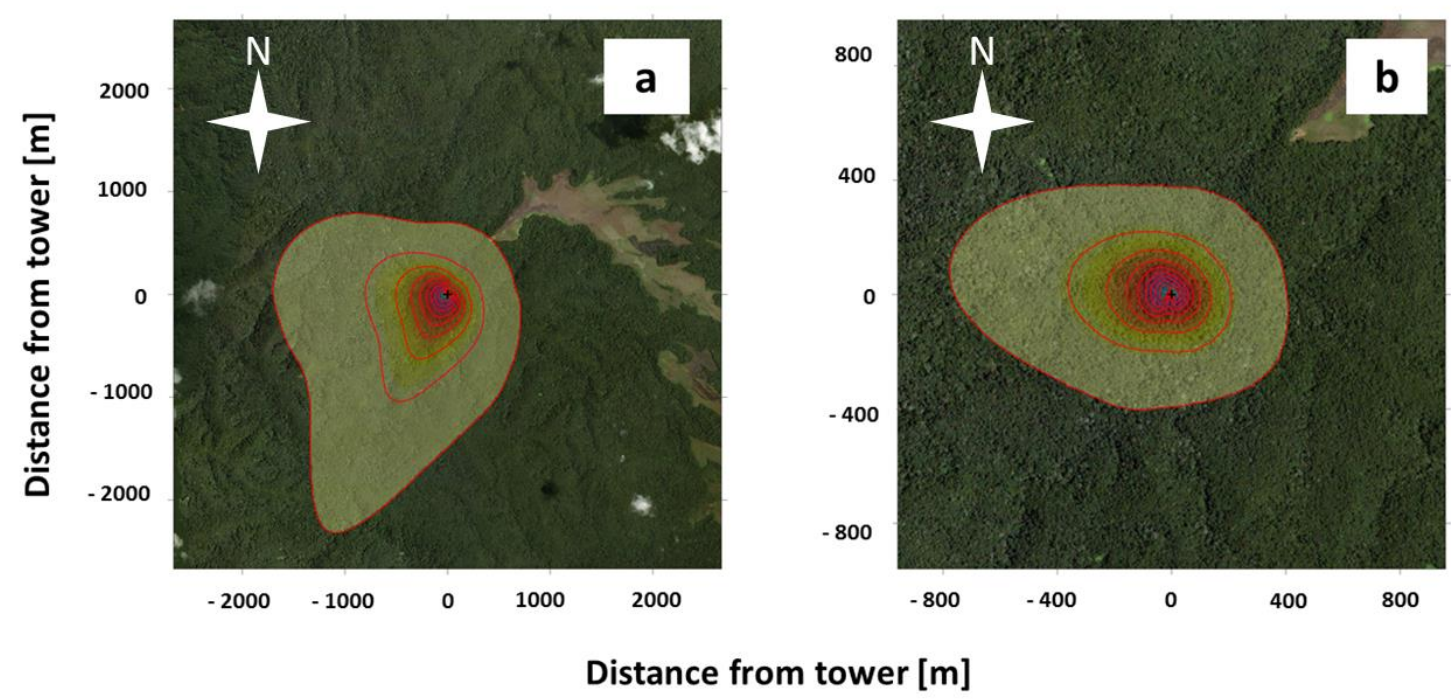

Figure 39: Eddy-covariance footprint area for a) night-time (global radiation $<10 \mathrm{~W} \mathrm{~m}^{-1}$ ) and b) day-time during the reference period. Red lines delineate 10 to $90 \%$ of footprint area in $10 \%$ steps.

\subsubsection{Meteorological drivers of EC-derived NEE}

The PI-curve of day-time EC-CO $\mathrm{CO}_{2}$ flux was significant $(\mathrm{p}<0.005)$ for both global radiation $\left(\mathrm{R}^{2}=\right.$ 0.38 , Figure 40$)$ and PAR $\left(\mathrm{R}^{2}=0.35\right)$. A time-lag of half an hour decreased the correlation with global radiation to $\mathrm{R}^{2}=0.3$ and was not investigated further. Dividing the data into morning (06:30 until 11:30) and afternoon improved the fit only slightly for morning hours (global radiation $\mathrm{R}^{2}=$ 0.4, PAR R $\mathrm{R}^{2}=0.38$ ), but not for fluxes in the afternoon.

At one of the EC-tower sites in Borneo, the fit of the PI-curve with solar radiation was $\mathrm{R}^{2}=$ 0.56-0.57, depending on soil water content (Saitoh et al., 2005) and a similar impact of global radiation on NEE $\left(\mathrm{R}^{2}=0.56\right)$ was found in a principal component analysis of a generalised additive model during wet seasons for the rainforest in French Guiana (Aguilos et al., 2018). For PAR an $\mathrm{R}^{2}=0.48$ (Goulden et al., 2004) was reported for an Amazonian rainforest and 51\% of NEE variability in a rainforest in Costa Rica (Loescher et al., 2003). 


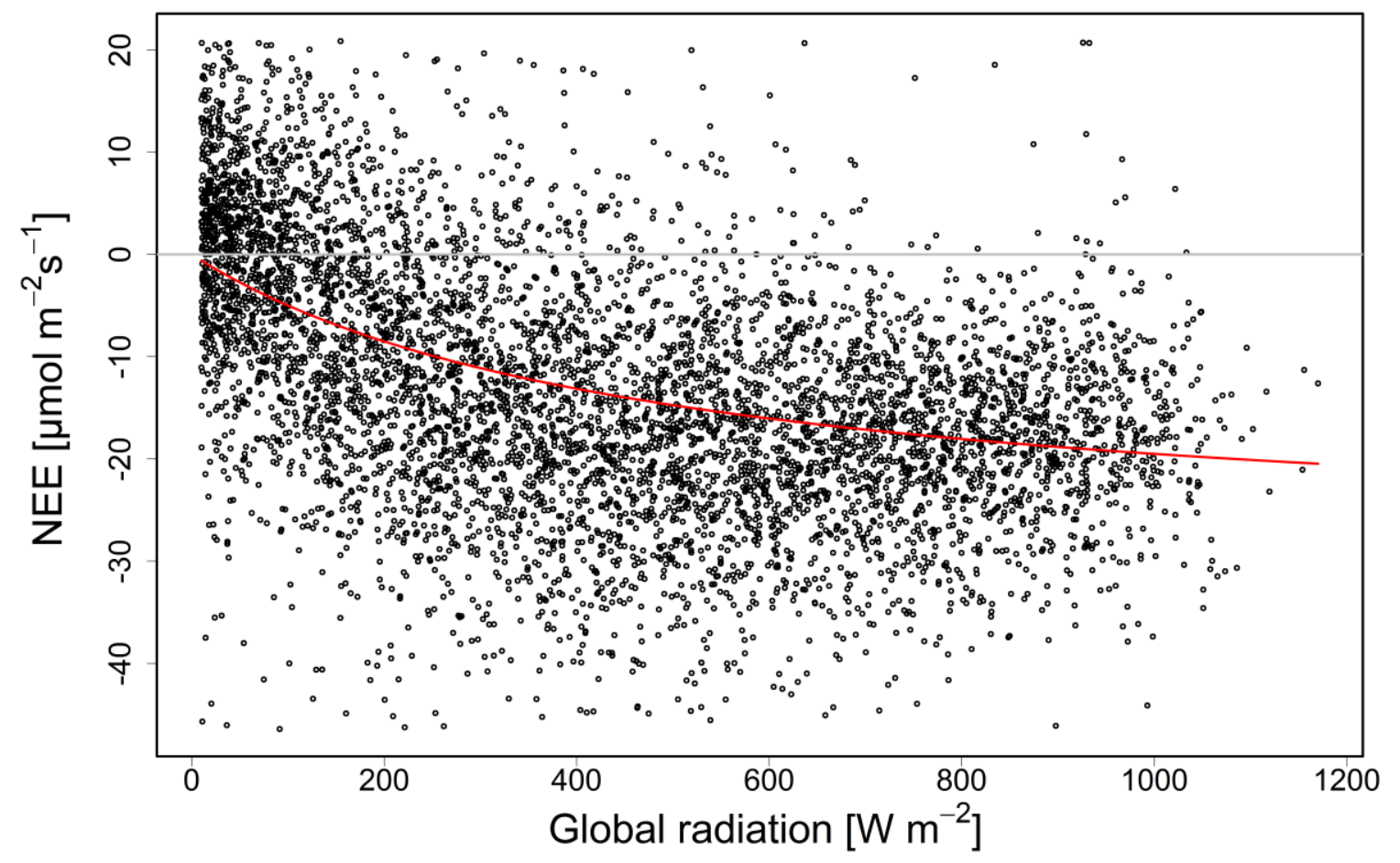

Figure 40: Fit of the photosynthesis-irradiance curve (red) between NEE based on EC measurements and global radiation, $\mathrm{R}^{2}=0.38$.

The shape of the PI-curves estimated for our site closely resembles NEE-radiation relationships found at other tropical rainforest sites, but there is a clear difference in the intercept value. Where the intercept found in this analysis is -0.4 , it is positive in all other studies (Goulden et al., 2004; Kosugi et al., 2008; Loescher et al., 2003; Saleska et al., 2003). As a positive intercept indicates that NEE is dominated by RE at zero radiation input, as it is to be expected, the light curve found for this site can only be used when examining relative but not absolute changes in NEE.

Fitting the PI-curve to all day-time global radiation and flux data binned according to $\mathrm{u}^{*}$ ranges revealed a much higher correlation at lower wind speeds (Table 15, Figure 41). When the input data was filtered according to a $-25 \mu \mathrm{mol} \mathrm{CO}_{2} \mathrm{~m}^{-2} \mathrm{~s}^{-1}$ flux limit, the correlations were relatively similar regardless of $\mathrm{u}^{*}$ (Table 15). The overall fit without binning increased for the filtered data to $\mathrm{R}^{2}=0.42$, but the negative intercept remained.

The differences between $\mathrm{u}^{*}$-bin PI-curve fits with and without threshold suggests that there is a decoupling of photosynthetic activity and simultaneously measured $\mathrm{CO}_{2}$-fluxes, especially for high wind speeds. Atmospheric eddies seldom reached deeper than half of the canopy height in an Amazonian rainforest (Santana et al., 2018). If that is similarly the case in Bariri, it could explain 
the low overall explanatory strength of the PI-curve as well as the connection between $\mathrm{u}^{*}$, flux threshold and the fit of the PI-curve for different wind speeds.

Table 15 Correlation of EC-CO $\mathrm{CO}_{2}$-fluxes predicted by the PI-function with measured values. Flux limit set to $-25 \mu \mathrm{mol} \mathrm{CO} \mathrm{Cm}^{-2} \mathrm{~s}^{-1}$.

\begin{tabular}{lcc}
\hline $\mathbf{u}^{*}$-bin & \multicolumn{2}{c}{$\mathbf{R}^{2}$} \\
\hline & no limit & flux limit \\
\hline$(0,0.2]$ & 0.33 & 0.32 \\
$(0.2,0.3]$ & 0.31 & 0.32 \\
$(0.3,0.4]$ & 0.23 & 0.28 \\
$(0.4,0.5]$ & 0.2 & 0.26 \\
$(0.5,1]$ & 0.26 & 0.31 \\
$(1,1.5]$ & 0.17 & 0.32 \\
\hline
\end{tabular}



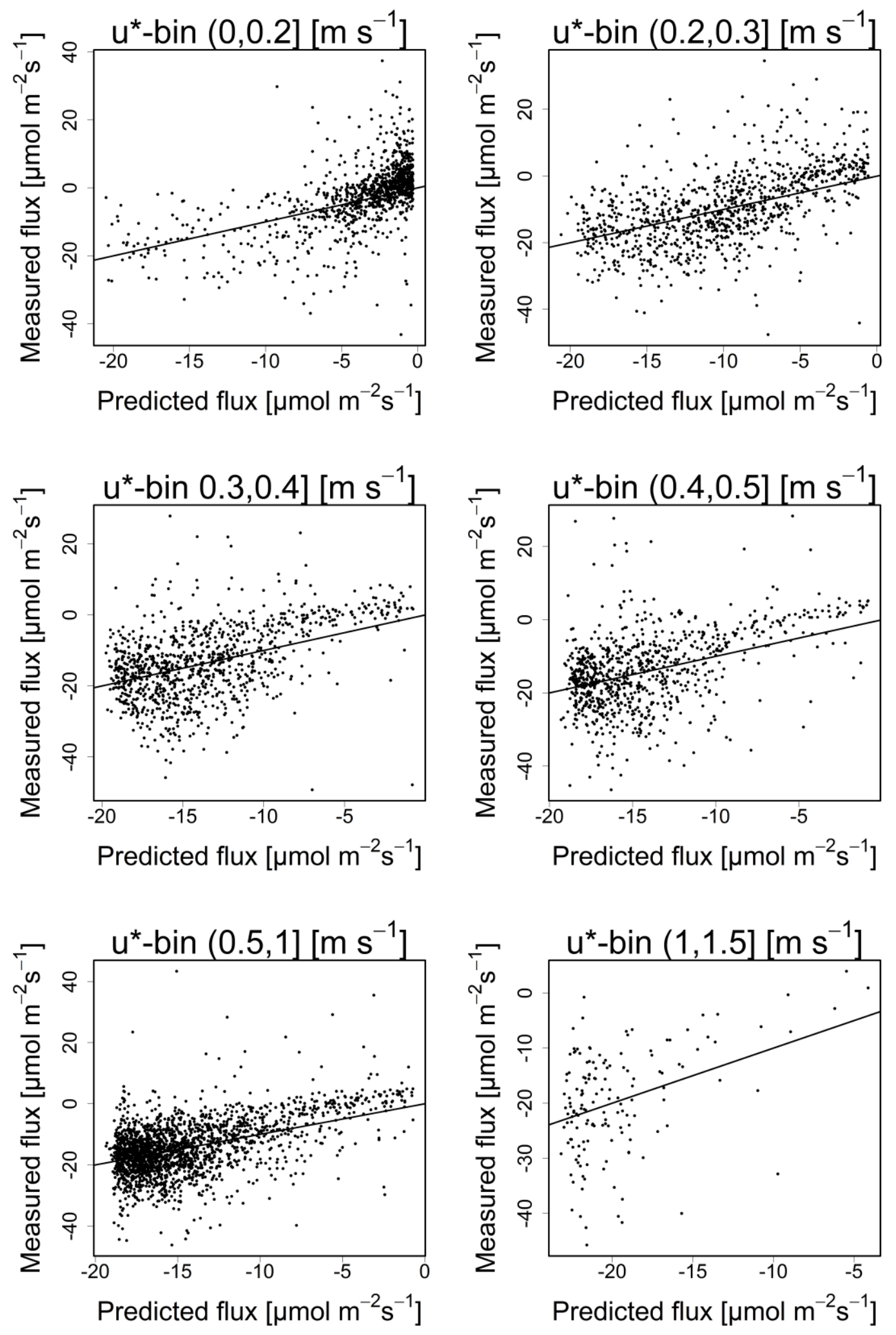

Figure 41: Measured day-time $\mathrm{CO}_{2}$-fluxes versus fluxes predicted by the PI-curve, binned according to friction velocity $\mathrm{u}^{*}$. The 1:1 line is plotted for orientation. 
The correlations of meteorological parameters with the residuals of the PI-curve are quite similar for global radiation and PAR. While air temperature, diffuse radiation and VPD are all significantly $(\mathrm{p}<0.005)$ correlated in some form, their respective impacts are extremely uneven. Negative correlation in this context means, that $\mathrm{CO}_{2}$-uptake increases with an increase in the variable. For residuals of the global radiation model, simple linear and logistics regression of air temperature and VPD have a positive correlation, diffuse radiation is negatively correlated. For the PAR model, both air temperature and diffuse radiation are negatively correlated. However, all besides diffuse radiation have a negligible explanatory power in both cases (Table 16).

The positive impact of increased diffuse radiation on $\mathrm{CO}_{2}$-uptake has been observed before at this site (Ross, 2007) as well as in many different ecosystems from forests to grasslands and wheat fields (Gu et al., 2002; Law et al., 2002; Min and Wang, 2008; Yamasoe et al., 2006). For temperate and tropical forests it has been shown that this positive effect of increased diffuse radiation fraction of total radiation has an optimum at a certain level of cloud cover or aerosol layer depth, after which $\mathrm{CO}_{2}$-uptake declines again due to the limited amount of total radiation reaching the forest (Min and Wang, 2008; Yamasoe et al., 2006).

Table 16 Performance of regression models describing the correlation between meteorological parameters and residuals of the PI-curve prediction versus measured EC values. Non-significant models are marked by " $\mathrm{n}-\mathrm{s}$ ".

\begin{tabular}{lcc}
\hline Meteorological variable and model & \multicolumn{2}{c}{$\mathbf{R}^{\mathbf{2}}$} \\
\hline Air temperature simple linear & Global radiation & PAR \\
Air temperature second order polynomial & $\mathrm{n}-\mathrm{s}$ & 0.002 \\
Air temperature logistic & 0.02 & 0.02 \\
Diffuse radiation simple linear & $\mathrm{n}-\mathrm{s}$ & 0.003 \\
Diffuse radiation second order polynomial & 0.11 & 0.11 \\
Diffuse radiation logistic & $\mathrm{n}-\mathrm{s}$ & $\mathrm{n}-\mathrm{s}$ \\
VPD simple linear & 0.08 & 0.08 \\
VPD second order polynomial & 0.001 & $\mathrm{n}-\mathrm{s}$ \\
\hline
\end{tabular}




\subsubsection{PAR canopy transmission}

Photosynthetically active radiation (PAR) transmission was significantly and negatively correlated with diffuse radiation fraction of global radiation for the fixed-point measurements $(p<0.005$, $\mathrm{R}^{2}=0.18$ ). While the trend was still the same for the 36-points aggregate, it was not significant $\left(\mathrm{p}=0.8, \mathrm{R}^{2}=0.09\right)$. This could indicate an increased uptake of radiation by the canopy under cloudy conditions, but needs further investigation. If such an increased radiation uptake is present however, it could explain the impact diffuse radiation has on the residuals of the PI curve in so far, that a high percentage of diffuse radiation leads to more efficient photosynthetic exploitation of total incoming radiation. Higher degrees of PAR interception have been linked to higher levels of carbon allocation in other forest ecosystems (McCrady and Jokela, 1998) and very little incoming PAR was measured at the forest floor relative to incoming PAR measured above the canopy ( $1 \%$ at the fixed point, 3.3\% averaged over all 36 measurement points, see Figure 42). Similar results have been obtained in the Pasoh rainforest in Malaysia, where a uniform vertical leaf area density resulted in a steady decline of available PAR with decreasing height (Kosugi et al., 2012). This is not surprising, as PAR interception increases with canopy structure complexity (Atkins et al., 2018), which should be high in the species rich tropical montane rainforests of Sulawesi (Brambach et al., 2017). A shortcoming of the campaign presented here is however, that global radiation was not measured simultaneously next to the PAR sensor. Therefore, impacts of rays of sunshine piercing the canopy and directly hitting the PAR sensor, which are most likely to cause the peaks in Figure 42, are impossible to disentangle from the data.

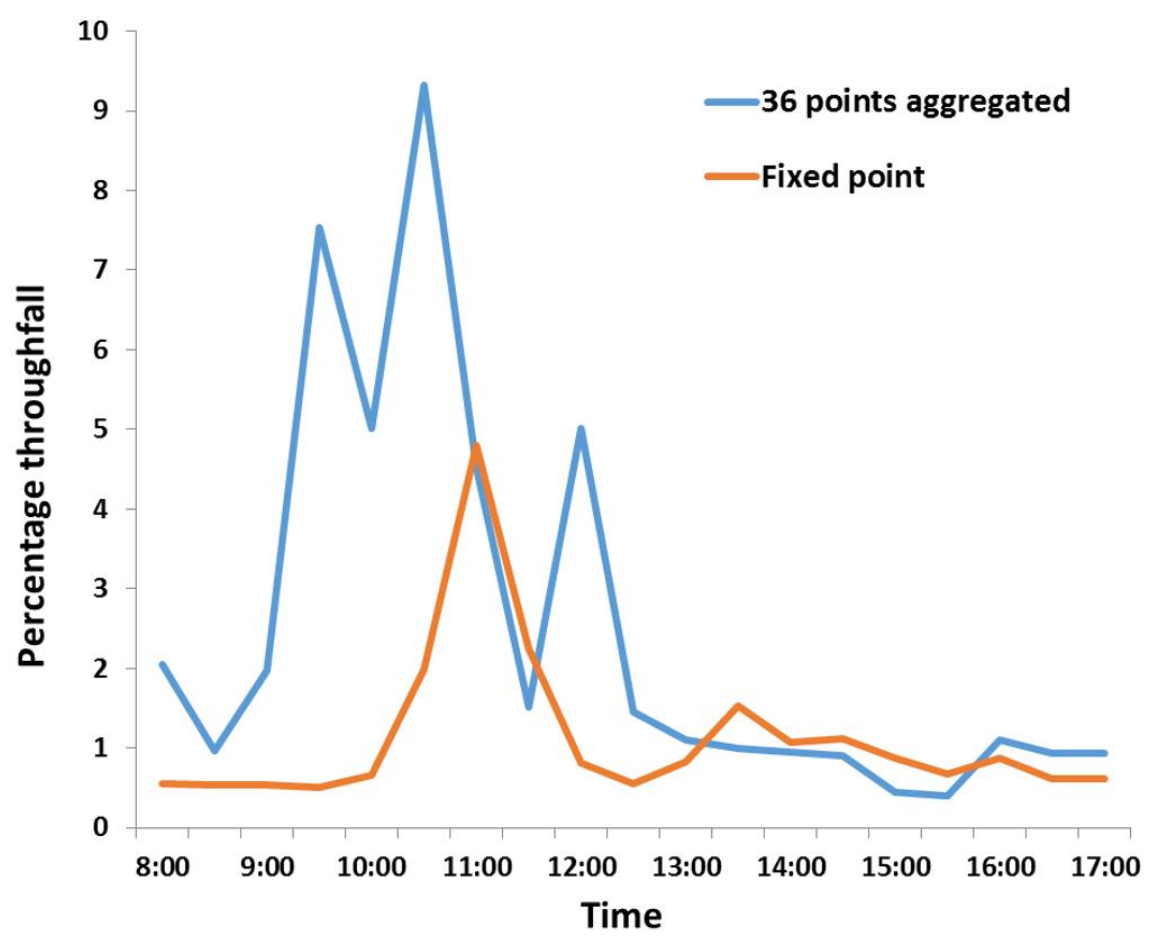

Figure 42 Diel pattern of percentage of PAR transmission relative to PAR above the canopy. 


\subsubsection{Eddy-Covariance night-time flux estimation results}

The four different night-time flux estimation approaches (Table 17) in conjunction with different levels of filtering led to a wide range in cumulative NEE (Figure 43) and therefore total NEE for the reference period (Table 18). The large range in annual NEE-sums resulting from the four night-time flux estimation methods is reflected in the estimates of mean night-time NEE (Table 17, Figure 44). It is also important to note, that the mean standard deviation of data points considered for night-time gap-filling for the MDS approach and the Lasslop method show an especially pronounced variability of the former $\left( \pm 12.1 \mu \mathrm{mol} \mathrm{m} \mathrm{m}^{-2} \mathrm{~s}^{-1}\right.$ MDS and \pm 3.21 $\mu \mathrm{mol} \mathrm{m} \mathrm{s}^{-1}$ Lasslop after filters $1-3, \pm 12.14 \mu \mathrm{mol} \mathrm{m} \mathrm{m}^{-2} \mathrm{~s}^{-1}$ and $\pm 3.35 \mu \mathrm{mol} \mathrm{m} \mathrm{m}^{-2} \mathrm{~s}^{-1}$ with QF8 additionally applied and finally $\pm 12.38 \mu \mathrm{mol} \mathrm{m}^{-2} \mathrm{~s}^{-1}$ as well as $\pm 2.95 \mu \mathrm{mol} \mathrm{m} \mathrm{m}^{-2} \mathrm{~s}^{-1}$ with QF6 added). In a global evaluation, the Lasslop model has been shown to have the largest deviations in evergreen broadleaf forests like Bariri in comparison to other ecosystems (Lasslop et al., 2010).

Night-time flux estimation using the methods from Reichstein et al. (2005) (MDS) and Lasslop et al. (2010) results in mean night-time respiration estimates beneath the level of soil respiration alone (6.2 $\pm 1.8 \mu \mathrm{mol} \mathrm{m}^{-2} \mathrm{~s}^{-1}$, see chapter 3), regardless of the selection of QF filters. If a QF threshold is applied, the Lasslop et al. approach estimates an even lower night-time respiration (Table 17, Figure 44). The values obtained for night-time respiration according to van Gorsel et al. (2007) increase with the $\mathrm{u}^{*}$-threshold estimate and is always above soil respiration levels (Table 17). Mixfor-SVAT has been parameterised with soil and leaf respiration data from the site and total night-time respiration is therefore always above soil respiration levels.

The mean nocturnal fluxes resulting from the first two approaches are extremely low, while the van Gorsel approach and the Mixfor-SVAT model lead to estimates comparatively close to values reported from other sites. For an Amazonian lowland rainforest near Manaus, mean night-time values of $7.8 \mu \mathrm{mol} \mathrm{m} \mathrm{m}^{-2} \mathrm{~s}^{-1}$ based on soil, stem and leaf respiration measurements and $8.4 \mu \mathrm{mol} \mathrm{m} \mathrm{m}^{-2} \mathrm{~s}^{-1}$ from EC measurements under sustained high turbulence conditions were reported, although soil respiration at the site was only $3.2 \mu \mathrm{mol} \mathrm{m}^{-2} \mathrm{~s}^{-1}$ (Chambers et al., 2004). If we were to simply assume the same amount of stem and leaf respiration, but retaining the locally measured soil respiration (chapter 3), estimates come close to the Mixfor-SVAT model results with $9.9 \mu \mathrm{mol} \mathrm{m} \mathrm{m}^{-1}$. 
Table 17 Mean night-time $\mathrm{CO}_{2}$-fluxes and their standard deviations for different night-time flux estimation methods and filtering strategies. The van Gorsel approach has no SD as it is a constant value. Soil respiration based on chamber measurements is of $6.2 \pm 1.84 \mu \mathrm{mol} \mathrm{m} \mathrm{m}^{-2}$.

\begin{tabular}{|c|c|c|c|}
\hline $\begin{array}{l}\text { Night-time flux estimation } \\
\text { method }\end{array}$ & Filter 1-3 & $\begin{array}{c}\text { Filter 1-3 and QF } \\
8\end{array}$ & $\begin{array}{c}\text { Filter 1-3 and QF } \\
6\end{array}$ \\
\hline & \multicolumn{3}{|c|}{ 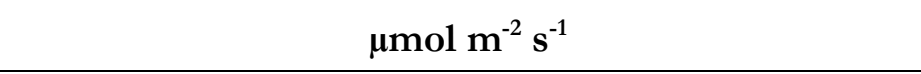 } \\
\hline Reichstein et al. (2005)(MDS) & $4.38 \pm 5.16$ & $4.23 \pm 5.13$ & $5.88 \pm 4.5$ \\
\hline Lasslop et al. (2010) & $4.96 \pm 2.8$ & $4.46 \pm 2.6$ & $4.79 \pm 2.65$ \\
\hline van Gorsel et al. (2007) & $7.08 \pm 0$ & $6.83 \pm 0$ & $7.26 \pm 0$ \\
\hline Mixfor-SVAT & $9.01 \pm 1.47$ & $9.01 \pm 1.47$ & $9.01 \pm 1.47$ \\
\hline
\end{tabular}

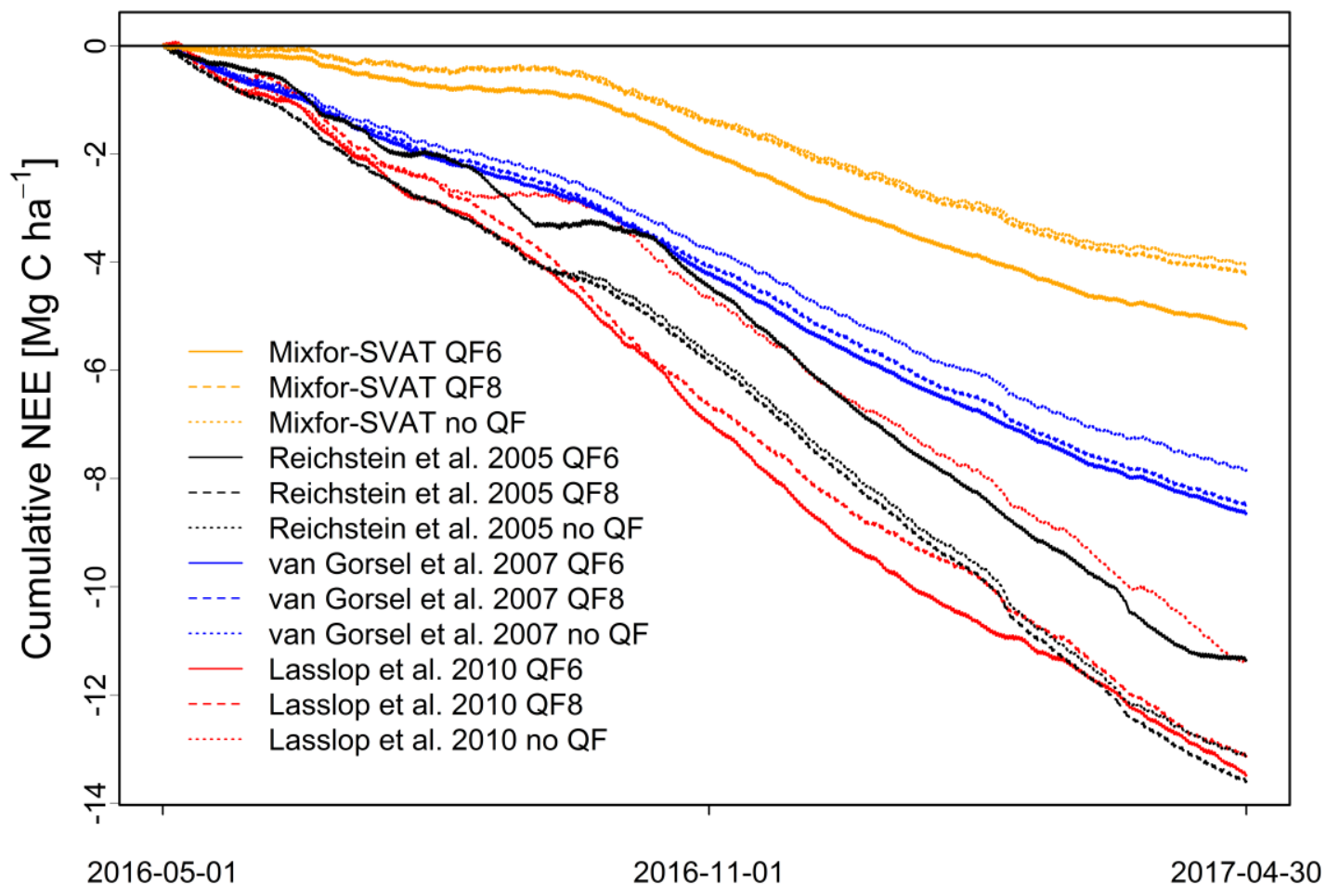

Figure 43: Cumulative NEE over time in $\mathrm{Mg} \mathrm{C} \mathrm{ha}{ }^{-1}$ for the reference period from May 2016 to April 2017. Filtering has little effect on overall tendencies of night-time estimation strategies. 
Table 18 Sum of NEE for the reference period per night-time flux estimation method applied and with different filters in place.

\begin{tabular}{lccc}
\hline $\begin{array}{l}\text { Night-time flux estimation } \\
\text { method }\end{array}$ & $\begin{array}{c}\text { Filter } \\
\mathbf{1 - 3}\end{array}$ & $\begin{array}{c}\text { Filter } \mathbf{1 - 3} \text { and QF } \\
\mathbf{8}\end{array}$ & $\begin{array}{c}\text { Filter 1-3 and QF } \\
\mathbf{6}\end{array}$ \\
\hline & \multicolumn{3}{c}{$\mathbf{M g ~ h a}^{-1} \mathbf{y}^{-1}$} \\
\hline Reichstein et al. (2005)(MDS) & -13.13 & -13.6 & -11.35 \\
Lasslop et al. (2010) & -11.41 & -13.13 & -13.48 \\
van Gorsel et al. (2007) & -7.84 & -8.48 & -8.64 \\
Mixfor-SVAT & -4.07 & -4.22 & -5.29 \\
\hline
\end{tabular}

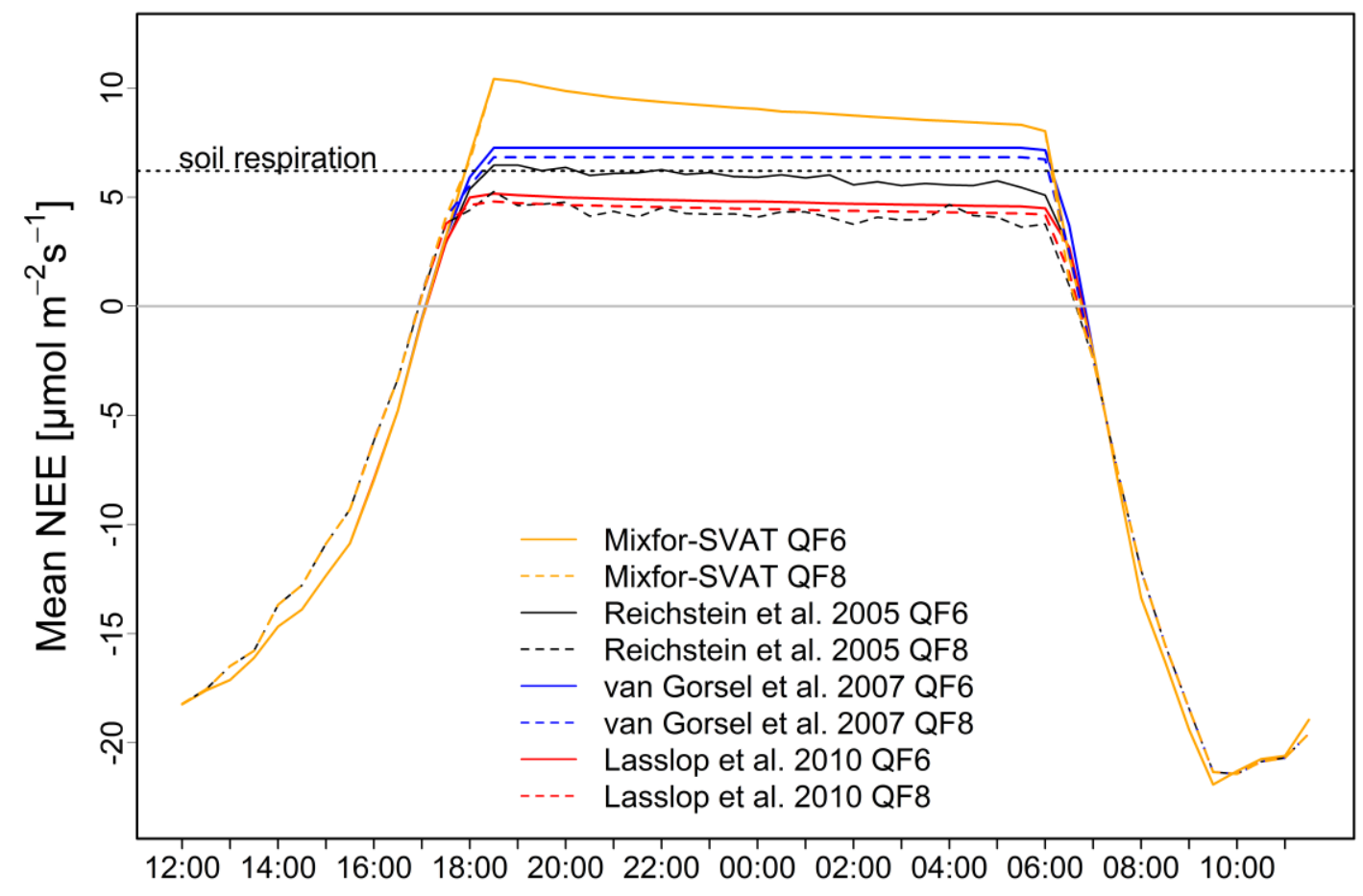

Figure 44: Mean diel NEE in $\mu \mathrm{mol} \mathrm{m} \mathrm{m}^{-2} \mathrm{~s}^{-1}$ with QF 8 \& QF 6 threshold applied. The MDS and Lasslop approach both result in mean night-time fluxes below soil respiration. 
At another well studied Amazonian site, nocturnal flux estimations were measured via EC as 6-7 $\mu \mathrm{mol} \mathrm{m} \mathrm{m}^{-2} \mathrm{~s}^{-1}$ (Goulden et al., 2004), but evidence for advection losses was discovered later on (Goulden et al., 2006). Night-time fluxes from a site situated only a few kilometres away from theirs are 8.6 $\pm 0.1 \mu \mathrm{mol} \mathrm{m} \mathrm{m}^{-1}$ based on EC and storage measurements, $7.9 \pm 0.8 \mu \mathrm{mol} \mathrm{m}{ }^{-2} \mathrm{~s}^{-1}$ from using a Radon-222 tracer and $7.6 \mu \mathrm{mol} \mathrm{m} \mathrm{m}^{-2}$ when combining chamber based measurements and coarse wood debris surveys (Hutyra et al., 2008).

From the site in French Guiana, night-time fluxes have not been published separately, but annual RE of the forest is highly variable while being always below GPP (Aguilos et al., 2018). Based on

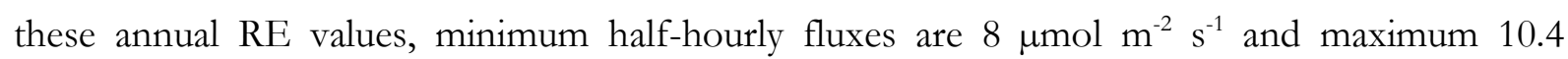
$\mu \mathrm{mol} \mathrm{m} \mathrm{s}^{-1}$. The Costa Rican site has a mean nocturnal NEE of $4.82 \pm 0.6 \mu \mathrm{mol} \mathrm{m}{ }^{-2} \mathrm{~s}^{-1}$ without a $\mathrm{u}^{*}$ filter and $7.05 \mu \mathrm{mol} \mathrm{m} \mathrm{m}^{-2} \mathrm{~s}^{-1}$ with a $\mathrm{u}^{*}>0.4 \mathrm{~m} \mathrm{~s}^{-1}$ threshold (Loescher et al., 2003).

It could be argued, that these sites have higher RE than Bariri because of a higher mean annual temperature. The only other EC-tower site in an evergreen tropical rainforest with a comparable temperature level, located in North-East Australia, has also a relatively low RE. Based on mean annual RE (Beringer et al., 2016), a mean respiration rate of $5.44 \pm 1 \mu \mathrm{mol} \mathrm{m} \mathrm{m}^{-2} \mathrm{~s}^{-1}$ can be assumed for the site. However, this site has the lowest annual RE and GPP rates in a comparison study of 13 EC-tower sites in tropical rainforests around the globe (Fu et al., 2018), resulting in a net sink of $-3.2 \pm 2.3 \mathrm{MgC} \mathrm{ha} \mathrm{yr}^{-1}$ (Beringer et al., 2016). This is not only way below the annual carbon budgets resulting from the MDS and Lasslop approaches' night-time estimates for Bariri, but a RE below soil respiration (see chapter 3) has to be rejected regardless of temperature effects.

For the geographically closest sites in Borneo, estimates of nocturnal fluxes are only available for Pasoh. There, soil chamber respiration measurements show a night-time soil efflux of $3.8 \pm 0.4 \mu \mathrm{mol}$ $\mathrm{CO}_{2} \mathrm{~m}^{-2} \mathrm{~s}^{-1}$ and NEE based on EC and storage measurements after $\mathrm{u}^{*}$ filtering of $4.7 \pm 0.2 \mu \mathrm{mol}$ $\mathrm{m}^{-2} \mathrm{~s}^{-1}$. Considering additional stem and leaf respiration, the authors suggest a gross underestimation of nocturnal $\mathrm{CO}_{2}$ fluxes at the site (Kosugi et al., 2008). The night-time measurements at the second Borneo site in intact rainforest, Lambir Hills, would lead to an annual carbon budget of $-4.83 \mathrm{Mg} \mathrm{Cha-1} \mathrm{y}^{-1}$, but were assumed to be faulty and were not published by the authors. Instead they used the intercept of a light response curve to estimate nocturnal NEE, akin to the method proposed by Lasslop et al. (2010), leading to an annual budget of $0.75 \mathrm{Mg} \mathrm{Cha} \mathrm{h} \mathrm{y}^{-1}$ (Saitoh et al., 2005). 


\subsubsection{MDS and Lasslop approach}

That the MDS approach leads to an underestimation of nocturnal fluxes is no surprise as it is dependent on the quality of the existing night-time data and there are a number of problems with that data in the case of the Bariri site. First of all, the usual argument for a certain $\mathrm{u}^{*}$ threshold to filter out faulty data, is not supported by the measurements as there is no connection between $\mathrm{u}^{*}$, storage flux and EC-measurements during the night (see 4.3.4). Secondly, as less than $20 \%$ of night-time data remains after an $\mathrm{u}^{*}$ threshold had been set via the change point detection method (Barr et al., 2013), these can certainly not be seen as representing the majority of nights (Kruijt et al., 2004). Yet as they are the only remaining data points, they are nevertheless used to fill all night-time gaps, leading to the high mean standard deviation of data considered for each gap ( $\pm 12.1-12.38 \mu \mathrm{mol} \mathrm{m}^{-2} \mathrm{~s}^{-1}$ depending on QF). A similar discarding of night-time fluxes for low $\mathrm{u}^{*}$ values lead to an uncertainty between 2 and $8 \mathrm{MgC} \mathrm{ha}^{-1} \mathrm{y}^{-1}$ for annual sums at an Amazonian site (Kruijt et al., 2004).

While the Lasslop approach mostly circumvents the use of problematic night-time data to separate NEE into gross primary production and RE, the resulting night-time fluxes are nevertheless unrealistic as they fail to predict mean fluxes above the level of soil respiration (see chapter 3). One error source might be the temperature sensitivity of RE which is still estimated from night-time data (Lasslop et al., 2010; Wutzler et al., 2018) and is thus affected by the general problems of such data at the Bariri site. Another indication comes from the photosynthetic-irradiance curve (see 4.3.5) showing negative NEE (e.g. uptake of $\mathrm{CO}_{2}$ ) at zero incoming radiation and limited explanatory power compared to other study sites. Additionally, the Lasslop approach uses VPD to account for the depression in NEE in the afternoon. Due to the bad security situation at the site during most of 2016, no $\mathrm{H}_{2} \mathrm{O}$-calibrations were carried out during that time and VPD derived from the LI-7500 might be incorrect.

Interestingly though, the Bariri site is not the only rainforest where such a mismatch exists. In their global evaluation of the approach, Lasslop et al. (2010) found that for a site in the Amazonian rainforest (named BR-MA2 in their paper, the only rainforest in the comparison), modelled NEE did not follow measured patterns and NEE vs. model drivers behaved quite differently than at the other sites. That site is located on a plateau and it has been shown that storage $\mathrm{CO}_{2}$ accumulates in the surrounding valleys, most likely through lateral drainage flows (de Araújo et al., 2010, 2008). Additionally, storage profile $\mathrm{CO}_{2}$-concentrations there show a similar diurnal pattern as the Bariri site (de Araújo et al., 2008). They observed a strong efflux of $\mathrm{CO}_{2}$ after calm nights (de Araújo et al., 2002), which the Lasslop model could not replicate. Overall, mean annual bias between modelled and observed data is highest for the rainforest site (Lasslop et al., 2010). While no clear 
answer for the underestimation of night-time RE at the Bariri site by the Lasslop approach can be determined with the data at hand, the most likely error source are again flux losses from drainage flows. According to Lasslop et al. (2010), problems originating from the complexity of a site need to be resolved before the model can be successfully used.

\subsubsection{Van Gorsel approach}

In comparison to the MDS and Lasslop approach, the strategy proposed by van Gorsel et al. (2007) yields with 6.83 to $7.26 \mu \mathrm{mol} \mathrm{m} \mathrm{m}^{-2}$ (depending on filters, see Table 17) a nocturnal flux estimate above soil respiration at the site and an estimate much closer to the values reported from other tropical sites. Nevertheless, the resulting annual budgets (Table 18) are still above nearly every other rainforest NEE budget reported so far. The only budgets of this magnitude are estimates for dry season uptake in French Guiana of $-7.66 \pm 0.55 \mathrm{Mg} \mathrm{C} \mathrm{ha}^{-1} \mathrm{y}^{-1}$ (Rowland et al., 2013) and an exceptionally productive year at the Costa Rican site with -5.97 to $-7.92 \mathrm{Mg} \mathrm{C} \mathrm{ha}^{-1} \mathrm{y}^{-1}$ (Loescher et al., 2003).

The best way to validate the nocturnal flux estimates would be comprehensive and independent RE measurements from all relevant sources. Unfortunately, only limited leaf gas exchange rates of 5 tree species measured during the day are available for Bariri. Based on these measurements, a mean foliage respiration of $3.1 \pm 0.1 \mu \mathrm{mol} \mathrm{m} \mathrm{m}^{-2} \mathrm{~s}^{-1}$ was estimated with the MAESTRA forest canopy model (Rakkibu, 2008). Considering the estimated LAI of $7.2 \mathrm{~m}^{2} \mathrm{~m}^{-2}$ at the site, this is comparable to leaf respiration estimates from the Amazon where an average of $2.6 \mu \mathrm{mol} \mathrm{m} \mathrm{m}^{-2}$ was calculated for a forest with an LAI of $4.2 \mathrm{~m}^{2} \mathrm{~m}^{-2}$ (Chambers et al., 2004). There, however, respiration rates ranged between $1.6 \mu \mathrm{mol} \mathrm{m} \mathrm{s}^{-1}$ and $3.5 \mu \mathrm{mol} \mathrm{m}^{-2} \mathrm{~s}^{-1}$, with lower values during the night, which was attributed to lower leaf temperature. If based on these values a night-time foliage respiration of $\sim 2 \mu \mathrm{mol} \mathrm{m} \mathrm{m}^{-2}$ is assumed for Bariri and the additional respiration from stems considered, even the van Gorsel approach does not yield a high enough night-time RE.

A proper interpretation of the results is additionally inhibited by a lack of comparable studies using the van Gorsel approach. The only time the method was tested for RE estimates of a rainforest site was in the aforementioned global comparison study. However, no results were reported because no temperature dependency could be determined for nocturnal respiration due to stable night-time temperature (van Gorsel et al., 2009).

The most likely explanation for the low RE estimate is insufficient mixing of the sub-canopy air volume. For instance, at one Amazonian site, EC-flux + storage flux did not reach the level of ecosystem respiration in the early evening determined via a range of independent measurements (Hutyra et al., 2007), if advection was not accounted for (Tóta et al., 2008). Consequently this would have led to an underestimation by the van Gorsel approach. Based on $\mathrm{CO}_{2}$-profil measurements 96 
(4.3.2), the existence of a thin stable soil boundary layer close to the ground where $\mathrm{CO}_{2}$-enrichment starts around noon and which is not adequately represented by the storage flux is not unlikely. Wind velocities and turbulence close to zero near the ground have been observed at many rainforest sites (Santana et al., 2018, 2017; Santos et al., 2016; Tóta et al., 2008). While no definitive reason can be given for the underestimation of RE by the van Gorsel approach, it is nevertheless clearly the best strategy based on EC and storage measurements to account for missing $\mathrm{CO}_{2}$-fluxes at the site.

\subsubsection{Mixfor-SVAT model results}

As the Mixfor-SVAT model estimates RE based on locally measured stand parameters, biological properties such as leaf, stem and soil respiration and meteorological conditions (Olchev et al., 2008), underestimation due to nocturnal advective transport can be avoided. Modelled night time respiration is $9.01 \pm 1.47 \mu \mathrm{mol} \mathrm{m} \mathrm{m}^{-2}$. This leads to an annual NEE estimate which is with -4.07 to $-5.29 \mathrm{Mg} \mathrm{ha}^{-1} \mathrm{y}^{-1}$ still in the upper range of values reported from lowland rainforests, at the edge of the pantropical average NEE of $-4.1 \mathrm{Mg} \mathrm{ha}^{-1} \mathrm{y}^{-1}$ estimated by Luyssaert et al. (2007) and well above the pantropical average of $-1.85 \pm 0.69 \mathrm{Mg} \mathrm{ha}^{-1} \mathrm{y}^{-1}$ compiled by Anderson-Teixeira et al. (2016). However, there is a range of possible explanations for a strong sink at the site (see section 5.2). The strength and weaknesses of the model have been discussed in length by Olchev et al. (2008). 


\subsection{Conclusion}

Despite difficult conditions, NEE and meteorological variables were successfully measured over more than three site years. While the installation of a $\mathrm{CO}_{2}$-concentration measurement profile and consecutive calculation of the sub-sensor storage flux was not enough to resolve the problem of an overestimation of the carbon sink strength at the Bariri site, it lead to an improved understanding of flux dynamics and further evidence for advective losses.

Although the explanatory power of solar irradiance is unusually low at this site, the positive influence of diffuse radiation on carbon uptake has been confirmed. Furthermore, effects of air temperature and VPD on NEE were investigated and revealed to be negligible.

There is ample evidence for an underestimation of fluxes during calm nights at the Bariri EC-tower site and standard approaches to correct for such fail, leading to an overestimation of the carbon sink. The more unconventional approach using mean maximum NEE after sunset to replace night-time data improved the annual budget estimate, yet NEE still remained below comparable estimates from around the globe. This is markedly different when employing modelled nocturnal RE fluxes. While more chamber based measurements are certainly needed to calibrate and validate the Mixfor-SVAT model properly, the estimated annual uptake of -4.07 to $-5.29 \mathrm{Mg} \mathrm{C} \mathrm{ha-1} \mathrm{y}^{-1} \mathrm{can}$ be seen as the first solid approximation of NEE of a montane rainforest worldwide. 


\section{Synopsis}

\subsection{Summary}

The dissertation "Carbon Fluxes and Pools in a Montane Rainforest in Sulawesi, Indonesia" addresses questions concerning the $\mathrm{CO}_{2}$-cycle of a montane rainforest from three different perspectives. With forest inventory techniques, changes in aboveground woody biomass (AGB) were studied over the years; Soil chamber measurements provided crucial insights into characteristics and dynamics of soil $\mathrm{CO}_{2}$ respiration; and last but not least Eddy-Covariance (EC) measurements were used to estimate the net ecosystem exchange (NEE) of the whole ecosystem. The study site is a dense old-growth montane rainforest on a plateau $1440 \mathrm{~m}$ a.s.l. surrounded by valleys and hills, where a measurement tower equipped with meteorological sensors and an EC system was built in 2002. Attempts by previous projects to quantify annual $\mathrm{CO}_{2}$ assimilation and respiration rates at the site with EC alone led to unrealistically high uptake estimates. This was mainly attributed to an underestimation of night-time respiration due to a lack of turbulent wind conditions (Ross, 2007), a common problem for application of EC, especially in the tropics (Acevedo et al., 2009; Aubinet, 2008; Hutyra et al., 2008; Van Gorsel et al., 2007).

At first it was assumed, that the installation of a set of new sensors would resolve this issue. Therefore, at the beginning, EC measurements were continued with the same instrumentation as before plus a newly installed $\mathrm{CO}_{2}$-profile measurement system. EC measurement systems at their core consist of a sonic anemometer to measure three dimensional wind speed and direction coupled with a gas analyser, placed above the ecosystem of interest. To work properly, turbulent mixing of the atmosphere as well as a mean vertical wind speed of zero is necessary. The profile system addresses the concern, that $\mathrm{CO}_{2}$-concentrations in the sub-canopy space below the EC sensor might increase during the night, when turbulent mixing is absent and the venting of this air volume could be missed (Baldocchi et al., 2000).

As it soon became clear, that this addition alone could not explain the missing respiration, a second approach was used to determine the strength of the biggest source of nocturnal respiration, namely soil respiration $\left(\mathrm{R}_{\mathrm{s}}\right)$. $\mathrm{R}_{\mathrm{s}}$ consists of autotrophic respiration from roots as well as heterotrophic respiration from microbial organisms and chemical reactions. Over the course of one month, $\mathrm{R}_{\mathrm{s}}$ rates were measured at different times of day at 22 locations around the measurement tower (chapter 3). 
To assess the forest's carbon uptake or loss from a different angle, a succession of forest inventories was carried out. This third approach is completely independent of all other measurements, but can only be used practically to determine changes in above-ground biomass of larger trees instead of the whole ecosystem and has its own sources of uncertainties (chapter 2).

The findings of the soil respiration measurements, forest inventories and external modelling results were then integrated in the analysis of the EC measurements (chapter 4). For this reason, EC measurements and fluxes derived from those will be described last, although it was the starting point of the project.

\subsubsection{Forest inventory}

The foundation of my forest inventories are measurements of diameter at breast height (DBH), tree height and tree position taken in 2006 on three 40 by $60 \mathrm{~m}$ plots near the measurement tower (Culmsee et al., 2010; Culmsee and Pitopang, 2009). One of those plots was subsequently re-measured in 2011 during another project (Brambach et al., 2017). Only this plot with its individual trees could be re-established and re-measured in 2014 and 2017 as too many number tags on the other two plots from 2006 were lost. The three repeated inventories 2011/2014/2017 are the basis of my analysis of spatial patterns as well as DBH-height model performance. The findings from Culmsee et al. (2010) were used in conjunction with a large scale inventory of 10 ha around the tower carried out in 2017, to detect changes in basal area (BA) and AGB.

\subsubsection{Allometric model performance and sample design}

The repeated inventories were used to establish the performance of a $\log -\log$, a Michaelis-Menten and a Weibull type diameter-height model. Besides the general question of which model performed best at the study site, I was interested in how well models parameterised based on data from one year would predict tree heights based on DBH measurements of another year, e.g. their temporal stability. If model performance would be stable over longer time periods, work intensive height measurements could be undertaken less frequently than DBH measurements.

Based on residual standard error (RSE) and bias the Michaelis-Menten and Weibull models performed best. They were also suitable for height predictions based on different inventory years and overall performed much better than pantropical or regional models would have, if results from Pasoh (Malaysia) are any indication (Ledo et al., 2016).

\subsubsection{Spatial patterns, structure and biomass}

The analysis of spatial patterns did not reveal strong indications for deviation from complete spatial randomness which allowed the use of a regular grid sampling design for the large scale inventory campaign in 2017. 
BA remained very similar in comparison to previous results published by Culmsee et al. (2010), yet AGB increased by $2.54 \mathrm{Mg} \mathrm{ha}^{-1} \mathrm{y}^{-1}$ from 2006 to 2017 (Table 19). Based on inventory data from 2011, 2014 and 2017 the diameter distribution in the forest remained relatively stable and similar to many old-growth rainforests (Culmsee et al., 2010; Fisher et al., 2013; Lusk and Smith, 1998).

Table 19 Inventory results for the Bariri site based on data from 2006 (Culmsee et al., 2010) and 2017.

\begin{tabular}{ccccc}
\hline Year & BA $\left[\mathbf{m}^{\mathbf{2}} \mathbf{h a}^{-1}\right]$ & AGB $\left[\mathbf{M g ~ h a}{ }^{-1}\right]$ & n Plots & Total plot area $[\mathrm{ha}]$ \\
\hline $\mathbf{2 0 0 6}$ & $37.1 \pm 0.9$ & $293.4 \pm 13.0$ & 3 & 0.72 \\
$\mathbf{2 0 1 7}$ & $37.86 \pm 0.38$ & $321.38 \pm 9.64$ & 64 & 1.28 \\
\hline
\end{tabular}

\subsubsection{Soil respiration}

$\mathrm{R}_{\text {s }}$ measurements were conducted with a LI-8100-103 mobile survey chamber (LI-COR Biosciences, USA) at 22 locations along a transect. One measurement took two minutes. Together with the time necessary to move between locations, measuring all 22 locations took about two hours. Besides soil $\mathrm{CO}_{2}$ emissions, soil temperature and soil humidity were recorded. For all locations, tree distances and DBH of trees in an $8 \mathrm{~m}$ radius was determined. $\mathrm{R}_{\mathrm{s}}$ was measured over the course of one month as often as possible. This resulted in a total of 21 measurement campaigns of which 6 were conducted at dawn (05:00-07:00), 6 at midday (11:00-13:00), 5 at dusk (17:0019:00) and 3 at night (23:00-01:00). The smaller amount of night-time measurement campaigns is a result of frequent heavy rains at night, which often caused dead branches or trees to fall.

\subsubsection{Chamber measurement results and variability}

Measurements indicate a mean $\mathrm{R}_{\mathrm{s}}$ of $6.2 \pm 1.84 \mu \mathrm{mol} \mathrm{m} \mathrm{m}^{-2} \mathrm{~s}^{-1}$ with temporal $\mathrm{R}_{\mathrm{s}}$ variability $(\mathrm{CV}=60 \%)$ being much lower than spatial variability $(\mathrm{CV}=136 \%)$. When fitted to a linear regression model, $\mathrm{R}_{\mathrm{s}}$ is significantly correlated with soil temperature $(\mathrm{p}<0.0005)$, but the latter has limited impact $\left(\mathrm{R}^{2}=0.24\right)$. Surprisingly, soil moisture seemed to be of no import to $\mathrm{R}_{\mathrm{s}}$ during the observed time period, showing to significant correlation. In contrast, mean $\mathrm{DBH}$ and $\mathrm{BA}$ of trees in a radius of 3 $\mathrm{m}$ around a measurement location were a good predictor for $\mathrm{R}_{\mathrm{s}}$. The best fit (conditional $\mathrm{R}^{2}=0.88$ (Nakagawa and Schielzeth, 2013)) and lowest AIC was achieved with a linear mixed effect model incorporating $\mathrm{BA}$, organic layer thickness and soil temperature. 


\subsubsection{Representativeness of soil respiration measurements}

As the abovementioned chamber measurements were performed during one month, it was necessary to determine, how representative the weather conditions during this month were for the site. Although many meteorological parameters are often quite stable in the tropics, some such as rainfall can be influenced by strong seasonal patterns. The measurement month of April 2017 showed no significant differences in soil moisture and global radiation in comparison to the longterm data from 2014 to 2017 , however air temperature was slightly cooler $\left(1.05{ }^{\circ} \mathrm{C}, 95 \% \mathrm{CI} 1.18\right.$, $0.91)$ and soil temperature warmer $\left(0.28{ }^{\circ} \mathrm{C}, 95 \% \mathrm{CI} 0.26,0.29\right)$.

Another question regarding the representativeness of these measurements stems from the influence of autotrophic respiration on total soil respiration. As there were neither enough time nor resources available to determine root densities, the forest inventory data was used as proxy. Based on that, tree diameter distribution at the soil respiration measurement locations is not significantly different to that found in the surrounding 10 ha of forest.

In light of the marginal differences in weather conditions and the similarity in tree distribution, the mean $R_{s}$ presented in this thesis can be considered to be representative for the site during the project period (December 2013 - April 2017).

\subsubsection{Eddy-Covariance}

The Eddy-Covariance system at the Bariri tower site consists of an USA-1 three dimensional sonic anemometer (METEK, Germany) in conjunction with a LI-7500A (Licor Inc., USA) infrared gas analyser (IRGA). In 2014 an air storage $\mathrm{CO}_{2}$-concentration measurement setup, consisting of intake tubes installed in six different heights at the tower connected to a LI-820 (Licor Inc., USA) IRGA was added. The tower is also fitted with a full set of meteorological sensors. Measurements were running intermittently from December 2013 to the end of April 2017. Due to instrument failures and other impeding circumstances, only the last 12 month were used as a basis for in-depth analysis. The focus of my work was on the establishment of defensible annual NEE estimates by addressing the night-time flux loss problem and investigating possible meteorological drivers of NEE.

\subsubsection{Night-time fluxes}

As early results indicated that the addition of air storage $\mathrm{CO}_{2}$-concentration measurement system did not mitigate the underestimation of night-time respiration, four approaches were tested to resolve this problem. First, the two standard gap-filling procedures developed by Reichstein et al. (2005) and Lasslop et al. (2010) which are used by FLUXNET sites were considered. Both were discarded as they estimated night-time respiration levels below $\mathrm{R}_{\mathrm{s}}$. 
The third approach was suggested by van Gorsel et al. (2007) based on experiences in an open wet sclerophyll forest in Australia. They observed a peak in $\mathrm{CO}_{2}$-efflux from the ecosystem shortly after sunset and before wind speeds dropped for the rest of the night. In connection with a temperature dependent decrease function, they found this respiration peak to be in good agreement with soil chamber measurements and ecophysiological models. When adapted to Bariri, this approach yields an estimate for mean night-time ecosystem respiration of 6.83-7.26 $\mu$ mol $\mathrm{CO}_{2}$ $\mathrm{m}^{-2} \mathrm{~s}^{-1}$, slightly above $\mathrm{R}_{\mathrm{s}}$. On an annual scale, this translates to a strong sink with a NEE of -7.84 to $-8.64 \mathrm{Mg} \mathrm{Cha}^{-1} \mathrm{y}^{-1}$. Such a strong sink is difficult to explain with above ground woody biomass presumably increasing at a rate of $2.54 \mathrm{Mg} \mathrm{ha}^{-1} \mathrm{y}^{-1}$ e.g. $\sim 1.27 \mathrm{Mg} \mathrm{Cha}^{-1} \mathrm{y}^{-1}$.

The last strategy takes advantage of the Mixfor-SVAT model developed by Olchev et al. (2008). This model had already been used to describe fluxes at the Bariri site in the past and was updated and run with the new $\mathrm{R}_{\mathrm{s}}$ data by Alexander Olchev. The newly fitted model leads to an estimated mean night-time respiration of $9.01 \pm 1.47 \mu \mathrm{mol} \mathrm{CO} \mathrm{C}^{-2} \mathrm{~s}^{-1}$, resulting in an estimated annual NEE of -4.07 to $-5.29 \mathrm{MgC} \mathrm{ha} \mathrm{y}^{-1}$.

\subsubsection{Meteorological drivers}

Fitting a photosynthesis-irradiance (PI) curve to the EC-data explained $35 \%$ of day-time $\mathrm{CO}_{2}$-flux variations. The proportion of diffuse radiation had the greatest influence on the residuals of the PI-curve, but it was small $\left(\mathrm{R}^{2}=0.11\right)$. Measurements of photosynthetically active radiation transmission indicate an increase in radiation absorption under cloudy conditions which could explain this effect. All other meteorological parameters did not have a decisive impact. 


\subsection{The Bariri forest in comparison to montane old-growth rainforests}

around the world and arguments for a strong carbon sink at the site AGB (320.56 $\left.\pm 9.64 \mathrm{Mg} \mathrm{ha}^{-1}\right)$ and BA (37.86 $\left.\pm 0.38 \mathrm{~m}^{2} \mathrm{ha}^{-1}\right)$ as well as changes therein estimated for the Bariri site are well within ranges reported from other tropical montane old-growth rainforests (Aiba and Kitayama, 1999; Alves et al., 2010; Brown et al., 1993; Culmsee et al., 2010; Ensslin et al., 2015; Hertel et al., 2009; Malizia et al., 2020; Marshall et al., 2012; Moser et al., 2011; Peña et al., 2018; Requena Suarez et al., 2019). Standard tree diameter-height models performed as well as at other tropical sites (Ledo et al., 2016; Sullivan et al., 2018) and proofed to be stable over long time periods, as the forest structure changed little over the years.

Soil $\mathrm{CO}_{2}$ respiration at Bariri is with $6.2 \pm 1.84 \mu \mathrm{mol} \mathrm{m} \mathrm{m}^{-2} \mathrm{~s}^{-1}$ at the upper range of reported fluxes from tropical rainforests around the world and had very little temporal variation. Soil moisture had no observable impact on respiration at all, while soil temperature changes were correlated weakly but significantly with fluxes. In contrast, a strong influence of BA in a $3 \mathrm{~m}$ radius was discovered. Results from other sites in tropical rainforests indicate that local conditions influence $\mathrm{R}_{\mathrm{s}}$ so strongly that generalisations are hard to make. The interaction of local soil type, climate, topography, vegetation and fauna is so diverse, that factors that were found to have a significant impact in one location had none in others. Therefore, each site has to be treated differently and judged accordingly (Bréchet et al., 2011; Chambers et al., 2004; Davidson et al., 2004, 1998; Hashimoto et al., 2004; Rubio and Detto, 2017; Sotta et al., 2004, 2006; van Straaten et al., 2011; Wood et al., 2013; Zhou et al., 2013; Zimmermann et al., 2009a, 2010).

For annual NEE estimates based on EC, no directly comparable site exists, as all other EC-tower sites in the tropics are in lowland areas. When findings from these sites are nevertheless considered for comparison, only two of my NEE estimates come close to the range found in such forests. (Aguilos et al., 2018; Andreae et al., 2002; Grace et al., 1995; Hutyra et al., 2008; Kosugi et al., 2008; Loescher et al., 2003; Malhi et al., 1998; Miller et al., 2004; Saitoh et al., 2005; Saleska et al., 2003; Zeri et al., 2014). Based on my forest inventory results, $R_{s}$ measurements and previous work on leaf respiration by Rakkibu (2008), discarding night-time measurements completely and using Mixfor-SVAT (Olchev et al., 2008) night-time fluxes, is the only way to reach realistic estimates. When using these modelled night-time fluxes, the Bariri site is shown to be a strong sink with an uptake of -4.07 to $-5.29 \mathrm{MgC} \mathrm{ha}^{-1} \mathrm{y}^{-1}$. As only about 1.27 Mg C ha- $\mathrm{y}^{-1}$ of these where found to be bound in aboveground biomass of trees with a $\mathrm{DBH} \geq 10 \mathrm{~cm}$, it becomes imperative to consider where the remaining carbon could be stored. 
In terms of aboveground storage, climbers may play an important role. Eyewitness reports from local assistants indicate sustained harvesting of rattan by the local population in the forest previous to the establishment of the study site, which is regrowing ever since.

There are also ample arguments to be made for a sustained soil carbon sink at the site. An altitudinal transect study in the Peruvian Andes using translocated soil cores showed increased soil carbon allocation to below-ground carbon stocks with increasing altitude (Zimmermann et al., 2009a) and a decrease in below-ground productivity (Girardin et al., 2010). If this trend is true for the montane rainforest at the Bariri site, it could explain part of the higher uptake in comparison to lowland rainforests.

Additionally, the soil at the Bariri site has been described as Rhodic Ferralsol (Brambach et al., 2017) and has extremely low cation exchange capacity and pH (van Straaten, unpublished data). Rhodic Ferralsols have a very high capacity to fix phosphorous, while iron and aluminium oxides present in such soils can play a large role in soil chemistry (Wambeke, 1974). Iron and aluminium oxides in turn are known to fix aromatic compounds in stable soil carbon pools under low $\mathrm{pH}$ values in forests (Schrumpf et al., 2013). Low phosphorous availability limits soil microbiological activity, which has been linked to increased carbon losses through leaching in the wet tropics (Wieder et al., 2009). Furthermore, heterotrophic respiration is likely more sensitive to temperature than autotrophic respiration and limited microbiological activity could strongly influence soil respiration, as litter decomposition can be responsible for $\sim 37 \%$ of total respiration rates (Zimmermann et al., 2009b).

A further argument supporting sustained high annual carbon uptake at the Bariri site in comparison to other tropical EC-sites, is the allocation of carbon to different parts of trees under varying climatic conditions. A negative influence of high night-time temperatures on tree diameter growth has been observed in a rainforest in Costa Rica (Clark et al., 2010), while for European tree species a correlation of lower coarse wood debris decay rates with lower temperatures has been confirmed (Herrmann and Bauhus, 2013). If this is assumed to hold for all tropical biomes, these two factors together could lead to a higher percentage of total forest carbon stored in living and dead wood biomass in colder montane rainforests than in hotter lowland rainforests. A further argument for high forest biomass at Bariri is again the observed soil chemistry. Soil cations and phosphorous content was negatively correlated with stand level biomass and positively with tree turnover rate in the Amazon basin (Quesada et al., 2012), which means that forests on soils poor in both are likely to have a high amount of woody biomass. Coarse wood debris in turn has high lignin content and high lignin concentrations have a detrimental impact on biotic decomposition of plant matter (Austin and Ballaré, 2010; Meentemeyer, 1978), therefore this could lead to larger long-term dead 
wood carbon stocks in montane regions. Additionally, lignocellulose derived substrates and therefore a large part of woody biomass decomposition products are more likely to form stable bonds with iron and aluminium oxides than other dissolved organic matter components (Kaiser and Guggenberger, 2000), furthering the argument for large stable soil carbon pools at Bariri.

Last but not least, increased $\mathrm{CO}_{2}$ concentrations in the atmosphere and increased nitrogen fertilisation from anthropogenic nitrogen emissions have been linked to increasing carbon uptake of ecosystems (Carey et al., 2001; Galloway et al., 2004).

There are many reasons to suspect a strong carbon sink of the ecosystem at the Bariri site, as elucidated in the previous two sections. Together with Rattan regrowth, such effects on soil respiration and plant matter decomposition in conjunction with continuous and sufficient water supply as well as high incoming radiation, could explain the overall high carbon uptake.

\subsection{Open questions}

Further forest inventories as well as surveys of biomass changes in rattan would be valuable for further improving AGB estimates. Measuring $\mathrm{R}_{\mathrm{s}}$ rates over longer time spans as well as a larger area would be very helpful in understanding this major component of RE. Together with further leafand stem respiration measurements, ecosystem RE at the site could be determined independently of EC measurements, which could lead to a better understanding of the carbon cycle at the site. $R_{s}$ measurements should also be accompanied by an analysis of soil carbon and changes thereof. Furthermore, a more fine grained survey of plants together with long-term PAR measurements at $\mathrm{R}_{\mathrm{s}}$ measurement locations could lead to better insights into the control of the surrounding vegetation on $\mathrm{R}_{\mathrm{s}}$-fluxes. While knowing root biomass at these locations would be interesting too, this would preclude long-term measurements which I belief are more important at this point. Last but not least, a thorough investigation of advective fluxes and the influence of large eddies on NEE is needed, if this complex site is to become a continuous source of well constraint NEE estimates. 


\subsection{Conclusion}

This thesis strengthens the assumption that the forest at the Bariri site has been a constant carbon sink in the recent past. By providing robust BA, AGB and mean annual AGB estimates for the forest at the site, a conservative lower bound for NEE is established. This fulfils my first main objective and resolves one part of the previously uncertain contribution of ecosystem elements to the carbon cycle at the site (Figure 45, a).

I observed temporally stable $\mathrm{R}_{\mathrm{s}}$ over one month and at different times of the day, while measuring at very divers locations. Combined with the stable meteorological conditions at the site, this gives a solid estimation of this major component of RE (Figure $45 \mathrm{~b}$ ). This is invaluable information for addressing the third main objective, although further research on the temporal stability of $\mathrm{R}_{\mathrm{s}}$ are needed, as it might be different under more unusual meteorological conditions. While this study presents the first estimation of tree density impacts on $R_{s}$ in a tropical montane rainforest, the fact that strong impacts of mean $\mathrm{DBH}$ and $\mathrm{BA}$ on $\mathrm{R}_{\mathrm{s}}$ were only found inside a 3 m radius around measurement locations warrants further investigations into the influence of vegetation density on these fluxes.

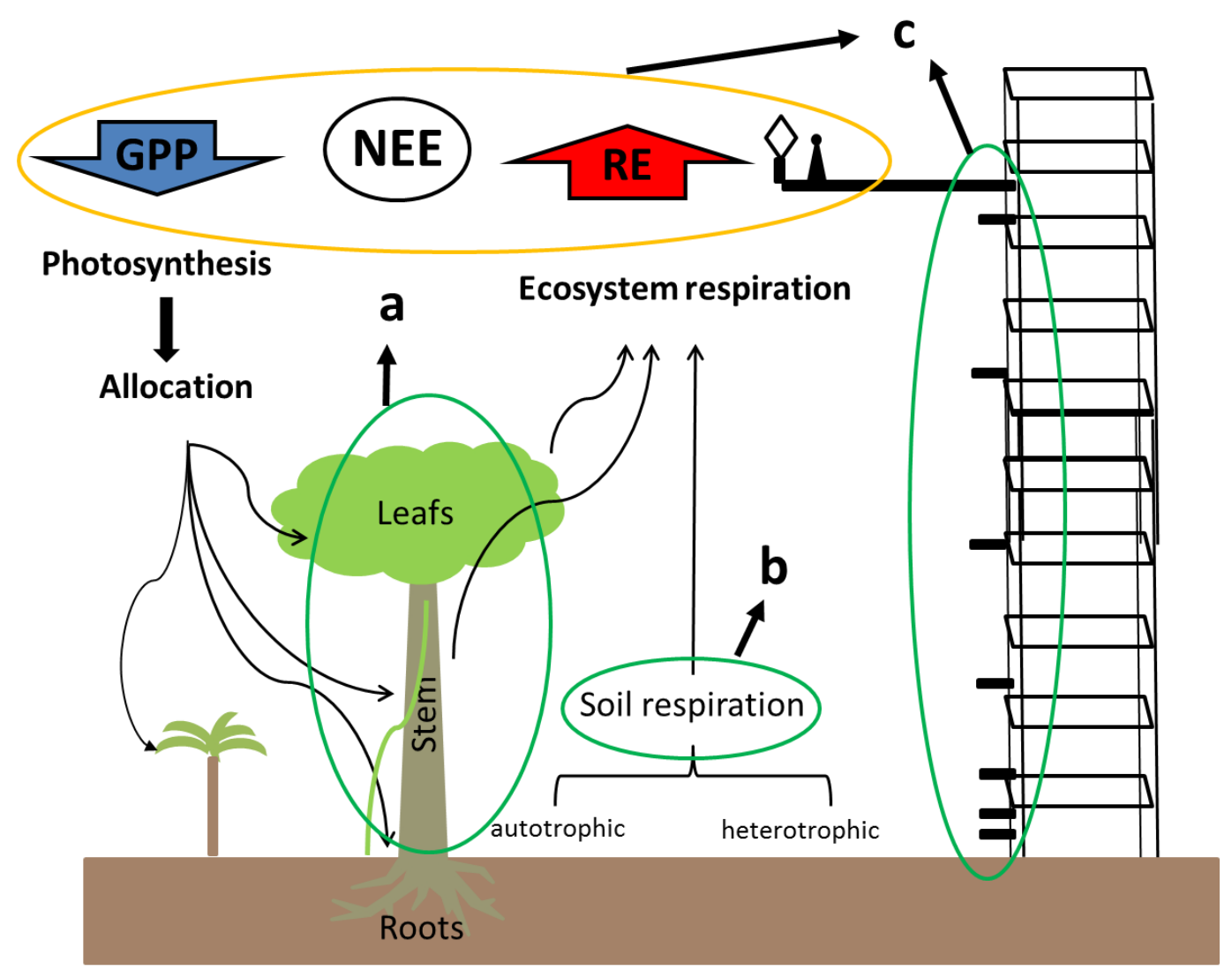

Figure 45: Resolved questions about the main components of the carbon cycle at Bariri marked in green, partly resolved questions in orange a) Aboveground biomass of trees with a DBH $\geq 10$ $\mathrm{cm}$ b) soil respiration measurements and c) Eddy-covariance including storage term. 
The difficult conditions at the site, which prevented regular and necessary maintenance, lead to a range of data gaps. Nevertheless a defensible annual NEE estimate was achieved for one site-year. Although the measurement of the storage flux was not enough to resolve the systematic bias of EC measurements at the Bariri site, it closes an important gap in our knowledge about flux dynamics at the site and eliminates one possibility for the current overestimation of NEE (Figure 45 c). While further research is necessary to achieve good annual NEE estimates from measurements alone, employing the newly parameterised Mixfor-SVAT model to replace problematic measured night-time fluxes finally leads to an estimated annual uptake of -4.07 to -5.29 $\mathrm{MgC} \mathrm{ha} \mathrm{y}^{-1}$, the first solid approximation of NEE of a montane rainforest worldwide. 


\section{Bibliography}

Acevedo, O. C., Moraes, O. L. L., Degrazia, G. A., Fitzjarrald, D. R., Manzi, A. O. and Campos, J. G.: Is friction velocity the most appropriate scale for correcting nocturnal carbon dioxide fluxes?, Agric. For. Meteorol., 149(1), 1-10, doi:10.1016/j.agrformet.2008.06.014, 2009.

Adachi, M., Bekku, Y. S., Rashidah, W., Okuda, T. and Koizumi, H.: Differences in soil respiration between different tropical ecosystems, Appl. Soil Ecol., 34(2-3), 258-265, doi:10.1016/j.apsoil.2006.01.006, 2006.

Aguilos, M., Hérault, B., Burban, B., Wagner, F. and Bonal, D.: What drives long-term variations in carbon flux and balance in a tropical rainforest in French Guiana?, Agric. For. Meteorol., 253254, 114-123, doi:10.1016/j.agrformet.2018.02.009, 2018.

Aiba, S. and Kitayama, K.: Structure, composition and species diversity in an altitude-substrate matrix of rain forest tree communities on Mount Kinabalu, Borneo, Plant Ecol., 140(2), 139-157, doi:10.1023/A:1009710618040, 1999.

Alves, L. F., Vieira, S. A., Scaranello, M. A., Camargo, P. B., Santos, F. A. M., Joly, C. A. and Martinelli, L. A.: Forest structure and live aboveground biomass variation along an elevational gradient of tropical Atlantic moist forest (Brazil), For. Ecol. Manag., 260(5), 679-691, doi:10.1016/j.foreco.2010.05.023, 2010.

Anderson-Teixeira, K. J., Wang, M. M. H., McGarvey, J. C. and LeBauer, D. S.: Carbon dynamics of mature and regrowth tropical forests derived from a pantropical database (TropForC-db), Glob. Change Biol., 22(5), 1690-1709, doi:10.1111/gcb.13226, 2016.

Andreae, M. O., Artaxo, P., Brandão, C., Carswell, F. E., Ciccioli, P., Costa, A. L. da, Culf, A. D., Esteves, J. L., Gash, J. H. C., Grace, J., Kabat, P., Lelieveld, J., Malhi, Y., Manzi, A. O., Meixner, F. X., Nobre, A. D., Nobre, C., Ruivo, M. d L. P., Silva-Dias, M. A., Stefani, P., Valentini, R., Jouanne, J. von and Waterloo, M. J.: Biogeochemical cycling of carbon, water, energy, trace gases, and aerosols in Amazonia: The LBA-EUSTACH experiments, J. Geophys. Res. Atmospheres, LBA 33-1-LBA 33-25, doi:10.1029/2001JD000524@10.1002/(ISSN)2169-8996.LBAMZ1, 2002.

de Araújo, A. C., Nobre, A. D., Kruijt, B., Elbers, J. A., Dallarosa, R., Stefani, P., Randow, C. von, Manzi, A. O., Culf, A. D., Gash, J. H. C., Valentini, R. and Kabat, P.: Comparative measurements of carbon dioxide fluxes from two nearby towers in a central Amazonian rainforest: The Manaus LBA site, J. Geophys. Res. Atmospheres, LBA 58-1-LBA 58-20, doi:10.1029/2001JD000676@10.1002/(ISSN)2169-8996.LBAMZ1, 2002.

de Araújo, A. C., Dolman, A. J., Waterloo, M. J., Gash, J. H. C., Kruijt, B., Zanchi, F. B., de Lange, J. M. E., Stoevelaar, R., Manzi, A. O., Nobre, A. D., Lootens, R. N. and Backer, J.: The spatial variability of $\mathrm{CO} 2$ storage and the interpretation of eddy covariance fluxes in central Amazonia, Agric. For. Meteorol., 150(2), 226-237, doi:10.1016/j.agrformet.2009.11.005, 2010.

de Araújo, A. C. de, Kruijt, B., Nobre, A. D., Dolman, A. J., Waterloo, M. J., Moors, E. J. and Souza, J. S. de: Nocturnal Accumulation of Co2 Underneath a Tropical Forest Canopy Along a Topographical Gradient, Ecol. Appl., 18(6), 1406-1419, doi:10.1890/06-0982.1, 2008. 
Asao, S., Bedoya-Arrieta, R. and Ryan, M. G.: Variation in foliar respiration and wood CO2 efflux rates among species and canopy layers in a wet tropical forest, Tree Physiol., 35(2), $148-$ 159, doi:10.1093/treephys/tpu107, 2015.

Atkins, J. W., Fahey, R. T., Hardiman, B. S. and Gough, C. M.: Forest Canopy Structural Complexity and Light Absorption Relationships at the Subcontinental Scale, J. Geophys. Res. Biogeosciences, 123(4), 1387-1405, doi:10.1002/2017JG004256, 2018.

Aubinet, M.: Eddy Covariance $\mathrm{CO}_{2}$ Flux Measurements in Nocturnal Conditions: An Analysis of the Problem, Ecol. Appl., 18(6), 1368-1378, 2008.

Aubinet, M., Grelle, A., Ibrom, A., Rannik, Ü., Moncrieff, J., Foken, T., Kowalski, A. S., Martin, P. H., Berbigier, P., Bernhofer, Ch., Clement, R., Elbers, J., Granier, A., Grünwald, T., Morgenstern, K., Pilegaard, K., Rebmann, C., Snijders, W., Valentini, R. and Vesala, T.: Estimates of the Annual Net Carbon and Water Exchange of Forests: The EUROFLUX Methodology, in Advances in Ecological Research, vol. 30, edited by A. H. Fitter and D. G. Raffaelli, pp. 113-175, Academic Press., 1999.

Aubinet, M., Heinesch, B. and Yernaux, M.: Horizontal and Vertical Co2 Advection In A Sloping Forest, Bound.-Layer Meteorol., 108(3), 397-417, doi:10.1023/A:1024168428135, 2003.

Aubinet, M., Berbigier, P., Bernhofer, C., Cescatti, A., Feigenwinter, C., Granier, A., Grünwald, T., Havrankova, K., Heinesch, B., Longdoz, B., Marcolla, B., Montagnani, L. and Sedlak, P.: Comparing CO2 Storage and Advection Conditions at Night at Different Carboeuroflux Sites, Bound.-Layer Meteorol., 116(1), 63-93, doi:10.1007/s10546-004-7091-8, 2005.

Aubinet, M., Feigenwinter, C., Heinesch, B., Bernhofer, C., Canepa, E., Lindroth, A., Montagnani, L., Rebmann, C., Sedlak, P. and Van Gorsel, E.: Direct advection measurements do not help to solve the night-time $\mathrm{CO} 2$ closure problem: Evidence from three different forests, Agric. For. Meteorol., 150(5), 655-664, doi:10.1016/j.agrformet.2010.01.016, 2010.

Austin, A. T. and Ballaré, C. L.: Dual role of lignin in plant litter decomposition in terrestrial ecosystems, Proc. Natl. Acad. Sci., 107(10), 4618-4622, doi:10.1073/pnas.0909396107, 2010.

Baccini, A., Goetz, S. J., Walker, W. S., Laporte, N. T., Sun, M., Sulla-Menashe, D., Hackler, J., Beck, P. S. A., Dubayah, R., Friedl, M. A., Samanta, S. and Houghton, R. A.: Estimated carbon dioxide emissions from tropical deforestation improved by carbon-density maps, Nat. Clim. Change, 2(3), 182, doi:10.1038/nclimate1354, 2012.

Baddeley, A. and Turner, R.: spatstat : An R Package for Analyzing Spatial Point Patterns, J. Stat. Softw., 12(6), doi:10.18637/jss.v012.i06, 2005.

Baldocchi, D., Finnigan, J., Wilson, K., U, K. T. P. and Falge, E.: On Measuring Net Ecosystem Carbon Exchange Over Tall Vegetation on Complex Terrain, Bound.-Layer Meteorol., 96(1-2), 257-291, doi:10.1023/A:1002497616547, 2000.

Baldocchi, D. D.: Assessing the eddy covariance technique for evaluating carbon dioxide exchange rates of ecosystems: past, present and future, Glob. Change Biol., 9(4), 479-492, doi:10.1046/j.1365-2486.2003.00629.x, 2003.

Barr, A. G., Richardson, A. D., Hollinger, D. Y., Papale, D., Arain, M. A., Black, T. A., Bohrer, G., Dragoni, D., Fischer, M. L., Gu, L., Law, B. E., Margolis, H. A., McCaughey, J. H., Munger, J. W., Oechel, W. and Schaeffer, K.: Use of change-point detection for friction-velocity threshold 
evaluation in eddy-covariance studies, Agric. For. Meteorol., 171-172, 31-45, doi:10.1016/j.agrformet.2012.11.023, 2013.

Bates, D., Mächler, M., Bolker, B. and Walker, S.: Fitting Linear Mixed-Effects Models Using lme4, J. Stat. Softw., 67(1), 1-48, doi:10.18637/jss.v067.i01, 2015.

Beer, C., Reichstein, M., Tomelleri, E., Ciais, P., Jung, M., Carvalhais, N., Rödenbeck, C., Arain, M. A., Baldocchi, D., Bonan, G. B., Bondeau, A., Cescatti, A., Lasslop, G., Lindroth, A., Lomas, M., Luyssaert, S., Margolis, H., Oleson, K. W., Roupsard, O., Veenendaal, E., Viovy, N., Williams, C., Woodward, F. I. and Papale, D.: Terrestrial Gross Carbon Dioxide Uptake: Global Distribution and Covariation with Climate, Science, 329(5993), 834-838, doi:10.1126/science.1184984, 2010.

Bengtsson, H.: R.utils: Various Programming Utilities. [online] Available from: https://CRAN.Rproject.org/package=R.utils (Accessed 2 March 2019), 2019.

Beringer, J., Hutley, L. B., McHugh, I., Arndt, S. K., Campbell, D., Cleugh, H. A., Cleverly, J., Resco de Dios, V., Eamus, D., Evans, B., Ewenz, C., Grace, P., Griebel, A., Haverd, V., HinkoNajera, N., Huete, A., Isaac, P., Kanniah, K., Leuning, R., Liddell, M. J., Macfarlane, C., Meyer, W., Moore, C., Pendall, E., Phillips, A., Phillips, R. L., Prober, S. M., Restrepo-Coupe, N., Rutledge, S., Schroder, I., Silberstein, R., Southall, P., Yee, M. S., Tapper, N. J., Gorsel, E. van, Vote, C., Walker, J. and Wardlaw, T.: An introduction to the Australian and New Zealand flux tower network - OzFlux, Biogeosciences, 13(21), 5895-5916, doi:https://doi.org/10.5194/bg13-5895-2016, 2016.

Biagioni, S., Haberzettl, T., Wang, L.-C., St-Onge, G. and Behling, H.: Unravelling the past 1,000 years of history of human-climate-landscape interactions at the Lindu plain, Sulawesi, Indonesia, Veg. Hist. Archaeobotany, 25(1), 1-17, doi:10.1007/s00334-015-0523-1, 2016.

Boisvenue, C. and Running, S. W.: Impacts of climate change on natural forest productivity evidence since the middle of the 20th century, Glob. Change Biol., 12(5), 862-882, doi:10.1111/j.1365-2486.2006.01134.x, 2006.

Bonal, D., Bosc, A., Ponton, S., Goret, J.-Y., Burban, B., Gross, P., Bonnefond, J.-M., Elbers, J., Longdoz, B., Epron, D., Guehl, J.-M. and Granier, A.: Impact of severe dry season on net ecosystem exchange in the Neotropical rainforest of French Guiana, Glob. Change Biol., 14(8), 1917-1933, doi:10.1111/j.1365-2486.2008.01610.x, 2008.

Bonan, G. B.: Forests and Climate Change: Forcings, Feedbacks, and the Climate Benefits of Forests, Science, 320(5882), 1444-1449, doi:10.1126/science.1155121, 2008.

Bond-Lamberty, B. P. and Thomson, A. M.: A Global Database of Soil Respiration Data, Version 3.0, , doi:10.3334/ORNLDAAC/1235, 2014.

Bradford, M., Metcalfe, D., Ford, A., Liddell, M. and McKeown, A.: Floristics, stand structure and aboveground biomass of a 25 -ha rainforest plot in the wet tropics of Australia, J. Trop. For. Sci., 26(4), 543-553, 2014.

Brambach, F., Leuschner, C., Tjoa, A. and Culmsee, H.: Diversity, endemism, and composition of tropical mountain forest communities in Sulawesi, Indonesia, in relation to elevation and soil properties, Perspect. Plant Ecol. Evol. Syst., 27, 68-79, doi:10.1016/j.ppees.2017.06.003, 2017. 
Bréchet, L., Ponton, S., Alméras, T., Bonal, D. and Epron, D.: Does spatial distribution of tree size account for spatial variation in soil respiration in a tropical forest?, Plant Soil, 347(1-2), 293, doi:10.1007/s11104-011-0848-1, 2011.

Brown, S.: Estimating Biomass and Biomass Change of Tropical Forests: A Primer, Food \& Agriculture Org., 1997.

Brown, S., Gillespie, A. J. R. and Lugo, A. E.: Biomass Estimation Methods for Tropical Forests with Applications to Forest Inventory Data, For. Sci., 35(4), 881-902, 1989.

Brown, S., Iverson, L. R., Prasad, A. and Liu, D.: Geographical distributions of carbon in biomass and soils of tropical Asian forests, Geocarto Int., 8(4), 45-59, doi:10.1080/10106049309354429, 1993.

Burba and Anderson, D.: A Brief Practical Guide to Eddy Covariance Flux Measurements: Principles and Workflow Examples for Scientific and Industrial Applications, LI-COR Biosciences., 2010.

Burba, G. G., McDERMITT, D. K., Grelle, A., Anderson, D. J. and Xu, L.: Addressing the influence of instrument surface heat exchange on the measurements of $\mathrm{CO} 2$ flux from open-path gas analyzers, Glob. Change Biol., 14(8), 1854-1876, doi:10.1111/j.1365-2486.2008.01606.x, 2008.

Cannon, C. H., Summers, M., Harting, J. R. and Kessler, P. J. A.: Developing Conservation Priorities Based on Forest Type, Condition, and Threats in a Poorly Known Ecoregion: Sulawesi, Indonesia, Biotropica, 39(6), 747-759, doi:10.1111/j.1744-7429.2007.00323.x, 2007.

Canty, A. and Ripley, B.: boot: Bootstrap R (S-Plus) Functions. [online] Available from: https://cran.r-project.org/web/packages/boot/index.html, 2017.

Carey, E. V., Sala, A., Keane, R. and Callaway, R. M.: Are old forests underestimated as global carbon sinks?, Glob. Change Biol., 7(4), 339-344, doi:10.1046/j.1365-2486.2001.00418.x, 2001.

Chambers, J. Q., Tribuzy, E. S., Toledo, L. C., Crispim, B. F., Higuchi, N., Santos, J. dos, Araújo, A. C., Kruijt, B., Nobre, A. D. and Trumbore, S. E.: Respiration from a Tropical Forest Ecosystem: Partitioning of Sources and Low Carbon Use Efficiency, Ecol. Appl., 14(4), S72-S88, 2004.

Chave, J., Andalo, C., Brown, S., Cairns, M. A., Chambers, J. Q., Eamus, D., Fölster, H., Fromard, F., Higuchi, N., Kira, T., Lescure, J.-P., Nelson, B. W., Ogawa, H., Puig, H., Riéra, B. and Yamakura, T.: Tree allometry and improved estimation of carbon stocks and balance in tropical forests, Oecologia, 145(1), 87-99, doi:10.1007/s00442-005-0100-x, 2005.

Chave, J., Réjou-Méchain, M., Búrquez, A., Chidumayo, E., Colgan, M. S., Delitti, W. B. C., Duque, A., Eid, T., Fearnside, P. M., Goodman, R. C., Henry, M., Martínez-Yrízar, A., Mugasha, W. A., Muller-Landau, H. C., Mencuccini, M., Nelson, B. W., Ngomanda, A., Nogueira, E. M., Ortiz-Malavassi, E., Pélissier, R., Ploton, P., Ryan, C. M., Saldarriaga, J. G. and Vieilledent, G.: Improved allometric models to estimate the aboveground biomass of tropical trees, Glob. Change Biol., 20(10), 3177-3190, doi:10.1111/gcb.12629, 2014.

Chiu, S. N., Stoyan, D., Kendall, W. S. and Mecke, J., Eds.: Stochastic Geometry and its Applications, John Wiley \& Sons, Ltd, Chichester, UK., 2013. 
Chu, H., Baldocchi, D. D., John, R., Wolf, S. and Reichstein, M.: Fluxes all of the time? A primer on the temporal representativeness of FLUXNET, J. Geophys. Res. Biogeosciences, 122(2), 289307, doi:10.1002/2016JG003576, 2017.

Clark, D. B. and Kellner, J. R.: Tropical forest biomass estimation and the fallacy of misplaced concreteness, J. Veg. Sci., 23(6), 1191-1196, doi:10.1111/j.1654-1103.2012.01471.x, 2012.

Clark, D. B., Clark, D. A. and Oberbauer, S. F.: Annual wood production in a tropical rain forest in NE Costa Rica linked to climatic variation but not to increasing CO2, Glob. Change Biol., 16(2), 747-759, doi:10.1111/j.1365-2486.2009.02004.x, 2010.

Condit, R.: Research in large, long-term tropical forest plots, Trends Ecol. Evol., 10(1), 18-22, doi:10.1016/S0169-5347(00)88955-7, 1995.

Culmsee, H. and Pitopang, R.: Tree diversity in sub-montane and lower montane primary rain forests in Central Sulawesi, Blumea - Biodivers. Evol. Biogeogr. Plants, 54(1-1), 119-123, doi:10.3767/000651909X475473, 2009.

Culmsee, H., Leuschner, C., Moser, G. and Pitopang, R.: Forest aboveground biomass along an elevational transect in Sulawesi, Indonesia, and the role of Fagaceae in tropical montane rain forests, J. Biogeogr., 37(5), 960-974, doi:10.1111/j.1365-2699.2009.02269.x, 2010.

Culmsee, H., Pitopang, R., Mangopo, H. and Sabir, S.: Tree diversity and phytogeographical patterns of tropical high mountain rain forests in Central Sulawesi, Indonesia, Biodivers. Conserv., 20(5), 1103-1123, doi:10.1007/s10531-011-0019-y, 2011.

Davidson, E., V. Verchot, L., Cattanio, J., Ackerman, I. and Carvalho, J. E. M.: Effects of soil water content on soil respiration in forests and cattle pastures of eastern Amazonia., 2000.

Davidson, E. A., Ishida, F. Y. and Nepstad, D. C.: Effects of an experimental drought on soil emissions of carbon dioxide, methane, nitrous oxide, and nitric oxide in a moist tropical forest, Glob. Change Biol., 10(5), 718-730, doi:10.1111/j.1365-2486.2004.00762.x, 2004.

Davidson, EriC. A., Belk, E. and Boone, R. D.: Soil water content and temperature as independent or confounded factors controlling soil respiration in a temperate mixed hardwood forest, Glob. Change Biol., 4(2), 217-227, doi:10.1046/j.1365-2486.1998.00128.x, 1998.

De Deyn, G. B., Cornelissen, J. H. C. and Bardgett, R. D.: Plant functional traits and soil carbon sequestration in contrasting biomes, Ecol. Lett., 11(5), 516-531, doi:10.1111/j.14610248.2008.01164.x, 2008.

Doughty, C. E., Goulden, M. L., Miller, S. D. and Rocha, H. R. da: Circadian rhythms constrain leaf and canopy gas exchange in an Amazonian forest, Geophys. Res. Lett., 33(15), doi:10.1029/2006GL026750, 2006.

Ensslin, A., Rutten, G., Pommer, U., Zimmermann, R., Hemp, A. and Fischer, M.: Effects of elevation and land use on the biomass of trees, shrubs and herbs at Mount Kilimanjaro, Ecosphere, 6(3), art45, doi:10.1890/ES14-00492.1, 2015.

Falge, E., Reth, S., Brüggemann, N., Butterbach-Bahl, K., Goldberg, V., Oltchev, A., Schaaf, S., Spindler, G., Stiller, B., Queck, R., Köstner, B. and Bernhofer, C.: Comparison of surface energy exchange models with eddy flux data in forest and grassland ecosystems of Germany, Ecol. Model., 188(2), 174-216, doi:10.1016/j.ecolmodel.2005.01.057, 2005. 
Feigenwinter, C., Bernhofer, C. and Vogt, R.: The Influence of Advection on the Short Term CO2-Budget in and Above a Forest Canopy, Bound.-Layer Meteorol., 113(2), 201-224, doi:10.1023/B:BOUN.0000039372.86053.ff, 2004.

Feigenwinter, C., Bernhofer, C., Eichelmann, U., Heinesch, B., Hertel, M., Janous, D., Kolle, O., Lagergren, F., Lindroth, A., Minerbi, S., Moderow, U., Mölder, M., Montagnani, L., Queck, R., Rebmann, C., Vestin, P., Yernaux, M., Zeri, M., Ziegler, W. and Aubinet, M.: Comparison of horizontal and vertical advective CO2 fluxes at three forest sites, Agric. For. Meteorol., 148(1), 12-24, doi:10.1016/j.agrformet.2007.08.013, 2008.

Feldpausch, T. R., Banin, L., Phillips, O. L., Baker, T. R., Lewis, S. L., Quesada, C. A., AffumBaffoe, K., Arets, E. J. M. M., Berry, N. J., Bird, M., Brondizio, E. S., de Camargo, P., Chave, J., Djagbletey, G., Domingues, T. F., Drescher, M., Fearnside, P. M., França, M. B., Fyllas, N. M., Lopez-Gonzalez, G., Hladik, A., Higuchi, N., Hunter, M. O., Iida, Y., Salim, K. A., Kassim, A. R., Keller, M., Kemp, J., King, D. A., Lovett, J. C., Marimon, B. S., Marimon-Junior, B. H., Lenza, E., Marshall, A. R., Metcalfe, D. J., Mitchard, E. T. A., Moran, E. F., Nelson, B. W., Nilus, R., Nogueira, E. M., Palace, M., Patiño, S., Peh, K. S.-H., Raventos, M. T., Reitsma, J. M., Saiz, G., Schrodt, F., Sonké, B., Taedoumg, H. E., Tan, S., White, L., Wöll, H. and Lloyd, J.: Heightdiameter allometry of tropical forest trees, Biogeosciences, 8(5), 1081-1106, doi:10.5194/bg-81081-2011, 2011.

Feldpausch, T. R., Lloyd, J., Lewis, S. L., Brienen, R. J. W., Gloor, M., Monteagudo Mendoza, A., Lopez-Gonzalez, G., Banin, L., Abu Salim, K., Affum-Baffoe, K., Alexiades, M., Almeida, S., Amaral, I., Andrade, A., Aragão, L. E. O. C., Araujo Murakami, A., Arets, E. J. M. M., Arroyo, L., Aymard C., G. A., Baker, T. R., Bánki, O. S., Berry, N. J., Cardozo, N., Chave, J., Comiskey, J. A., Alvarez, E., de Oliveira, A., Di Fiore, A., Djagbletey, G., Domingues, T. F., Erwin, T. L., Fearnside, P. M., França, M. B., Freitas, M. A., Higuchi, N., E. Honorio C., Iida, Y., Jiménez, E., Kassim, A. R., Killeen, T. J., Laurance, W. F., Lovett, J. C., Malhi, Y., Marimon, B. S., MarimonJunior, B. H., Lenza, E., Marshall, A. R., Mendoza, C., Metcalfe, D. J., Mitchard, E. T. A., Neill, D. A., Nelson, B. W., Nilus, R., Nogueira, E. M., Parada, A., Peh, K. S.-H., Pena Cruz, A., Peñuela, M. C., Pitman, N. C. A., Prieto, A., Quesada, C. A., Ramírez, F., Ramírez-Angulo, H., Reitsma, J. M., Rudas, A., Saiz, G., Salomão, R. P., Schwarz, M., Silva, N., Silva-Espejo, J. E., Silveira, M., Sonké, B., Stropp, J., Taedoumg, H. E., Tan, S., ter Steege, H., Terborgh, J., TorelloRaventos, M., van der Heijden, G. M. F., Vásquez, R., Vilanova, E., Vos, V. A., White, L., Willcock, S., Woell, H. and Phillips, O. L.: Tree height integrated into pantropical forest biomass estimates, Biogeosciences, 9(8), 3381-3403, doi:10.5194/bg-9-3381-2012, 2012.

Finnigan, J.: A comment on the paper by Lee (1998): “On micrometeorological observations of surface-air exchange over tall vegetation," Agric. For. Meteorol., 97(1), 55-64, doi:10.1016/S0168-1923(99)00049-0, 1999.

Finnigan, J. J., Clement, R., Malhi, Y., Leuning, R. and Cleugh, H. A.: A Re-Evaluation of LongTerm Flux Measurement Techniques Part I: Averaging and Coordinate Rotation, Bound.-Layer Meteorol., 107(1), 1-48, doi:10.1023/A:1021554900225, 2003.

Fisher, J. B., Malhi, Y., Torres, I. C., Metcalfe, D. B., van de Weg, M. J., Meir, P., Silva-Espejo, J. E. and Huasco, W. H.: Nutrient limitation in rainforests and cloud forests along a 3,000-m elevation gradient in the Peruvian Andes, Oecologia, 172(3), 889-902, doi:10.1007/s00442-0122522-6, 2013.

Foken, T.: Angewandte Meteorologie mikrometeorologische Methoden, Springer-Verlag Berlin Heidelberg, Berlin, Heidelberg. [online] Available from: http://dx.doi.org/10.1007/978-3-54038204-1 (Accessed 25 March 2014), 2006. 
Foken, T.: The Energy Balance Closure Problem: An Overview, Ecol. Appl., 18(6), 1351-1367, doi:10.1890/06-0922.1, 2008.

Fortin, M.-J., Drapeau, P. and Legendre, P.: Spatial autocorrelation and sampling design in plant ecology, in Progress in theoretical vegetation science, edited by G. Grabherr, L. Mucina, M. B. Dale, and C. J. F. Ter Braak, pp. 209-222, Springer Netherlands, Dordrecht., 1990.

Freire, L. S., Gerken, T., Ruiz-Plancarte, J., Wei, D., Fuentes, J. D., Katul, G. G., Dias, N. L., Acevedo, O. C. and Chamecki, M.: Turbulent mixing and removal of ozone within an Amazon rainforest canopy, J. Geophys. Res. Atmospheres, 122(5), 2791-2811, doi:10.1002/2016JD026009, 2017.

Fu, Z., Gerken, T., Bromley, G., Araújo, A., Bonal, D., Burban, B., Ficklin, D., Fuentes, J. D., Goulden, M., Hirano, T., Kosugi, Y., Liddell, M., Nicolini, G., Niu, S., Roupsard, O., Stefani, P., Mi, C., Tofte, Z., Xiao, J., Valentini, R., Wolf, S. and Stoy, P. C.: The surface-atmosphere exchange of carbon dioxide in tropical rainforests: Sensitivity to environmental drivers and flux measurement methodology, Agric. For. Meteorol., 263, 292-307, doi:10.1016/j.agrformet.2018.09.001, 2018.

Galloway, J. N., Dentener, F. J., Capone, D. G., Boyer, E. W., Howarth, R. W., Seitzinger, S. P., Asner, G. P., Cleveland, C. C., Green, P. A., Holland, E. A., Karl, D. M., Michaels, A. F., Porter, J. H., Townsend, A. R. and Vöosmarty, C. J.: Nitrogen Cycles: Past, Present, and Future, Biogeochemistry, 70(2), 153-226, doi:10.1007/s10533-004-0370-0, 2004.

Gavrikov, V. and Stoyan, D.: The use of marked point processes in ecological and environmental forest studies, Environ. Ecol. Stat., 2(4), 331-344, doi:10.1007/BF00569362, 1995.

Gibbs, H. K., Brown, S., Niles, J. O. and Foley, J. A.: Monitoring and estimating tropical forest carbon stocks: making REDD a reality, Environ. Res. Lett., 2(4), 045023, doi:10.1088/17489326/2/4/045023, 2007.

Girardin, C. a. J., Malhi, Y., Aragão, L. E. O. C., Mamani, M., Huasco, W. H., Durand, L., Feeley, K. J., Rapp, J., Silva-Espejo, J. E., Silman, M., Salinas, N. and Whittaker, R. J.: Net primary productivity allocation and cycling of carbon along a tropical forest elevational transect in the Peruvian Andes, Glob. Change Biol., 16(12), 3176-3192, doi:10.1111/j.1365-2486.2010.02235.x, 2010.

Göckede, M., Bernhofer, C., Rotenberg, E., Valentini, R., Banza, J., Koeble, R., Fuhrer, J., Marek, M. V., Mauder, M., Yakir, D., Manca, G., Knohl, A., Migliavacca, M., Pereira, J. S., Markkanen, T., Elbers, J. A., Eugster, W., Bonnefond, J. M., Aubinet, M., Carrara, A., Dellwik, E., Foken, T., Vesala, T., Rebmann, C., Laurila, T., Pilegaard, K. I. M., Seufert, G., Aurela, M., Moncrieff, J. B., Soussana, J.-F., Grünwald, T., Papale, D., Granier, A., Janssens, I. A., Brunet, Y., Moors, E. J., Ourcival, J.-M., Longdoz, B., Matteucci, G., Clement, R. J., Rambal, S., Heinesch, B., Verbeeck, H., Pita, G. P. A., Soussana, J.-F., Matteucci, G., Sedlák, P., Minerbi, S., Rodrigues, A. D., SanzSanchez, M. J. and Montagnani, L.: Quality control of CarboEurope flux data: Part I: Footprint analyses to evaluate sites in forest ecosystems, ETH Zurich, doi:10.3929/ethz-b-000006696, 2007.

van Gorsel, E., Leuning, R., Cleugh, H. A., Keith, H., Kirschbaum, M. U. F. and Suni, T.: Application of an alternative method to derive reliable estimates of nighttime respiration from eddy covariance measurements in moderately complex topography, Agric. For. Meteorol., 148(67), 1174-1180, doi:10.1016/j.agrformet.2008.01.015, 2008. 
van Gorsel, E., Delpierre, N., Leuning, R., Black, A., Munger, J. W., Wofsy, S., Aubinet, M., Feigenwinter, C., Beringer, J., Bonal, D., Chen, B., Chen, J., Clement, R., Davis, K. J., Desai, A. R., Dragoni, D., Etzold, S., Grünwald, T., Gu, L., Heinesch, B., Hutyra, L. R., Jans, W. W. P., Kutsch, W., Law, B. E., Leclerc, M. Y., Mammarella, I., Montagnani, L., Noormets, A., Rebmann, C. and Wharton, S.: Estimating nocturnal ecosystem respiration from the vertical turbulent flux and change in storage of CO2, Agric. For. Meteorol., 149(11), 1919-1930, doi:10.1016/j.agrformet.2009.06.020, 2009.

Goulden, M. L., Munger, J. W., Fan, S.-M., Daube, B. C. and Wofsy, S. C.: Measurements of carbon sequestration by long-term eddy covariance: methods and a critical evaluation of accuracy, Glob. Change Biol., 2(3), 169-182, doi:10.1111/j.1365-2486.1996.tb00070.x, 1996.

Goulden, M. L., Miller, S. D., Rocha, H. R. da, Menton, M. C., Freitas, H. C. de, Figueira, A. M. e S. and Sousa, C. A. D. de: Diel and Seasonal Patterns of Tropical Forest Co2 Exchange, Ecol. Appl., 14(sp4), 42-54, doi:10.1890/02-6008, 2004.

Goulden, M. L., Miller, S. D. and Rocha, H. R. da: Nocturnal cold air drainage and pooling in a tropical forest, J. Geophys. Res. Atmospheres, 111(D8), doi:10.1029/2005JD006037, 2006.

Grace, J., Lloyd, J., McIntyre, J., Miranda, A. C., Meir, P., Miranda, H. S., Nobre, C., Moncrieff, J., Massheder, J., Malhi, Y., Wright, I. and Gash, J.: Carbon Dioxide Uptake by an Undisturbed Tropical Rain Forest in Southwest Amazonia, 1992 to 1993, Science, 270(5237), 778-780, doi:10.1126/science.270.5237.778, 1995.

Gu, L., Baldocchi, D., Verma, S. B., Black, T. A., Vesala, T., Falge, E. M. and Dowty, P. R.: Advantages of diffuse radiation for terrestrial ecosystem productivity, J. Geophys. Res.

Atmospheres, 107(D6), ACL 2-1-ACL 2-23, doi:10.1029/2001JD001242, 2002.

Gu, L., Falge, E. M., Boden, T., Baldocchi, D. D., Black, T. A., Saleska, S. R., Suni, T., Verma, S. B., Vesala, T., Wofsy, S. C. and Xu, L.: Objective threshold determination for nighttime eddy flux filtering, Agric. For. Meteorol., 128(3-4), 179-197, doi:10.1016/j.agrformet.2004.11.006, 2005.

Gushchina, D., Heimsch, F., Osipov, A., June, T., Rauf, A., Kreilein, H., Panferov, O., Olchev, A. and Knohl, A.: Effects Of The 2015-2016 El Niño Event On Energy And CO2 Fluxes Of A Tropical Rainforest In Central Sulawesi, Indonesia, Geogr. Environ. Sustain. [online] Available from: https://ges.rgo.ru/jour/article/view/746 (Accessed 15 July 2019), 2019.

Häbel, H., Kuronen, M., Henttonen, H. M., Kangas, A. and Myllymäki, M.: The effect of spatial structure of forests on the precision and costs of plot-level forest resource estimation, For. Ecosyst., 6(1), doi:10.1186/s40663-019-0167-1, 2019.

Hansen, M. C., Potapov, P. V., Moore, R., Hancher, M., Turubanova, S. A., Tyukavina, A., Thau, D., Stehman, S. V., Goetz, S. J., Loveland, T. R., Kommareddy, A., Egorov, A., Chini, L., Justice, C. O. and Townshend, J. R. G.: High-Resolution Global Maps of 21st-Century Forest Cover Change, Science, 342(6160), 850-853, doi:10.1126/science.1244693, 2013.

Hanson, P. J., Wullschleger, S. D., Bohlman, S. A. and Todd, D. E.: Seasonal and topographic patterns of forest floor CO2 efflux from an upland oak forest, Tree Physiol., 13(1), 1-15, doi:10.1093/treephys/13.1.1, 1993.

Hashimoto, S., Tanaka, N., Suzuki, M., Inoue, A., Takizawa, H., Kosaka, I., Tanaka, K., Tantasirin, C. and Tangtham, N.: Soil respiration and soil $\mathrm{CO}_{2}$ concentration in a tropical forest, Thailand, J. For. Res., 9(1), 75-79, doi:10.1007/s10310-003-0046-y, 2004. 
Hayek, M. N., Wehr, R., Longo, M., Hutyra, L. R., Wiedemann, K., Munger, J. W., Bonal, D., Saleska, S. R., Fitzjarrald, D. R. and Wofsy, S. C.: A novel correction for biases in forest eddy covariance carbon balance, Agric. For. Meteorol., 250-251, 90-101, doi:10.1016/j.agrformet.2017.12.186, 2018.

van der Heijden, G. M. F., Powers, J. S. and Schnitzer, S. A.: Lianas reduce carbon accumulation and storage in tropical forests, Proc. Natl. Acad. Sci., 112(43), 13267-13271, doi:10.1073/pnas.1504869112, 2015.

Herrmann, S. and Bauhus, J.: Effects of moisture, temperature and decomposition stage on respirational carbon loss from coarse woody debris (CWD) of important European tree species, Scand. J. For. Res., 28(4), 346-357, doi:10.1080/02827581.2012.747622, 2013.

Hertel, D., Moser, G., Culmsee, H., Erasmi, S., Horna, V., Schuldt, B. and Leuschner, Ch.: Below- and above-ground biomass and net primary production in a paleotropical natural forest (Sulawesi, Indonesia) as compared to neotropical forests, For. Ecol. Manag., 258(9), 1904-1912, doi:10.1016/j.foreco.2009.07.019, 2009.

Hirano, T., Segah, H., Harada, T., Limin, S., June, T., Hirata, R. and Osaki, M.: Carbon dioxide balance of a tropical peat swamp forest in Kalimantan, Indonesia, Glob. Change Biol., 13(2), 412-425, doi:10.1111/j.1365-2486.2006.01301.x, 2007.

Hirano, T., Segah, H., Kusin, K., Limin, S., Takahashi, H. and Osaki, M.: Effects of disturbances on the carbon balance of tropical peat swamp forests, Glob. Change Biol., 18(11), 3410-3422, doi:10.1111/j.1365-2486.2012.02793.x, 2012.

Houghton, R. A.: Aboveground Forest Biomass and the Global Carbon Balance, Glob. Change Biol., 11(6), 945-958, doi:10.1111/j.1365-2486.2005.00955.x, 2005.

Howell, S.: Politics of appearances: Some reasons why the UN-REDD project in Central Sulawesi failed to unite the various stakeholders, Asia Pac. Viewp., 56(1), 37-47, doi:10.1111/apv.12081, 2015.

Huete, A. R., Restrepo-Coupe, N., Ratana, P., Didan, K., Saleska, S. R., Ichii, K., Panuthai, S. and Gamo, M.: Multiple site tower flux and remote sensing comparisons of tropical forest dynamics in Monsoon Asia, Agric. For. Meteorol., 148(5), 748-760, doi:10.1016/j.agrformet.2008.01.012, 2008.

Hughes, R. F., Kauffman, J. B. and Jaramillo, V. J.: Biomass, Carbon, and Nutrient Dynamics of Secondary Forests in a Humid Tropical Region of México, Ecology, 80(6), 1892-1907, doi:10.1890/0012-9658(1999)080[1892:BCANDO]2.0.CO;2, 1999.

Hunter, M. O., Keller, M., Victoria, D. and Morton, D. C.: Tree height and tropical forest biomass estimation, Biogeosciences, 10, 8385-8399, doi:10.5194/bg-10-8385-2013, 2013.

Hutyra, L. R., Munger, J. W., Saleska, S. R., Gottlieb, E., Daube, B. C., Dunn, A. L., Amaral, D. F., de Camargo, P. B. and Wofsy, S. C.: Seasonal controls on the exchange of carbon and water in an Amazonian rain forest, J. Geophys. Res. Biogeosciences, 112(G3), doi:10.1029/2006JG000365, 2007.

Hutyra, L. R., Munger, J. W., Hammond-Pyle, E., Saleska, S. R., Restrepo-Coupe, N., Daube, B. C., de Camargo, P. B. and Wofsy, S. C.: Resolving systematic errors in estimates of net ecosystem 
exchange of CO2 and ecosystem respiration in a tropical forest biome, Agric. For. Meteorol., 148(8-9), 1266-1279, doi:10.1016/j.agrformet.2008.03.007, 2008.

Iost, S.: Soil respiration, microbial respiration and mineralisation in soils of montane rainforests of Southern Ecuador: influence of altitude, [online] Available from: http://www.qucosa.de/recherche/frontdoor/?tx_slubopus4frontend[id]=812 (Accessed 18 December 2017), 2007.

Itoh, M., Kosugi, Y., Takanashi, S., Hayashi, Y., Kanemitsu, S., Osaka, K., Tani, M. and Nik, A. R.: Temporal and spatial variations of soil carbon dioxide, methane, and nitrous oxide fluxes in a Southeast Asian tropical rainforest, Biogeosciences Discuss., 7(5), 6847-6887, doi:10.5194/bgd7-6847-2010, 2010

Jobbágy, E. G. and Jackson, R. B.: The Vertical Distribution of Soil Organic Carbon and Its Relation to Climate and Vegetation, Ecol. Appl., 10(2), 423-436, doi:10.1890/10510761(2000)010[0423:TVDOSO]2.0.CO;2, 2000.

Jurasinski, G., Koebsch, F., Guenther, A. and Beetz, S.: flux: Flux rate calculation from dynamic closed chamber measurements. [online] Available from: https://CRAN.Rproject.org/package $=$ flux (Accessed 5 June 2019), 2014.

Kaimal, J. C., Wyngaard, J. C., Izumi, Y. and Coté, O. R.: Spectral characteristics of surface-layer turbulence, Q. J. R. Meteorol. Soc., 98(417), 563-589, doi:10.1002/qj.49709841707, 1972.

Kaiser, K. and Guggenberger, G.: The role of DOM sorption to mineral surfaces in the preservation of organic matter in soils, Org. Geochem., 31(7), 711-725, doi:10.1016/S01466380(00)00046-2, 2000.

Katayama, A., Kume, T., Komatsu, H., Ohashi, M., Nakagawa, M., Yamashita, M., Otsuki, K., Suzuki, M. and Kumagai, T.: Effect of forest structure on the spatial variation in soil respiration in a Bornean tropical rainforest, Agric. For. Meteorol., 149(10), 1666-1673, doi:10.1016/j.agrformet.2009.05.007, 2009.

Katayama, A., Kume, T., Ohashi, M., Matsumoto, K., Nakagawa, M., Saito, T., Kumagai, T. and Otsuki, K.: Characteristics of wood CO2 efflux in a Bornean tropical rainforest, Agric. For. Meteorol., 220, 190-199, doi:10.1016/j.agrformet.2016.01.140, 2016.

Kelley, D. and Richards, C.: oce: Analysis of Oceanographic Data. [online] Available from: https://CRAN.R-project.org/package=oce, 2017.

Kessler, M., Keßler, P. J. A., Gradstein, S. R., Bach, K., Schmull, M. and Pitopang, R.: Tree diversity in primary forest and different land use systems in Central Sulawesi, Indonesia, Biodivers. Conserv., 14(3), 547-560, doi:10.1007/s10531-004-3914-7, 2005.

Kindermann, G., McCallum, I., Fritz, S. and Obersteiner, M.: A global forest growing stock, biomass and carbon map based on FAO statistics, Silva Fenn., 42(3), 387-396, doi:10.14214/sf.244, 2008.

King D. A., Davies S. J., Supardi M. N. Nur and Tan S.: Tree growth is related to light interception and wood density in two mixed dipterocarp forests of Malaysia, Funct. Ecol., 19(3), 445-453, doi:10.1111/j.1365-2435.2005.00982.x, 2005. 
Kitayama, K. and Aiba, S.-I.: Ecosystem structure and productivity of tropical rain forests along altitudinal gradients with contrasting soil phosphorus pools on Mount Kinabalu, Borneo, J. Ecol., 90(1), 37-51, doi:10.1046/j.0022-0477.2001.00634.x, 2002.

Kitching, R. L., Bickel, D., Creagh, A. C., Hurley, K. and Symonds, C.: The biodiversity of Diptera in Old World rain forest surveys: a comparative faunistic analysis, J. Biogeogr., 31(7), 1185-1200, doi:10.1111/j.1365-2699.2004.01096.x, 2004.

Kleinn, C.H.: Lecture Notes for the Teaching Module Forest Inventory, Faculty of Forest Sciences and Forest Ecology. Georg August Universität, Germany., 2007.

Kljun, N., Calanca, P., Rotach, M. W. and Schmid, H. P.: A simple two-dimensional parameterisation for Flux Footprint Prediction (FFP), Geosci. Model Dev., 8(11), 3695-3713, doi:10.5194/gmd-8-3695-2015, 2015.

Koehler, B., Corre, M. D., Veldkamp, E. and Sueta, J. P.: Chronic nitrogen addition causes a reduction in soil carbon dioxide efflux during the high stem-growth period in a tropical montane forest but no response from a tropical lowland forest on a decadal time scale, Biogeosciences, 6(12), 2973-2983, doi:10.5194/bg-6-2973-2009, 2009.

Körner, Ch.: Leaf Diffusive Conductances in the Major Vegetation Types of the Globe, in Ecophysiology of Photosynthesis, edited by E.-D. Schulze and M. M. Caldwell, pp. 463-490, Springer Berlin Heidelberg, Berlin, Heidelberg., 1995.

Kosugi, Y., Mitani, T., Itoh, M., Noguchi, S., Tani, M., Matsuo, N., Takanashi, S., Ohkubo, S. and Rahim Nik, A.: Spatial and temporal variation in soil respiration in a Southeast Asian tropical rainforest, Agric. For. Meteorol., 147(1-2), 35-47, doi:10.1016/j.agrformet.2007.06.005, 2007.

Kosugi, Y., Takanashi, S., Ohkubo, S., Matsuo, N., Tani, M., Mitani, T., Tsutsumi, D. and Nik, A. R.: CO2 exchange of a tropical rainforest at Pasoh in Peninsular Malaysia, Agric. For. Meteorol., 148(3), 439-452, doi:10.1016/j.agrformet.2007.10.007, 2008.

Kosugi, Y., Takanashi, S., Yokoyama, N., Philip, E. and Kamakura, M.: Vertical variation in leaf gas exchange parameters for a Southeast Asian tropical rainforest in Peninsular Malaysia, J. Plant Res., 125(6), 735-748, doi:10.1007/s10265-012-0495-5, 2012.

Kruijt, B., Elbers, J. A., Randow, C. von, Araújo, A. C., Oliveira, P. J., Culf, A., Manzi, A. O., Nobre, A. D., Kabat, P. and Moors, E. J.: The Robustness of Eddy Correlation Fluxes for Amazon Rain Forest Conditions, Ecol. Appl., 14(sp4), 101-113, doi:10.1890/02-6004, 2004.

Kumagai, T., Saitoh, T. M., Sato, Y., Morooka, T., Manfroi, O. J., Kuraji, K. and Suzuki, M.: Transpiration, canopy conductance and the decoupling coefficient of a lowland mixed dipterocarp forest in Sarawak, Borneo: dry spell effects, J. Hydrol., 287(1), 237-251, doi:10.1016/j.jhydrol.2003.10.002, 2004.

Larjavaara, M. and Muller-Landau, H. C.: Measuring tree height: a quantitative comparison of two common field methods in a moist tropical forest, Methods Ecol. Evol., 4(9), 793-801, doi:10.1111/2041-210X.12071, 2013.

Lasslop, G., Reichstein, M., Papale, D., Richardson, A. D., Arneth, A., Barr, A., Stoy, P. and Wohlfahrt, G.: Separation of net ecosystem exchange into assimilation and respiration using a light response curve approach: critical issues and global evaluation: SEPARATION OF NEE 
INTO GPP AND RECO, Glob. Change Biol., 16(1), 187-208, doi:10.1111/j.13652486.2009.02041.x, 2010.

Law, B. E., Falge, E., Gu, L., Baldocchi, D. D., Bakwin, P., Berbigier, P., Davis, K., Dolman, A. J., Falk, M., Fuentes, J. D., Goldstein, A., Granier, A., Grelle, A., Hollinger, D., Janssens, I. A., Jarvis, P., Jensen, N. O., Katul, G., Mahli, Y., Matteucci, G., Meyers, T., Monson, R., Munger, W., Oechel, W., Olson, R., Pilegaard, K., Paw U, K. T., Thorgeirsson, H., Valentini, R., Verma, S., Vesala, T., Wilson, K. and Wofsy, S.: Environmental controls over carbon dioxide and water vapor exchange of terrestrial vegetation, Agric. For. Meteorol., 113(1-4), 97-120, doi:10.1016/S0168-1923(02)00104-1, 2002.

Law, R., Illian, J., Burslem, D. F. R. P., Gratzer, G., Gunatilleke, C. V. S. and Gunatilleke, I. a. U. N.: Ecological information from spatial patterns of plants: insights from point process theory, J. Ecol., 97(4), 616-628, doi:10.1111/j.1365-2745.2009.01510.x, 2009.

Le Dantec, V., Epron, D. and Dufrêne, E.: Soil CO2 efflux in a beech forest: comparison of two closed dynamic systems, Plant Soil, 214(1), 125-132, doi:10.1023/A:1004737909168, 1999.

Ledo, A., Cornulier, T., Illian, J. B., Iida, Y., Kassim, A. R. and Burslem, D. F. R. P.: Reevaluation of individual diameter : height allometric models to improve biomass estimation of tropical trees, Ecol. Appl., 26(8), 2376-2382, doi:10.1002/eap.1450, 2016.

Lee, X.: On micrometeorological observations of surface-air exchange over tall vegetation, Agric. For. Meteorol., 91(1-2), 39-49, doi:10.1016/S0168-1923(98)00071-9, 1998.

Lefcheck, J. S.: piecewiseSEM: Piecewise structural equation modeling in R for ecology, evolution, and systematics, Methods Ecol. Evol., 7(5), 573-579, doi:10.1111/2041-210X.12512, 2016.

Lloyd, J. and Taylor, J. A.: On the Temperature Dependence of Soil Respiration, Funct. Ecol., 8(3), 315-323, doi:10.2307/2389824, 1994.

Loescher, H. W., Oberbauer, S. F., Gholz, H. L. and Clark, D. B.: Environmental controls on net ecosystem-level carbon exchange and productivity in a Central American tropical wet forest, Glob. Change Biol., 9(3), 396-412, doi:10.1046/j.1365-2486.2003.00599.x, 2003.

Long, S. P., Farage, P. K. and Garcia, R. L.: Measurement of leaf and canopy photosynthetic CO2 exchange in the field, J. Exp. Bot., 47(11), 1629-1642, doi:10.1093/jxb/47.11.1629, 1996.

Losi, C. J., Siccama, T. G., Condit, R. and Morales, J. E.: Analysis of alternative methods for estimating carbon stock in young tropical plantations, For. Ecol. Manag., 184(1), 355-368, doi:10.1016/S0378-1127(03)00160-9, 2003.

Lusk, C. H. and Smith, B.: Life History Differences and Tree Species Coexistence in an OldGrowth New Zealand Rain Forest, Ecology, 79(3), 795-806, doi:10.1890/00129658(1998)079[0795:LHDATS]2.0.CO;2, 1998.

Luyssaert, S., Inglima, I., Jung, M., Richardson, A. D., Reichstein, M., Papale, D., Piao, S. L., Schulze, E.-D., Wingate, L., Matteucci, G., Aragao, L., Aubinet, M., Beer, C., Bernhofer, C., Black, K. G., Bonal, D., Bonnefond, J.-M., Chambers, J., Ciais, P., Cook, B., Davis, K. J., Dolman, A. J., Gielen, B., Goulden, M., Grace, J., Granier, A., Grelle, A., Griffis, T., Grünwald, T., Guidolotti, G., Hanson, P. J., Harding, R., Hollinger, D. Y., Hutyra, L. R., Kolari, P., Kruijt, B., Kutsch, W., Lagergren, F., Laurila, T., Law, B. E., Le Maire, G., Lindroth, A., Loustau, D., 
Malhi, Y., Mateus, J., Migliavacca, M., Misson, L., Montagnani, L., Moncrieff, J., Moors, E., Munger, J. W., Nikinmaa, E., Ollinger, S. V., Pita, G., Rebmann, C., Roupsard, O., Saigusa, N., Sanz, M. J., Seufert, G., Sierra, C., Smith, M.-L., Tang, J., Valentini, R., Vesala, T. and Janssens, I. A.: CO2 balance of boreal, temperate, and tropical forests derived from a global database, Glob. Change Biol., 13(12), 2509-2537, doi:10.1111/j.1365-2486.2007.01439.x, 2007.

Malhi, Y.: The productivity, metabolism and carbon cycle of tropical forest vegetation, J. Appl. Ecol., 65-75, doi:10.1111/j.1365-2745.2011.01916.x@10.1111/(ISSN)1365-

2664.NovelEcosystemsintheAnthropocene, 2012.

Malhi, Y., Nobre, A. D., Grace, J., Kruijt, B., Pereira, M. G. P., Culf, A. and Scott, S.: Carbon dioxide transfer over a Central Amazonian rain forest, J. Geophys. Res. Atmospheres, 103(D24), 31593-31612, doi:10.1029/98JD02647, 1998.

Malizia, A., Blundo, C., Carilla, J., Acosta, O. O., Cuesta, F., Duque, A., Aguirre, N., Aguirre, Z., Ataroff, M., Baez, S., Calderón-Loor, M., Cayola, L., Cayuela, L., Ceballos, S., Cedillo, H., Ríos, W. F., Feeley, K. J., Fuentes, A. F., Álvarez, L. E. G., Grau, R., Homeier, J., Jadan, O., Llambi, L. D., Rivera, M. I. L., Macía, M. J., Malhi, Y., Malizia, L., Peralvo, M., Pinto, E., Tello, S., Silman, M. and Young, K. R.: Elevation and latitude drives structure and tree species composition in Andean forests: Results from a large-scale plot network, PLOS ONE, 15(4), e0231553, doi:10.1371/journal.pone.0231553, 2020.

Marshall, A. R., Willcock, S., Platts, P. J., Lovett, J. C., Balmford, A., Burgess, N. D., Latham, J. E., Munishi, P. K. T., Salter, R., Shirima, D. D. and Lewis, S. L.: Measuring and modelling aboveground carbon and tree allometry along a tropical elevation gradient, Biol. Conserv., 154, 20-33, doi:10.1016/j.biocon.2012.03.017, 2012.

Mauder, M., Cuntz, M., Drüe, C., Graf, A., Rebmann, C., Schmid, H. P., Schmidt, M. and Steinbrecher, R.: A strategy for quality and uncertainty assessment of long-term eddy-covariance measurements, Agric. For. Meteorol., 169, 122-135, doi:10.1016/j.agrformet.2012.09.006, 2013.

McCrady, R. L. and Jokela, E. J.: Canopy Dynamics, Light Interception, and Radiation Use Efficiency of Selected Loblolly Pine Families, For. Sci., 44(1), 64-72, doi:10.1093/forestscience/44.1.64, 1998.

Meentemeyer, V.: Macroclimate and Lignin Control of Litter Decomposition Rates, Ecology, 59(3), 465-472, doi:10.2307/1936576, 1978.

Metcalfe, D. B., Meir, P., Aragão, L. E. O. C., Malhi, Y., da Costa, A. C. L., Braga, A., Gonçalves, P. H. L., de Athaydes, J., de Almeida, S. S. and Williams, M.: Factors controlling spatio-temporal variation in carbon dioxide efflux from surface litter, roots, and soil organic matter at four rain forest sites in the eastern Amazon, J. Geophys. Res. Biogeosciences, 112(G4), G04001, doi:10.1029/2007JG000443, 2007.

Miller, S. D., Goulden, M. L., Menton, M. C., Rocha, H. R. da, Freitas, H. C. de, e Silva Figueira, A. M. and Sousa, C. A. D. de: Biometric and Micrometeorological Measurements of Tropical Forest Carbon Balance, Ecol. Appl., 14(4), S114-S126, 2004.

Min, Q. and Wang, S.: Clouds modulate terrestrial carbon uptake in a midlatitude hardwood forest, Geophys. Res. Lett., 35(2), doi:10.1029/2007GL032398, 2008.

Moffat, A. M., Papale, D., Reichstein, M., Hollinger, D. Y., Richardson, A. D., Barr, A. G., Beckstein, C., Braswell, B. H., Churkina, G., Desai, A. R., Falge, E., Gove, J. H., Heimann, M., 
Hui, D., Jarvis, A. J., Kattge, J., Noormets, A. and Stauch, V. J.: Comprehensive comparison of gap-filling techniques for eddy covariance net carbon fluxes, Agric. For. Meteorol., 147(3), 209232, doi:10.1016/j.agrformet.2007.08.011, 2007.

Moncrieff, J. B., Malhi, Y. and Leuning, R.: The propagation of errors in long-term measurements of land-atmosphere fluxes of carbon and water, Glob. Change Biol., 2(3), 231240, doi:10.1111/j.1365-2486.1996.tb00075.x, 1996.

Moser, G., Leuschner, C., Hertel, D., Graefe, S., Soethe, N. and Iost, S.: Elevation effects on the carbon budget of tropical mountain forests (S Ecuador): the role of the belowground compartment, Glob. Change Biol., 17(6), 2211-2226, doi:10.1111/j.1365-2486.2010.02367.x, 2011.

Nakagawa, S. and Schielzeth, H.: A general and simple method for obtaining R2 from generalized linear mixed-effects models, Methods Ecol. Evol., 4(2), 133-142, doi:10.1111/j.2041210x.2012.00261.x, 2013.

Olchev, A., Ibrom, A., Ross, T., Falk, U., Rakkibu, G., Radler, K., Grote, S., Kreilein, H. and Gravenhorst, G.: A modelling approach for simulation of water and carbon dioxide exchange between multi-species tropical rain forest and the atmosphere, Ecol. Model., 212(1-2), 122-130, doi:10.1016/j.ecolmodel.2007.10.021, 2008.

Olchev, A., Ibrom, A., Panferov, O., Gushchina, D., Kreilein, H., Popov, V., Propastin, P., June, T., Rauf, A., Gravenhorst, G. and Knohl, A.: Response of CO2 and $\mathrm{H} 2 \mathrm{O}$ fluxes in a mountainous tropical rainforest in equatorial Indonesia to El Niño events, Biogeosciences, 12(22), 6655-6667, doi:10.5194/bg-12-6655-2015, 2015.

Pan, Y., Birdsey, R. A., Fang, J., Houghton, R., Kauppi, P. E., Kurz, W. A., Phillips, O. L., Shvidenko, A., Lewis, S. L., Canadell, J. G., Ciais, P., Jackson, R. B., Pacala, S., McGuire, A. D., Piao, S., Rautiainen, A., Sitch, S. and Hayes, D.: A Large and Persistent Carbon Sink in the World's Forests, Science, 1201609, doi:10.1126/science.1201609, 2011.

Pan, Y., Birdsey, R. A., Phillips, O. L. and Jackson, R. B.: The Structure, Distribution, and Biomass of the World's Forests, Annu. Rev. Ecol. Evol. Syst., 44(1), 593-622, doi:10.1146/annurev-ecolsys-110512-135914, 2013.

Papale, D.: Data Gap Filling, in Eddy Covariance, edited by M. Aubinet, T. Vesala, and D. Papale, pp. 159-172, Springer Netherlands, Dordrecht., 2012.

Papale, D., Reichstein, M., Aubinet, M., Canfora, E., Bernhofer, C., Kutsch, W., Longdoz, B., Rambal, S., Valentini, R., Vesala, T. and Yakir, D.: Towards a standardized processing of Net Ecosystem Exchange measured with eddy covariance technique: algorithms and uncertainty estimation, Biogeosciences, 3(4), 571-583, 2006.

Pélissier, R.: Tree spatial patterns in three contrasting plots of a southern Indian tropical moist evergreen forest, J. Trop. Ecol., 14(1), 1-16, doi:10.1017/S0266467498000017, 1998.

Peña, M. A., Feeley, K. J. and Duque, A.: Effects of endogenous and exogenous processes on aboveground biomass stocks and dynamics in Andean forests, Plant Ecol., 219(12), 1481-1492, doi:10.1007/s11258-018-0895-2, 2018.

Phillips O. L., Malhi Y., Vinceti B., Baker T., Lewis S. L., Higuchi N., Laurance W. F., Vargas P. Núñez, Martinez R. Vásquez, Laurance S., Ferreira L. V., Stern M., Brown S. and Grace J.: 
Changes in growth of tropical forests: evaluating potential biases, Ecol. Appl., 12(2), 576-587, doi:10.1890/1051-0761(2002)012[0576:CIGOTF]2.0.CO;2, 2002.

Potapov, P., Hansen, M., Stehman, S. V., Pittman, K. and Turubanova, S.: Gross forest cover loss in temperate forests: biome-wide monitoring results using MODIS and Landsat data, J. Appl. Remote Sens., 3(1), 033569, doi:10.1117/1.3283904, 2009.

Purves, D. W., Lichstein, J. W., Strigul, N. and Pacala, S. W.: Predicting and understanding forest dynamics using a simple tractable model, Proc. Natl. Acad. Sci., 105(44), 17018-17022, doi:10.1073/pnas.0807754105, 2008.

Quesada, C. A., Phillips, O. L., Schwarz, M., Czimczik, C. I., Baker, T. R., Patino, S., Fyllas, N. M., Hodnett, M. G., Herrera, R., Almeida, S., Davila, E. A., Arneth, A., Arroyo, L., Chao, K. J., Dezzeo, N., Erwin, T., Di Fiore, A., Higuchi, N., Coronado, E. H., Jimenez, E. M., Killeen, T., Lezama, A. T., Lloyd, G., Lopez-Gonzalez, G., Luizao, F. J., Malhi, Y., Monteagudo, A., Neill, D. A., Vargas, P. N., Paiva, R., Peacock, J., Penuela, M. C., Cruz, A. P., Pitman, N., Priante, N., Prieto, A., Ramirez, H., Rudas, A., Salomao, R., Santos, A. J. B., Schmerler, J., Silva, N., Silveira, M., Vasquez, R., Vieira, I., Terborgh, J. and Lloyd, J.: Basin-wide variations in Amazon forest structure and function are mediated by both soils and climate, Biogeosciences, 9(6), 2203-2246, doi:10.5194/bg-9-2203-2012, 2012.

R Core Team: R: A Language and Environment for Statistical Computing, R Foundation for Statistical Computing, Vienna, Austria. [online] Available from: https://www.R-project.org/, 2016.

Raich, J. W. and Tufekciogul, A.: Vegetation and soil respiration: Correlations and controls, Biogeochemistry, 48(1), 71-90, doi:10.1023/A:1006112000616, 2000.

Rakkibu, M. G.: Photosynthesis in a tropical montane rainforest of Southeast Asia: Field measurements and model analysis, [online] Available from: https://ediss.unigoettingen.de/handle/11858/00-1735-0000-0006-B10C-8 (Accessed 12 July 2019), 2008.

Rebmann, C., Zeri, M., Lasslop, G., Mund, M., Kolle, O., Schulze, E.-D. and Feigenwinter, C.: Treatment and assessment of the CO2-exchange at a complex forest site in Thuringia, Germany, Agric. For. Meteorol., 150(5), 684-691, doi:10.1016/j.agrformet.2009.11.001, 2010.

Reichstein, M., Falge, E., Baldocchi, D., Papale, D., Aubinet, M., Berbigier, P., Bernhofer, C., Buchmann, N., Gilmanov, T., Granier, A., Grünwald, T., Havránková, K., Ilvesniemi, H., Janous, D., Knohl, A., Laurila, T., Lohila, A., Loustau, D., Matteucci, G., Meyers, T., Miglietta, F., Ourcival, J.-M., Pumpanen, J., Rambal, S., Rotenberg, E., Sanz, M., Tenhunen, J., Seufert, G., Vaccari, F., Vesala, T., Yakir, D. and Valentini, R.: On the separation of net ecosystem exchange into assimilation and ecosystem respiration: review and improved algorithm, Glob. Change Biol., 11(9), 1424-1439, doi:10.1111/j.1365-2486.2005.001002.x, 2005.

Reichstein, M., Stoy, P. C., Desai, A. R., Lasslop, G. and Richardson, A. D.: Partitioning of Net Fluxes, in Eddy Covariance: A Practical Guide to Measurement and Data Analysis, edited by M. Aubinet, T. Vesala, and D. Papale, pp. 263-289, Springer Netherlands, Dordrecht., 2012.

Réjou-Méchain, M., Tanguy, A., Piponiot, C., Chave, J. and Hérault, B.: biomass: an r package for estimating above-ground biomass and its uncertainty in tropical forests, Methods Ecol. Evol., 8(9), 1163-1167, doi:10.1111/2041-210X.12753, 2017. 
Requena Suarez, D., Rozendaal, D. M. A., De Sy, V., Phillips, O. L., Alvarez-Dávila, E., Anderson-Teixeira, K., Araujo-Murakami, A., Arroyo, L., Baker, T. R., Bongers, F., Brienen, R. J. W., Carter, S., Cook-Patton, S. C., Feldpausch, T. R., Griscom, B. W., Harris, N., Hérault, B., Honorio Coronado, E. N., Leavitt, S. M., Lewis, S. L., Marimon, B. S., Monteagudo Mendoza, A., Kassi N’dja, J., N’Guessan, A. E., Poorter, L., Qie, L., Rutishauser, E., Sist, P., Sonké, B., Sullivan, M. J. P., Vilanova, E., Wang, M. M. H., Martius, C. and Herold, M.: Estimating aboveground net biomass change for tropical and subtropical forests: Refinement of IPCC default rates using forest plot data, Glob. Change Biol., 25(11), 3609-3624, doi:10.1111/gcb.14767, 2019.

Roos, M. C., Keßler, P. J. A., Gradstein, S. R. and Baas, P.: Species diversity and endemism of five major Malesian islands: diversity-area relationships, J. Biogeogr., 31(12), 1893-1908, doi:10.1111/j.1365-2699.2004.01154.x, 2004.

Ross, T.: Eddy-Kovarianz Messungen über einem tropischen Regenwald in komplexem Gelände, [online] Available from: https://ediss.uni-goettingen.de/handle/11858/00-1735-0000-0006B45C-9 (Accessed 12 January 2019), 2007.

Rowland, L., Hill, T. C., Stahl, C., Siebicke, L., Burban, B., Zaragoza-Castells, J., Ponton, S., Bonal, D., Meir, P. and Williams, M.: Evidence for strong seasonality in the carbon storage and carbon use efficiency of an Amazonian forest, Glob. Change Biol., 20(3), 979-991, doi:10.1111/gcb.12375, 2013.

Rubio, V. E. and Detto, M.: Spatiotemporal variability of soil respiration in a seasonal tropical forest, Ecol. Evol., 7(17), 7104-7116, doi:10.1002/ece3.3267, 2017.

Ryan, J. A. and Ulrich, J. M.: xts: eXtensible Time Series. [online] Available from: https://CRAN.R-project.org/package=xts, 2014.

Saatchi, S. S., Harris, N. L., Brown, S., Lefsky, M., Mitchard, E. T. A., Salas, W., Zutta, B. R., Buermann, W., Lewis, S. L., Hagen, S., Petrova, S., White, L., Silman, M. and Morel, A.:

Benchmark map of forest carbon stocks in tropical regions across three continents, Proc. Natl. Acad. Sci., 108(24), 9899-9904, doi:10.1073/pnas.1019576108, 2011.

Saitoh, T. M., Kumagai, T., Sato, Y. and Suzuki, M.: Carbon Dioxide Exchange over a Bornean Tropical Rainforest, J. Agric. Meteorol., 60(5), 553-556, doi:10.2480/agrmet.553, 2005.

Saleska, S. R., Miller, S. D., Matross, D. M., Goulden, M. L., Wofsy, S. C., Rocha, H. R. da, Camargo, P. B. de, Crill, P., Daube, B. C., Freitas, H. C. de, Hutyra, L., Keller, M., Kirchhoff, V., Menton, M., Munger, J. W., Pyle, E. H., Rice, A. H. and Silva, H.: Carbon in Amazon Forests: Unexpected Seasonal Fluxes and Disturbance-Induced Losses, Science, 302(5650), 1554-1557, doi:10.1126/science.1091165, 2003.

Santana, R. A., Dias-Júnior, C. Q., da Silva, J. T., Fuentes, J. D., do Vale, R. S., Alves, E. G., dos Santos, R. M. N. and Manzi, A. O.: Air turbulence characteristics at multiple sites in and above the Amazon rainforest canopy, Agric. For. Meteorol., 260-261, 41-54, doi:10.1016/j.agrformet.2018.05.027, 2018.

Santana, R. A. S. de, Dias-Júnior, C. Q., Vale, R. S. do, Tóta, J. and Fitzjarrald, D. R.: Observing and Modeling the Vertical Wind Profile at Multiple Sites in and above the Amazon Rain Forest Canopy, Adv. Meteorol., doi:10.1155/2017/5436157, 2017. 
Santos, D. M., Acevedo, O. C., Chamecki, M., Fuentes, J. D., Gerken, T. and Stoy, P. C.: Temporal Scales of the Nocturnal Flow Within and Above a Forest Canopy in Amazonia, Bound.-Layer Meteorol., 161(1), 73-98, doi:10.1007/s10546-016-0158-5, 2016.

Schrumpf, M., Kaiser, K., Guggenberger, G., Persson, T., Kögel-Knabner, I. and Schulze, E.-D.: Storage and stability of organic carbon in soils as related to depth, occlusion within aggregates, and attachment to minerals, Biogeosciences, 10(3), 1675-1691, doi:https://doi.org/10.5194/bg10-1675-2013, 2013.

Simbolon, H.: THE GROWTH DYNAMICS ON TREE SPECIES OF FAGACEAE FAMILY IN A TROPICAL MONTANE RAIN FOREST OF WEST JAVA, INDONESIA, Ber. Biol., 5(6), doi:10.14203/beritabiologi.v5i6.1071, 2001.

Søe, A. R. B. and Buchmann, N.: Spatial and temporal variations in soil respiration in relation to stand structure and soil parameters in an unmanaged beech forest, Tree Physiol., 25(11), 14271436, doi:10.1093/treephys/25.11.1427, 2005.

Sogachev, A., Menzhulin, G. V., Heimann, M. and Lloyd, J.: A simple three-dimensional canopy - planetary boundary layer simulation model for scalar concentrations and fluxes, Tellus B Chem. Phys. Meteorol., 54(5), 784-819, doi:10.3402/tellusb.v54i5.16729, 2002.

Sotta, E. D., Meir, P., Malhi, Y., Donato nobre, A., Hodnett, M. and Grace, J.: Soil CO2 efflux in a tropical forest in the central Amazon, Glob. Change Biol., 10(5), 601-617, doi:10.1111/j.15298817.2003.00761.x, 2004.

Sotta, E. D., Veldkamp, E., Guimarães, B. R., Paixão, R. K., Ruivo, M. L. P. and Almeida, S. S.: Landscape and climatic controls on spatial and temporal variation in soil CO2 efflux in an Eastern Amazonian Rainforest, Caxiuanã, Brazil, For. Ecol. Manag., 237(1), 57-64, doi:10.1016/j.foreco.2006.09.027, 2006.

Sotta, E. D., Veldkamp, E., Schwendenmann, L., Guimarães, B. R., Paixão, R. K., Ruivo, M. de L. P., LOLA da COSTA, A. C. and Meir, P.: Effects of an induced drought on soil carbon dioxide (CO2) efflux and soil CO2 production in an Eastern Amazonian rainforest, Brazil, Glob. Change Biol., 13(10), 2218-2229, doi:10.1111/j.1365-2486.2007.01416.x, 2007.

Stahl, C., Burban, B., Wagner, F., Goret, J.-Y., Bompy, F. and Bonal, D.: Influence of Seasonal Variations in Soil Water Availability on Gas Exchange of Tropical Canopy Trees, Biotropica, 45(2), 155-164, doi:10.1111/j.1744-7429.2012.00902.x, 2013.

van Straaten, O., Veldkamp, E. and Corre, M. D.: Simulated drought reduces soil CO2 efflux and production in a tropical forest in Sulawesi, Indonesia, Ecosphere, 2(10), art119, doi:10.1890/ES11-00079.1, 2011.

Sullivan, M. J. P., Lewis, S. L., Hubau, W., Qie, L., Baker, T. R., Banin, L. F., Chave, J., CuniSanchez, A., Feldpausch, T. R., Lopez-Gonzalez, G., Arets, E., Ashton, P., Bastin, J.-F., Berry, N. J., Bogaert, J., Boot, R., Brearley, F. Q., Brienen, R., Burslem, D. F. R. P., Canniere, C. de, Chudomelová, M., Dančák, M., Ewango, C., Hédl, R., Lloyd, J., Makana, J.-R., Malhi, Y., Marimon, B. S., Junior, B. H. M., Metali, F., Moore, S., Nagy, L., Vargas, P. N., Pendry, C. A., Ramírez-Angulo, H., Reitsma, J., Rutishauser, E., Salim, K. A., Sonké, B., Sukri, R. S., Sunderland, T., Svátek, M., Umunay, P. M., Martinez, R. V., Vernimmen, R. R. E., Torre, E. V., Vleminckx, J., Vos, V. and Phillips, O. L.: Field methods for sampling tree height for tropical forest biomass estimation, Methods Ecol. Evol., doi:10.1111/2041-210X.12962, 2018. 
Sun, J., Burns, S. P., Delany, A. C., Oncley, S. P., Turnipseed, A. A., Stephens, B. B., Lenschow, D. H., LeMone, M. A., Monson, R. K. and Anderson, D. E.: CO2 transport over complex terrain, Agric. For. Meteorol., 145(1), 1-21, doi:10.1016/j.agrformet.2007.02.007, 2007.

Tan, Z., Zhang, Y., Yu, G., Sha, L., Tang, J., Deng, X. and Song, Q.: Carbon balance of a primary tropical seasonal rain forest, J. Geophys. Res. Atmospheres, 115(D4), doi:10.1029/2009JD012913, 2010.

Tóta, J., Fitzjarrald, D. R., Staebler, R. M., Sakai, R. K., Moraes, O. M. M., Acevedo, O. C., Wofsy, S. C. and Manzi, A. O.: Amazon rain forest subcanopy flow and the carbon budget: Santarém LBA-ECO site: OBSERVING SUBCANOPY FLOWS IN THE AMAZON, J. Geophys. Res. Biogeosciences, 113(G1), n/a-n/a, doi:10.1029/2007JG000597, 2008.

Tóta, J., Roy Fitzjarrald, D. and da Silva Dias, M. A. F.: Amazon Rainforest Exchange of Carbon and Subcanopy Air Flow: Manaus LBA Site-A Complex Terrain Condition, Sci. World J., doi:10.1100/2012/165067, 2012.

Van Gorsel, E., Leuning, R., Cleugh, H. A., Keith, H. and Suni, T.: Nocturnal carbon efflux: reconciliation of eddy covariance and chamber measurements using an alternative to the $\mathrm{u}^{*}$ threshold filtering technique, Tellus B, 59(3), 397-403, doi:10.1111/j.1600-0889.2007.00252.x, 2007.

Wambeke, A. van: Management properties of ferralsols, Food and Agriculture Organization of the United Nations, Rome., 1974.

Webb, E. K., Pearman, G. I. and Leuning, R.: Correction of flux measurements for density effects due to heat and water vapour transfer, Q. J. R. Meteorol. Soc., 106(447), 85-100, doi:10.1002/qj.49710644707, 1980.

Wickham, H.: Reshaping Data with the reshape Package, J. Stat. Softw., 21(12), 1-20, 2007.

Wickham, H.: ggplot2: Elegant Graphics for Data Analysis, Springer-Verlag New York. [online] Available from: http://ggplot2.org, 2009.

Wickham, H.: The Split-Apply-Combine Strategy for Data Analysis, J. Stat. Softw., 40(1), 1-29, 2011.

Wickham, H., François, R., Henry, L., Müller, K. and RStudio: dplyr: A Grammar of Data Manipulation. [online] Available from: https://CRAN.R-project.org/package=dplyr (Accessed 2 March 2019), 2019.

Wieder, W. R., Cleveland, C. C. and Townsend, A. R.: Controls over leaf litter decomposition in wet tropical forests, Ecology, 90(12), 3333-3341, doi:10.1890/08-2294.1, 2009.

Wiegand, T., Gunatilleke, S., Gunatilleke, N. and Okuda, T.: ANALYZING THE SPATIAL STRUCTURE OF A SRI LANKAN TREE SPECIES WITH MULTIPLE SCALES OF CLUSTERING, Ecology, 88(12), 3088-3102, doi:10.1890/06-1350.1, 2007.

Wilczak, J. M., Oncley, S. P. and Stage, S. A.: Sonic Anemometer Tilt Correction Algorithms, Bound.-Layer Meteorol., 99(1), 127-150, doi:10.1023/A:1018966204465, 2001.

Wood, T. E., Detto, M. and Silver, W. L.: Sensitivity of Soil Respiration to Variability in Soil Moisture and Temperature in a Humid Tropical Forest, PLOS ONE, 8(12), e80965, doi:10.1371/journal.pone.0080965, 2013. 
Wutzler, T., Lucas-Moffat, A., Migliavacca, M., Knauer, J., Sickel, K., Šigut, L., Menzer, O. and Reichstein, M.: Basic and extensible post-processing of eddy covariance flux data with REddyProc, Biogeosciences, 15(16), 5015-5030, doi:https://doi.org/10.5194/bg-15-5015-2018, 2018.

Yamasoe, M. A., Randow, C. von, Manzi, A. O., Schafer, J. S., Eck, T. F. and Holben, B. N.: Effect of smoke and clouds on the transmissivity of photosynthetically active radiation inside the canopy, Atmospheric Chem. Phys., 6(6), 1645-1656, doi:https://doi.org/10.5194/acp-6-16452006, 2006.

Zeileis, A. and Grothendieck, G.: zoo: S3 Infrastructure for Regular and Irregular Time Series, J. Stat. Softw., 14(6), 1-27, doi:10.18637/jss.v014.i06, 2005.

Zeppetello, L. V., Parsons, L., Spector, J., Naylor, R., Battisti, D., Masuda, Y. and Wolff, N. H.: Large scale tropical deforestation drives extreme warming, Environ. Res. Lett., doi:10.1088/17489326/ab96d2, 2020.

Zeri, M., Sá, L. D. A., Manzi, A. O., Araújo, A. C., Aguiar, R. G., Randow, C. von, Sampaio, G., Cardoso, F. L. and Nobre, C. A.: Variability of Carbon and Water Fluxes Following Climate Extremes over a Tropical Forest in Southwestern Amazonia, PLOS ONE, 9(2), e88130, doi:10.1371/journal.pone.0088130, 2014.

Zhou, Z., Jiang, L., Du, E., Hu, H., Li, Y., Chen, D. and Fang, J.: Temperature and substrate availability regulate soil respiration in the tropical mountain rainforests, Hainan Island, China, J. Plant Ecol., 6(5), 325-334, doi:10.1093/jpe/rtt034, 2013.

Zimmermann, M., Meir, P., Bird, M. I., Malhi, Y. and Ccahuana, A. J. Q.: Climate dependence of heterotrophic soil respiration from a soil-translocation experiment along a $3000 \mathrm{~m}$ tropical forest altitudinal gradient, Eur. J. Soil Sci., 60(6), 895-906, doi:10.1111/j.1365-2389.2009.01175.x, 2009a.

Zimmermann, M., Meir, P., Bird, M., Malhi, Y. and Ccahuana, A.: Litter contribution to diurnal and annual soil respiration in a tropical montane cloud forest, Soil Biol. Biochem., 41(6), 13381340, doi:10.1016/j.soilbio.2009.02.023, 2009b.

Zimmermann, M., Meir, P., Bird, M. I., Malhi, Y. and Ccahuana, A. J. Q.: Temporal variation and climate dependence of soil respiration and its components along a $3000 \mathrm{~m}$ altitudinal tropical forest gradient, Glob. Biogeochem. Cycles, 24(4), GB4012, doi:10.1029/2010GB003787, 2010. 


\section{List of figures}

Figure 1: Schematic overview of the main components of the carbon cycle in a rainforest. ..........2

Figure 2: Location of the study site in central Sulawesi, Indonesia...................................................5

Figure 3: Overview of the $\mathrm{CO}_{2}$-cycle components estimated by the three approaches used in this thesis. a) Estimation of aboveground biomass and changes therein through forest inventories; $b$ ) Soil respiration measurements along a transect with a mobile soil chamber system; c) NEE estimation through eddy-covariance measurements coupled with a $\mathrm{CO}_{2}$-concentration profile measurement system.

Figure 4: Probability density curves of the DBH-distribution 2006 and 2017. Means are not significantly different (t-test). The $\mathrm{x}$-axis has been cut off at the maximum of the 2006-data to allow better visual comparison.

Figure 5: Proportion of DBH classes in the 4 data sets. DBH classes are set to 10-20 (1), >20-30

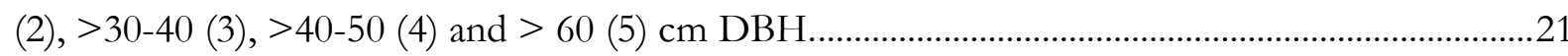

Figure 6: There is no significant difference (ANOVA) in mean DBH per transect........................21

Figure 7: Probability density-curves of DBH for all 4 data sets. The two largest trees of the $10 \mathrm{HA}$ inventory have been removed from the calculation for this plot to allow for visual comparison.

Figure 8: Proportion of DBH classes in the 4 data sets. DBH classes are set to 10-20 (1), >20-30 (2), >30-40 (3), >40-50 (4) and > 60 (5) $\mathrm{cm} \mathrm{DBH.}$

Figure 9: Above-ground biomass distribution of trees inside the NE-plot over time.

Figure 10: Point-correlation functions describing the spatial relatedness of trees inside the 3 plots from Culmsee et al. Sequence is NE (a), S (b), W (c). Red line represents CSR, black lines observed $g$ at different radii, gray area defines the $95 \%$ significance level of CSR.

Figure 11: Stoyan's kmm-functions describing the competition of trees based on DBH measurements at certain distances to each other inside the 3 plots from Culmsee et al. Sequence is NE (a), S (b), W (c). The red line represents no competition, black lines observed $k$ at different radii, gray area defines the $95 \%$ significance level.

Figure 12: Tree positions inside the so-called North-East plot established by Culmsee et al. 2006. Circle size indicates DBH.

Figure 13: Stoyan's kmm-functions describing the competition of trees based on DBH measurements at certain distances to each other inside the NE plot established by Culmsee et al. in 2006 in chronological order a) 2006, b) 2011, c) 2014, d) 2017. The red line represents no competition, black lines observed $k$ at different radii, gray area defines the $95 \%$ significance level.

Figure 14: Point-correlation functions describing the spatial relatedness of trees inside the NE plot established by Culmsee et al. in 2006 in chronological order a) 2006, b) 2011, c) 2014, d) 2017. Red line represents CSR, black lines observed $g$ at different radii, gray area defines the $95 \%$ significance level of CSR.

Figure 15: Measurement locations, hut and eddy covariance tower. Sampling design was chosen to cover spatial heterogeneity along the main wind direction and measurability during night time.

Figure 16: Average soil respiration in $\mu \mathrm{mol} \mathrm{m} \mathrm{m}^{-1}$ per location and time of the day. Data from 21 measurements campaigns from $1^{\text {st }}$ of April to $28^{\text {th }}$ of April 2017. Number of measurements per time window are: Dawn $=6, \mathrm{Day}=6$, Dusk $=5$, Night $=3$. 
Figure 17: Probability density curves of inter-location (full line, short tick marks) and intra-location standard deviation (dashed line, long tick marks) of measured soil respiration. Inter-location variance represents the $\mathrm{R}_{\mathrm{s}}$ variability among the individual locations observed in separate measurement campaigns, while intra-location variance is $R_{s}$ variability over time measured at the individual locations.

Figure 18: From top to bottom a) Soil respiration from $n=22$ soil collars measured in $n=21$ campaigns, outliers have been removed; b) air temperature (line) at $48 \mathrm{~m}$ above the ground and soil temperature (dots) in $10 \mathrm{~cm}$ depth; c) global radiation at $70 \mathrm{~m}$ above the ground, d) soil moisture in $30 \mathrm{~cm}$ depth. Parameters b-d were measured at the EC-tower.

Figure 19: Probability density-curves of mean soil moisture [\% volume] measured half-hourly in $30 \mathrm{~cm}$ depth at a soil moisture and temperature profile near the EC-tower. The full line represents the time from $1^{\text {st }}$ to $28^{\text {th }}$ of April 2017, when des $R_{s}$ measurements took place and the dashed line data from the $1^{\text {st }}$ of September 2014 to the $31^{\text {st }}$ of March 2017 as long-term reference.

Figure 20: Diel cycle of mean air temperature $\left[{ }^{\circ} \mathrm{C}\right]$ measured half-hourly in $48 \mathrm{~m}$ height at the EC-tower. The full line represents the time from 1-28 April 2017. The dashed line is based on data from the $1^{\text {st }}$ of September 2014 to the $31^{\text {st }}$ of March $2017 \pm$ one standard deviation (shaded area).

Figure 21: Probability density-curves of mean soil temperature $\left[{ }^{\circ} \mathrm{C}\right]$ measured half-hourly in 10 $\mathrm{cm}$ depth at a soil moisture and temperature profile near the EC-tower. The full line represents the time from $1^{\text {st }}$ to $28^{\text {th }}$ of April 2017 and the dashed line data from the $1^{\text {st }}$ of September 2014 to the $31^{\text {st }}$ of March 2017.

Figure 22: Probability density-curves of BA in an $8 \mathrm{~m}$ radius at a) all forest inventory plots (full line, short tick marks) and $b) R_{s}$ measurement locations (dashed line, long tick marks). The forest at the $R_{s}$ measurement locations is nearly identical in distribution of $B A$ to the surrounding 10 ha. There are two outliers from the inventory not visible in this graph

Figure 23: Overview of air temperature a), global radiation b), VPD c) and precipitation d) at the study site from December 2013 to April 2017......

Figure 24: Wind direction and wind speed separated into day and night, aggregated from $4^{\text {th }}$ December 2013 to $28^{\text {th }}$ April 2017

Figure 25: Diel cycle of wind speed, friction velocity and atmospheric stability at the site. The grey area represents the standard deviation.

Figure 26: Distribution of stability classes of the mean vertical wind

Figure 27: Diel pattern of $\mathrm{CO}_{2}$ - concentration per measurement level, averaged over all available measurements from $2^{\text {nd }}$ October 2015 to $28^{\text {th }}$ April 2017. Level 025 is $0.25 \mathrm{~m}$ above the ground, Level 1 one meter and so forth.

Figure 28: Diel pattern of hourly $\mathrm{CO}_{2}-$ storage flux aggregated from $2^{\text {nd }}$ October 2015 to $28^{\text {th }}$ April 2017. The grey area represents the hourly standard deviation, the dotted line zero flux. .....75 Figure 29: Fingerprint of NEE and latent heat (LE) fluxes observed at the site from $4^{\text {th }}$ of December 2013 to $28^{\text {th }}$ of April 2017. .76

Figure 30: Exemplary spectra of sonic temperature a), $\mathrm{CO}_{2}$ b) and $\mathrm{H}_{2} \mathrm{O}$ c) measurements performed by the first $(2013$ - 2015) and the second $(2015$ - 2017,d/e/f) LI-7500A infrared gas analyser installed. Dots represent binned averages, red lines the theoretical $-2 / 3$ slope and grey lines raw data. 
Figure 31: Exemplary co-spectra of sonic temperature a), $\mathrm{CO}_{2}$ b) and $\mathrm{H}_{2} \mathrm{O}$ c) measurements performed by the first $(2013$ - 2015) and the second $(2015$ - 2017, d/e/f) LI-7500A infrared gas analyser installed at the tower. Dots represent binned averages, red lines the theoretical $-4 / 3$ slope and grey lines raw data...

Figure 32: Mean daily fluxes of $H, L E$ and $R_{n}$ during the reference period and before the removal of $\mathrm{R}_{\mathrm{n}}$-data measured at noon

Figure 33: Latent and sensible heat flux vs. net radiation, based on midday 30-min values. The blue line is the regression with intercept 0 , the dashed line is the 1:1 line

Figure 34: Latent and sensible heat flux vs. net radiation, based on all 30-min values besides 12:00. The blue line is the regression with intercept 0 , the dashed line is the 1:1 line

Figure 35: Stability classes remaining in all data from 2013 to 2017 after each filter is applied. The fraction is always relative to the total amount of data points after the first filter has been applied.

Figure 36: Stability classes remaining during the reference period after each filter is applied. The fraction is always relative to the total amount of data points after the first filter has been applied.

Figure 37: Night-time fluxes of canopy storage, eddy-covariance (EC) and both combined (NEE) in relation to friction velocity $\left(\mathrm{u}^{*}\right)$. No clear dependence of storage enrichment on $\mathrm{u}^{*}$ is apparent.

Figure 38: Eddy-covariance footprint area during the reference period for a) ( $z-d) / L>0.2$, b) $0.2 \geq(\mathrm{z}-\mathrm{d}) / \mathrm{L} \leq-0.2$, and c) $-0.2>(\mathrm{z}-\mathrm{d}) / \mathrm{L}$. Red lines delineate 10 to $90 \%$ of footprint area in $10 \%$ steps

Figure 39: Eddy-covariance footprint area for a) night-time (global radiation $<10 \mathrm{~W} \mathrm{~m}^{-1}$ ) and b) day-time during the reference period. Red lines delineate 10 to $90 \%$ of footprint area in $10 \%$ steps.

Figure 40: Fit of the photosynthesis-irradiance curve (red) between NEE based on EC measurements and global radiation, $\mathrm{R}^{2}=0.38$

Figure 41 Measured day-time $\mathrm{CO}_{2}$-fluxes versus fluxes predicted by the PI-curve, binned according to friction velocity $\mathrm{u}^{*}$. The $1: 1$ line is plotted for orientation.

Figure 42 Diel pattern of percentage of PAR transmission relative to PAR above the canopy...90 Figure 43 Cumulative NEE over time in $\mathrm{Mg} \mathrm{C} \mathrm{ha-1}$ for the reference period from May 2016 to April 2017. Filtering has little effect on overall tendencies of night-time estimation strategies.....92 Figure 44 Mean diel NEE in $\mu \mathrm{mol} \mathrm{m} \mathrm{m}^{-2}$ with QF 8 \& QF 6 threshold applied. The MDS and Lasslop approach both result in mean night-time fluxes below soil respiration.

Figure 45: Resolved questions about the main components of the carbon cycle at Bariri marked in green, partly resolved questions in orange a) Aboveground biomass of trees with a $\mathrm{DBH} \geq 10$ $\mathrm{cm} \mathrm{b)} \mathrm{soil} \mathrm{respiration} \mathrm{measurements} \mathrm{and} \mathrm{c)} \mathrm{Eddy-covariance} \mathrm{including} \mathrm{storage} \mathrm{term.}$ 107 


\section{List of tables}

Table 1 Performance of height models parametrized using all available tree heights per inventory

Table 2 Residual standard error (RSE) and bias of Weibull and Michaelis-Menten (M-M) models fitted to different inventories (column names) when applied to all height trees of another inventory (row names).

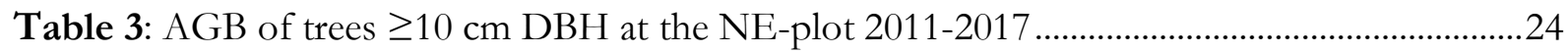

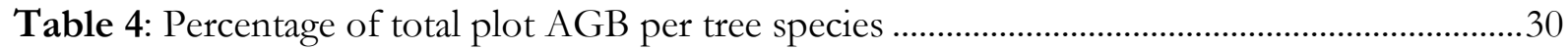

Table 5: Species specific increment per year for all trees from 2011 to 2014 .....................................31

Table 6: Species specific increment per year for all trees from 2014 to 2017 ....................................31

Table 7: Species specific increment per year for all trees $<20 \mathrm{~m}$ from 2011 to 2014 .....................32

Table 8: Species specific increment per year for all trees $<20 \mathrm{~m}$ from 2014 to 2017 .....................32

Table 9: Species specific increment per year for all trees $\geq 20 \mathrm{~m}$ from 2011 to 2014 .....................32

Table 10: Species specific increment per year for all trees $\geq 20 \mathrm{~m}$ from 2014 to 2017 ..................33

Table 11: Correlation of $R_{s}$ with simultaneously measured $T_{s}, M_{s}$ and global radiation across all

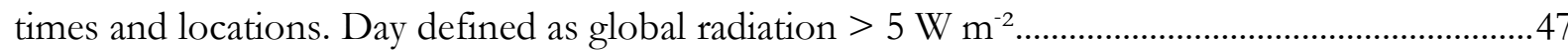

Table 12: $\mathrm{R}^{2}$ and respective $\mathrm{p}$-values for correlations between mean $\mathrm{R}_{\mathrm{s}}$ (per location using all measurement times or during the day with 'Day' defined as global radiation $>5 \mathrm{~W} \mathrm{~m}^{-2}$ ) with mean $\mathrm{DBH}$ and $\mathrm{BA}$ in different radii around each measurement locations as well as with organic layer depth, $\mathrm{D}_{\mathrm{OL}}$. All correlations are positive.

Table 13: Correlation coefficients, $\mathrm{p}$-values and AIC of multiple linear regressions of Rs with DOL, Ts and either DBH or BA. The equation used is denoted by the numbers (3.1) and (3.2). 48

Table 14: Multiple linear model (MLR) and linear mixed effect model (LME) comparison.........48

Table 15 Correlation of EC-CO ${ }_{2}$-fluxes predicted by the PI-function with measured values. Flux limit set to $-25 \mu \mathrm{mol} \mathrm{CO} 2 \mathrm{~m}^{-2} \mathrm{~s}^{-1}$. .87

Table 16 Performance of regression models describing the correlation between meteorological parameters and residuals of the PI-curve prediction versus measured EC values. Non-significant models are marked by " $n-\mathrm{s}$ ".

Table 17 Mean night-time $\mathrm{CO}_{2}$-fluxes and their standard deviations for different night-time flux estimation methods and filtering strategies. The van Gorsel approach has no SD as it is a constant value. Soil respiration based on chamber measurements is of $6.2 \pm 1.84 \mu \mathrm{mol} \mathrm{m}^{-2} \mathrm{~s}^{-1} \ldots . . .92$ Table 18 Sum of NEE for the reference period per night-time flux estimation method applied and with different filters in place

Table 19 Inventory results for the Bariri site based on data from 2006 (Culmsee et al., 2010) and 2017. 


\section{Acknowledgements}

I would like to thank Prof. Alexander Knohl and Heiner Kreilein for supervising this thesis, their advice and support during the last years and the great opportunity to work at a very interesting research site. This research was financed by the DFG (KN 582/8-1, BARIRIFLUX) and the bioclimatology group of the faculty of forest sciences and forest ecology of the University of Göttingen, for which I am very grateful.

I would also like to thank Heike Culmsee and Fabian Brambach, who provided me with the raw data of their inventories at the site. Likewise I would like to thank Oliver van Straaten for in-depth information about the soil in the area around the tower and advise on writing. Peter Annighöfer supported me in planning my large-scale inventory and made it possible for me to lend a Vertex from the Dep. of Silviculture \& Forest Ecology of the Temperate Zones. Fernando Moyano supported me a lot during the writing of the soil oriented chapter, while Christian Stiegler gave valuable advice concerning the EC-chapter. Dietmar Fellert provided technical support during the first phase of the project. Edgar Tunsch helped a lot with the technical aspects of the measurements, kept the tower running and retrieved crucial data under the most difficult circumstances. Without him, there would have been no "reference" period without large data gaps. Less obvious but at least as important was the support of the bioclimatology secretary as well as the central administration in getting all necessary documents and processing the funds and receipts. I would also like to thank my fellow researcher at the Bariri site, Mattia Bonazza, for his companionship during our long stay in Indonesia in the first year of the project. Not being alone in dealing with Indonesian bureaucracy, paper work and all the other obstacles that come with living abroad was a life-saver. Furthermore, I would like to thank all other members of the bioclimatology group for their camaraderie, support and advice. It was a very interesting time!

Outside of the professional environment, more people than I can name here helped me through the last, sometimes very difficult, years. The people at the Prince John Diving Resort gave me a much needed place to unwind during stays in Indonesia and introduced me to the fascinating world of diving. My friends, old and new, provided me with distraction, encouragement, laughter, music and much, much more, thus providing me with the resilience necessary to complete this project. Without you, I would have despaired and given up long ago.

Last but not least, I would like to thank my family, especially my parents Gabriela and Thomas. They give me the feeling that all will be OK, no matter what - which is one of the main reasons I came so far in my studies since I first enrolled in Göttingen. Thank you. 